\title{
ENHANCING LEARNING WITH OUTDOOR EXPERIENTIAL SUPPORT SPACES
}

\author{
by: \\ Kelvin Lee, \\ Bachelor of Architectural Science, Ryerson University, Toronto, 2004 \\ Bachelor of Education, Ontario Institute for Studies in Education, University of \\ Toronto, 2006
}

\begin{abstract}
A design thesis project
presented to Ryerson University

in partial fulfillment of the

requirements for the degree of

Master of Architecture

in the program of Architecture
\end{abstract}

Toronto, Ontario, Canada, 2010

CKelvin Lee 2010 

Author's Declaration

I hereby declare that I am the sole author of this Thesis Project

I authorize Ryerson University to lend this Thesis Project to other institutions or individuals for the purpose of scholarly research.

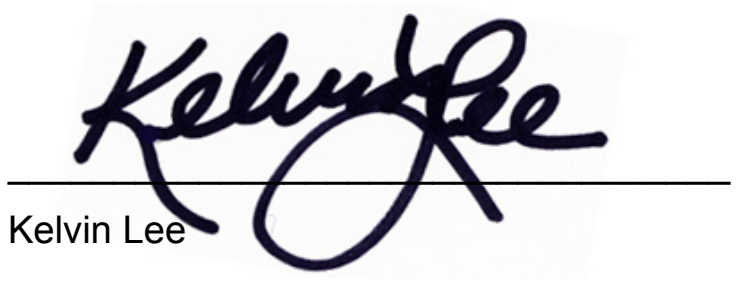

I further authorize Ryerson University to reproduce this thesis Project by photocopying or by other means, in total or in part, at the request of other institutions or individuals for the purpose of scholarly research.

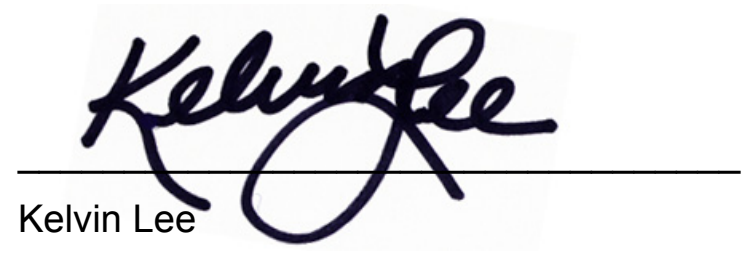

ii 


\title{
ENHANCING LEARNING WITH OUTDOOR EXPERIENTIAL SUPPORT SPACES
}

Principles from educational theorists, health references and the adaptation of the outdoor environment will be applied to the design of learning environments to enhance learning, improve creativity, risk taking, and problem solving skills in children.

Master of Architecture 2010

Kelvin Lee,

Master of Architecture

Ryerson University

\begin{abstract}
There is substantial evidence that primary school students whose education incorporates outdoor settings benefit from this addition to traditional classroom learning. Educational theories introduced by John Dewey, Maria Montessori, and Rudolph Steiner have provided a significant foundation for experiential learning in natural outdoor settings. This thesis explores educational environments that combine indoor and outdoor spaces. The result of this research is the design of three learning spaces sited in a natural environment that support education in a natural science curriculum. These three environments are proposed to supplement the provincial elementary curriculum, and involve three different natural conditions. These outdoor classrooms will provide children with exposure to the natural environment even as they learn within the boundaries of a controlled setting.
\end{abstract}




\section{Acknowledgements}

Many people have provided their time, thoughts, guidance and energies throughout the development of this thesis; to each of you I offer my thanks;

To my thesis advisor Dr. Kendra Schank Smith whose guidance, support, feedback, and advice has been integral to my process and growth.

To Vincent Hui for all his moral support, guidance and motivation to help push my design skills to a level where I never thought I would achieve.

To Sally Katsopoulos for being on the committee for giving me your thoughts and suggestions

To Dr. Clive Schwartz from Sick Kids Children's Hospital for all his motivation, guidance and advices; while at the same time making children's lives better everyday.

To Sharon Galvin for helping me with editing, your professional editing skills helped me get the points across much more clearly

To Patrick Lee for spending his time with me on all the working drawings

To the children that gave up their play time to assist with the images in this thesis.

I would also like to thank the late Margery Winkler, this thesis is dedicated to you; my friend, mentor, and professor, without you I would not be writing this thesis at all, your guidance and friendship through the years have changed the way I look at life, you have changed everyone's life that you touch, you are missed everyday and forever. 
This is dedicated to my family, and friends who have supported me throughout my education and my life. As well, this is dedicated to all that helped shape who I am; through school, sports and camp throughout the years. 


\section{TABLE OF CONTENTS}

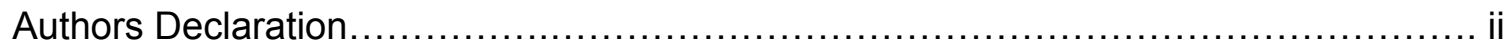

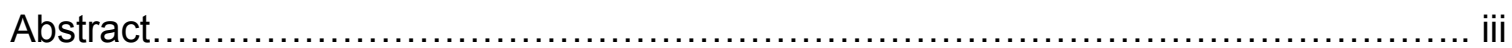

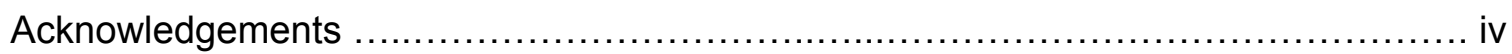

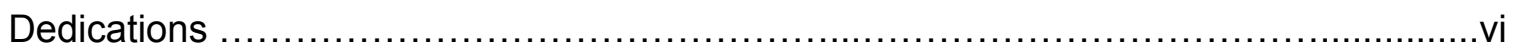

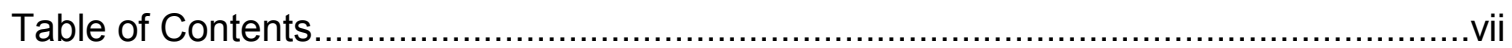

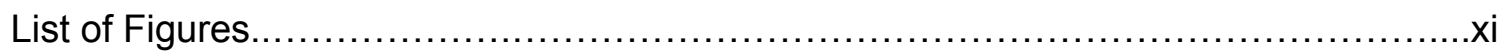

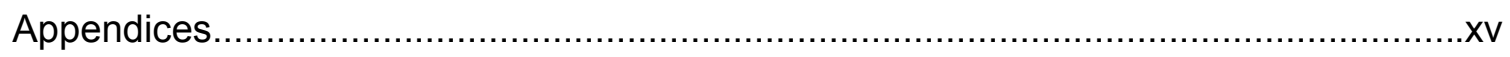

Introduction, Background Statement and Problem Statement..........................

\section{AN INSIGHT AND COMPARSION OF INFLUENTIAL EDUCATION THEORIES}

1.0 An insight and comparison of influential education theories..................................

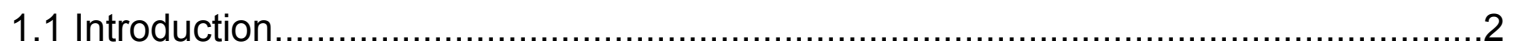

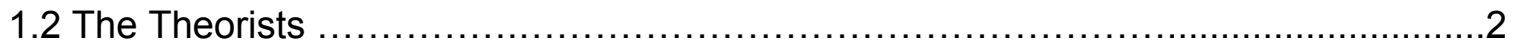

1.3 Spiritual ideas - A form of escape from reality? ...............................................4

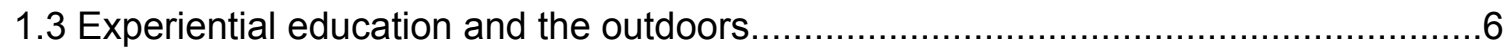

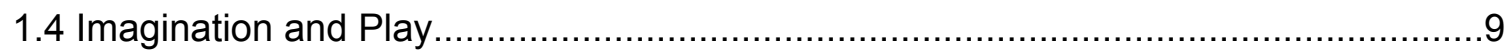

1.5 Piaget's Stages of Cognitive Development...........................................................13

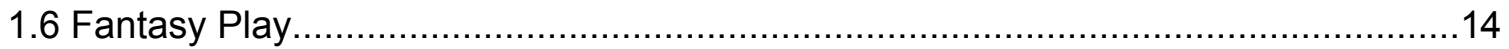

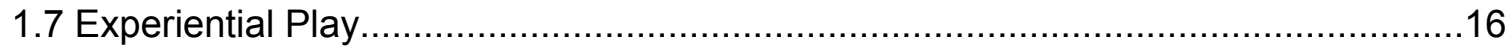

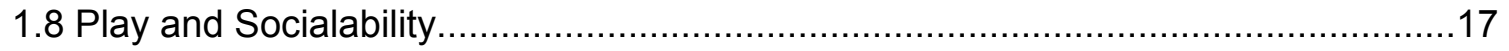

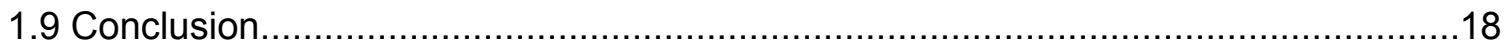

\section{A CRITICAL APPROACH TO LEARNING ENVIRONMENTS THROUGH A MEDICAL PERSPECTIVE}

2.0 A critical approach to learning environments through a medical perspective............19

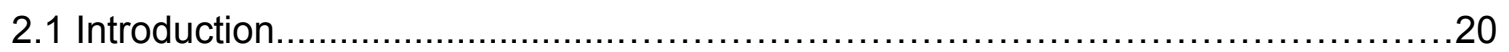

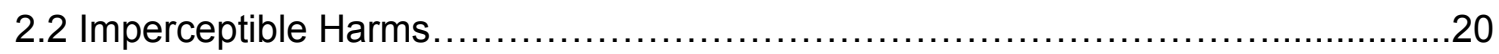

2.3 Air Pollution, Associated Behaviours and Health Concerns...................................24

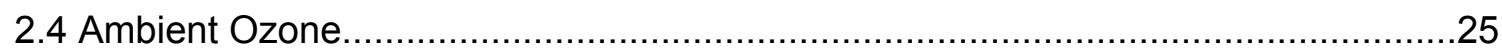

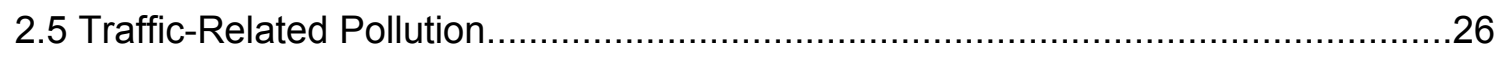

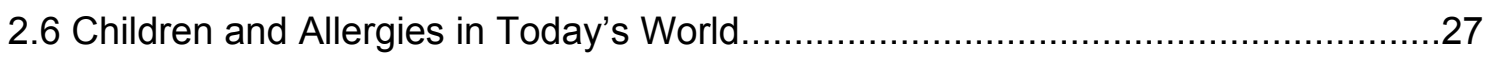




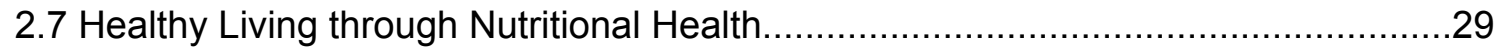

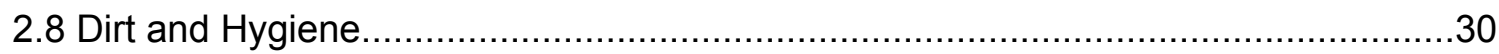

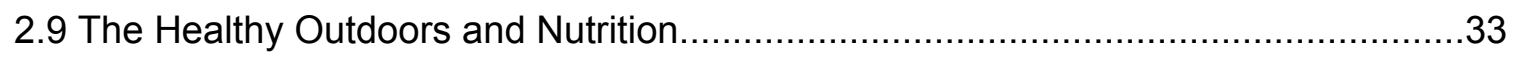

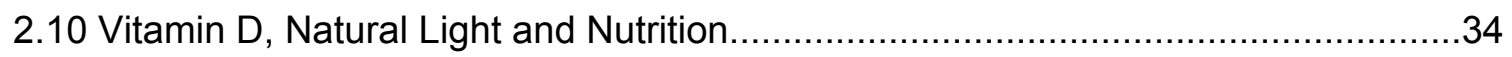

2.11 Health Effects of Ultra Violet Rays in Children.................................................37

2.12 Physical and Psychological: Nature, Attention and Attention Deficit.....................38

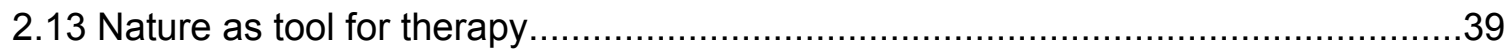

2.14 Challenges and Criticisms of Nature as Therapy........................................... 42

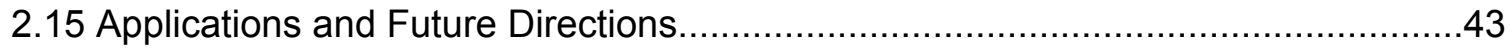

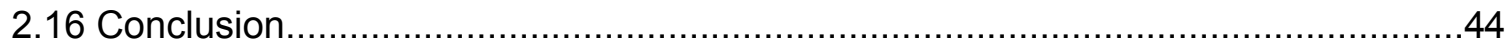

\section{THE NATURAL OUTDOORS}

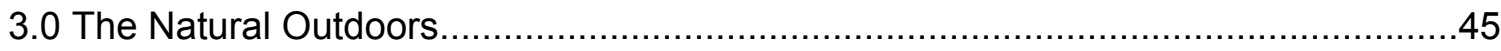

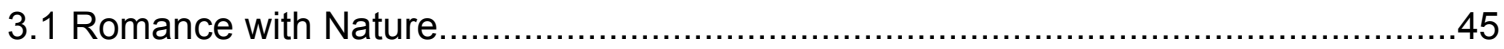

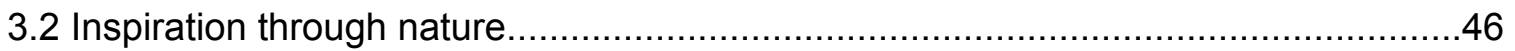

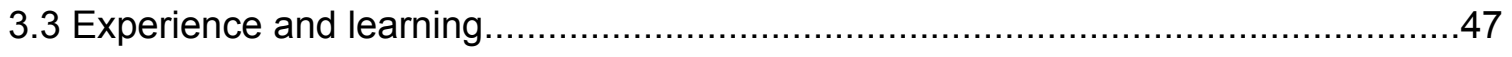

\section{PRECEDENT ANALYSIS}

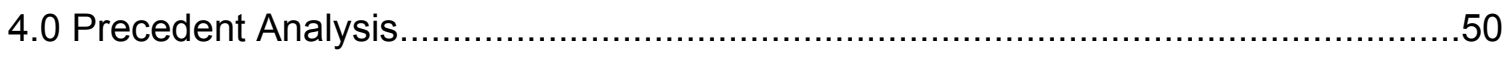

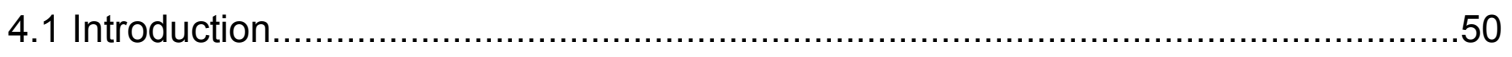

\section{Luginsland Kindergarten}

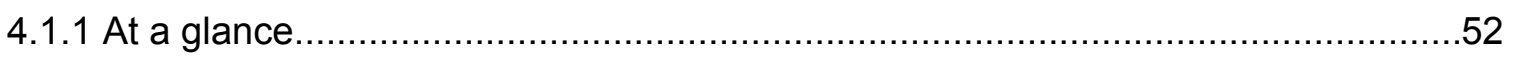

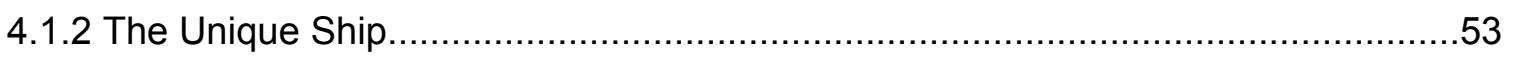

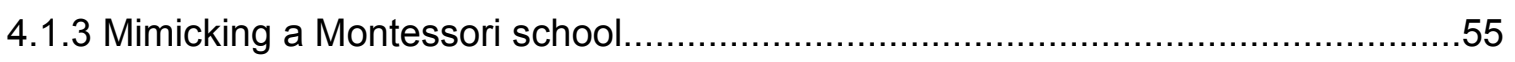

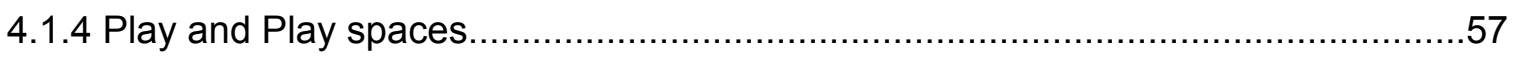

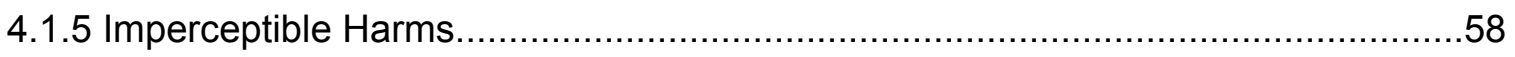

4.1.6 The Building as a teaching tool for nutritional health.....................................60

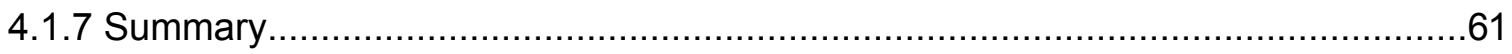

\section{Fuji Kindergarten}

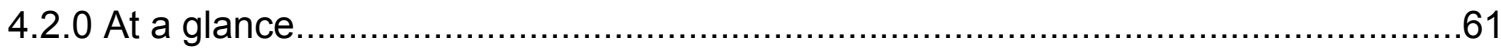

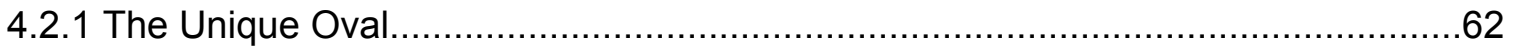

4.2.2 Experiential education and the Montessori Method........................................64 


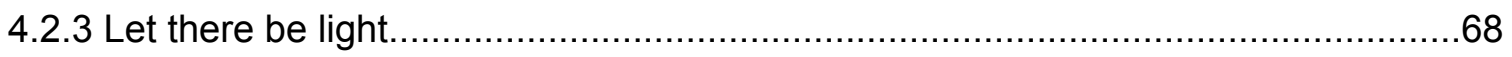

4.2.4 Imperceptible Harms near the Oval.......................................................6

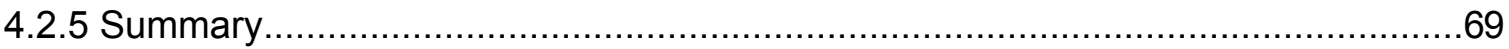

\section{Outdoor Classroom Pavilions at Eib's Pond Park and at Roy Wilken's Park}

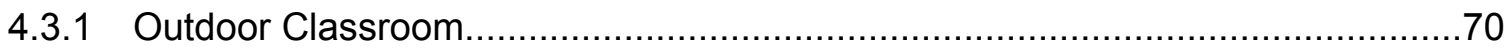

4.3.2 Simple structure, simple space, valuable experience...................................70

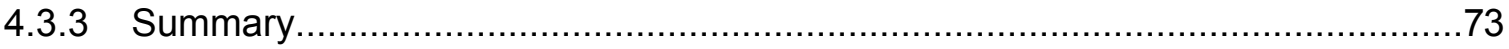

\section{DESIGN RESPONSE}

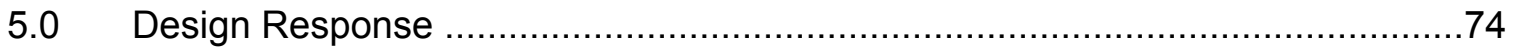

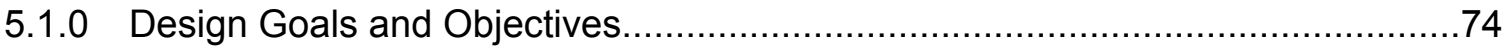

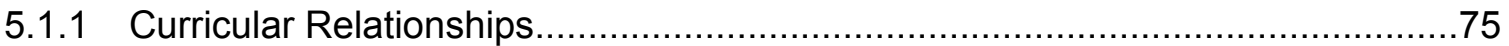

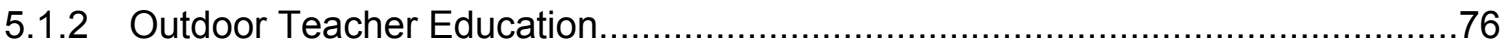

5.1 .3 Initial design sketches and draft diagrams..................................................

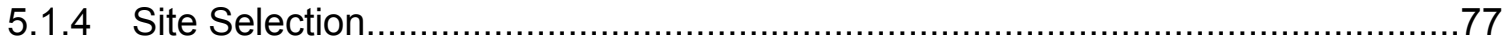

5.1.5 The Project's Impact on neighbourhood residents........................................78

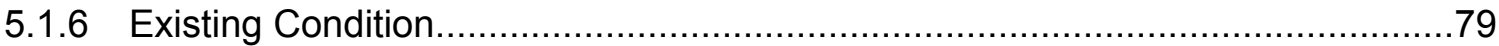

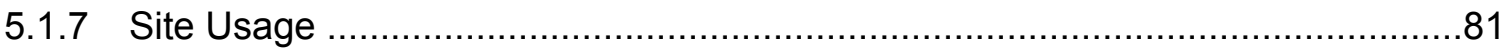

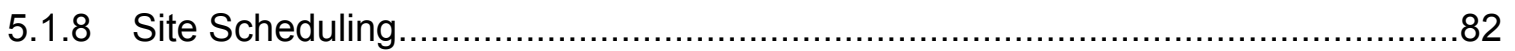

5.1 .9 The outdoor experiential support spaces............................................... 83

\section{Experiential Pit}

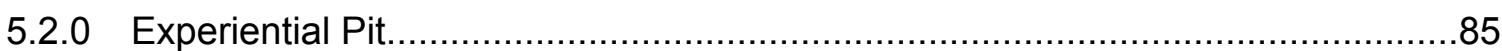

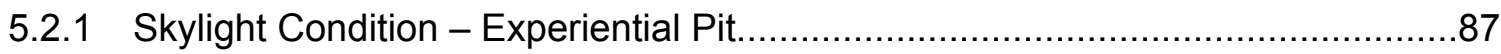

5.2 .2 Entry Ramp - Experiential Pit...............................................................

5.2.3 Floor Plans and Sections - Experiential Pit..............................................92

5.2.4 The Learning Pit (Learning tool) - Experiential Pit......................................95

5.2.5 Earth Window (Learning tool) - Experiential Pit.........................................96

\section{H20 Pavillion}

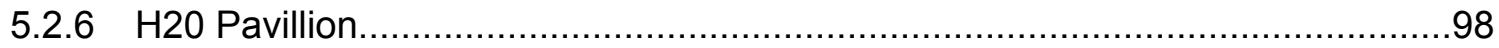

5.2.7 Plan and Section - H20 Pavillion........................................................... 100

5.2.8 Indoor / Outdoor - H20 Pavillion........................................................102 
5.2.9 Experience Wall (Learning tool) - H20 Pavillion............................................102

5.3.0 In-ground storage for learning tools - H20 Pavillion....................................105

\section{Tree Pavillion}

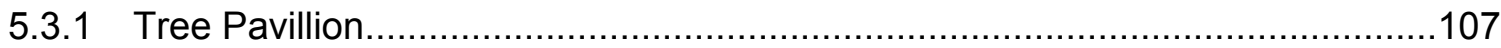

5.3.2 Access ramp, lookout points and lookout posts - Tree Pavillion....................110

5.3.3 Plan and Section - Tree Pavillion...........................................................112

5.3.4 Woven Willow Weed Skin - Tree Pavillion...............................................114

5.3.5 Structure - Tree Pavillion............................................................................ 116

\section{Summary and Conclusions}

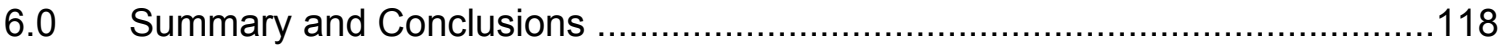

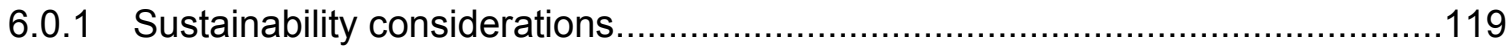

6.0.2 Speculation and Future Application.......................................................121

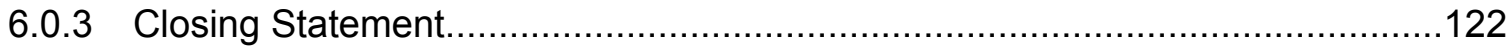

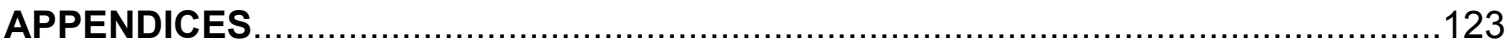

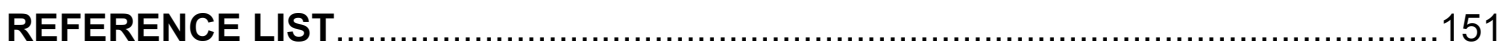




\section{LIST OF FIGURES}

Figure 1.0.1: Children interacting with each other through hands on experiential education in the outdoors 7

Figure 1.0.2: A guided nature walk in the wilderness outdoors with water. .9

Figure 1.0.3: A boy hiding under a structure, fallen trees were gathered from the forest to make this fort. 10

Figure 1.0.4: Example of imaginative play 11

Figure 1.0.5: Jean Piaget's stages of cognitive development chart. Credit: Beilin, H......14

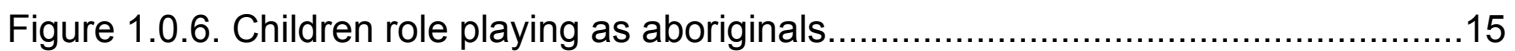

Figure 1.0.7. A boy using charcoal found a fire pit for camouflage game......................16

Figure 1.0.8: Children in the outdoors wearing ninja headbands (Fantasy) and engaging

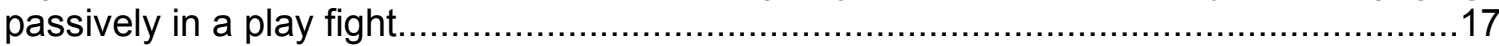

Figure 2.0: Top 10 Environmental Toxins. Credit: Mercola \& Droege............................23

Figure 2.0.1: Mind map of Environment to Cardiovascular and Respiratory diseases.

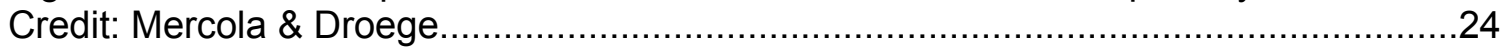

Figure 2.0.2. School bus exhaust while idling. Credit: Zeldin. D..............................26

Figure 2.0.3: Effects of genetic predisposition (Each individual) and environmental factors (Indoor and outdoor) on asthma. Credit: www.blogcdn.com ..........................28

Figure 2.0.4: A children's garden in Toronto Botanical Gardens. ..............................30

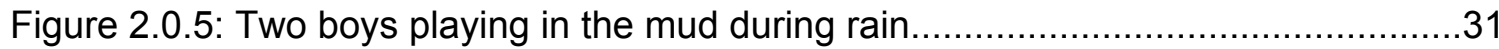

Figure 2.0.6: A young girl holding a fish that she found near the pond.......................32

Figure 2.0.7: Students from a grade one class on a hike in the winter for a mapping exercise

Figure 2.0.8: A Bright sun dropping into the wilderness..........................................

Figure 2.0.9: Children having a lesson in a partly shaded area on a sunny day............37

Figure 3.0.1: West Elevation of the Luginsland Kindergarten. Credit: Behnish and Partner.......

Figure 3.0.2: The Kindergarten Ship with the Neckar Valley backdrop for an ideal setting.

. Credit: Behnish and Partner. .53

Figure 3.0.3: Site Plan of Luginsland Kindergarten showing the sloped slope of site. 
Credit: Behnish and Partner

Figure 3.0.3: The interior view of one of a play space inside the Luginsland Kindergarten. Credit: Behnish and Partner......

Figure 3.0.4: Floor Plan of Lower Level (Ground Floor Plan) and Main Entrance Level

(First Floor Plan). Credit: Behnish and Partner.....

Figure 3.0.5: Section of the Luginsland Kindergarten. Credit: Behnish and Partner.......57

Figure 3.0.6: Wilderness Green Spaces around the Luginsland Kindergarten Credit:

Google Map.

Figure 3.0.7: Stuttgart Air Quality Details. Credit: www.airqualitynow.eu .59

Figure 3.0.8: Proximity of the surroundings near Luginsland Kindergarten. Credit: Google Maps.

Figure 3.0.9: Birds eye view of the Fuji Kindergarten. Credit: Sato. K.

Figure 3.1.0: Photo of Fiat Works by Architect Giaccomo Matte-Trucco in Turin, Italy in 1920. Credit: http://loguestudiodesign.com/ .....

Figure 3.1.1: Open learning spaces of the Fuji Kindergarten. Credit: Sato. K 63

Figure 3.1.2: A child sliding down from the roof. Credit: Sato. $\mathrm{K}$. .65

Figure 3.1.3: Opening day of the Fuji Kindergarten, when all the children dangled their legs through the thin balustrades. Credit: Sato. K 65

Figure 3.14: Circular sinks for hand washing and socializing................................66

Figure 3.15: Children are encouraged to climb the Zelkova Trees on the roof...............67

Figure 3.16: A view from the learning space at the Fuji Kindergarten.......................67

Figure 3.1.7: Proximity of the surrounding highways and streets at the Fuji Kindergarten. Credit: Google Maps.

Figure 3.1.8: The lack of green wilderness space near the Fuji Kindergarten. Credit:

Google Maps.

Figure 3.1.9: View towards Pavillion at Eib's Pond Park. Credit: TUNS Press................70

Figure 3.2.0: Section and Site Plan of Pavillion at Eib's Pond Park. Credit TUNS

Press.

Figure 3.2.1: Towards inside the Pavillion at Eib's Pond Park. Credit TUNS Press.......72

Figure 3.2.2: Pavillion at Roy Wilken's Park. Credit. TUNS Press. 
Figure 3.2.3: Plan of Pavillion at Roy Wilken's Park. Credit: TUNS Press.....................73

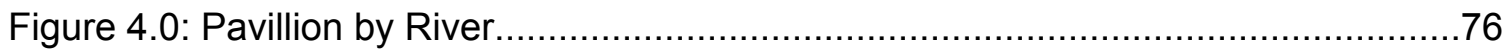

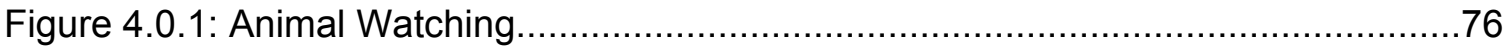

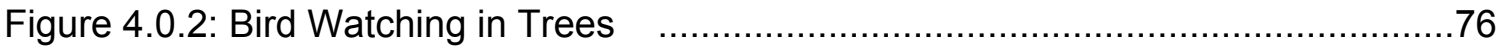

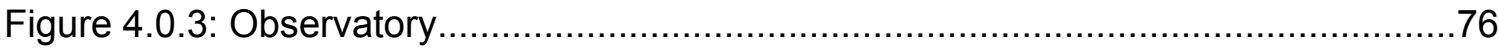

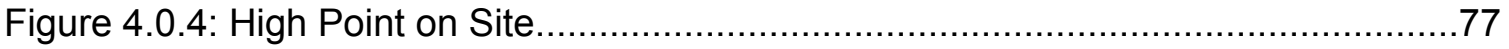

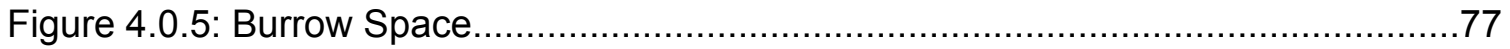

Figure 4.0.6: A map of Ward 10, shaded area represents the selected site of Forest

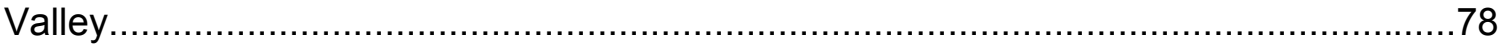

Figure 4.0.7: Site map of the current forest valley outdoor education center................80

Figure 4.0.8: Schedule of usage for Monday to Friday throughout the seasons............81

Figure 4.0.9: Schedule of usage for Saturday and Sunday throughout the seasons......82

Figure 4.1.0: Site Map showing the location of the pavilions...................................84

Figure 4.1.1: Immediate Site Map for Experiential Pit........................................ 86

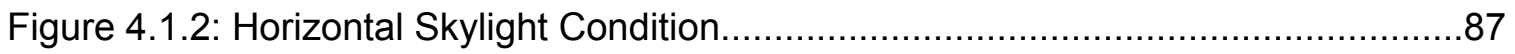

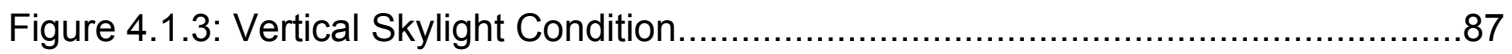

Figure 4.1.4: Horizontal Skylight Condition at the selected hours in June.....................88

Figure 4.1.5: Vertical Skylight Condition at the selected hours in June.......................89

Figure 4.1.6: Experiential Pit roof deck learning space.......................................90

Figure 4.1.7: View looking south at the Experiential Pit......................................91

Figure 4.1.8: Floor Plan with closed pit condition.............................................92

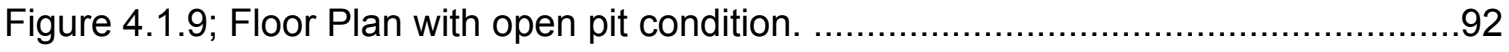

Figure 4.2.0: Immediate site and building section looking east showing the pit space....93

Figure 4.2.1: Immediate site and building section looking east...............................94

Figure 4.2.2: Students in the Experiential Pit learning Space .....................................

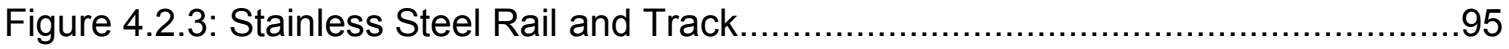


Figure 4.2.4 Track with urethane wheels.

Figure 4.2.5: A curious child looking at the earth window inside the Experiential Pit (Original Photo Credit: Hearn, J) ....

Figure 4.2.6: Exploded Axonometric of Experiential Pit.......................................97

Figure 4.2.7: Looking south at $\mathrm{H} 20$ Pavillion across the river.................................98

Figure 4.2.8: Immediate Site Map for H20 Pavillion............................................99

Figure 4.2.9: Floor Plan H20 Pavillion..................................................................100

Figure 4.3.0: Site section of H20 Pavillion looking east and showing the level

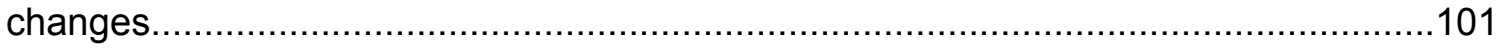

Figure 4.3.1 Interior of the $\mathrm{H} 20$ Pavilion showing the scale of the experience wall and the

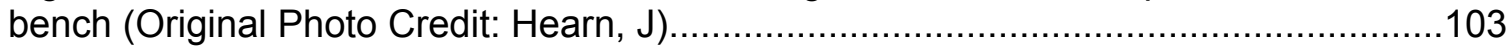

Figure 4.3.2 Students using group buckets to share their findings in the $\mathrm{H} 20$ Pavillion (Original Photo Credit: Hearn Family)...............................................................104

Figure 4.3.3: Primary aged students on instructional stairs (Learning tool)..................104

Figure 4.3.4: In-ground storage inside the H20 Pavillion......................................105

Figure 4.3.5: Exploded Axonometric of the H20 Pavillion.......................................106

Figure 4.3.6: A view toward north at the Tree Pavillion........................................107

Figure 4.3.7: Site Plan of the Tree Pavillion.......................................................108

Figure 4.3.8: Site Elevation of the Tree Pavillion facing north................................109

Figure 4.3.9: Looking north at the Tree Pavillion and the ramp lookout posts..............110

Figure 4.4.0: Site section, looking east at the ramp lookout posts and stairs..............111

Figure 4.4.1: Floor Plan of Tree Pavillion........................................................112

Figure 4.4.2: Site section "A" looking east at the Tree Pavillion...............................113

Figure 4.4.3: Woven Willow Weed Model..........................................................114

Figure 4.4.4: Woven Willow Weed Top View and Vertical Section.............................114

Figure 4.4.5: Primary school students exploring the Tree Pavillion ...........................115

Figure 4.4.6: Looking at the Tree Pavillion from below.......................................116

Figure 4.4.7: Exploded Axonometric of Tree Pavillion................................................117 


\section{LIST OF APPENDICES}

\section{Appendix A - Experimental Pit}

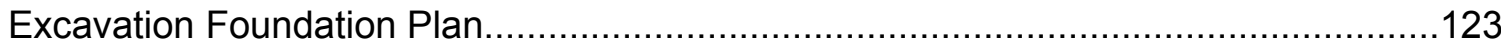

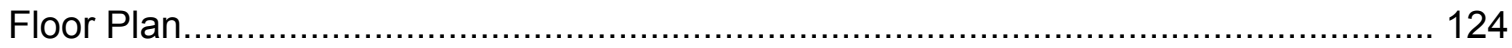

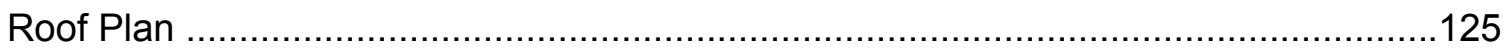

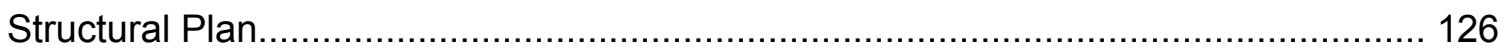

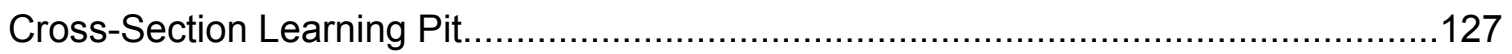

\section{Appendix B- Experimental Pit}

Open / Closed Learning Condition............................................................. 128

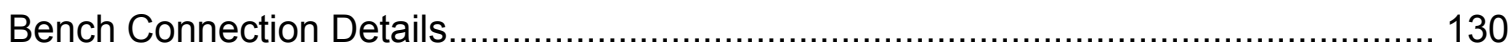

\section{Appendix C- Experimental Pit}

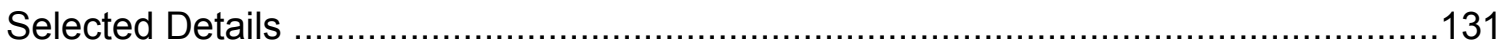

\section{Appendix D- $\mathrm{H}_{2} \mathrm{O}$ Pavillion}

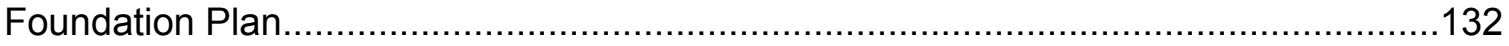

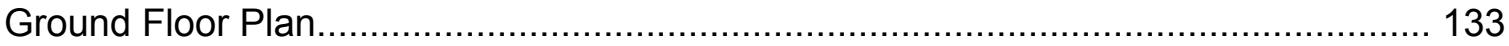

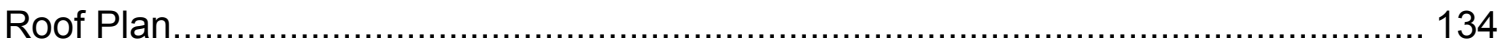

\section{Appendix E- $\mathrm{H}_{2} \mathrm{O}$ Pavillion}

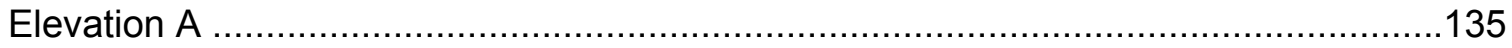

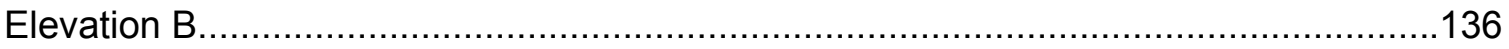

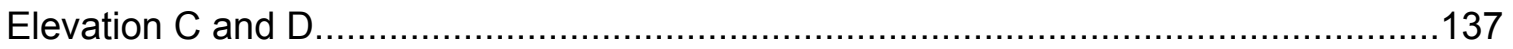

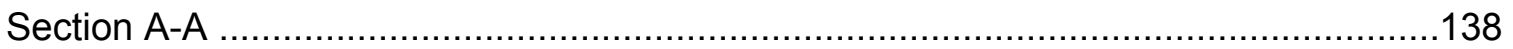




\section{Appendix $\mathrm{F}-\mathrm{H}_{2} \mathrm{O}$ Pavillion}

Selected Connections

\section{Appendix $\mathrm{G}-\mathrm{H}_{2} \mathrm{O}$ Pavillion}

Selected Details .140

\section{Appendix H-Tree Pavillion}

Foundation Plan .142

Primary Structure Plan. 143

Secondary Structure Plan .144

Primary Structure Plan .145

Roof Plan 146

\section{Appendix I- Tree Pavillion}

Selected Details...

\section{Appendix J- Tree Pavillion}

Showing structure below. 149 
xvii 


\section{Introduction, problem statement, and background information:}

Children's needs are often overlooked and their voices unheard in our fast-paced society. This has resulted in a lack of quality experiential educational opportunities for children in today's cities. My experiences as a veteran counsellor, working with children in an outdoor setting and as a professional educator have led me to question the rationale behind the design of these spaces. Child care centers and schools often display a visual bias; many designers and educators believe that a building with many colours and images of outdoor nature will provide a "good enough" learning environment in which to experience the elements of the outdoors.

Today's children lack environmental stimuli that previous generations took for granted. Basic elements such as natural playscapes, natural light and ventilation have become a rarity in the urban school environment. To add to this shortcoming, the little time that children do spend outside of school and experiencing the outdoors is often wasted on playing digital video games in minivans while on family trips. City children suffer from a Nature-Deficit disorder, poorly designed schools, and child care facilities that only contribute to the deficiency.

There is scientific evidence that the first years of life are crucial to the development of a child. Research also confirms that "babies raised by caring attentive adults in a safe, predictable environments, are better learners than those raised getting less attention in less secure settings." (Olds, 2001) Designs that promote children's natural developmental needs must provide environments whose elements incorporate the outdoors.

In North America, there is a need for awareness and change to modify how children's facilities are designed. By contrast, in European countries architects and educators collaborate to create educational spaces that maintain the highest architectural quality.

To raise the quality of our country's learning and educational levels, children must have a positive early start to learning. As architects, we should provide learning environments that are uplifting and exciting for children, since they are our future. 


\subsection{An insight and comparison of influential education theories}

\subsection{Introduction}

Numerous theories abound in our ever-changing educational systems. Although these theories are aimed at enhancing learning and providing a better understanding of the whole child, every child is unique and no single theory can fairly represent an individual. For the most part I have chosen to present $20^{\text {th }}$-century theorists. To make comparisons of theories relevant, it is important to provide insight into what they have actually contributed and how they have influenced the field of education. This thesis will compare the theories of John Dewey, Maria Montessori, and Rudolph Steiner; their influence on experiential learning is evident around the world. The comparisons will largely focus on children from the preschool age of 3 to the elementary school age of 12 .

Architectural spaces influence children in numerous ways, from affecting their health to enhancing their inspiration to learn more. A space such as a classroom or a daycare center should be viewed not just as a place for guardianship but more as a place where endless possibilities await. Well designed spaces that adapt to young learners and accommodate their multiple intelligences can be used as tools to enhance learning and creativity, especially during the first few years of life. There is significant historical background and many respected theories to provide guidance and inspiration, and to pave the way towards a better understanding of children's education in our society.

\subsection{The theorists}

John Dewey was an American philosopher, educator, psychologist, and educational reformer. He was one of the most influential educational thinkers of the $20^{\text {th }}$ century. Dewey believed that true education comes through stimulation in social situations and that the educational process can be separated into two parts, psychological and sociological, with psychological being the base. He stated that children have their own instincts and tendencies, but that these cannot be understood until translated into social modes. He also believed that education reflects, generates, and guides social change. His educational theories that were presented in a 1897 document titled My Pedagogic Creed. In it Dewey discussed the school as primarily a social institution and a form of community life. He believed schools were failing because of a lack of community. Dewey's belief developed into an advocacy of experiential education, a philosophy of 
education that focuses on the transactive memory process between teacher and student occurring when they share direct experience with the learning environment and its contents. (Itin, 1999) Other theorists have concurred with Dewey's beliefs and have put forward their own theories to contribute to the field of education.

Maria Montessori was an Italian physician, educator, and philosopher; she is best known for her philosophy of the Montessori Method of education. She believed in the dictum of "a child as seed", someone who needs a living environment to develop. The Montessori learning environment is obstacle-free in order to stimulate the potency of a child's hidden potential. It results in a learning space where children are at the centre of all activities, learn by themselves and are free to select any activity they want. In addition, Montessori classrooms provide an atmosphere that is pleasant and attractive with everything from furniture to manipulatives adapted to each age group's scale. This permits children to learn at their own pace and interact with others in a natural and peaceful environment.

In an ideal Montessori classroom, children have open access to the outdoors. In addition to natural outdoor environments, learning spaces incorporate small animals, furniture made from natural materials such as wood, and some even include indoor gardens. All these considerations allow the children to experience the natural world as much as possible, given that they are still under modern constraints. Montessori schools ideally adhere to a three-year age range of pupils to encourage an interactive social and learning environment. This system permits for flexibility in learning pace and allows older children to become teachers by sharing what they have learned. (Montessori, 1936)

Rudolph Steiner was a philosopher, literary scholar, educator, artist, playwright, and social thinker. Most importantly, he was the founder of Waldorf education. Waldorf education is a pedagogy based on interdisciplinary learning that integrates practical, artistic and intellectual elements. (Rist \& Schneider, 1979) The Waldorf approach emphasises the role of imagination and imitation in learning. Extensive time is given for guided free play in a home-like classroom environment. A scheme extends to the particulars of having natural materials in the learning and play spaces. The layout of spaces provides productive work areas for children. Such an environment is considered by Waldorf pedagogues to be supportive of the physical, emotional and intellectual growth of the child through assimilative learning. (Rist \& Schneider, 1979) Steiner's 
Anthroposophy theory is considered spiritual since it cultivates a form of thinking independent of sensory experience. (McDermott, 1984) Steiner's educational philosophy has been commended for being based upon peace and tolerance. (UNESCO, 1994)

There are many similarities and differences between the three educational philosophers. All these theorists agree that learning is a social process. In schools today, a lack of community is demonstrated in their architectural designs, their curricula, and also the proximities of the school. If he were alive today to see what education has become, John Dewey would agree that $21^{\text {st- }}$ century children have been robbed of the sociological half of the balance.

\subsection{Spiritual ideas - A form of escape from reality?}

Theories relating to spirituality have limits. Steiner's spiritual ideas cannot be proven scientifically; they are simply theories and idealized ideas. These spiritual ideas have been revisited recently in response to the chaotic and busy lives of children today and their parents' desire for them to enjoy carefree childhood. A large portion of the population embraced Steiner's philosophies after World War I, a time when people could embrace a sense of freedom, and support spiritual ideas. Steiner coined a phrase to describe this era and modes of expression specific to it: "Social Three Folding". His movement advocated democracy in political life, freedom in cultural life, and cooperation/community in economic life. This movement was based on the philosophy of anthroposophy founded by Steiner (Tummer, 2001), who had written his first book, The Education of the Child, in 1907. The first school based upon these principles was opened in 1919 in response to a request by Emil Molt, owner and managing director of the Waldorf-Astoria Cigarette Company in Stuttgart, Germany. This is the origin of the name Waldorf, now trademarked for use in association with this educational method. (Hemleben, 1975) In Waldorf education, stories and fairy tales familiarize children with the journey of humanity and may help guide them in life. Maria Montessori would agree that children need to see the greater picture as it can help a child to determine his or her role in society. Montessori students are encouraged to seek the truth and understand the life paths ahead of them. They are guided as they seek their callings in life. (Montessori, 1936) Steiner's philosophies advocated the deferment of learning to read and write until age seven and incorporated spiritual ideas; it also promoted surrealism and escape from reality. This notion of the surreal life often resulted in people living a lie and 
avoiding their everyday responsibilities. Children at all ages have responsibilities; one responsibility of young children is to go to school, learn, and be challenged to the best of their abilities so that they can contribute positively to society at all stages of their lives.

Dewey in contrast, took the realist vision, which is seen as the middle ground between spirituality (with religion) and science. Dewey wanted neither formal science nor spirituality. He believed that there is a balance between the psychological and sociological in the spectrum of learning experiences. Along this spectrum, with reference to Steiner's beliefs, the discomfiture of the child's inability to comprehend and write at age seven would have both psychological and sociological effects later in childhood. Children do not spend every day of the year at school, so when they were outside the forced surrealism of the classroom, they would find that their social counterparts demonstrate a higher learning experience. For instance, they would be able to read a book, a magazine or an advertisement. Psychological effects resulting from this negative social experience would include the primary effects of self-doubt and emotional indifference from their peers.

Generally, Dewey was a pragmatist; he had difficulties with Steiner's emphasis on the spiritual in contrast to the material. Steiner's idea of spirituality inclined toward seeing life as surreal, and did not connect children to reality. A more thorough discussion of spiritual spaces will be available later in the research when looking into the relationship between spirituality and architectural spaces. Despite the differences between these theorists, there came to be a progression towards a balance between spirituality and reality on a deeper level. Both Dewey and Steiner supported an integrated vision of education that recognized the whole child. 


\subsection{Experiential education and the outdoors}

Dewey, Montessori and Steiner all have valuable views on learning atmosphere and experiential education. The theory of direct learning experiences through experiential education is something that is agreed on by all three theorists. Experiential education is a philosophy of education that focuses on the transactive process between teacher and student in concert with the learning environment and content. (Itin, 1999) In this thesis, the term "experiential" is defined as a vision of being outdoors in nature, of allowing children to engage with the natural environment, of learning through doing with various hands-on activities designed for outdoor education, and as a study of natural science that aligns with the provincial curriculum.

John Dewey was the most renowned advocate of experiential education, possibly paving the path for future research. This initial study was first explored in his influential book Experience and Education published in 1938. In this book, Dewey pointed out that authoritarian and traditional public education was too concerned with delivering knowledge, and was not effective in providing actual experiences nor in understanding the whole child. (Dewey, 1956) Montessori and Steiner both believed that children's stimulation to learn might be dependent on whether the space is indoor, outdoor, hybrid, or if it is associated with or has interactions with nature. The term "hybrid" used in this thesis represents a learning space that merges outdoor nature and indoor space. Hybrid spaces will be discussed in more detail later in the thesis. The Montessori and Waldorf curricula both stress children's' interaction with natural elements as they are working and playing. The idea of natural elements includes specific natural wood furniture within the learning spaces, and the restriction of plastic-related materials in all the learning spaces used by children and staff. The Montessori teaching method encourages the use of natural spaces as a learning tool. Montessori also suggested that lessons should be held outdoors whenever possible. (Montessori, 1936) 


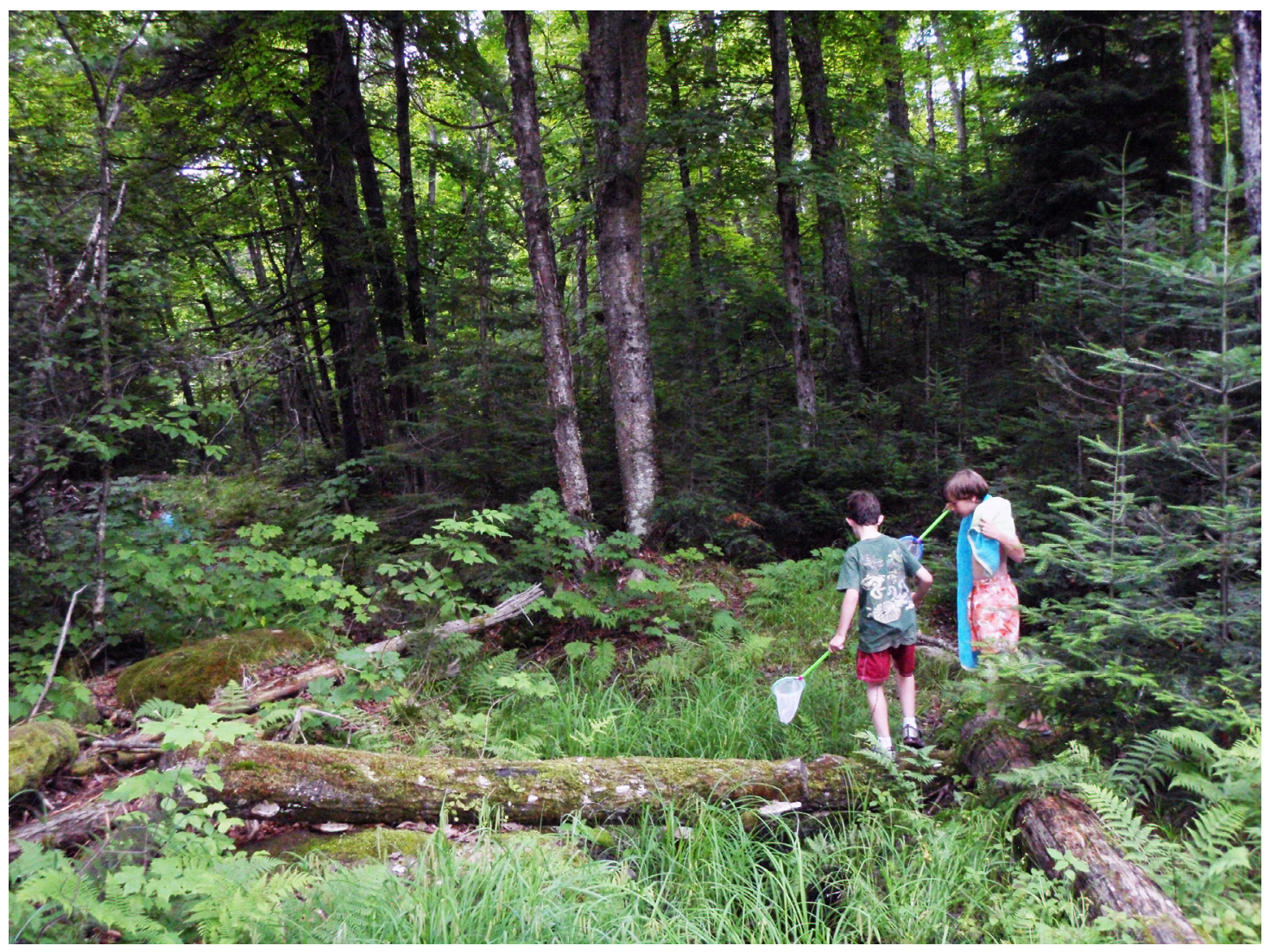

Figure 1.0.1: Children interacting with each other through hands on experiential education in the outdoors.

Dewey, Montessori and Steiner have influenced many contemporary ideas about experiential learning. The work of Dr. Joe Frost, Rachel Carson and Richard Louv has built upon these ideas that support experiential education in the outdoors. Joe Frost, Professor Emeritus at the University of Texas, is a global playground consultant and past president of both the Association for Childhood Education International and International Play Association. He focuses on childhood play and learning. Like the three main influential theorists mentioned above, he believes that children should play in ideal outdoor settings and that " when children are in movement and can take an active role in building their own environment, they learn to take risks, develop aesthetic appreciation, strategize, mimic adult roles, practice new skills and make mistakes" (Frost, 2006). In addition, Frost believes that adults are "messing up" children's play because they don't properly supervise play opportunities. Frost proposes that adults can enhance children's play by "ensuring extensive time for free outdoor play, by teaching children about nature through hands-on experiences, and can enhance development by 
balancing play with physical work, technology play academic, and quiet times for doing nothing and reflecting." (Frost, 2006)

Rachel Carson is another contemporary theorist who supports children sharing time with outdoor nature. She believes that children should have fun exploring nature. One of her main philosophies is that adults should share experiences in outdoor nature with children; for instance, on hikes sights and sounds of interest could be pointed out. In her book The Senses of Wonder Carson writes "The focus should not be on scientifically naming the flora and fauna, it is more important for children to make an emotional connection with nature." (Carson, 1965)

The term "natural space" in this thesis represents spaces that are interactive with outdoor nature; this could be in the form of outdoor green spaces and spaces that integrate the indoors and the outdoors. Such spaces could be green balconies, walkout classrooms or pavilions. Natural spaces can also be indoor spaces with natural openings, sky lights or other creative forms of indoor interaction with nature. In ideal Montessori Schools, natural experiences may include gardens, terrariums inhabited by small animals, and nature walks in the woods where such things as the interdependence of plants and animals and the essential role that water plays to life can be pointed out.

There are countless publications and references that support the use of experiential education with nature. One influential book on this topic is Last Child in the woods: Saving our children from Nature Deficit disorder. (Louv, 2005) Richard Louv coined the term Nature Deficit Disorder. He was referring to the trend of children not spending enough time engaging with outdoor nature. Louv spent ten years travelling around the United States speaking with parents and children in both rural and urban areas about their experiences in outdoor nature. He argued that paranoid parents have literally "scared children straight out of the woods and fields," while promoting a controversial culture of fear that favours "safe" regimented sports over imaginative play. (Louv, 2005)

Joe Frost, Rachel Carson, and Richard Louv's research agree with their predecessors Dewey, Steiner, Montessori (and several others) that children need to engage with nature for experiential learning and for psychological health in today's society. 


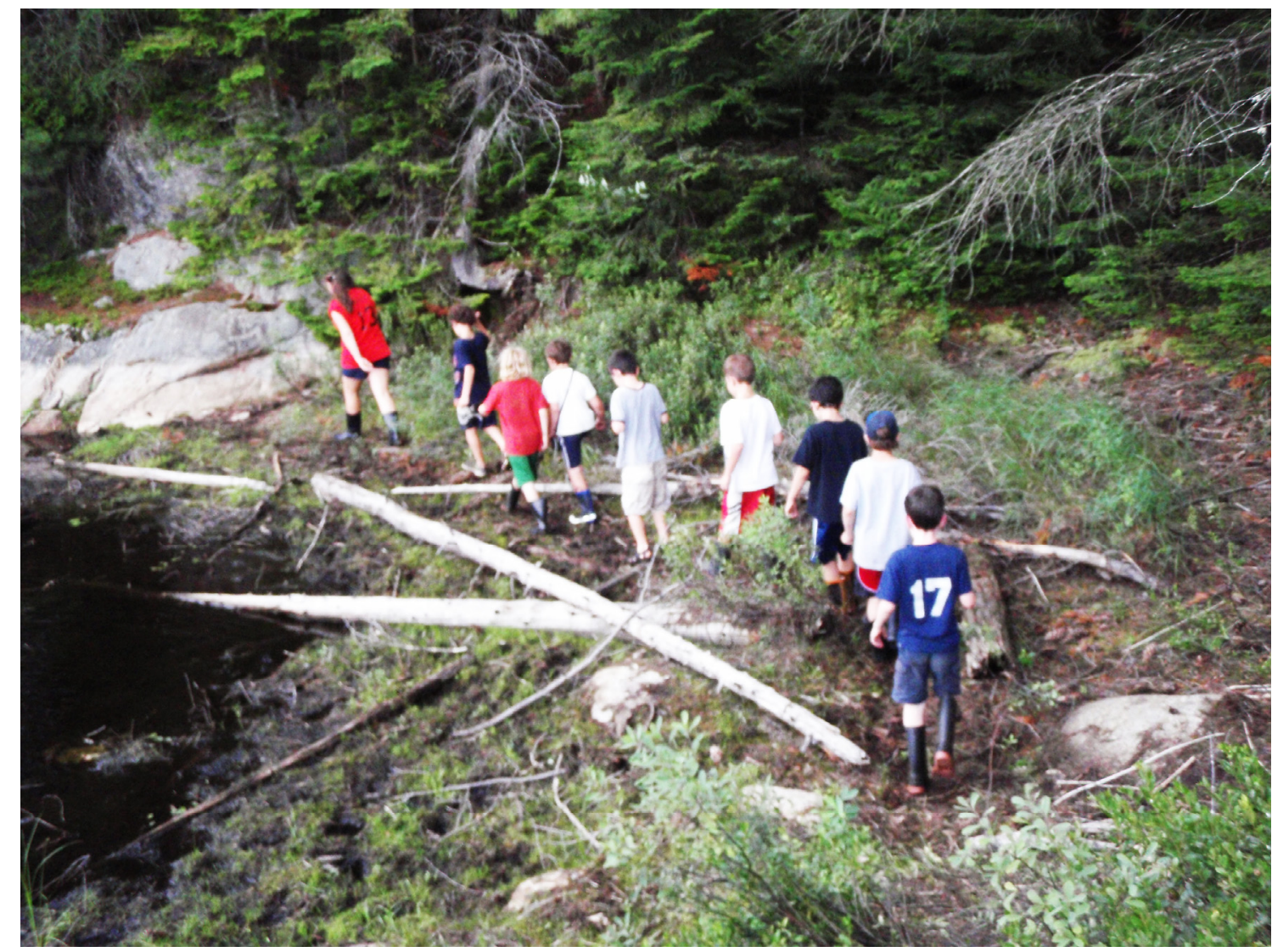

Figure 1.0.2: A guided nature walk in the wilderness outdoors with water.

\subsection{Imagination and Play}

Use of imagination and play can be viewed in many ways. The attainment of knowledge is a subconscious benefit as children engage in imitation and make-believe. Play can be viewed as a child's audition for the future. There are many types of play; the two main types are categorized by educators as free play and organized play. Free play may be defined as allowing children to play without rules or regulations. An example of free play would be allowing children to give free rein to their imaginations and creativity in an outdoor playground. Organized play, on the other hand, involves play with rules and within boundaries. One example is wilderness survival: some children are carnivores, some omnivores, others herbivores and the goal is survival. Sport is another example of organized play. Every sport involves rules, and children learn to play with rules and restrictions. 


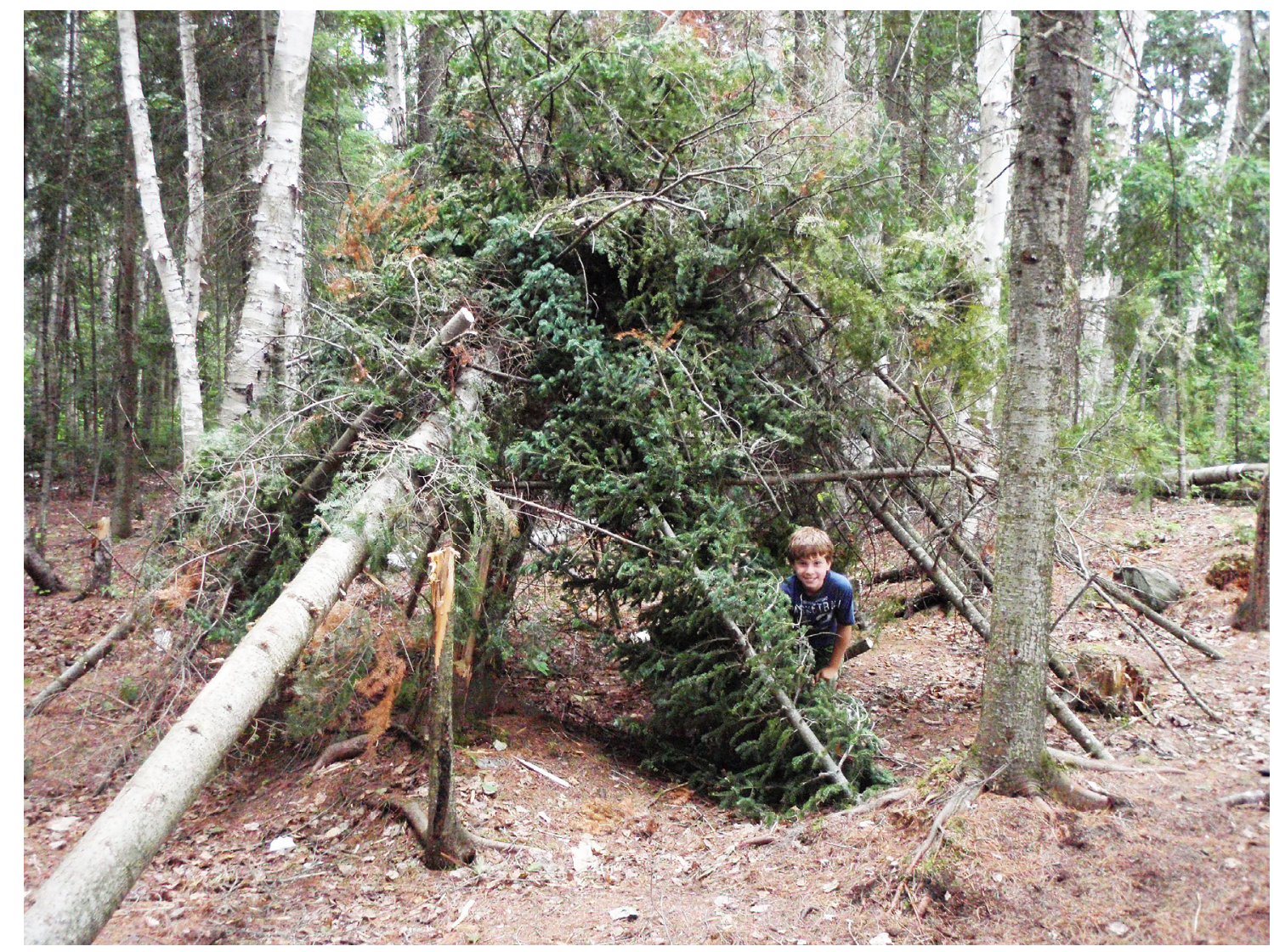

Figure 1.0.3: A boy hiding under a structure, fallen trees were gathered from the forest to make this fort.

Both free play and organized play permit creativity and imagination, although through different ways of thinking. Dr. Edward S. Casey is a distinguished scholar whose concentration is in phenomenology, philosophical psychology, aesthetics, and the theory of psychoanalysis. According to his book Imagining: A Phenomenological Study, imagination is a phenomenon that is composed of an act phase and an object phase. He writes:

As such, the term is synonymous with the coordinate terms "imaginative experience" and (emphasizing its intentional character) "imaginative act-cumpresentation" or "act-presentation." The expressions "the imagination" and "an imagination," which are unnecessarily reifying, have been eliminated wherever possible. It should be noted that the generic term "imagination" as used in this essay is not interchangeable with creative imagination. Creative imagination--or more exactly, the creative use of imagination--is an application or extension of 
imagination proper. (Casey, 1976)

Imagination makes the sensory experience significant. It is what enables a child to understand and to make sense of any experience, familiar or imaginary. Imagination produces mental and visual imagery and allows children to think unconventionally, drawing on past memories. Imagination also enhances children's ability to be critical and uses personal interactions to create solutions for the future.

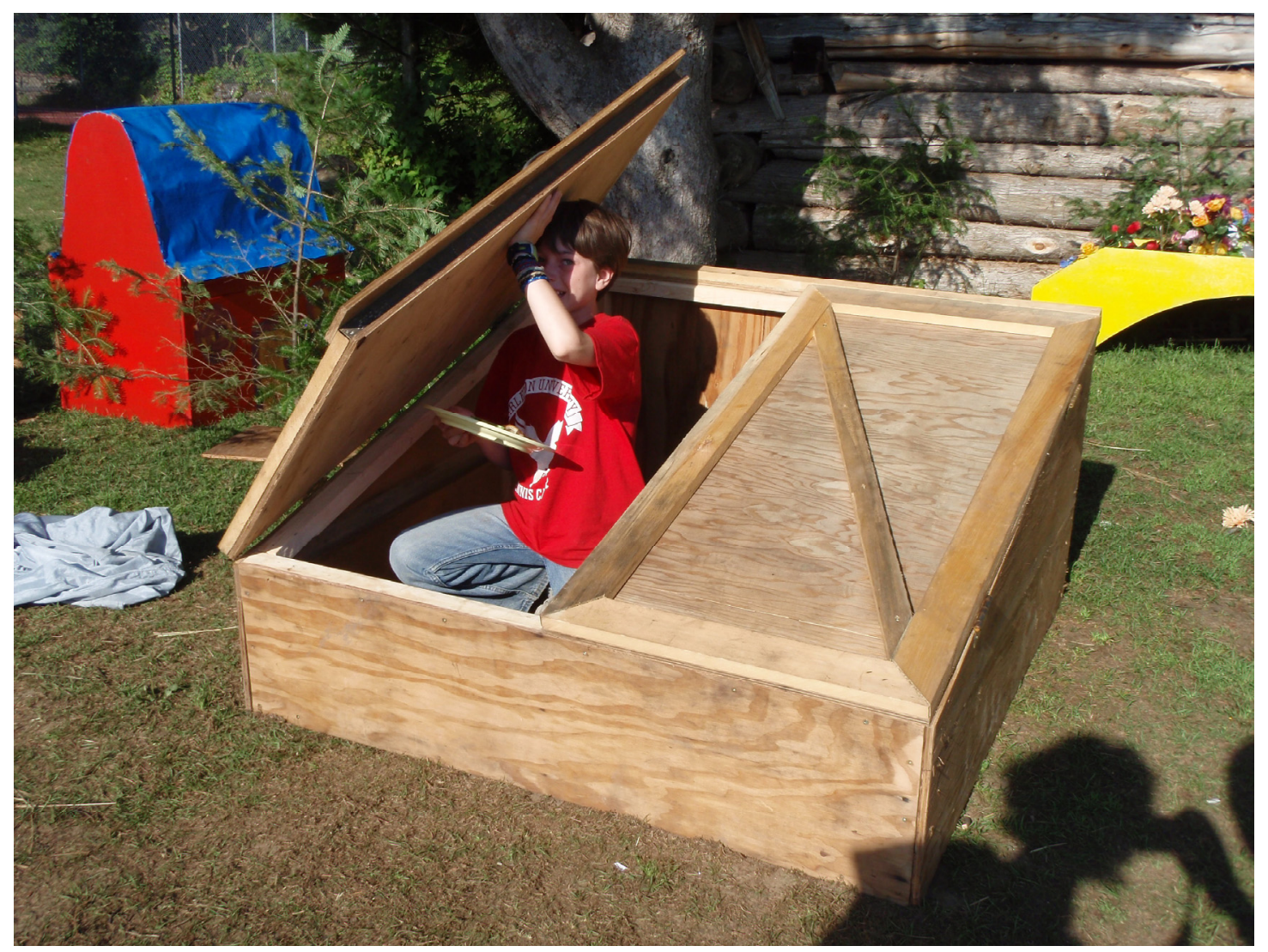

Figure 1.0.4: Example of imaginative play

The book Ambiguity of play by Sutton-Smith (1997) reviews studies concerning play from several disciplines. Sutton-Smith approached his research on play from the viewpoint of the disciplines of biology, anthropology, literary studies and performance. It deals with risky and vicarious play as well as with games that encourage children to pretend. Main concepts put forward by Sutton-Smith include the ideas of progress, fate, power, identity, imagery, self and frivolity. 
Its observational research resulted in a division of rhetoric and traced four of its modes from the ancient Greeks: Fate, Power, Identity, and Frivolous behaviour. It also identified three modern examples of rhetoric that stem from post-enlightenment thought: Progress, Imagery, and Self. (Frost, Wortham, \& Reifel, 2008) These examples of rhetoric open a discussion that involves different disciplines and includes different play forms, and also presents the theorist or researcher associated with them. For instance, the focus of one section is the disciplines of biology, psychology and education, all of which fall under the rhetoric of Progress and which can be associated with many theorists, scholars, and researchers.

The tenets of Steiner, Montessori, and Dewey's all highlight the idea of Imagination and Play as learning tools, categorised under the rhetoric of "Progress".

During the 1920 and 1930s, Lev Vygotsky's research expanded knowledge of the effects of play. Writing profusely about the association of children's social experiences with learning, Vygotsky's perspective, similar to John Dewey, considered the fundamental relationships between the social and the psychological worlds of people and particularly of children. The four basic principles that constitute the Vygotskian framework include:

- Children construct their knowledge

- Development cannot be separated from its social context

- Learning can lead development

- Language plays a central role in mental development (Social)

Vygotsky emphasized the social roots of cognition and the importance of the "zone of proximal development" in which interaction with knowledgeable peers plays an important role.

Cognition is a concept used in different ways by different disciplines, but its meaning is generally accepted to be the process of awareness or thought. Vygotsky defined "zone of proximal development" as the proximity of a child's actual mental age to the level that he or she may reach when they receive assistance in solving problems. Likewise, play creates a zone of proximal development in the child. (Vygotsky, 1978) With play, through imagination, the child always behaves beyond his average age and above his daily behaviour. A young hockey player may act and perform with more maturity, 
initiating leadership and communication with his teammates, if he has been given the role of Captain. Another example is when children play doctor and apply a bandage to a playmate "patient". Here they are acting older and thinking beyond their age because they are involved in creative problem solving. Play is not only itself a major means of development but also involves in condensed form all the elements of development. (Vygotsky, 1978) As was mentioned earlier, John Dewey pointed out that children's experience and that of their educational process can be separated into two parts: psychological and sociological. He theorised that play tended to fall into the sociological category. Imagination and play have many benefits and are prerequisites for later life experiences.

Another theorist who focused on the value of play was Jean Piaget. Although his theories of cognitive development are not the same as those of Vygotsky, they are comparable. Paiget's theory is separated into four stages, which is structurally different from those of Vygotsky and Paiget's. He divides children's ages into a matrix of stages, beginning with the Sensorimotor and followed by the Preoperational, Concrete Operation and Formal Operational.

Piaget considered that there were several factors in a child's cognitive development. Along with Dewey, Montessori and Vygotsky, Piaget felt that the most critical aspect of imagination and play was social interactions with peers. Piaget believed that social interactions lead to cognitive conflicts that turn into arguments and debates with peers. These conflicts force the child to try to see another's point of view. Piaget found that children are freer to confront ideas when working with peers through play, as compared to when they are interacting with adults. (Piaget, 1962) 


\subsection{Piaget's Stages of cognitive development}

$\begin{array}{ccc}\text { Stage } & \text { Age } & \text { Description } \\ \text { Sensorimotor } & 0-2 & \text { Reflex base, coordinate reflexes } \\ \text { Preoperational } & 2-6 \text { or } 7 & \text { Self-oriented, Egocentric } \\ \text { Concrete } & 6 \text { or } 7 \text { to } 11 \text { or } & \text { More than one view point, No abstract problems, } \\ \text { Operation } & 12 & \text { consider some outcomes } \\ \text { Formal } & 11 \text { or } 12 \text { and } & \text { Think abstractly, reason theoretically, not all people } \\ \text { Operational } & \text { up } & \text { reach this stage. }\end{array}$

Figure 1.5: Jean Piaget's stages of cognitive development chart.

The critical difference between Piaget's and Vygotsky's theories is that Piaget believed intelligence came from action. He believed children learn through interaction with their surroundings and that learning takes place after development. On the other hand, Vygotsky felt that learning happens before development can occur and that children learn through history and symbolism. Vygotsky also believed that children value input from their surroundings and from others. While Piaget's theory has four clear stages, Vygotsky didn't allege any stages at all. The similarity between Piaget and Vygotsky lies in that they both believe that the limits of cognitive growth are established by societal influences, as opposed to John Dewey's belief that education guides social change.

\subsection{Fantasy Play}

A play form that is comparable to imagination is fantasy. Fantasy play would fall under the category of arts and literature and be included under the rhetoric of imaginary. Fantasy play involves imagination, creativity and role playing. A child may choose to be someone else and thereby safely try out new situations. To do this the child behaves beyond their age and personality, and moves outside of their own life to take on or relate to another character, object or event. Through fantasy play, a child is able to examine, interpret and understand the complex nature of relationships and interactions, and to gain a sense of control over the world. The developmental benefits for children in fantasy play include encouragement of creativity, imagination, expression and spontaneity. It also aids their emotional flexibility and gives them opportunities to deal with or work through emotions. 


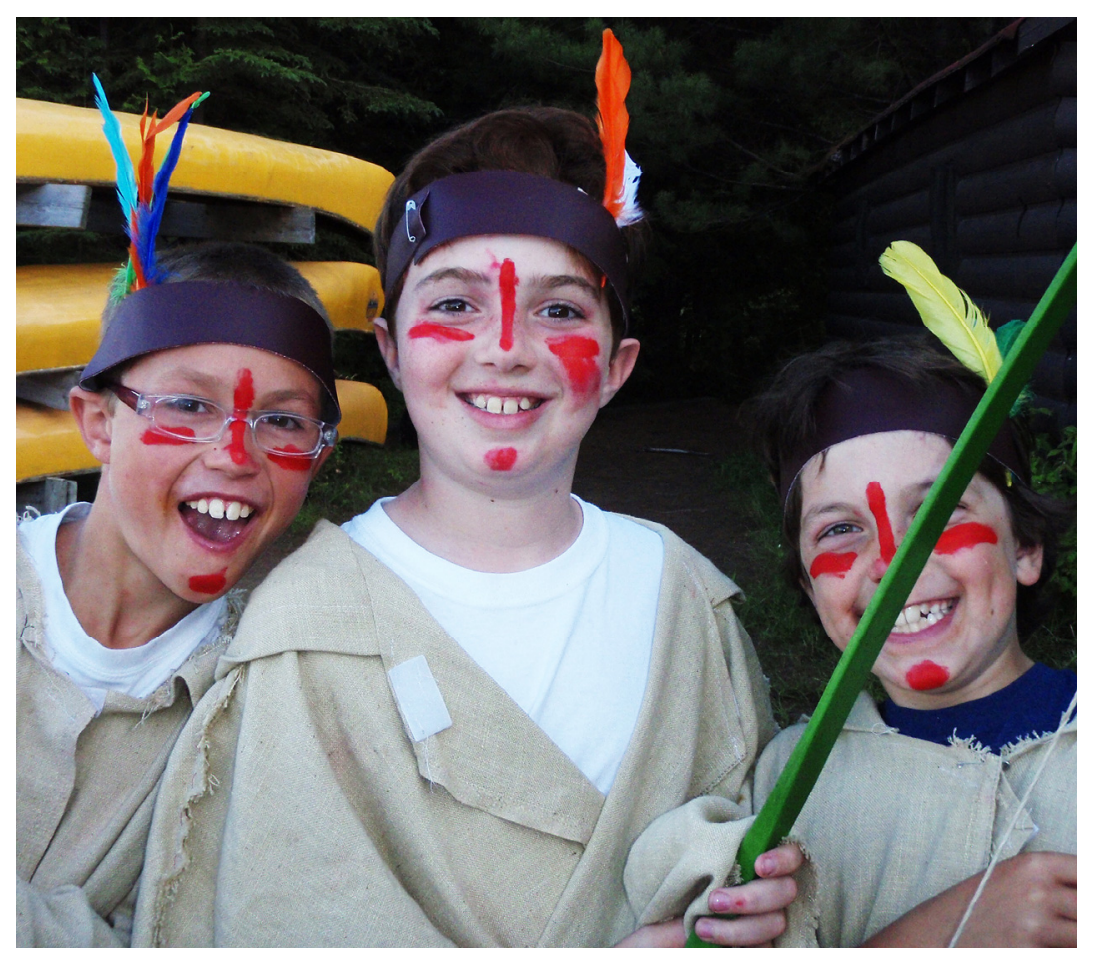

Figure 1.0.6. Children role playing as aboriginals.

Role playing helps children explore moral dilemmas, test choices and determine the consequences of their own actions. It also helps them develop insight into others, good communication and social skills, and an ability to observe and be sensitive to other people. (Koralek, Newman \& Colker, 1995)

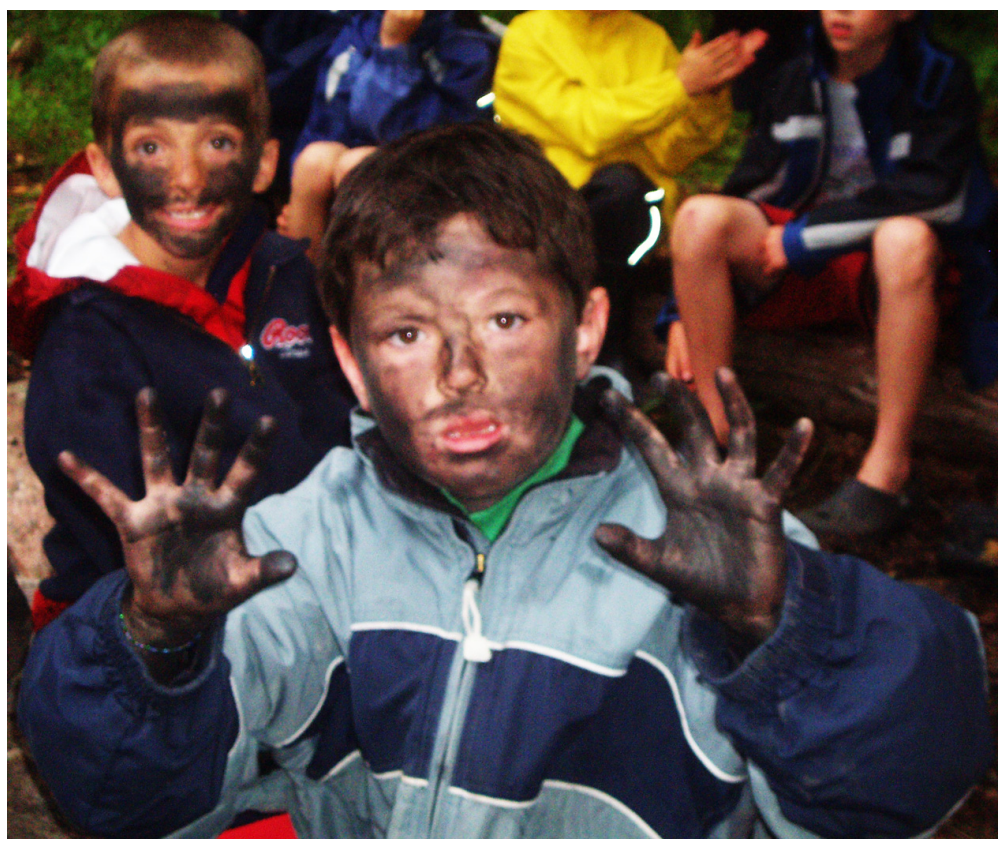

Figure 1.0.7. A boy using charcoal found a fire pit for camouflage game 


\subsection{Experiential play}

A different view of play and its paradoxes is seen through the eyes of researcher Gregory Bateson. He observed monkeys playing at a San Francisco Zoo and questioned whether the monkeys intuited their actions as play or conflict. He suggested that they were capable of sending social cues that indicated "this is play" (Bateson, 2000) and that "these actions in which we now engage do not denote what those actions for which they stand would denote" (Bateson, 2000).

The observations by Bateson developed into an influential concept that could serve as a framework for the understanding of social aspects of play as put forward by John Dewey. Play-fighting is an oxymoron; it suggests a paradox of aggressiveness and passivity; hence the saying "The nip denotes the bite."

Social skills can be directly related to children's free play. Free play is considered a form of experiential education since children often learn social cues from it and then use these in their daily lives. It relates not just to the sociological half of the balance but also significantly to the psychological half. As adults, sociological cues learned in childhood are often used to understand the nature of daily interactions in such situations as job interviews, presentations, and other professional interactions. There are moments when children and adults may question a situation or scene and ask themselves, "Is this play?" Teachers often experience situations where students are "play fighting" and the learning outcomes in such play forms are exactly as Bateson recorded. 


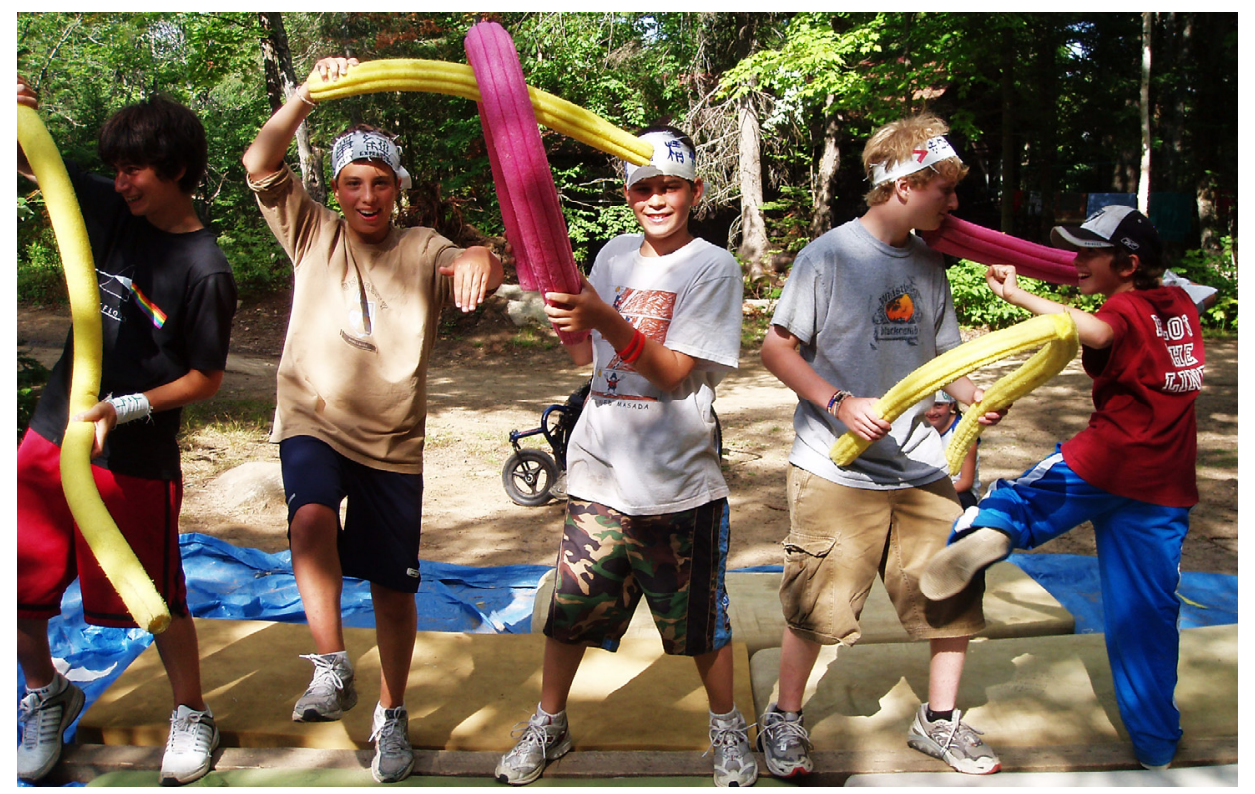

Figure 1.0.8: Children in the outdoors wearing ninja headbands (Fantasy) and engaging passively in a play fight.

\subsection{Play and Social ability.}

As mentioned earlier by John Dewey in his pedagogical creed, the educational process consists of a balance between the sociological and the psychological. An activity considered sociable in childhood is that of having arguments. Although arguing is not considered direct free play by many teaching professionals, it often occurs naturally among children during free play or recess. At home, parents typically have an aversion to arguments with their sons or daughters, but these are inevitable, especially during pre-teen years.

Children gain experience in arguing through play. Dr. Deborah Schiffrin, a researcher and professor who focused on sociolinguistics, discourse analysis, and pragmatics, wrote in her book Everyday argument: the organization of diversity in talk (referencing Georg Simmel, a well known sociologist) that free play activity becomes sociable when there is "no ulterior end, no content and no result outside itself" (Simmel, 1961, p.158, cited in Schiffrin, 1984, p.315). An argument, according to Schiffrin, can be considered sociable as long as the content does not become more important than the activity of arguing. Therefore, arguing for the sake of arguing may be a sociable activity, but it can also be related to "the nip denotes the bite" condition mentioned by Bateson. 


\subsection{Conclusion.}

The quality and diversity of education in the world today is greatly influenced by the philosophies, theories, ideas and approaches of John Dewey, Maria Montessori, and John Steiner. Even when it presents a difference in curriculum or in teaching methods, children deserve a well designed architectural space that has as its purpose the promotion of positive social learning experiences. The philosophies and theories of such respected individuals from various disciplines as Jean Piaget, Lev Vygotsky and others offer credible insight into possible ways children learn. It is important to gather unique perspectives from individuals with varying backgrounds to respond to the countless questions that are still unanswered.

As mentioned earlier in the idea of the surreal life, spiritual ideas may be merely an ideal and a way of hiding from reality. Is the reality of today's world too harsh for young children? Steiner hints that escaping from reality may mean "waiting till a child is ready" and suggests that this would be an ideal situation. Waldorf schools around the world practice Steiner's proposal of delaying learning to read and write until a certain age. They also claim that encouraging children in story- telling and make- believe is an investment for creativity in later life.

Another interesting question would be: can imagination and play be the main driving force in education? Having an outdoor stage that resembles a Shakespearean theatre could be exciting in a school environment. Would it be a driving force to enhance fantasy play and creativity? Should there be regulations that promote outdoor space near publicly funded schools? Or should forested areas be included in a school's surroundings as they are at most Waldorf schools?

A requirement that outdoor space is provided near publicly funded schools would be an idea that would certainly be welcomed by Richard Louv, Rachel Carson and Joe Frost, who believe that children in our society suffer from a nature deficit and that nature is needed to give balance to our fast-paced society.

Experiential outdoor education and learning through direct experience are proposals that would be welcomed by all the educational theorists. The countless theories and influences of experiential outdoor education may explain why there are outdoor 
education programs, wilderness camps, and residential summer camps all around the world. Further discussion and research will look at how natural elements can provide children with extended attention spans, positive health effects, and strategies to enhance learning.

The ideas, philosophies, and theories presented make it possible for architects and design professionals to create environments conducive to learning for children and educators. Children of tomorrow should have the opportunity to learn skills holistically. 


\subsection{A critical approach to learning environments through a medical perspective}

\subsection{Introduction}

Children's exposures to the environment are dissimilar to those of adults because of physiological and psychological differences.

The main difference is that forced quantitative exposure for a long period during childhood can affect the growth of the child. It is a child's job to explore their environment. The experiential behaviours of childhood are the primary and most beneficial way that children learn. Each child's behavioural development differs, and this will affect their environmental exposures. Children are full of energy and are born with a natural sense of curiosity. Their natural abilities enable them to be challenged while pushing boundaries without the learned fears that adults have.

Maria Montessori's research in experiential education concluded that the innocence of a child is a primary driving force in initial stages of learning and development. Schoolage children are at a stage of development where their physical strength and endurance is at peak, and at the same time they are acquiring skills of critical and abstract thinking. (Pediatrics, 2004) Children do not have the same abilities or life experiences that adults do and therefore may not think about cause and effects, and especially delayed effects. Children are sometimes placed in situations the effects of which can only be evaluated many years after their childhood. This is especially true in matters of health. A child's health can be affected by background, physiology, nutrition, lifestyle, and specific geographic location. The following sections illustrate childhood behaviours and ways in which these behaviours, together with physiologies, put them at risk in indoor and outdoor environments and affect them in later stages of life.

\subsection{Imperceptible harms.}

The world we live in is impure and often polluted. Pollution that is bearable by adults may not be as bearable for children. Children's bodies are proportionately smaller than those of adults and therefore have fewer organ tissues through which to absorb pollutants. (Day, 2007) The term pollution refers not just to stereotypical pollution that the general public thinks about, such as the image of a smoke stack by a factory. The 
pollution discussed here is at the micro level and is the type that can also harm children within their school and classroom spaces.

Micro-level pollution can come from the fumes that cleaning agents gives off, the "new smell" of the building materials, heating and ventilation systems, as well as from other sources within or surrounding the school. It is estimated by the World Health Organization that one in three buildings, including new and old ones, is 'sick' and unhealthy to be in. (Day, 2007) Mould often grows in older buildings without anyone being aware of it, and as a result children develop lung, skin and allergy problems. The problems do not apply only to older school buildings but to both the new and the old. It could be that the "clean" smell given off by a recently constructed school is due to chemical vapours associated with new synthetic materials.

Indoor air is exponentially less clean than the air of the natural outdoors. It is affected by a number of things including "cleaning agents, paint finishes, furnishings, furniture, building fabrics..." (Day, 2007) According to a publication by Physicians for Social Responsibility, a national organization of over 20,000 physicians and health care professionals concerned with global environmental pollution, developmental and neurological toxins are partly responsible for a range of physical and mental deficits in children. These include autism, and attention deficit hyperactivity disorder also known as ADHD. In fact, in America, attention deficit hyperactivity disorder or ADHD is conservatively estimated to affect "...3 to $6 \%$ of all school children. Some recent evidence suggests that the prevalence may be as high as $17 \%$ and the number of children in special education programs classified with learning disabilities increased 191\% from 1977 to 1994." (National Environment Trust, 2000)

In addition, a scientific panel organized by the National Academy of Sciences back in June 2001 , concluded that "as many as $3 \%$ of known developmental and neurological deficits in children were caused by exposure to known toxic substances, including developmental and neurological toxins." (National Environment Trust, 2000) This is rather disturbing, given that developmental toxins are like poisons that can change a child's mental and physical developmental paths. Furthermore, neurotoxin acts specifically on nerve cells, affecting muscle growth and motor skills as well as the central nervous system and the brain. The National Academy of Sciences concluded that " $25 \%$ 
of these problems may be the result of environmental and genetic factors working in a combination and the toxic substances may play a significant but undetermined role." (National Environment Trust, 2000)

This is especially true during the elementary school years, as young children develop more rapidly both physically and mentally as compared to any later stage during their entire lives. Children are uniquely vulnerable to the effects of substances that can interfere with the biological systems that guide development. Animal and human studies have confirmed that exposure to certain organic solvents as well as dioxins and PCBs during early developmental stages can cause hyperactivity, attention deficits, reduced $I Q$, and learning and memory deficiencies. (National Environment Trust, 2000)

In the past, PCBs were commonly used as stabilizing additives in the manufacture of flexible PVC coatings for electrical wiring and electronic components to enhance the heat and fire resistance of the PVC; some older buildings may still secrete PCBs. The creation of a healthy school should involve the school board, architects and planners. After it has opened, members of the community should involve themselves in it; this would include administrative staff, teachers, students, and selected members of the school board.

Cost should not even be a consideration in the planning and building of healthful schools. Children's health shouldn't come with a price tag. One of the most important factors in a healthy school is the air that the children breathe. It can have short and long- term effects, as will be discussed in the following section.

\begin{tabular}{|c|c|c|c|}
\hline & Pollutant & Risks & Major Source \\
\hline 1 & $\begin{array}{c}\text { PCBs } \\
\text { (polychlorinated } \\
\text { biphenyls) }\end{array}$ & Cancer, impaired fetal brain development. & $\begin{array}{c}\text { Farm-raised salmon; they are fed } \\
\text { meals of ground-up fish that have } \\
\text { absorbed PCBs in the environment. }\end{array}$ \\
\hline 2 & Pesticides & $\begin{array}{r}\text { Cancer, Parkinson's disease, miscarriage, } \\
\text { nerve damage, birth defects, blocking the } \\
\text { absorption of food nutrients. }\end{array}$ & $\begin{array}{r}\text { Food (fruits, vegetables and } \\
\text { commercially raised meats), bug }\end{array}$ \\
\hline 3 & $\begin{array}{c}\text { Mould and other } \\
\text { Fungal Toxins }\end{array}$ & $\begin{array}{r}\text { Cancer, heart disease, asthma, multiple } \\
\text { sclerosis, diabetes }\end{array}$ & $\begin{array}{r}\text { Cancer, heart disease, asthma, } \\
\text { multiple sclerosis, diabetes. }\end{array}$ \\
\hline
\end{tabular}




\begin{tabular}{|c|c|c|c|}
\hline 4 & Phthalates & $\begin{array}{l}\text { Endocrine system damage (phthalates } \\
\text { chemically mimic hormones and are } \\
\text { particularly dangerous to children). }\end{array}$ & $\begin{array}{l}\text { Plastic wrap, plastic bottles, plastic } \\
\text { food storage containers. All of these } \\
\text { can leach phthalates into our food. }\end{array}$ \\
\hline 5 & $\begin{array}{l}\text { Volatile Organic } \\
\text { Compounds }\end{array}$ & $\begin{array}{l}\text { Cancer, eye and respiratory tract irritation, } \\
\text { headaches, dizziness, visual disorders, } \\
\text { and memory impairment. }\end{array}$ & $\begin{array}{l}\text { Drinking water, carpet, paints, } \\
\text { deodorants, cleaning fluids, } \\
\text { varnishes, cosmetics, dry cleaned } \\
\text { clothing, moth repellants, air } \\
\text { fresheners. }\end{array}$ \\
\hline 6 & Dioxins & $\begin{array}{l}\text { Cancer, reproductive and developmental } \\
\text { disorders, chloracne (a severe skin } \\
\text { disease with acne-like lesions), skin } \\
\text { rashes, skin discoloration, excessive body } \\
\text { hair, mild liver damage. }\end{array}$ & $\begin{array}{l}\text { Animal fats: Over } 95 \text { per cent of } \\
\text { exposure comes from eating } \\
\text { commercial animal fats. }\end{array}$ \\
\hline 7 & Abestos & $\begin{array}{l}\text { Cancer, scarring of the lung tissue, } \\
\text { mesothelioma (a rare form of cancer). }\end{array}$ & $\begin{array}{l}\text { Insulation on floors, ceilings, water } \\
\text { pipes and heating ducts from the } \\
1950 \text { s to } 1970 \text { s. }\end{array}$ \\
\hline 8 & Heavy Metals & $\begin{array}{l}\text { Cancer, neurological disorders, } \\
\text { Alzheimer's disease, foggy head, fatigue, } \\
\text { nausea and vomiting, decreased } \\
\text { production of red and white blood cells, } \\
\text { abnormal heart rhythm, damage to blood } \\
\text { vessels. }\end{array}$ & $\begin{array}{c}\text { Drinking water, fish, vaccines, } \\
\text { pesticides, preserved wood, } \\
\text { antiperspirant, building materials, } \\
\text { dental amalgams, chlorine plants. }\end{array}$ \\
\hline 9 & Chloroform & $\begin{array}{c}\text { Cancer, potential reproductive damage, } \\
\text { birth defects, dizziness, fatigue, } \\
\text { headache, liver and kidney damage. }\end{array}$ & $\begin{array}{l}\text { Air, drinking water and food can } \\
\text { contain chloroform. }\end{array}$ \\
\hline 10 & Chlorine & $\begin{array}{l}\text { Sore throat, coughing, eye and skin } \\
\text { irritation, rapid breathing, narrowing of the } \\
\text { bronchi, wheezing, blue coloring of the } \\
\text { skin, accumulation of fluid in the lungs, } \\
\text { pain in the lung region, severe eye and } \\
\text { skin burns, lung collapse, reactive airways } \\
\text { dysfunction syndrome (RADS) (a type of } \\
\text { asthma). }\end{array}$ & $\begin{array}{l}\text { Household cleaners, drinking water } \\
\text { (in small amounts), air when living } \\
\text { near an industry (such as a paper } \\
\text { plant) that uses chlorine in industrial } \\
\text { processes. }\end{array}$ \\
\hline
\end{tabular}

Figure 2.0. - Top 10 Environmental Toxins 


\subsection{Air Pollution, associated behaviours and health concerns.}

Children are more vulnerable to the undesirable effects of air pollution than are adults. According to the Academy of American Pediatrics: "Eighty percent of alveoli are formed postnatally, and changes in the lung continue through adolescence." (Pediatrics, 2004) The alveoli are located in the respiratory area of the lungs. The blood brings carbon dioxide from the rest of the body for discharge into the alveoli, and the oxygen in the alveoli is consumed by the blood in the alveolar blood vessels, to be transfer to all the cells in the body. (Pediatrics, 2004) During childhood, especially throughout the postnatal period, the developing lung is extremely vulnerable to damage after exposure to environmental toxicants caused by pollutions. In addition, children have increased exposure to many air pollutants as compared to adults because they breathe more rapidly and are often more active than adults. Also, children spend more time outdoors as compared to adults, and have more exposure to air pollution. The individuals most vulnerable to pollutants are infants, children, the elderly, and those with cardiopulmonary (heart and lung) diseases.

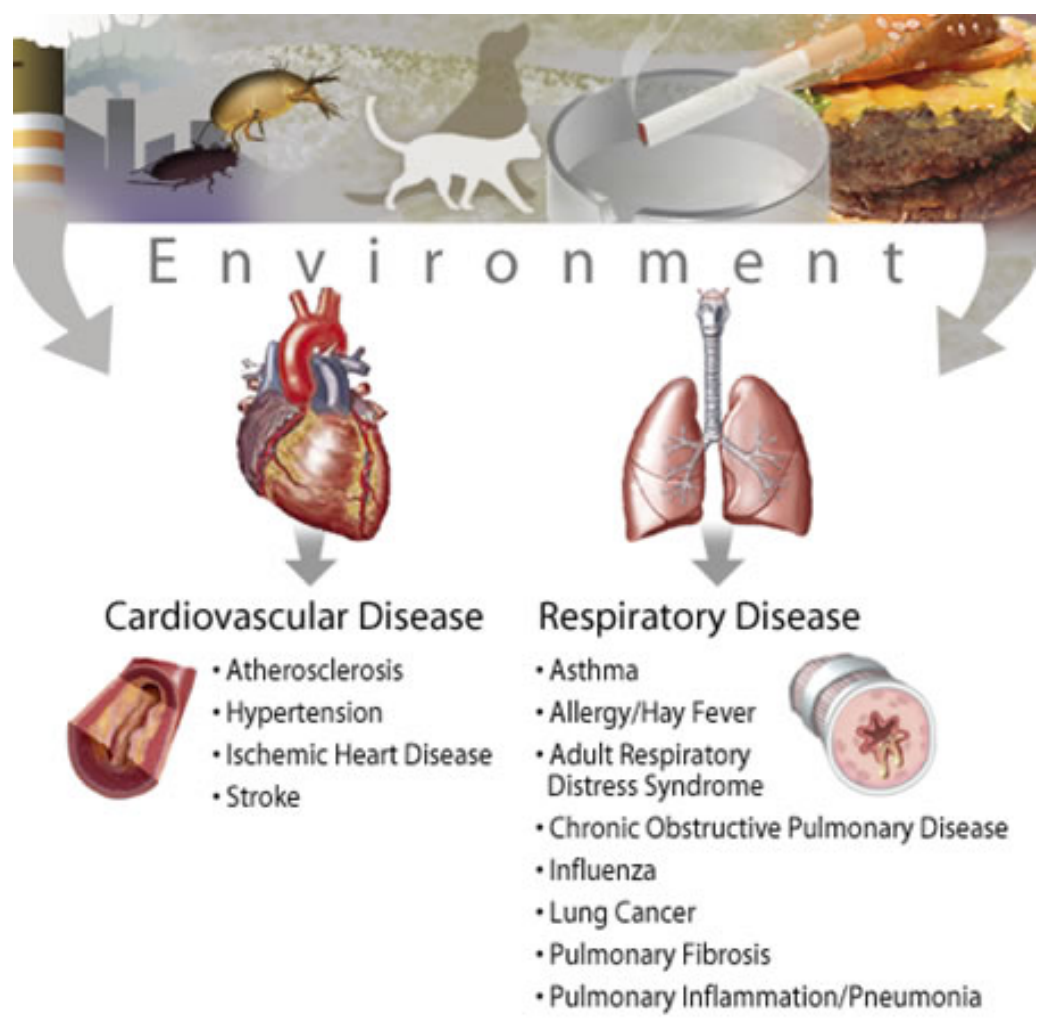

Figure 2.0.1: Mind map of Environment to Cardiovascular and Respiratory diseases 
Inhaled carbon monoxide will interfere with oxygen transport since haemoglobin binds to carbon monoxide preferentially compared to oxygen and can form carboxyhemoglobin, large quantities of which hinder oxygen delivery to the body. Other types of pollutants that create respiratory problems in children include ozone, sulphur, dioxide, particulate matter, nitrogen dioxide. They can bring on respiratory tract illness, exacerbate asthma and decrease lung function. (Daniels, Christopher \& Orgeig, 2003)

For adults, "particulate air pollution is associated with respiratory and cardiovascular hospitalizations, cardiovascular mortality, and lung cancer." (Daniels, Christopher \& Orgeig, 2003) When children are healthy, there may not be any obvious effects; in fact there may be no symptoms until adulthood, although those with more sensitive bodies may experience respiratory problems such as childhood asthma.

Another aspect of the situation is that indirect health indicators such as spending more time on medical visits and school absences disrupt a child's education and can lead to negative effects on a child's quality of life. Although many studies have tried to prove that outdoor air pollution worsens asthma, the actual effects of outdoor air pollution on the development of asthma have not been formally verified. (Daniels, Christopher \& Orgeig, 2003) Additional studies are needed to explore the relationship of outdoor air pollution to asthma. Ambient air pollution has also been associated with birth anomalies, as will be further discussed in the following section.

\subsection{Ambient Ozone}

Ambient ozone is created by the sunlight acting on nitrogen oxides and reactive hydrocarbons, both of which are emitted by motor vehicles and industrial sources. These levels tend to peak on "warm, sunny, windless days and often peak in midafternoon" (Pediatrics, 2004) the time when most school children are on break during the daily lunch recess. According to The American Academy of Pediatrics: "The ambient ozone is a powerful oxidant and respiratory tract irritant in adults and children, causing shortness of breath, chest pain when inhaling deeply, wheezing, and cough. Children have decreases in lung function, increased respiratory tract symptoms, and asthma exacerbations on days with higher levels of ambient ozone." (Pediatrics, 2004) There have been many cases of children being hospitalized, as well as visiting emergency rooms, for respiratory problems related to an increase of ambient ozone. (Pediatrics, 
Architects need to critically determine the design and location of schools in order to attempt to divert direct pollution that causes immediate effects in children. Direct pollution is pollution that includes traffic related pollutions.

\subsection{Traffic-Related Pollution}

Traffic-related pollution is a result of exhaust emissions and fuel evaporation and is a contributor to hazardous air pollutants. The main sources of air pollution in many urban communities are motor vehicles on major roads. There have been recent studies of Europe and Japan that found an increase in unfavourable health effects among those living near busy roads. (Zhu et al., 2002) Various recent studies examine the relationship between respiratory tract health and traffic levels. These studies confirm that there has been an increase in respiratory tract problems in children with symptoms such as wheezing, chronic productive cough and asthma-related medical visits. All these have been associated with living near areas of high traffic density, especially those with bus and truck traffic. (Delfino, 2002) Other studies have linked a range of childhood cancers to proximity to traffic. (Feychting, Svensson, \& Ahlbom, 1998)

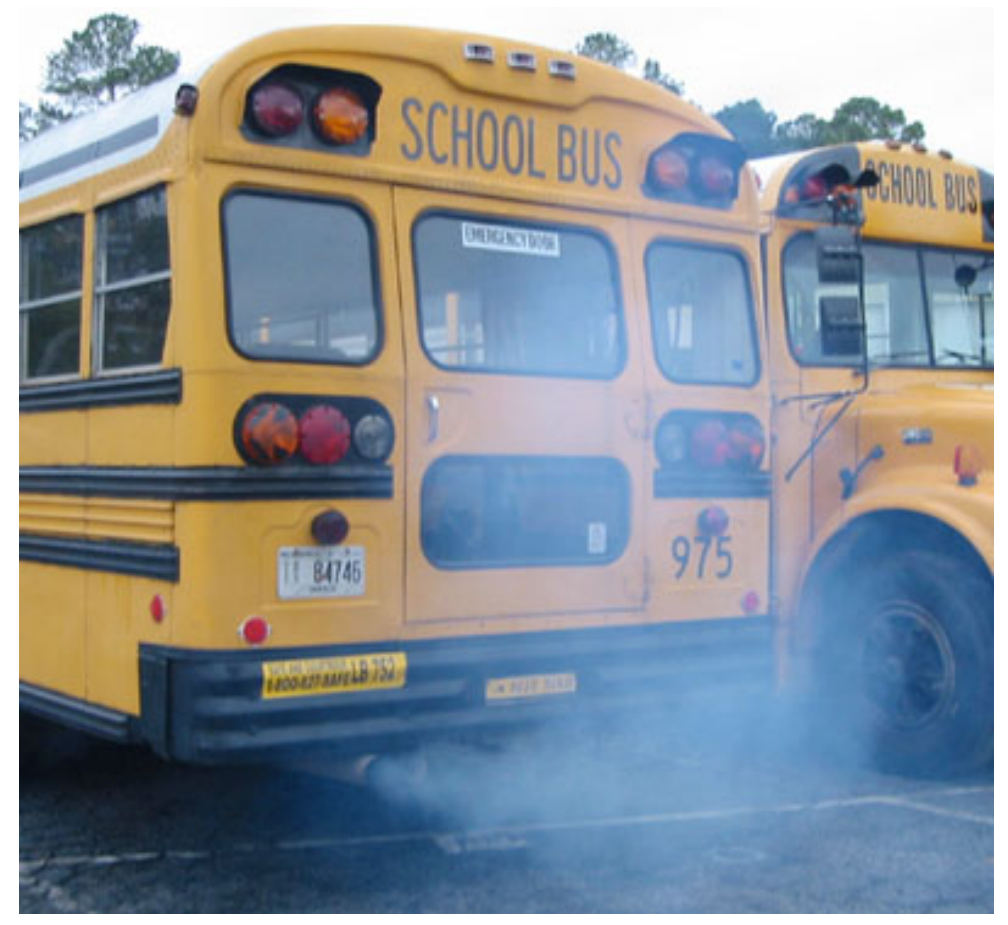

Figure 2.0.2. School bus exhaust while idling 
Traffic is often associated with school children, since most children in North America are daily transported to school by school buses. School buses in North America operate on diesel and diesel exhaust is a major contributing source of fine particulates and pollution in many urban areas. Numerous studies have also shown that consistent exposure to diesel exhaust is carcinogenic. (Lipson \& Campleman, 1999)

The term carcinogenic refers largely to the development of lung cancer in adulthood as a result of childhood pollution intake. According to the official journal of the American Academy of Pediatrics: "On the basis of extensive toxicologic and epidemiologic evidence, national and international health authorities, including the United States Environmental Protection Agency and the International Agency for Research on Cancer, have concluded that there is a considerable amount of evidence to link an association between exposure to diesel exhaust to the increase risk of lung cancer." (Pediatrics, 2004) In addition, fine particles in diesel will have immediate effects such as allergic and inflammatory responses and may also facilitate the advancement of new allergies. (Pediatrics, 2004)

\subsection{Children and allergies in today's world}

Ever wonder why more children in our society develop allergies and tend not to be as easily adaptable to all environments as children years ago? In an earlier section, it was mentioned that more children in today's world are being protected by indoor environments and do not have the chance to maximize their immune system during their childhood. This again relates to the "nature deficit" idea from Richard Louv. The air we breathe is full of natural dust particles, and even in the cleanest of rooms a person can shine a laser beam into any space and be able to see all the natural dust particles in the air.

For extremely clean parents, there is no need to worry since our natural filtering system, including our nose, is more than capable of filtering out the natural dust particles. But what about the unnatural dust particles that are mixed into the air? For example, unnatural materials such as fibreglass insulation can contain sharp filaments that can irritate the lung surface; this is why it can be dangerous without the occupants knowing it. (Day, 2007) Many children spend their first years in unhealthy buildings and develop problems that last into adulthood. They may grow out of their allergies when they are older and away from unhealthful buildings. Most indoor pollutions are not merely dust, 
but include chemicals in their mix. The fact is that when air is breathed into the lungs there is a chemical exchange in the blood vessels. Once the chemicals are in the blood, they can influence a child's brain activity and directly affect their health and behaviour. Many research studies around the world also focus on this same problem.

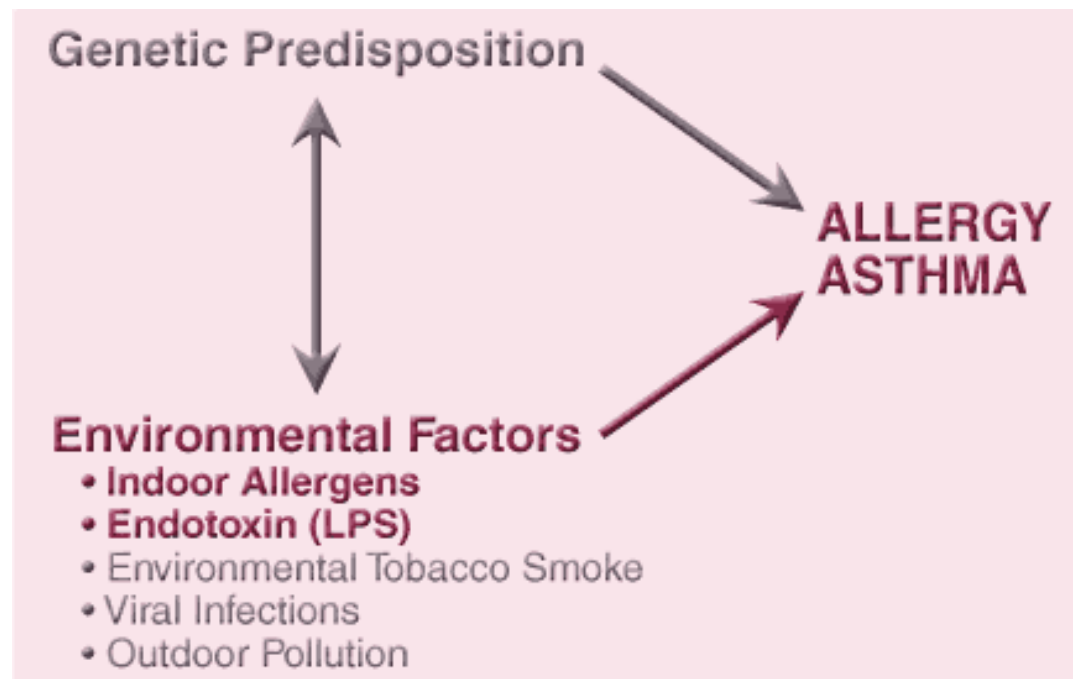

Figure 2.0.3: Effects of genetic predisposition (Each individual) and environmental factors (Indoor and outdoor) on asthma

A study from the American Academy of Pediatrics looked at the various exposure levels to different types of pollutants in children of varying ages over the course of a day in developed areas such as North America. A sum total of all exposures was required in order to get an idea of total exposure. By understanding children's activity patterns and knowing how much time they spent in micro-environments, we can understand exposure levels to potentially harmful indoor and outdoor environmental pollutants. Microenvironment is defined as the space a child occupies: it could be a lunch room, classroom, computer lab, play space or gym (and all these could be indoors or outdoors.) Information about the amount of time spent indoors is necessary to assess exposures related to indoor air environments. The study concluded that preschool and junior kindergarten children (ages 3-5) spend an average of 137 minutes a day inside a school. Children in senior kindergarten, grade ones and grade two (ages 6-8) spend an average of 292 minutes at school a day. Children in grades three, four, and five (ages 911) spend an average of 315 minutes a day indoors. In grades six, seven and eight (ages 12-14) the average is 344 minutes a day, even more than high school students (ages 15-17), who spend 314 minutes a day at school. With all the time spent 
indoors, there is plenty of time for young children to inhale these pollutants into their lungs each day, for ten months out of the year, multiplied by the number of years they are in school within the micro and macro environments in the school building. Children also engage in activities outside the school building that may put them in contact with contaminants in the environment. Other activities, such as time spent outdoors playing in grass, gravel, rivers and nature will be further discussed in a later section. Understanding the critical differences between adults and children is important when assessing environmental health risks to children. It is essential for children to be educated about the food they eat and how it affects their health, and school is the right place to undertake this task.

\subsection{Healthy living through Nutritional Health}

Nutrition is essential to a sense of well-being and to meet growth, development and activity needs of children. At school, students should be able to develop the appropriate skills and mind-set for healthy eating. A supportive environment will encourage children and youth to make educated decisions and help in establishing a blueprint for healthy living that will be carried into adulthood. A main problem is that many urban children do not have any opportunity to experience a working farm and the farming process. We as a society have become a generation of consumers only and this is a disadvantage in that many children do not even know where food comes from. Besides, children are also manipulated by the media to eat "yummy" fast food. Just imagine a child sitting for hours watching television and being exposed to the advertisements of McDonalds and Burger King, and then playing games on the computer for hours. In fact, that is a typical day for many children in our modern society.

Today's children need to gain knowledge through direct experience of how food is grown and to be educated in nutrition. The proposition here is that if the children can be acquainted with where their food comes from, they will have higher nutritional values themselves and also influence those around them to eat better. Schools of the future need to have access to nearby urban farms or to a farm of their own to grow their own foods.

In recent years many urban schools have had edible school yards: students grow a farm on part of their school yard and this direct experience helps schools and teachers to 


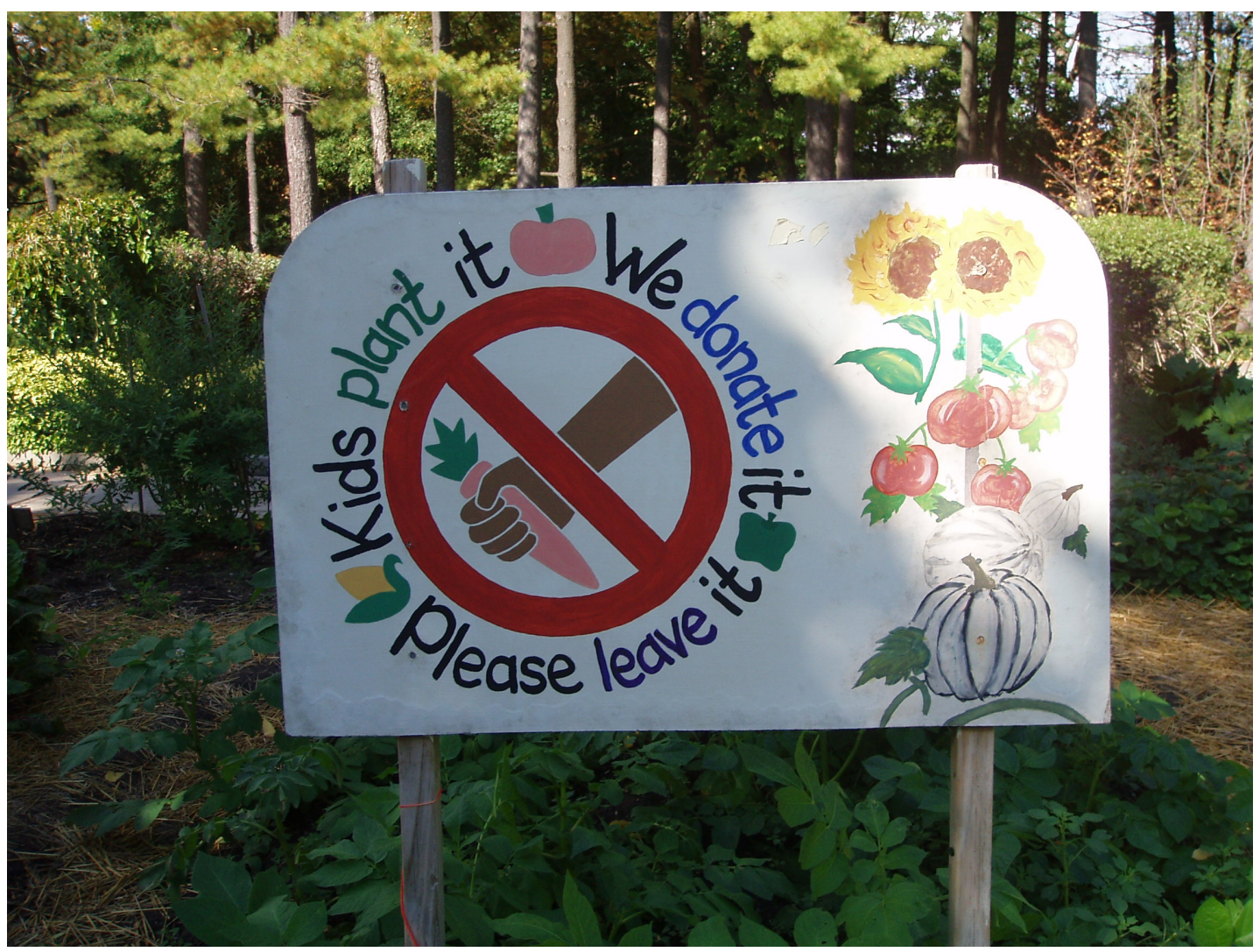

Figure 2.0.4: A children's garden in Toronto Botanical Gardens

educate students about food and nutrition. Along with direct farming experiences comes contact with dirt. Is dirt really dirty? Why do many parents have dirt phobia? The next section will discuss the effects of dirt and its relationship to hygiene.

\subsection{Dirt and Hygiene}

Depending on their educational level and cultural background, parents will have varying opinions about appropriate hygiene for their child. There are many parents who believe that schools are germ factories and spaces to harvest infections.

However, germs are not always bad; in fact, exposure to germs is seen as a positive thing by many paediatricians. The idea of exposing oneself to good germs can be explained in the hygiene hypothesis. This is a theory that holds that children of today's world who are not exposed to natural dirt and to bacteria may have weakened immune systems and therefore a greater chance of developing allergies and asthma in later life. 
(Prescott, 2001)

According to Dr. Stuart Levy, Director of the Center for Adaptation Genetics and Drug Resistance at the Tufts University School of Medicine, there is an increase in respiratory illnesses in places that are excessively clean. His studies also demonstrate that placing children in extremely clean confined environments can suppress those children's immune systems, making it more difficult for them to fight off infections in later childhood and making them vulnerable to infections in adulthood. Making the problem worse is an increasing occurrence of antibiotic-resistant bacteria due to overuse of antibiotics and other medications.

A study published in the March 2004 Annals of Internal Medicine confirmed that several cleaning agents advertised on television offer minimal protection against the most common germs that cause illness. The study involved two sample families: one used common antibacterial products from store shelves, and the other didn't use antibacterial products at all. At the end of the study, both sample families developed runny noses, cough, sore throat, fever, vomiting and diarrhea with equal frequency.

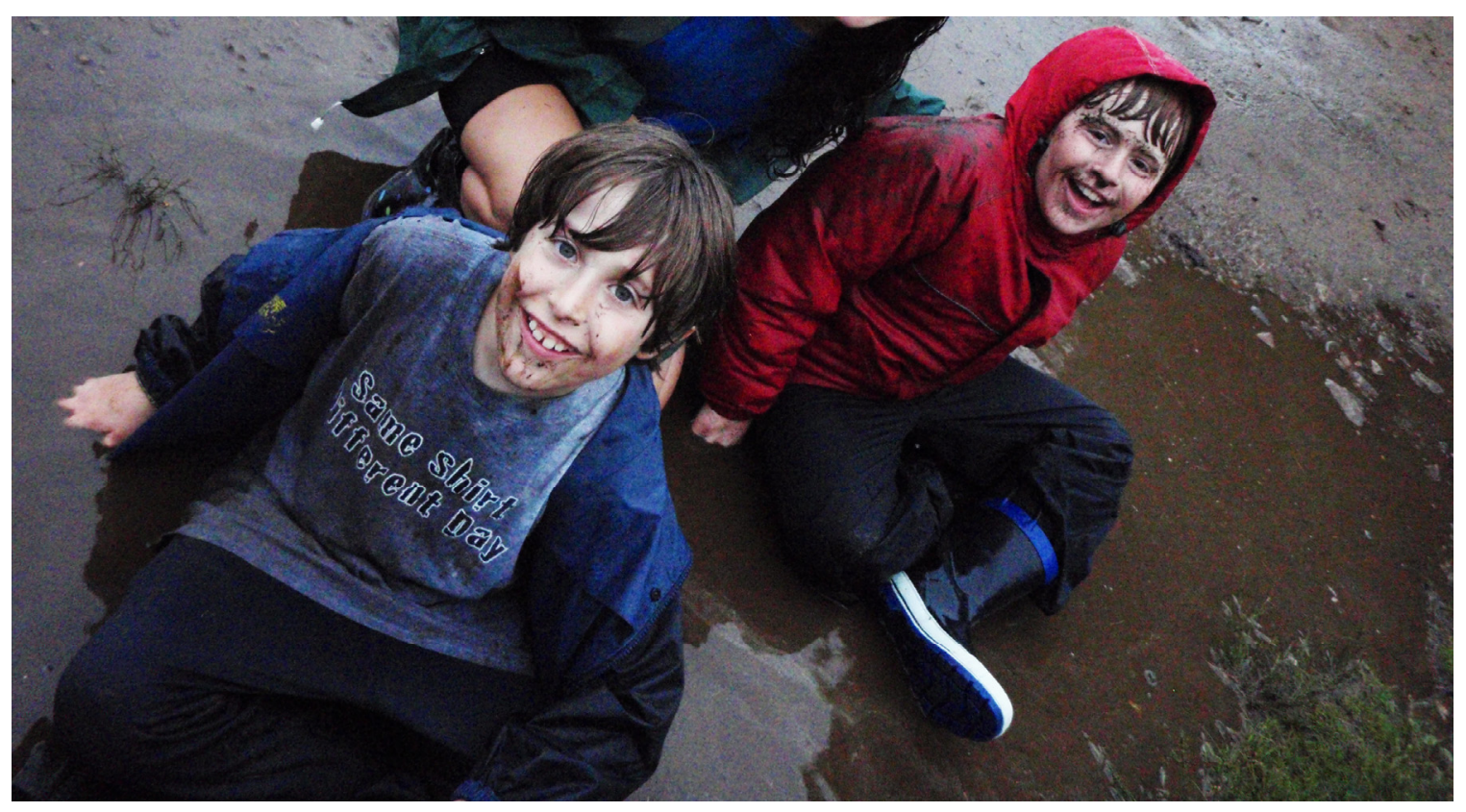

Figure 2.0.5: Two boys playing in the mud during rain 


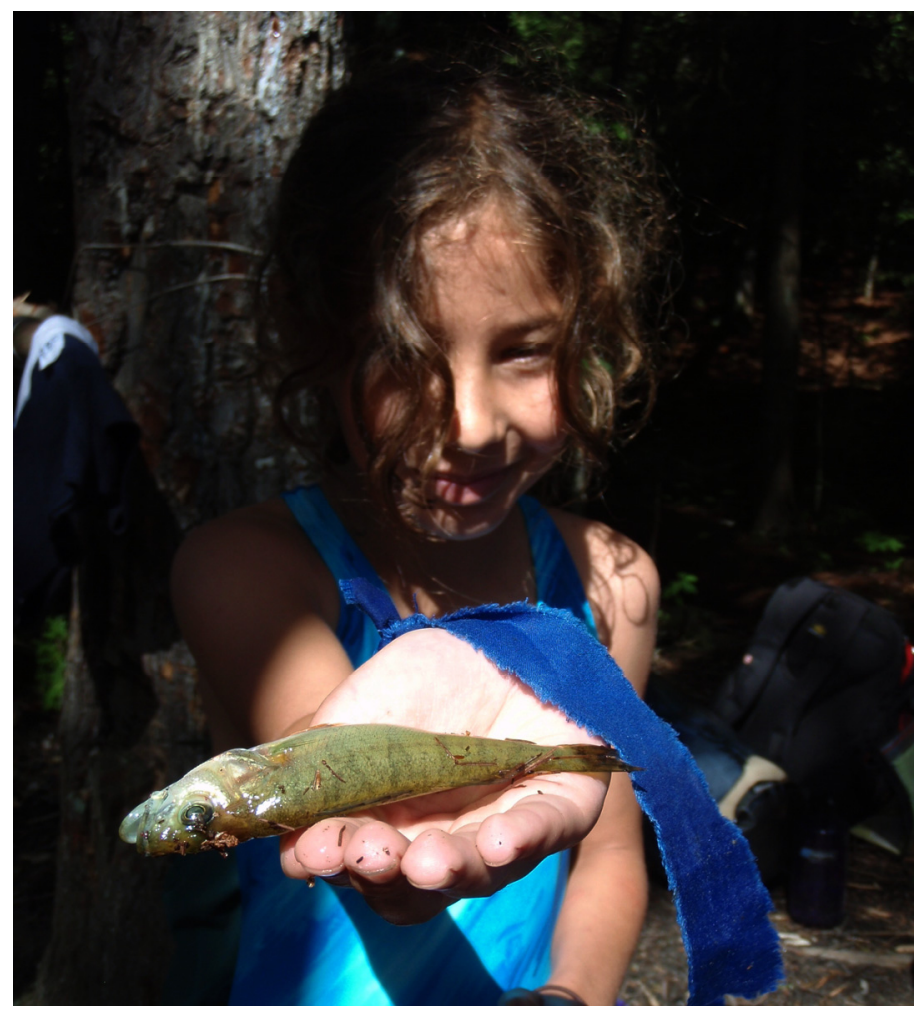

Figure 2.0.6: A young girl holding a fish that she found near the pond

Many parents in our society believe their children should spend more time indoors because of social biases and the preconceptions that playing outside can put their children at risk of catching bacteria easier. In fact, "each centimetre of our skin is host to an average of about 100,000 bacteria" (Selwyn, 1972) and according to the Children's Health Environmental Coalition, most of the microbes on and around us are harmless. Bacteria naturally inhabit our skin, digestive tract, the soil, and our homes", serving to sustain a balance in our lives. (Beavers, 2008) The references show that exposure to bacteria is not always as bad as the advertisements on the media make people believe. It follows that the more exposure children have to the outdoors, the wider are the antibody ranges that they will develop. Being outdoors is often linked to having a healthy lifestyle; this is seen in the media and is a popular conception generally. The next section will link healthy eating, dealt with in the previous section, to exercising in an outdoor environment. 


\subsection{The Healthy outdoors and Nutrition}

Nutrition and exercise go hand in hand. According to the 2009 Heart and Stroke Foundation Report on the Health of Children that reside in Ontario, kids ages 612 receive failing grades when it comes to eating healthy and getting a sufficient amount of exercise. Only 13 per cent of children eat five or more servings of fruits and vegetables daily while 57 per cent are physically active three or more times a week during the winter season. Three-quarters of children take in junk food three or more times a week. Little has changed over the past decade since the Heart and Stroke Foundation surveyed a national sample of parents of children of various ages. The 1998 report indicated that only one in five children ate the recommended five or more daily servings of vegetables; they consumed the same amount of high-fat, high-sugar or high-salt snack foods then as they do now. (Rainford, 2009) The report is not all negative: the portion of children who stay active during the summer over the past 10 years remained consistent in 2009 as compared to only 88 percent in 1998.

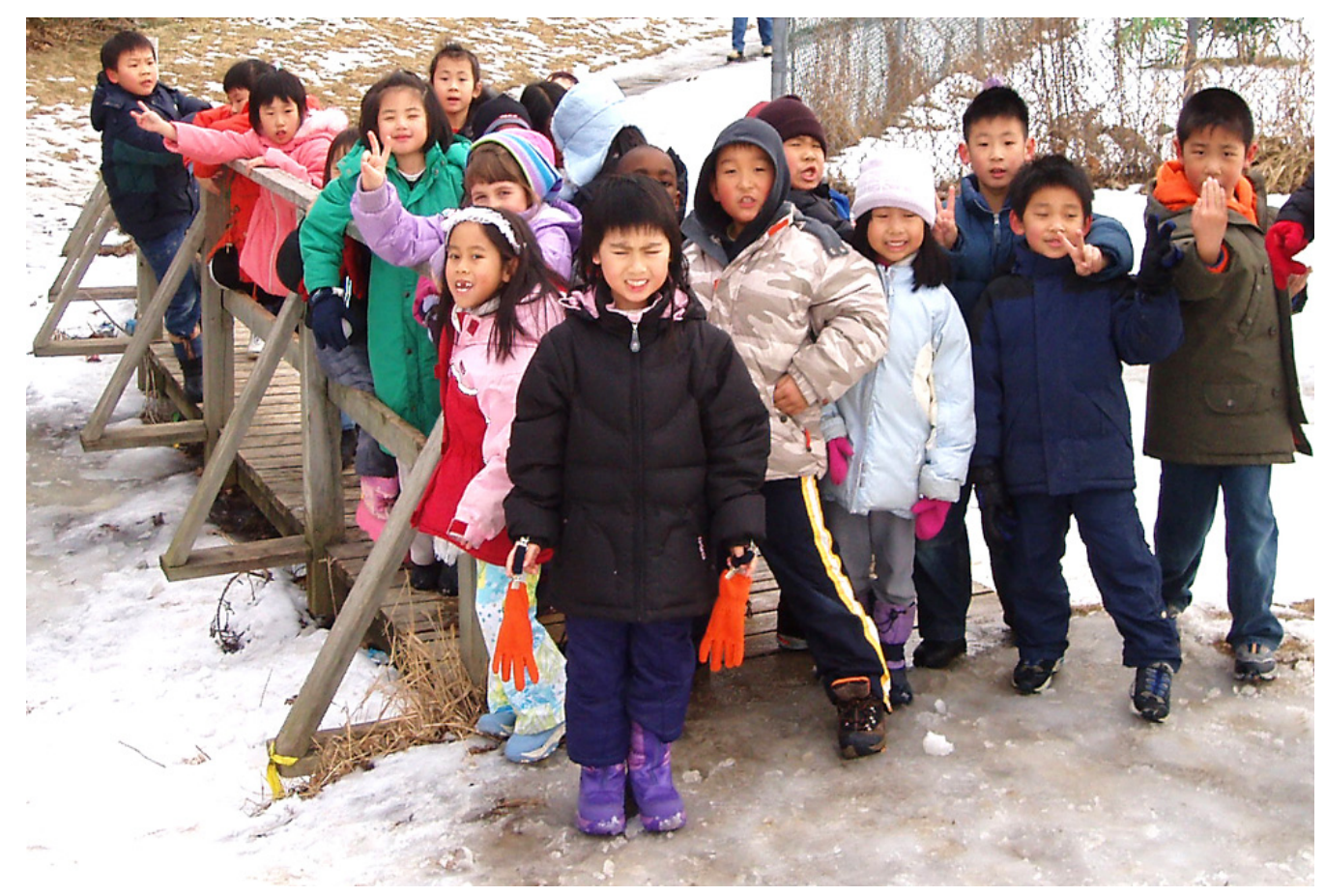

Figure 2.0.7: Students from a grade one class on a hike in the winter for a mapping exercise.

The problem is that once the weather turns cold, there is a dramatic decline in the number of children who remain active; only 57 percent of Ontario kids get substantial exercise more than three times a week as compared to 66 percent 10 years ago. The 
small amount of exercise they do get is not adequate to balance out the junk food consumed and as a result children are not as healthy as they should be. Dr. Sean Wharton, an obesity expert and the medical advisor to the Heart and Stroke Foundation states that the rate of obesity has grown to 26 per cent in Canada. (Heart and Stroke, 2009) In addition, Statistics Canada recorded that the rate of obese and overweight children has grown from 15 to 26 percent over the past 25 years; in Ontario the current rate is even higher at 28 percent. Statistics Canada also stated that children who spend more than two hours daily at a screen watching television, playing video games or using the computer are twice as likely to be obese and unhealthy as those who spend an hour or less in front of these devices. Wharton believes that "Childhood is a crucial time where habits are developed that, in many cases, can last a lifetime, we need parents to think about the importance of actions that promote a healthy weight as a means of prevention in the same way they look at washing your hands, brushing your teeth and getting your vaccines." (Heart and Stroke, 2009) How is it possible to live a healthy life if families don't have access to or can't afford basic, healthy food? The answer is simple: children are at school daily and should be taught and encouraged there to combine healthy eating with adequate exercise.

\subsection{Vitamin D, Natural Light and nutrition}

Humans are biological creatures and natural light is essential to all living creatures. A prime example of this necessity is photosynthesis: without light there would be no life. And it is not just light we need, but the right type of light. It is logical to assume our need for sunlight and natural light, rather than artificial light, is due to the human species having first emerged in the outdoors.

During the 19th century, urban smoke blocked sunlight to such an extent that rickets, a form of Vitamin D deficiency, started to spread. (Day, 2007) Recently, with the high-tech revolution, children are spending more time indoors and once again, a Vitamin D deficiency is re-emerging. This effect is also related to "Nature Deficit", a term coined in Richard Louv's Last Child in the Woods. A further discussion on nature deficit will be available later in this thesis report.

Vitamin D deficiency has a direct relationship to poor diet and lack of sunshine. The Canadian Cancer Society recommends that Canadians are take in1000IU (International 
Units) of Vitamin D a day. They also state that during the spring and summer seasons this can be accomplished through normal daily exposure to the sun. In the human body, Vitamin $D$ is essential for upholding calcium absorption in the body and maintaining sufficient serum calcium and phosphate concentrations to enable normal mineralization of bone and to prevent hypocalcemic tetany, a disease caused by an abnormally low level of calcium in the blood. It is also needed for bone growth and bone remodelling by osteoblasts, cells responsible for bone formation. Without sufficient vitamin D, bones can become thin, brittle, or misshapen. Vitamin $D$ has other roles in human health, including modulating neuromuscular and immune function and reducing inflammation. Many genes that encode proteins essential to cell production, differentiation and apoptosis are modulated in part by vitamin D. It has not yet been determined whether cells with vitamin $D$ receptors in the intact human are involved in this conversion. It's also found in cereal and some types of fish, including tuna, mackerel and sardines. But the best source is sunlight, because the body makes vitamin $D$ when sunshine hits the skin. (Vitamin D Society, 2007)

M.D. Sonja Kustka, a graduate of the University of Toronto Medical School, has an integrative approach that utilizes both traditional allopathic medicine and natural medicine and that is embraced by many people in the city of Toronto. In a recent interview she stated that most of her Toronto clients have to take vitamin D supplements. She believes that this Vitamin D deficiency problem have something to do with the pollution in and around the city; more than $90 \%$ of her patients are Vitamin $D$ deficient unless they are taking supplements. To solve this problem, she recommended that if children eat a healthy diet, with mostly organic foods, biodynamic foods and avoiding processed and fast foods, they won't then need to take supplements. In addition, she believes that exercise and playing outdoors in green settings are very important for a child's physical, emotional and mental well-being. (Kustka, 2009)

Children will be better focused and able to concentrate with natural air and natural light. Dr. Michal L. Melamed of the Albert Einstein College of Medicine of Yeshiva University recently lead a study on a similar topic and pointed out "Kids have more sedentary lifestyles today and are not spending as much time outdoors. The widespread use of sunscreens, which block UV-B rays, has only compounded the problem." The body uses UV-B sunlight to convert a form of cholesterol in the skin into vitamin D. (Melemed, 2009) 


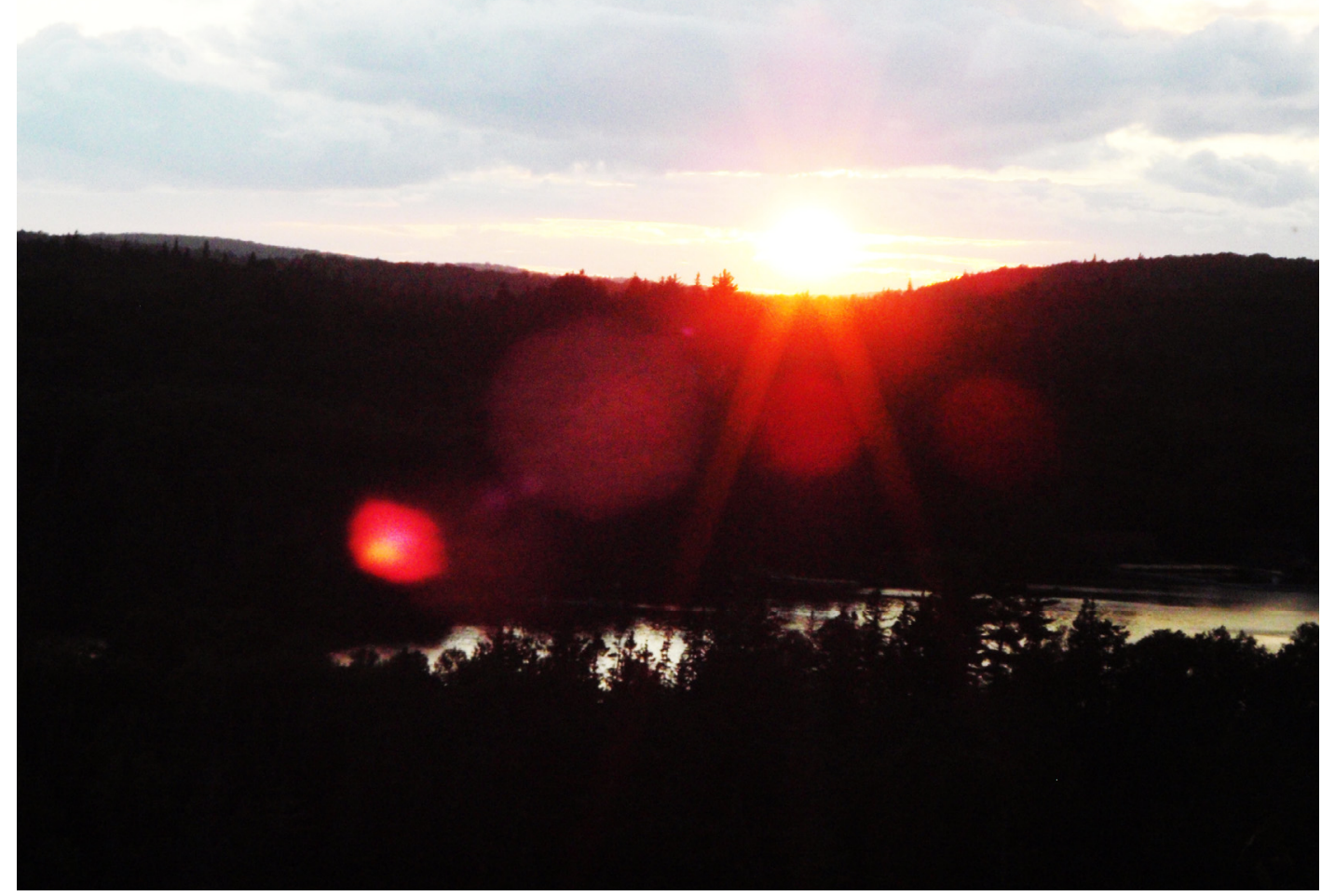

Figure 2.0.8: A bright sun disappearing into the wilderness forest

The suggestion from Dr. Melamed is that parents should turn off the television and send the children outside, as also adds: "Just 15 to 20 minutes a day should be enough. And unless they burn easily, don't put sunscreen on them until they've been out in the sun for 10 minutes, so they get the good stuff but not sun damage." (Melemed, 2009) The message here is that Vitamin $D$ deficiency is a real problem with consequences that can affect a child's physical growth and even long term cardiovascular health. From this data, researchers would recommend that we ensure that children get outdoors exercise and eat healthy once again. As vitamin $D$ is concerned, it is a clear fact that sun exposure to children should always be controlled. As mentioned above, children should get just enough sun but not so much that they suffer sun damage, which can have fatal effects. The following section will shine some light on the effects of sun exposure in childhood and its immediate and also delayed effects. 


\subsection{Health effects of Ultra Violet Rays in children}

Too much of anything isn't good for the body and this is especially true in regards to sun exposure in children. Although children are encouraged to obtain a limited amount of ultraviolet rays through sunlight, there are health risks associated with over-exposure. Painful sunburn is one immediate effect of over-exposure to sunlight and ultraviolet rays. Earlier, it was mentioned that children do not have the ability to think about causes and effects or to consider whether certain conditions might have effects felt only in adulthood. One delayed effect of over-exposure to sunlight and ultraviolet rays during childhood is adult skin cancer. Ultraviolet rays penetrate human skin tissue to a depth of 0.1-1 millimetre. Other organs that can be affected are the skin and the eyes. Ultraviolet ray exposure contributes to the development of a number of skin conditions including sunburn, aging and skin cancer. There are three types of skin cancer: melanoma, squamous cell carcinoma and basal cell carcinoma; all are caused by sun exposure. (Elwood \& Jopson, 2007)

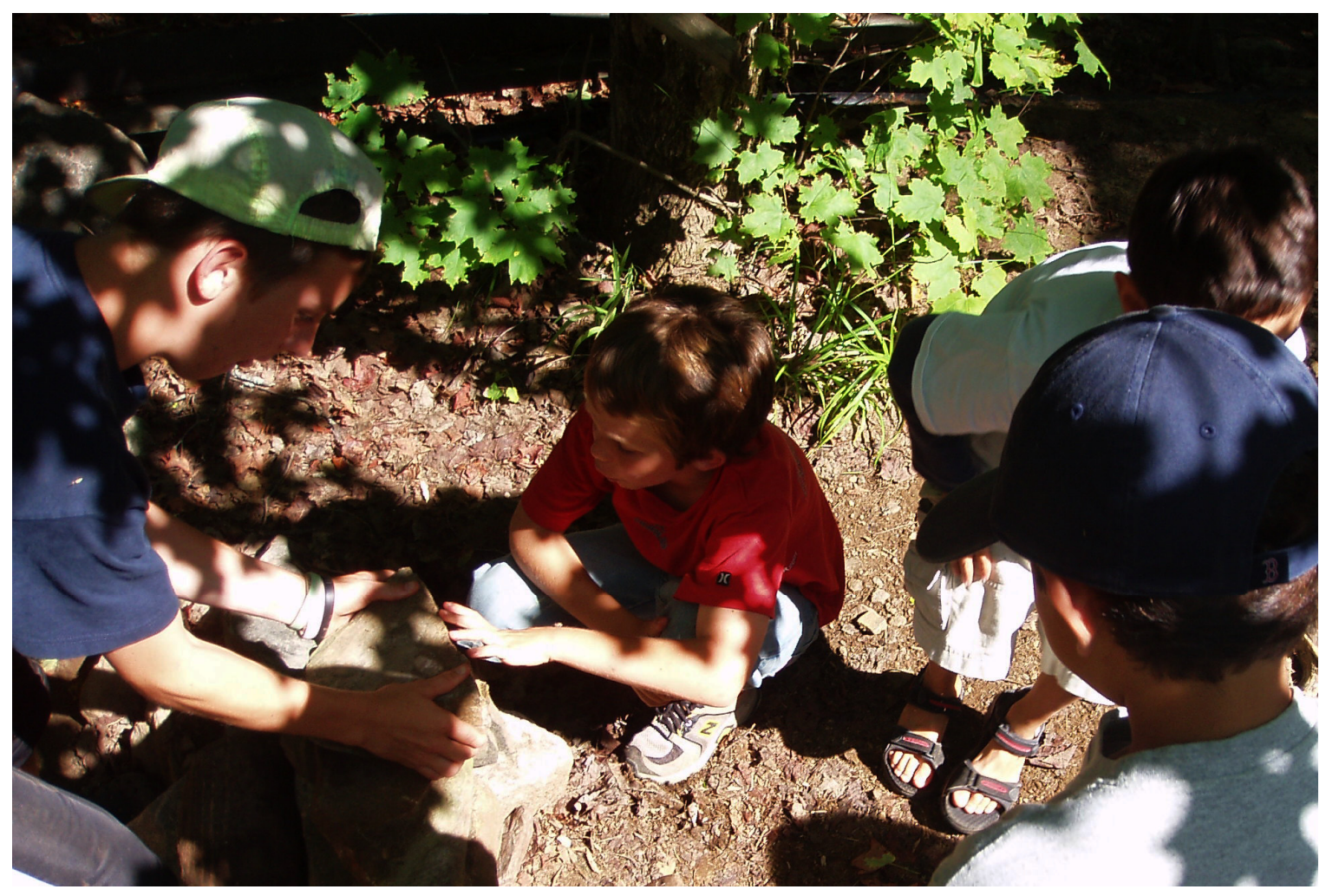

Figure 2.0.9: Children having a lesson in a partly shaded area on a sunny day 


\subsection{Physical and psychological: Nature, Attention and Attention Deficit}

This section will begin by examining the relationship between children and nature and presenting several studies on nature's developmental benefits. Since the most frequent behavioural symptom of ADHD is attention deficit, it is appropriate to examine several psychological theories of attention.

Attention-deficit/hyperactivity disorder (ADHD) is the most common neurobehavioral developmental disorder affecting school age children. This psychological condition dramatically reduces children's attention capacity. Attention deficit disorder affects the quality of life of the child and those around him/her, and many children tend to have difficulty socializing with others. As a result, this disorder affects the child's academics and overall personal growth. Recent research suggests that the symptoms of ADHD are caused by biological conditions. In addition, studies also show that children with ADHD have delayed brain maturation as well as lower levels of dopamine and noradrenaline.

Dopamine is a chemical that relays, amplifies and modulates signals between a neuron and another cell. Noradrenaline activates the sympathetic nervous system to increase the concentration of glucose in the blood, raises blood pressure and heartbeat rate, and increases muscular power and resistance to fatigue, this explaining the hyper disorder part of AD-"HD". (Fomenko, 2008) Unfortunately, current pharmacological treatments for ADHD have limited effectiveness, and can bring on dramatic psychological and cardiovascular side-effects. Recent researches from various medical professionals have found that direct exposure to nature is essential for healthy childhood development and for the physical and emotional health of children. As well, unstructured natural play environments have been associated with milder symptoms in children diagnosed with ADHD. The growing evidence implies that green play settings may be one approach in ADHD treatment. Although there are many types of medications for children to ensure they enjoy a day without the disruption of classes and with appropriate focus, alternative methods should be explored and employed in hope of lessening the amounts of these medications used.

In his essay Man and Nature, Raymond Williams suggests that nature may be one of the most "complex" words in the English language. In context of the essay, the meaning of the word nature can be used to describe the entire material universe. Basically, 
everything in our world from the earth, sand, fire, water, down to the spectrum of bacteria contribute to the web of nature. (William, 1980) The term "nature" is used to make a distinction between the natural and the artificial; the natural is not natural if it has been altered through artificial or synthetic materials or through human intervention.

The fact that something looks like wood doesn't mean that it is wood, and if it's not natural it may give off toxins. Observation of children's play from the author's personal experience as a summer camp counsellor and nature instructor suggests that children consistently prefer natural play settings to structured man-made ones. Several studies have shown that unstructured play in the natural environment offers children a dramatic benefit in physical development. In 2001, Fjørtoft \& Sageie conducted a study in a small 7.7 hectare forest located near a kindergarten in Bø, Telemark County in Norway. Their study sought to determine whether the motor development of young children was correlated with their play setting. It was found that children who engaged in unstructured outdoor play tested significantly better on the EUROFIT fitness scale, which measures motor ability and spatial coordination, than the control group. Earlier studies, including one carried out by Grahn et al. (1997) similarly concluded a relationship between motor development and the greenness of a child's playscape. (Fomenko, 2008) In addition to children's developmental benefits, natural environments have been shown to increase attentional functioning. Richard Louv in Last Child in the Woods attempts to link child's free play in the natural environment to a reduction in ADHD symptoms. To fully understand these conclusions, the psychological basis of attention and its integration into nature therapy will be examined.

\subsection{Nature as a tool for therapy}

In the 19th century, American psychologist and philosopher William James wrote a pioneering work which divided attention into two categories: voluntary and involuntary (James, 1892). Voluntary, or directed, attention is called upon when one uses effort to direct one's attention to something out of necessity. One example of directed attention would be attending a class that is boring in hopes of getting a good grade point average. James' theory is that one can sustain directed attention by restraining all other competing thoughts. In this way, the uninteresting subject of one's directed attention can be focused on for a limited period of time. However, extended use of directed attention causes one to exert considerable mental strain and to be subject to fatigue 
(Kaplan, 1995). Surprisingly, individuals with no history of attention-disorder gradually begin to take on the characteristic symptoms of ADHD as a result of attention fatigue. Coincidentally, researchers often use the Attention Deficit Disorders Evaluation Scale to measure attention fatigue in healthy individuals. (Kuo \& Taylor, 2004). In comparison to $A D H D$, attention fatigue is a reversible condition that dissipates once the individual's directed attention mechanism has had a chance to rest. According to Kaplan's Attention Restoration Theory, involuntary attention can foster recovery from attention fatigue in normal individuals. Natural environments have been shown to act as agents of involuntary attention by stimulating and engaging the mind with minimal effort (Hartig, Mans, \& Evans, 1991). In addition, various research studies have shown that natural settings may reduce hyperactivity and aid in impulse control. A study by Faber, Kuo \& Sullivan published in the Journal of Environmental Psychology arbitrarily assigned a sample of healthy children to apartment buildings with varying degrees of nearby nature. In the study, one group of children was assigned to buildings with moderately natural views of green space, while the other group's buildings had generic urban views. The group exposed to the natural views performed significantly better on various tests designed to measure impulse control and hyperactive behaviour. (Fomenko, 2008)

The research identifies nature as a tool for countering attention fatigue and for supporting impulse control in healthy children with no history of attention-disorder. (Kuo, Taylor \& Sullivan, 2002) ADHD draws out a much greater degree of attention fatigue among individuals; the Attention Restoration Theory can be used to moderate symptoms in the ADHD population as well. In the book Coping with ADD: Kuo \& Taylor completed a study that tested the hypothesis of whether activities in green settings alleviate attention deficit symptoms to a greater extent than activities in settings deprived of nature. The study surveyed parents of 96 children aged 7-12 diagnosed with ADHD by their paediatrician. The parents compiled a list of after-school and weekend activities their children engaged in and indicated whether the activity was held in an indoor, built outdoor or green outdoor setting. (Kuo \& Taylor, 2001) Kuo \& Taylor looked at the activities that parents themselves had selected to see if they had positive or negative effects on their child's symptoms and to establish the relationship, if any, between the effect of each activity on symptoms and the greenness of the setting they took place in. The parents rated the sum effect of each activity on their child's ADHD symptoms according to a post-activity attentional functioning (PAAF) rating system of 1 to 5 , with 1 
being much worse and 5 being much better. The research concluded that leisure activities in green outdoor settings received a significantly higher mean PAAF rating (3.53) than both built outdoor (3.24) and indoor (3.22) activities. As well, very few parents reported that green outdoor settings had negative effects on ADHD symptoms. To strengthen the hypothesis between natural settings and symptom reduction, a controlled field experiment by Kuo \& Taylor was later performed. (Kuo \& Taylor, 2004) In this experiment, attention-fatigue was first induced in a group of children diagnosed with ADHD by immersing the children in fifteen minutes of puzzle play. The children were then led on three guided walks with varying degrees of natural and urban elements. After each walk, an independent evaluator blind to the study administered a standardized assessment of the children's attentive function. Kuo \& Taylor found that attentional functioning was significantly greater after walks in the greenest setting than after walks in moderately green and urban settings. (Kuo \& Taylor, 2004) Since this study was controlled for a multitude of confounding factors such as age, gender, and common disorders, the study strengthened belief in a causal link between exposure to natural environments and reduction in the attention-deficit symptoms of ADHD (Fomenko, 2008)

Conversely, more evidence was needed to generalize these findings as applied to the wider population, since the study focused only on urban children aged 7- 12 years living in the U.S. Midwest. Later in 2004, Kuo \& Taylor conducted another study on the effects of activity settings on ADHD symptoms; this time the experiment was controlled for age, income, community type, region, and ADHD symptom severity. Similar to their previous studies, Kuo \& Taylor collected data comparing the effects of activities conducted in green outdoor settings to those of activities in other settings on ADHD symptoms. Furthermore, the effect on performing the activities alone, in pairs, or in larger groups was examined. Although the participants ranged widely in age (5-18 years old), location, income, and other characteristics, the results were consistent with those of the authors' previous studies (Kuo \& Taylor, 2001, Kuo \& Taylor, 2004). Specifically, statistical analysis showed that green outdoor activities significantly reduced ADHD symptoms when conducted alone, in pairs, or in larger groups. Since only two of the 339 respondents in this study cited nature as a probable cause of their child's reduction in symptoms, any subjective bias arising from a belief in nature as a therapeutic agent was likely eliminated. 
In summary, a number of practical studies conducted largely by Kuo \& Taylor (2001, 2002, 2004, 2004) at the Landscape and Human Health Laboratory suggested the possibility of nature as a tool for managing attentional-deficit symptoms in children with $A D H D$. The research performed to date has suggested that natural therapy for ADHD is effective in the short-term across a wide variety of age ranges, natural settings, symptom severities, and geographic locations. Further discussion investigating the duration and specificity of nature as an attention-enhancing treatment is forthcoming later in the thesis.

\subsection{Challenges and Criticisms of Nature as Therapy}

The research implicating green play settings as an alternative therapy promises a revolutionary treatment free of side-effects, monetary burden, adverse social consequences, and inconvenient medication regiments. Recently Kuo \& Taylor's research on nature's beneficial effects has been disseminated to the general public, largely through Richard Louv's book Last Child in the Woods (2005). It presents research, statistics and evidence-based arguments for nature's importance in healthy childhood development and as treatment for physical and neurological developmental disorders such as ADHD (Fomenko, 2008). With the widespread popularization of Louv's work, Kuo \& Taylor's research has provoked many critical responses from other researchers.

Another consideration is that pediatricians have been known to be inconsistent in their ADHD diagnoses: many of the children involved in these studies may have been misdiagnosed or healthy (Lambert, Sandoval \& Sassone, 1978; Schwartz, 2008). In addition, the studies cited did not measure the effects of nature exposure on healthy controls, making it unclear whether these effects can specifically enhance attention deficits of ADHD patients, or simply increase attention in both healthy and symptomatic subjects equally. However, Kuo \& Taylor (2005) responded to the many criticisms by pointing out that their research suggests that nature may be widely effective in treating $A D H D$, and that green play settings are merely potential treatments for the disorder. (Fomenko, 2008) Despite its methodological limitations, Kuo \& Taylor's research serves as a groundbreaking trigger for further inquiry into the effects of nature on restoring attention, and treating developmental disorders, specifically ADHD. 


\subsection{Applications \& Future Directions}

Kaplan's theory of attention and Kuo \& Taylor's ground-breaking studies, together with Louv's popular dissemination of nature's health benefits have not been ignored. Despite their recent emergence into the realm of peer-reviewed literature, Kuo \& Taylor's research has not only been cited in countless academic journals and books, but has also been used to generate publicity and attention to increase children's exposure to nature. For example, many government organizations such as the Georgia Forestry Commission heavily promote designing urban infrastructures such as schoolyards and playgrounds with trees in mind, citing benefits such as a therapeutic environment for children with developmental disorders (GFC, 2008). As well, a number of Canadian summer camps such as Camp Arowhon in Algonquin Park are admitting an increased amount of children with ADHD and other behavioural disorders, and investing sessional time to train staff on how to integrate such children into the social environment of camp. Although campers with ADHD must typically be prescribed psychostimulants in order to adequately socialize with peers and participate in activities, the effect of the surrounding natural environment has been observed to be directly responsible for a reduction in attention deficit symptoms. Many camp employees including this author have reported the therapeutic effect of wilderness canoe tripping, kayaking, frog-catching, outdoor games and activities that foster the use of involuntary attention on all children, as well as those with attention deficit symptoms. In many cases the normally hyperactive and inattentive children are so peacefully in awe of the natural world after such activities that administration of medication seems virtually unnecessary.

Although these anecdotal reports are not claimed as scientifically sound, they lend some degree of credibility to Kaplan's theory of attention and the conclusions of Kuo \& Taylor's studies on nature and attention. If future studies were to confirm and strengthen the existing research on the benefits of nature on children with attention challenges, an obvious future application would be to promote the integration of natural settings in the place where children spend most of their time: the school and learning environments. Furthermore, recent studies have been sufficiently influential to have impacted University educators and school boards. Exposure to natural settings through field trips and learning in outdoor classrooms are beginning to be cited as evidence-based strategies aimed at improving the attentional functioning of children in the academic setting (Zentall, 2005). 


\subsection{Conclusion}

The natural environment as described throughout the various sections can be seen as a natural supplement that acts as a tool for healthy living as well as a stimulant for learning. All children are entitled to a healthy learning environment throughout their childhood. This includes learning environments with clean air and natural surroundings. It begins with the specific location and placement of a school. The critical selection of construction and interior materials of the building are equally important. Children are dissimilar to adults physically and psychologically: they are innocent and live for the moment and lack life experience and the ability to consider later effects. This is true in regard to the learning environments where they spend the majority of their time during their childhood. Children will be quantitatively exposed to anything harmful in these spaces and their growth will be affected. Consequences may be immediate or may be delayed effects that could be fatal in adulthood. There are many unhealthy educational buildings around the world, and it is the responsibility of architects to work with school authorities to create healthier learning environments for all children. 


\subsection{The Natural Outdoors}

\subsection{Romance with Nature}

What is the romantic humanistic attitude towards nature? The Biophilia hypothesis can give us some insight. The Biophilia hypothesis refers to the natural connection between human beings and other living systems, and the term Biophilia means the love of life and living organisms. The specific concept of Biophilia was first explored by Erich Fromm who was a social psychologist, psychoanalyst, humanistic philosopher, and democratic socialist in the 1940s. Fromm describes Biophilia as a psychological orientation towards being attracted to all that is alive and vital. (Fromm, 1964) In the book Biophilia, Edward O. Wilson believes that all along human evolution we were deeply enmeshed with the intricacies of nature, and that we still have this affinity with nature ingrained in our genotype. Wilson uses the term in the same sense as Fromm when he suggested that Biophilia is the connection that human beings subconsciously seek with all other living things. He also believes that the deep affiliations humans feel with nature are likely rooted in our biology. (Wilson, 1984)

Philia is the opposite of phobia. A phobia is an intense and persistent fear of certain things in the natural world. Philia is one of four ancient Greek words for love, and as it pertains to the modern day is best defined as attractions and positive feelings felt toward certain habitats, activities, and objects in their natural surroundings. (Lewis, 1960) Although majority of people would automatically associate the term "nature" with plants such as are found in a park or forest, in fact the weather and animals are also constituents of it. The term Nature in this thesis is defined as biodiversity, outdoor wilderness, and natural abundance. Natural abundance is defined in this thesis as the "biological, cognitive and spiritual" aspects involved in positive physical connection to nature. (Louv, 2006)

In the carefully structured book Experiencing Nature: Affective, Cognitive and Evaluative Development in Children, the editors Peter Khan ${ }^{1}$ and Stephen Kellert ${ }^{2}$ stated that the

\footnotetext{
${ }^{1}$ Peter H. Kahn, Jr., is Research Associate Professor in the Department of Psychology at the University of Washington and Co-director of the Mina Institute in Covelo, California.

${ }^{2}$ Stephen R. Kellert is Tweedy Ordway Professor of Social Ecology at the Yale University School of
} 
developing a nurturing relationship with an animal is especially important during early and middle childhood. (Khan \& Kellert, 2002)

Humans and nature have a connection with each other that can't be easily broken and humans need nature for everything we do in life. In fact, students and teachers are often encouraged to have lessons in outdoor settings to re-stimulate the creativity that has been dormant due to having excessive time spent indoors.

\subsection{Inspiration through nature}

Many architects also manifest a romantic attitude towards nature in their designs. One notable architectural piece is Frank Lloyd Wright's Falling Water: the building is situated over a 30 feet water fall and water flows through the base of the house. The story behind the building of the house itself is fascinating. It was designed to be responsive to the Kaufmann family's interest in outdoor nature. The Kaufmanns, who owned the oncefamous Kaufmann Department Store, at the time also owned a summer camp known as Bear Run for the children of employees. As time and economic considerations made it a challenge for the families to send their children to the camp, the Kaufmann family decided to make it their personal natural retreat and hired architect Frank Lloyd Wright for this project.

Falling Water today remains a learning centre; it is home to a teacher residence program that helps school teachers use architecture to spark creative thinking across the curriculum while addressing various learning styles and multiple intelligences. Falling Water serves as a classroom for the teacher residents and provides them with an opportunity to examine how humans can respond to nature-inspired designs at the same time as they are made aware of issues of green design and sustainability that help to support and conserve the environment. ${ }^{3}$ Teachers who benefitted from this program will in return extend the knowledge they have gained to their students.

Forestry and Environmental Studies.

${ }^{3} \mathrm{http}: / /$ www.fallingwater.org/37/what-is-fallingwater 


\subsection{Experience and learning}

During morning exercise when people are walking their dogs usually children aren't in the picture. Many adults feel that they are the ones who need the exercise; this leads to the question: Where are the children? The fact is that a high number of families who live in the city are also nature deficit. The Nature Deficit Disorder, a term coined by Richard Louv and discussed earlier in this thesis can be diagnosed when children spend a majority of their time watching television, playing on the computer, or just spend time in confined indoor environments every spare moment. In fact, many modern families hire a "television" to look after their children. Children who lack exposure to outdoor nature lose their creativity, while their natural senses remain unchallenged. Outdoor nature provides unique challenges that a formal classroom ${ }^{4}$ cannot. To further explore this idea, we'll look at the ultimate question that is on every parent's mind: "What is needed for my child to be successful in adulthood?"

While spending a large amount of time in an outdoor natural environment during childhood cannot guarantee a person a large salary when they enter the workforce, it does help to develop an individual's ability to focus and concentrate, and this is especially true of children with attention disorders. ${ }^{5}$

${ }^{4}$ Formal Classroom: Individual desk in row systems to make students face the front of the class. This is the set up usually made for exams, in depth seminars and lectures where it is an authoritarian method of teacher student relationship; this discourages social interaction as students will find it difficult to discuss problems or class materials with each other.

${ }^{5}$ A study was conducted at the University of Illinois by child environment and behaviour researchers Andrea Faber Taylor and Frances E. Kuo. From previous studies Taylor and Kuo believed that there is a link between attention span and the environment the students study in. To confirm that link; Taylor and Kuo conducted a study in which they took children on walks in three different settings. Setting one is Green (with a lot of outdoor nature) and two less 'Green", as well the walks were kept as similar as possible to create a constant. The details of the study involved 17 children between the ages 7 to 12 year old. The children were taken on a walk through an urban downtown, a residential neighbourhood and a grassy tree filled park. Each child took all three walks on various days and after completing the walk, an experimenter who didn't know the walks each child completed assessed attention using a test known as Digit Span Backwards. The tests a series on numbers are said aloud and the child repeats them backwards. For the 
A study done by Kuo and Taylor at University of Illinois confirmed that the greenest spaces were most successful at improving attention. (Kuo and Taylor, 2008) In addition, the researchers believe that a dose of nature can have benefits for children other than just those with attention disorders. Kuo and Taylor believe that while children with Attention Deficit Hyper Disorder (ADHD) are at the far end of the attention functioning category, many regular children and adults also fall somewhere close to that spectrum. Many children suffer mental fatigue and have times when they are less able to focus on tasks and are easily distracted. All in all, the evidence suggests that natural settings can benefit everyone, even children who have not been diagnosed with ADHD. (Kuo and Taylor, 2008)

A child cannot be inspired when they are bored or when they are disinterested. However, it may be possible to provide inspiration and to promote flexible thinking when a child is engaged with outdoor nature. Nature may be able to provide lessons of ethics and morals and aid creativity at the same time as it teaches children to be empathetic. Practical skills can be developed as well, such as planning and survival skills that will help guide them in purposeful directions. (Day, 2007)

The outdoor environment provides the perfect engagement opportunity to foster empathy in children. One of the best ways of doing this is to cultivate relationships to animals; this includes exposure to indigenous animals both real and imagined. Children respond to animals well and relate to them naturally. Animals provide a sense of wonder for children and also foster a caring attitude and a sense of responsibility towards other living things such as plants and vegetation.

Children learn best when their interest is stimulated, and so the learning environment must be inspiring. Albert Einstein once said: "I never teach my pupils; I only attempt to provide the conditions in which they can learn." (Mayer and Holms, 1996) As mentioned in an earlier section, low attention spans in children without medical conditions can be

record, it is a test that practice does not improve performance. According to Faber Taylor, it was found that after the walk children generally had better concentration than when they did a walk downtown, or in a neighbourhood area. The greenest space was best at improving attention after exposure. (Taylor and Kuo, 2008) 
caused by the learning environment he or she inhabits; some formal classrooms can cause or exacerbate attention fatigue.

In conclusion, our love for nature is the "natural" result of our human condition. Numerous research studies conducted over the years prove that being in the natural outdoors provides more challenges to a child's senses than does being inside a regular classroom. Being outdoors encourages children to be physically active and healthy. In addition, outdoor environments can teach children to be empathetic towards living things, and is more inspiring than being indoors. 


\subsection{Precedent Analysis}

\subsection{Introduction}

Children's learning environments such as schools, early childhood education centers, outdoor education centers, children's museums and similar environments are not normally considered spectacular projects that would be sought after by either mainstream architects or the starchitects ${ }^{6}$. To design for the needs of children, an architect should not look exclusively at local and surrounding precedents, but critically examine pedagogical goals as well. They should consider the needs, usual activities and ages of the children who are going to occupy the building as carefully as the lists of rules, regulations, and guidelines. Considerations of how much money is available and where it will come from will always be of primary importance. This is a particular concern with educational buildings since they typically don't generate a large monetary profit. Since funding is limited, so is the amount of research that can be invested in each project. Nevertheless, designing effective and engaging learning environments for children remains one of the most important tasks facing our society.

Designing buildings for children always provides unique challenges. There are a number of educational and psychological theories that relate to social development and different learning styles, and different architectural languages are suitable for different learning environments. To quote Albert Einstein: "I never teach my pupils; I only attempt to provide the conditions in which they can learn." In environments where children come to experience and to comprehend the world around them, every detail plays a crucial role. (Schittich, 2008) The ultimate challenge for an architect is to suit a spatial form to a pedagogic concept and also engage assured values and abilities. (Schittich, 2008) This section presents a range of learning spaces through case studies on elementary schools, kindergartens, and outdoor classrooms in various countries. It will provide a critical study of the relationship between the research alluded to in previous

\footnotetext{
${ }^{6}$ Starchitect or also known as Stararchitect (star and Architect) is a term used by the media and publications to describe celebrity architects. These celebrity architects are seen as idols of architecture around the world for their talent or their network connections in convincing developers, financial institutions and municipalities to support their large projects. Several selected individuals include: Renzo Piano, Frank Gehry, IM Pei, Frank Lloyd Wright, Louis Khan, and Daniel Libeskind.
} 
sections and also deal with the final built form and how it settles in its immediate environment.

The Precedent Analysis includes the following Kindergartens:

1) Luginsland Kindergarten (Stuttgart, Germany) - Architect: Behnisch and Partner

2) Kindergarten in Tokyo (Tokyo, Japan) - Architect: Tezuka Architects, Tokyo

3) Outdoor Classroom Pavillion at Eib's Pond Park (Staten Island, New York, USA) - Marpillero Pollak Architects, USA)

4) Outdoor Classroom Pavillion at Roy Wilken's Park, (Southern Queens, New York, USA) - Marpillero Pollak Architects, USA 


\section{Luginsland Kindergarten}

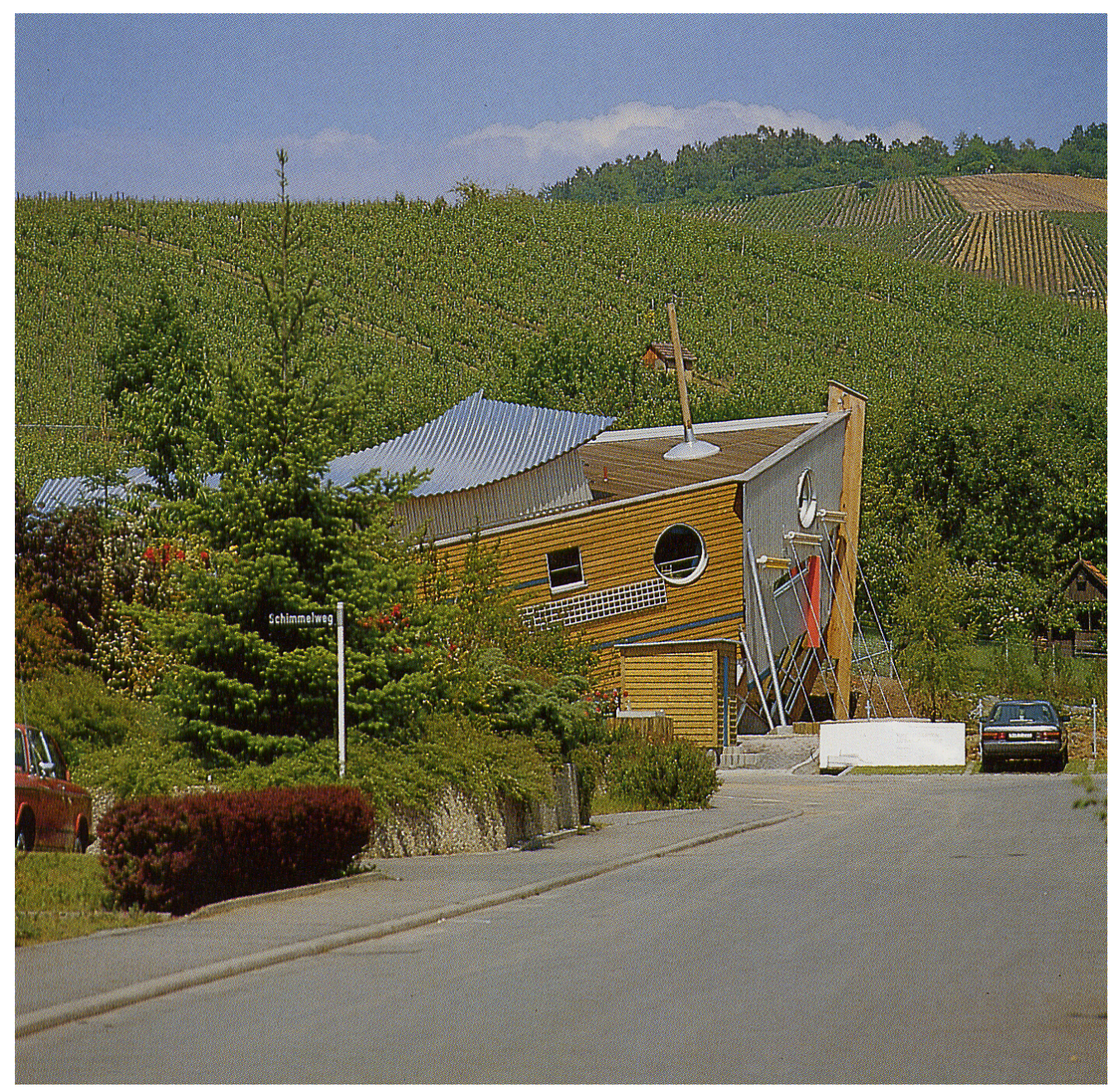

Figure 3.1: West Elevation of the Luginsland Kindergarten

\subsubsection{At a glance}

The Luginsland Kindergarten in Stuttgart, Germany designed by Behnisch and Partners, was planned for 56 preschool children in four subdivided groups. The building has a timber and steel structural frame, and at first glance it appears that the school's philosophy is focused on play.

Upon arrival at the Luginsland Kindergarten in Stuttgart Germany, children would notice a structure that resembles a recycled building. At closer glance, the building resolves itself into a metaphoric form with architectural elements. Children are able to identify this deconstructive architecture as a ship and at the same time make the connection that this building was designed and created for them. 


\subsubsection{The Unique Ship}

The overall uniqueness of the "Kindergarten Ship" allows children to experience a world that is truly their own. In a world full of rules and restrictions, this particular kindergarten building is still able to express itself playfully in both its materials and ideal location.

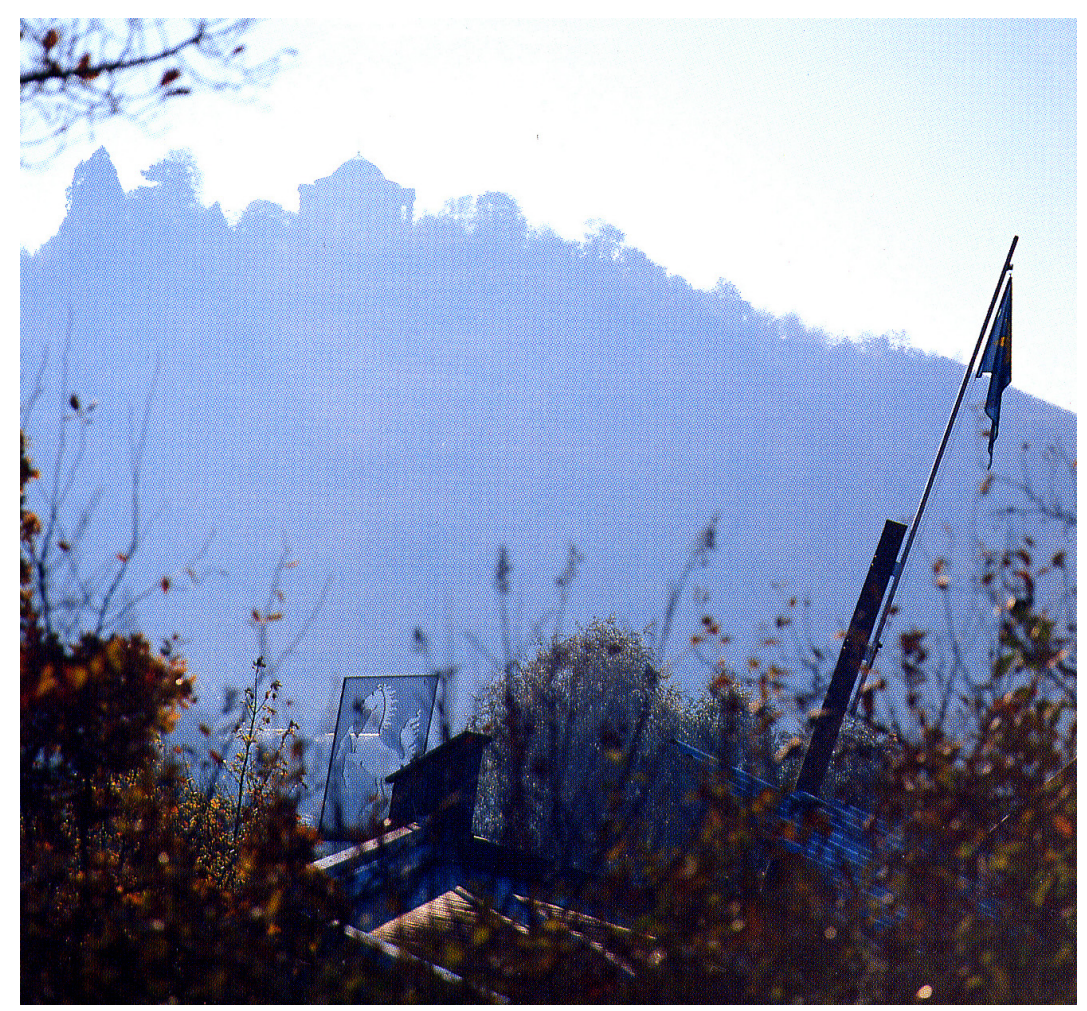

Figure 3.2: The Kindergarten Ship with the Neckar Valley backdrop for an ideal setting.

The site of the Luginsland Kindergarten is on the outskirts of Stuttgart Germany off a steep hillside in Neckar Valley. This area is home to nearby historic castles and country palaces and near several wilderness forests. The kindergarten's location is unique because of its natural outdoor surroundings as well as its close proximity to the residential community.

The building occupies the inside of the sloped site not its outside. As a result the entrance is on the main floor and the entryway overlooks the lower level and main hall. Children often feel safer when they are able to comprehend buildings they will occupy as they enter it. Environments that are unusual and unpleasant can foster negative emotions. In addition, environmental psychologists concur that any kind of unusual 
environment stimulates creativity. (Taylor \& Vlastos, 1975) The architect's design challenged all conventional learning environments around the world with a metaphorical structure resembling a ship in the midst of a vineyard. The theorists Maria Montessori (Montessori Schools), Rudolph Steiner (Waldorf Schools) and John Dewey all value experiential education. The use of the natural outdoors and the choice of the Luginsland Kindergarten's site part support their theories. The Kindergarten's surrounding environment includes vineyards, castles and palaces and will provide children with a theme for adventurous free play at the same time as it stimulates their creativity and imagination. (This is referred to in psychology as imaginative play.) Overall, the Kindergarten's location provides children and educators with controlled outdoor play spaces for a healthy learning environment.

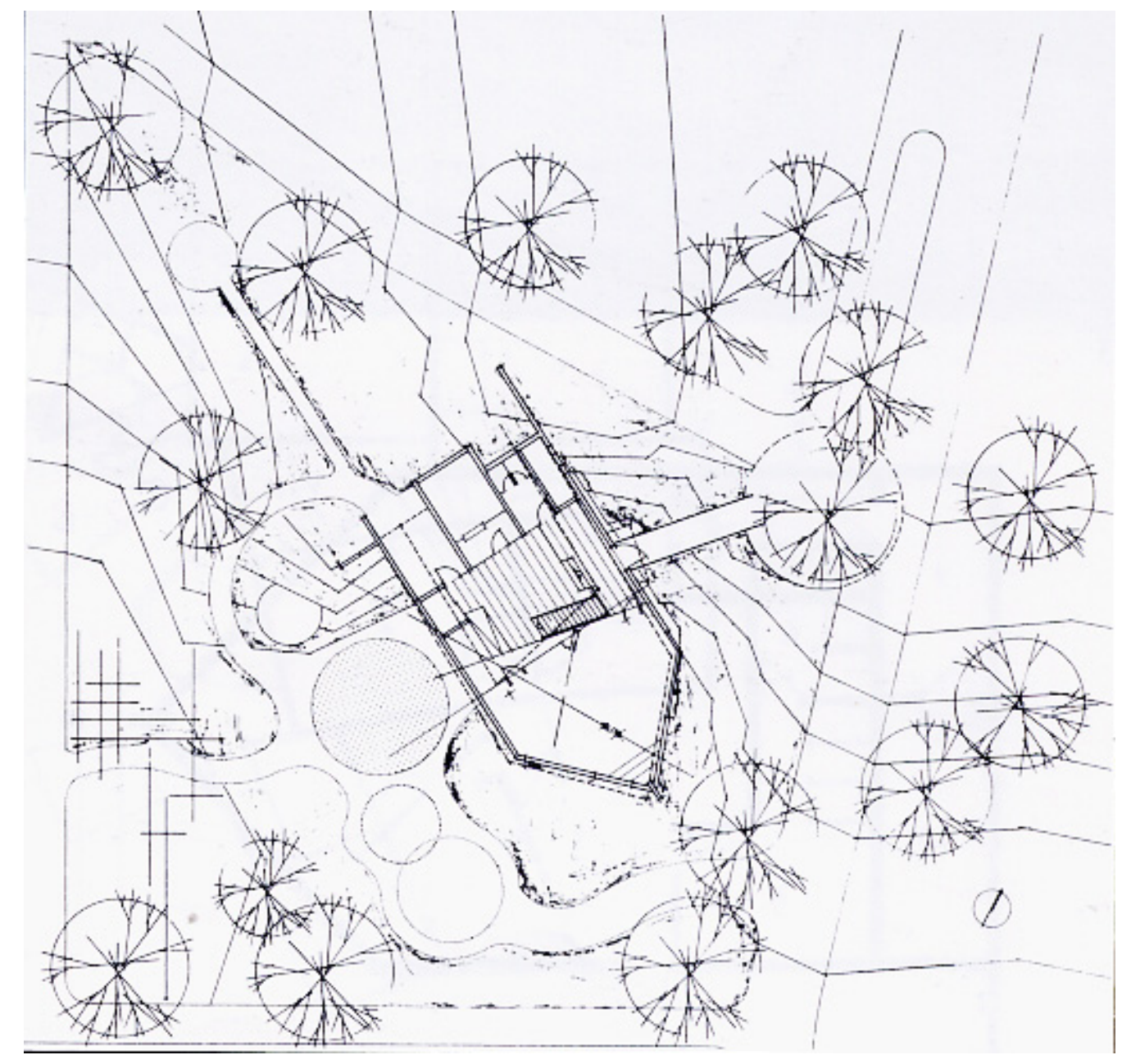

Figure 3.3: Site Plan of Luginsland Kindergarten showing the slope of site 


\subsubsection{Mimicking a Montessori school}

The ideal learning spaces of a Montessori School have certain noteworthy characteristics: they should incorporate direct natural light, low operable windows that allow for fresh air flow and also be draft- free with and natural wood flooring, furniture and doors. (Montessori Foundation \& North America Montessori Teachers Foundation) The washrooms are usually adjacent to the main classroom spaces and always employ scaled-down utilities for children ${ }^{7}$. The learning spaces in Montessori Schools are finished with acoustical ceiling tiles for sound control. In addition, a green house or a substantial amount of plants is standard at Montessori and Waldorf schools. Although the Luginsland Kindergarten does not brand itself as a Montessori or a Steiner/Waldorf school, it does embrace some of the characteristics of their school designs. From a distance, the Luginsland Kindergarten looks like a ship growing out of the earth. Closer up, it resembles a ship docked at a harbour and children enter the ship over the gangplank bridge. Like a Montessori school, this kindergarten admits natural light through its many low operable windows; also, the captain's cabin located on the top of the ship features a clerestory that emits natural light into the learning spaces on the main level. On darker days, the kindergarten operates on incandescent lights placed over activity areas in the learning spaces. They provide a sense of warmth and comfort during the darker days. As in all Montessori schools, the washrooms are adjacent to the main classrooms spaces and employ scaled-down utilities for younger children. The interior spaces are finished with plywood and laminated wood trusses which are predominantly exposed to show the natural wood grain. However, for acoustical reasons, the kindergarten does not employ ceiling tiles.

The building's unevenly shaped exterior defines the spaces within. The unconventional design is geared completely towards the children as it provides them with both a fairytale settling and an unusual learning environment that encourages creativity.

\footnotetext{
${ }^{7}$ Utilities include: Toilets, sinks, light switches, and water fountains.
} 


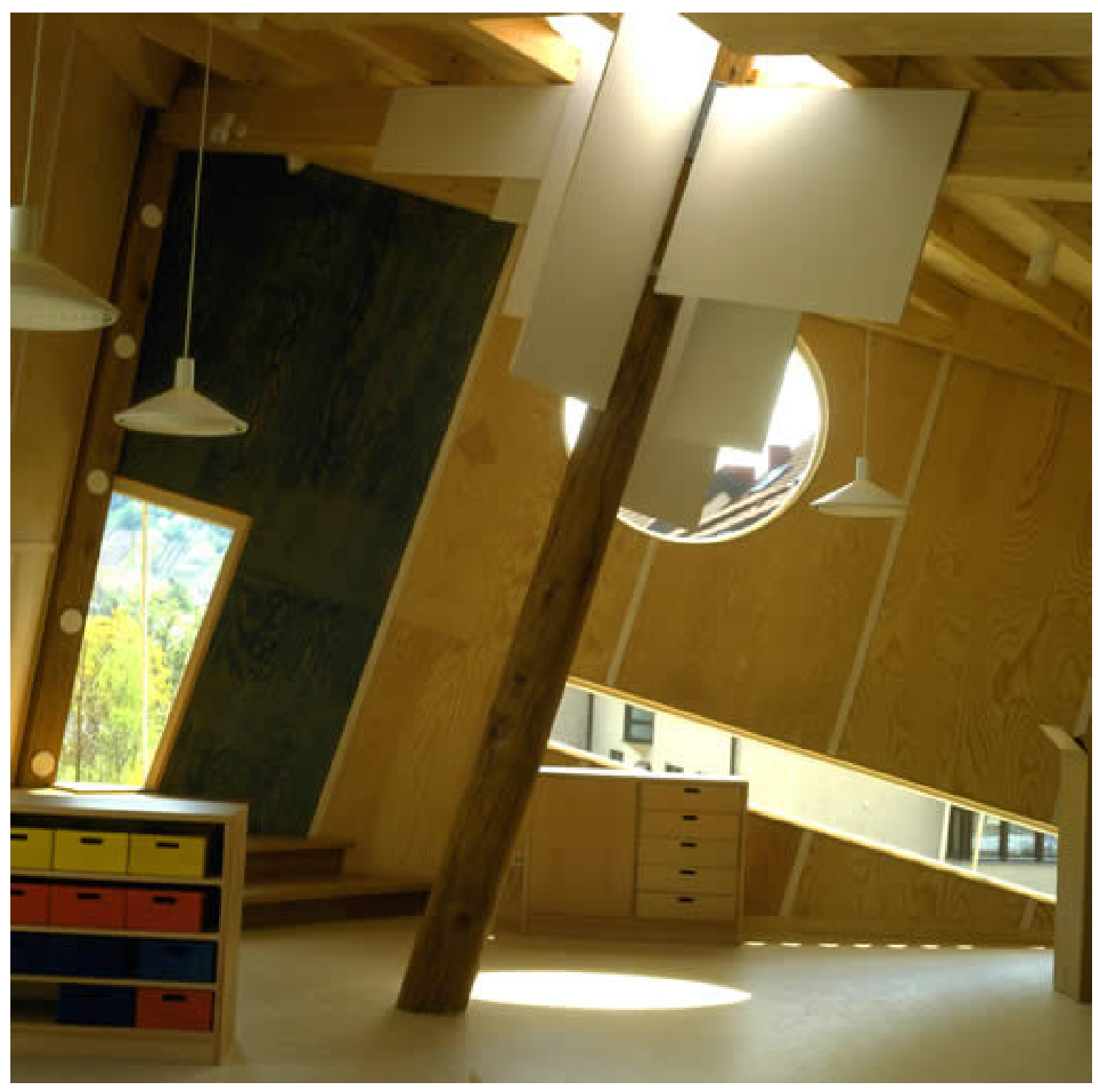

Figure 3.3: The interior view of one of a play space inside the Luginsland Kindergarten
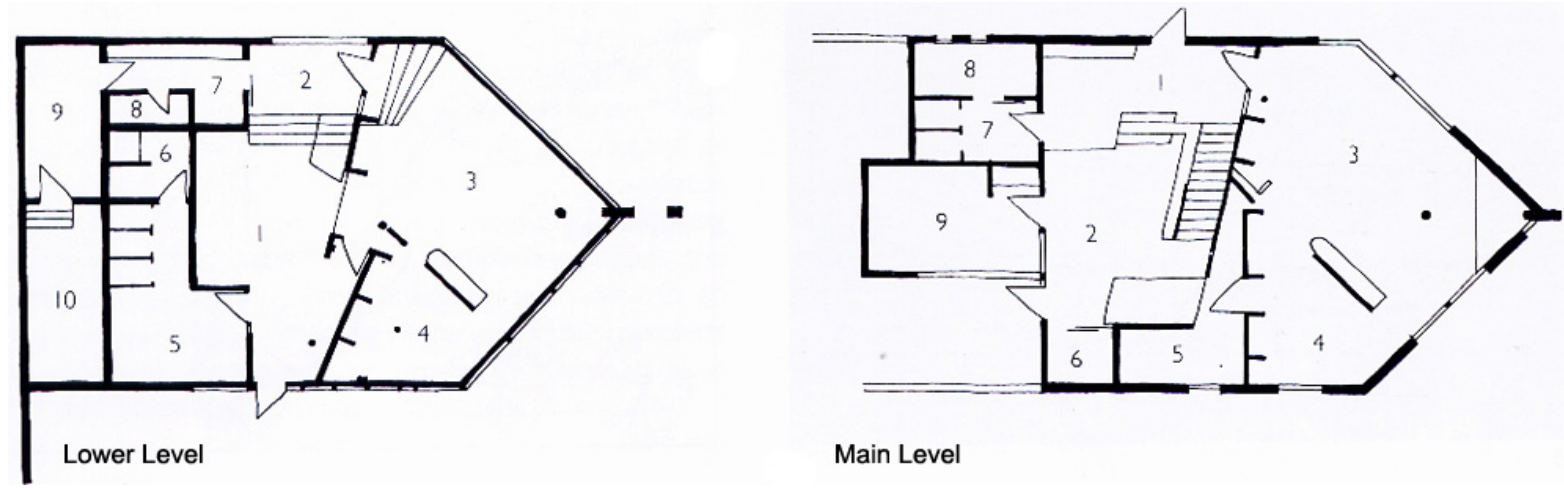

Main Level

Figure 3.4: Floor Plan of Lower Level (Ground Floor) and Main Entrance Level (First Floor) 

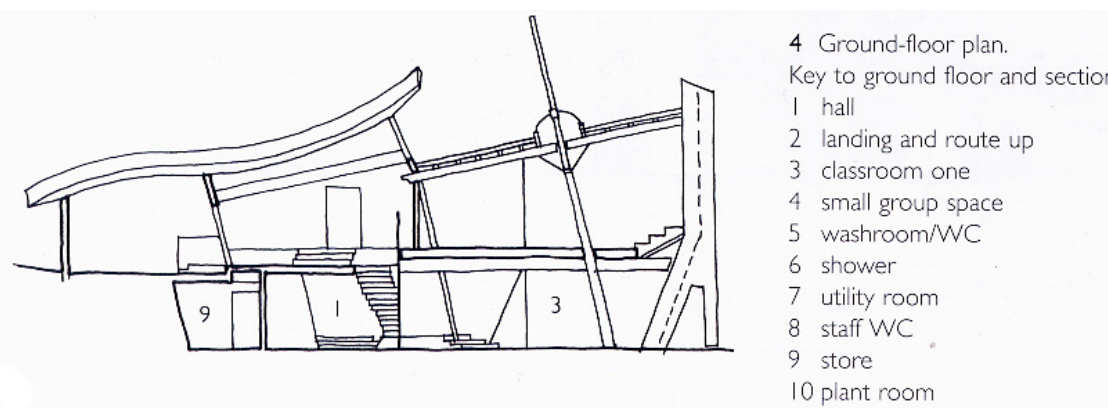

5 First-floor plan.

Key:

I landing and entrance from

street via bridge

2 hall

3 classroom

4 small group space

5 materials store

6 store

7 washroom MC

8 store

9 head teacher's office

Figure 3.5: Section of the Luginsland Kindergarten

The floor plan (Figure 3.4) illustrates that the spaces are irregularly shaped spaces, with the exception of the plant room (\#10 on the Lower Level). The spaces used by children have simple circulation and flexibility, and all learning spaces flow smoothly into each other. The rectilinear spaces are the ones less frequented by children, and are located on the west side of the building to avoid the direct sun of late afternoon.

\subsubsection{Play and Play spaces}

It was discussed in the initial section on educational theories that the steps to the modern rhetoric suggested by Sutton-Smith are initiated at the Progress stage. The Progress stage is also associated with Steiner, Montessori and Dewey's theories of Imagination and Play. The metaphorical ship is clearly discernible to children and is greatly devoted to imagination and play. The building's interior spaces allow for several play settings and the playing itself happens within the classrooms, small group spaces, and the main hall; all other spaces are for utilities, storage, and office and washroom space. The site's bucolic setting is comparable to those in fairy tales and provides a theme for fantasy play.

Free play ${ }^{8}$ as well as organized play will take place within the classroom spaces, as well as in the main hall of the Kindergarten. The small group spaces are in line with Piaget's theory of social interactions. Piaget would agree that providing an interactive and flexible space for free play encourages children to move freely and to engage in social interactions with each other. A challenge to active play at the Luginsland Kindergarten is the lack of open space within the facility itself. There is limited space for physical activity

\footnotetext{
${ }^{8}$ Free Play also includes Fantasy Play.
} 
on rainy days and educators must adapt activities for the indoors when weather conditions prevent outside play. On rainy days children will not receive regular physical activity because there are no spaces for running within the building.

In fact, this facility does not have as much space as "Bewegter Kindegarten" (Schuster, 2007), a pilot project of the City of Stuttgart to encourage physical activity in kindergarten-aged children through the playing of sports. Another challenge of this kindergarten is that it is located near several vineyards. Although they would be ideal settings, the setback is that children do not have direct access to them because the building is not openly connected. Also, there is a road between the vineyards, the open fields and the kindergarten. Ideally children and educators should have direct access to outdoor nature; in this case, the bucolic setting is more of a tease for them when they are within the Kindergarten's controlled outdoor play space ${ }^{9}$.

\subsubsection{Imperceptible Harms}

In reconsidering the imperceptible harms around child care facilities, we recall that children are more vulnerable to the effects of air pollution than are adults, and therefore it is critical to choose locations and construction materials carefully when designing a child care facility. The Luginsland Kindergarten located in Stuttgart, Germany is in an ideal location to promote natural clean air; it is on the outskirts of the city where there are still natural wilderness forests within a 3-kilometre radius (Figure 3.6), making the ambient ozone and air quality favourable for a children's learning environment (See Figure 3.7). In addition, the condition of the air in Stuttgart has been monitored day and night over the past several years through measuring stations because of the past high traffic concentration. (Urban Climate Stuttgart, 2009) Traffic-related pollution was found to be extremely low at this specific location. Also, the north-west side of the Kindergarten is a low-traffic residential area, and to the south-east are vineyards, wilderness forest and green spaces spread over a 5- kilometre radius. 


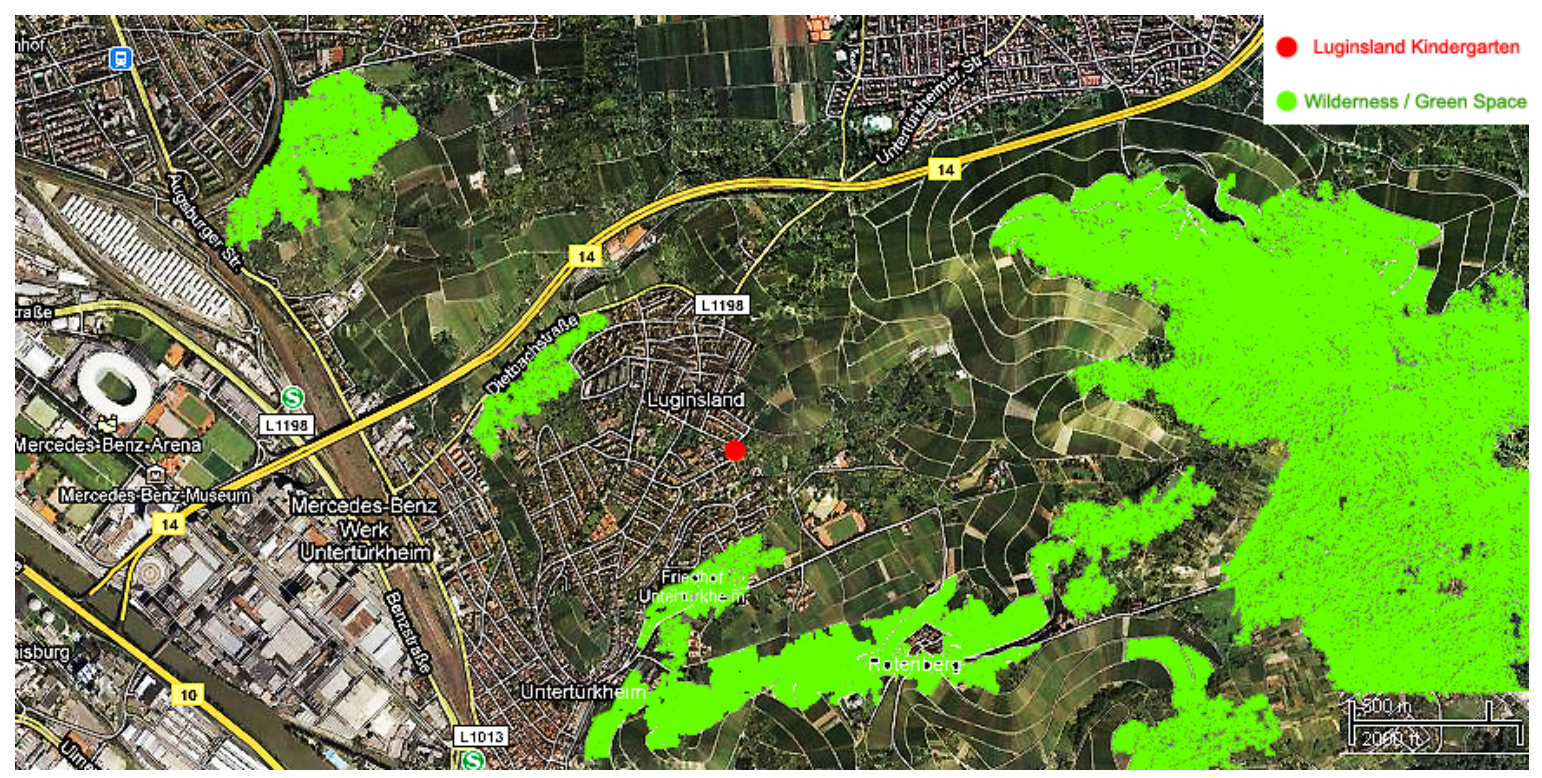

Figure 3.6: Wilderness Green Spaces around the Luginsland Kindergarten

\section{Stuttgart Air Quality Details}

\begin{tabular}{|c|c|}
\hline Pollution & Index Value \\
\hline Very Low & $\square 0 / 25$ \\
\hline Low & $25 / 50$ \\
\hline Medium & $=50 / 75$ \\
\hline High & $=75 / 100$ \\
\hline Very High & $\square>100$ \\
\hline
\end{tabular}

Last Update: $11 / 23 / 200916: 00$ UTC

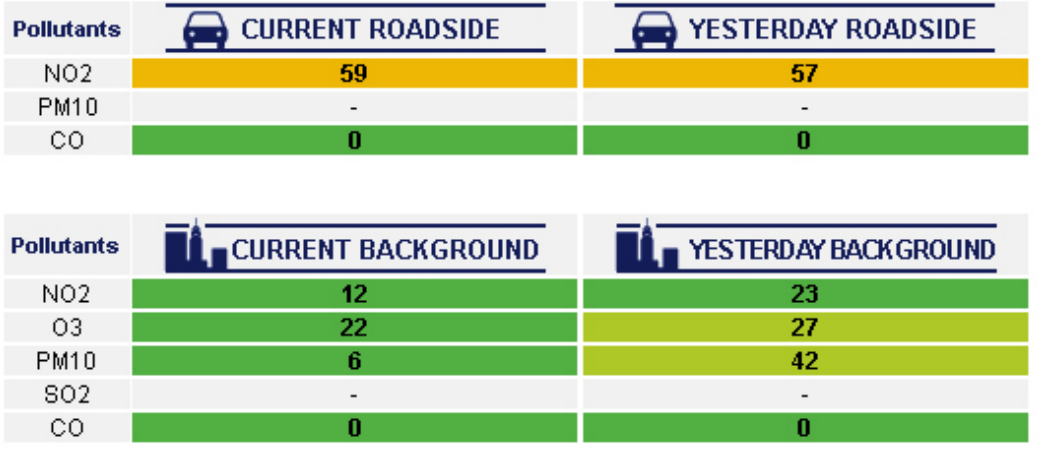

Figure 3.7: Stuttgart Air Quality Details 


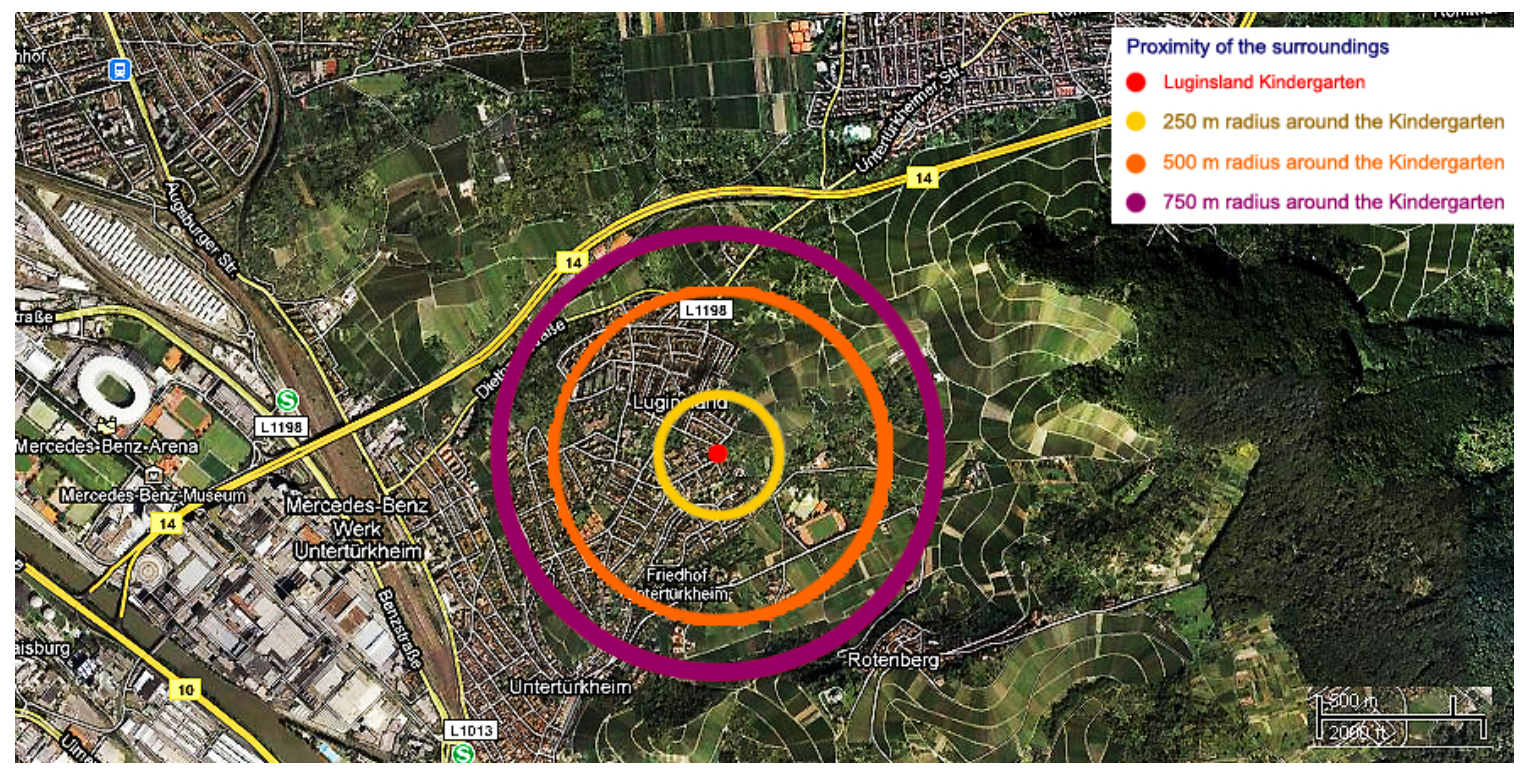

Figure 3.8: Proximity of the surroundings near Luginsland Kindergarten

The closest highway is over 1.5 Kilometres North of the Luginsland Kindergarten (see Figure 3.8) and the only road to the facility is a one- lane access road. Furthermore, the Kindergarten provides only three parking spaces for its staff and do there is no drop-off area or large parking lot. The reason for this is that, in the first case, parents would be encouraged to make a quick drop-off by parking on a lane road. For safety reasons, loitering is discouraged near schools.

\subsubsection{The Building as a teaching tool for nutritional health}

In an earlier section it was mentioned that nutrition is essential to a sense of well-being and to the growth, developmental and activity needs of children. Children are able to transfer the knowledge gained at supportive school environments to their families at home. The Luginsland Kindergarten, however, does not have the facilities to encourage healthy eating. In fact, unlike most kindergartens and day care centers it does not even have a kitchen area; children are expected to have breakfast prior to the start of each school day and to bring a bagged lunch. The disadvantage of not having a kitchen or a food preparation space at a facility such as this is that there is no opportunity to teach the children about healthy eating and the food- making process. 


\subsubsection{Summary}

The Luginsland Kindergarten is a good example of a building designed to stimulate creativity. It consists of a variety of spaces created with natural wood. The spaces are unusual and are "written" in a child's language, making them attractive. Although it is a small building and lacks the space to encourage indoor physical activity, it still effectively stimulates creativity using metaphors. The site is ideal and aligns with a number of the educational theories endorsed by Steiner, Montessori and Dewey. The kindergarten also addresses medical issues used in the thesis. If anyone were to find this building complicated, it would not be a child.

\section{Fuji Kindergarten}

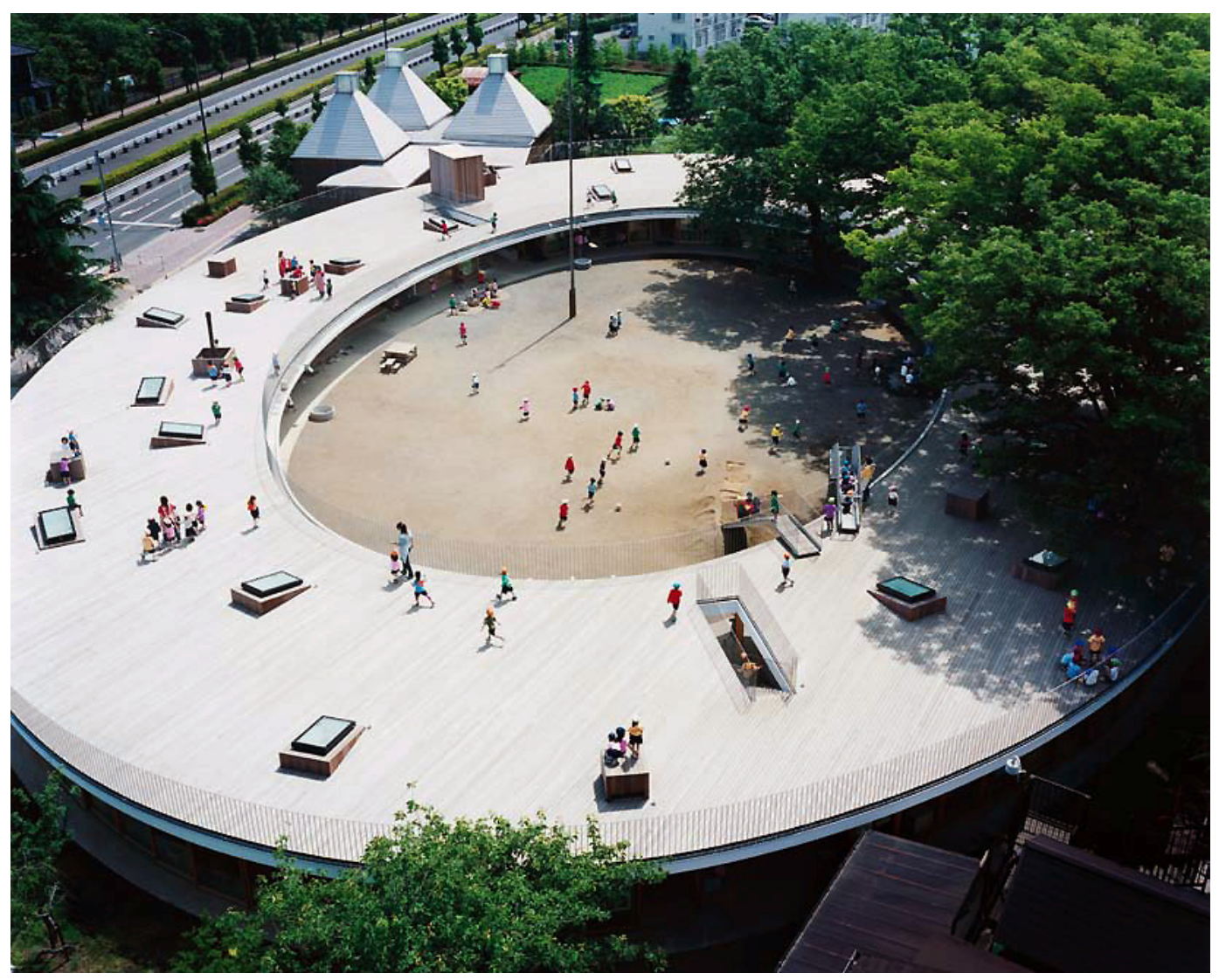

Figure 3.9: Birds eye view of the Fuji Kindergarten.

\subsubsection{At a glance}

The Fuji Kindergarten is located in Tachikawa on the outskirts of Tokyo, Japan. The building was designed by Tezuka Architects and completed in 2007 . It currently accommodates 560 preschool children between the ages of $3-5$, as well as 35 staff. The 
560 preschool children are sub-divided into 16 groups and are distributed in different learning spaces within the oval. The building is constructed with a steel structural frame, and the interior is completed with expose finished wood. The school's philosophy is evidently one of experiential education through the use of the school building as a tool.

\subsubsection{The Unique Oval}

The building is located in a residential neighbourhood in Tachikawa. At a quick glance, the Fuji Kindergarten is a building that is oval in plan, scaled to the height of children and consists of a mini racetrack on a roof. The idea of having an oval track on a roof was used by Giaccomo Matte-Trucco in Turin Italy in 1920 for the Fiat Works building where a real auto racing test track was placed on its roof.

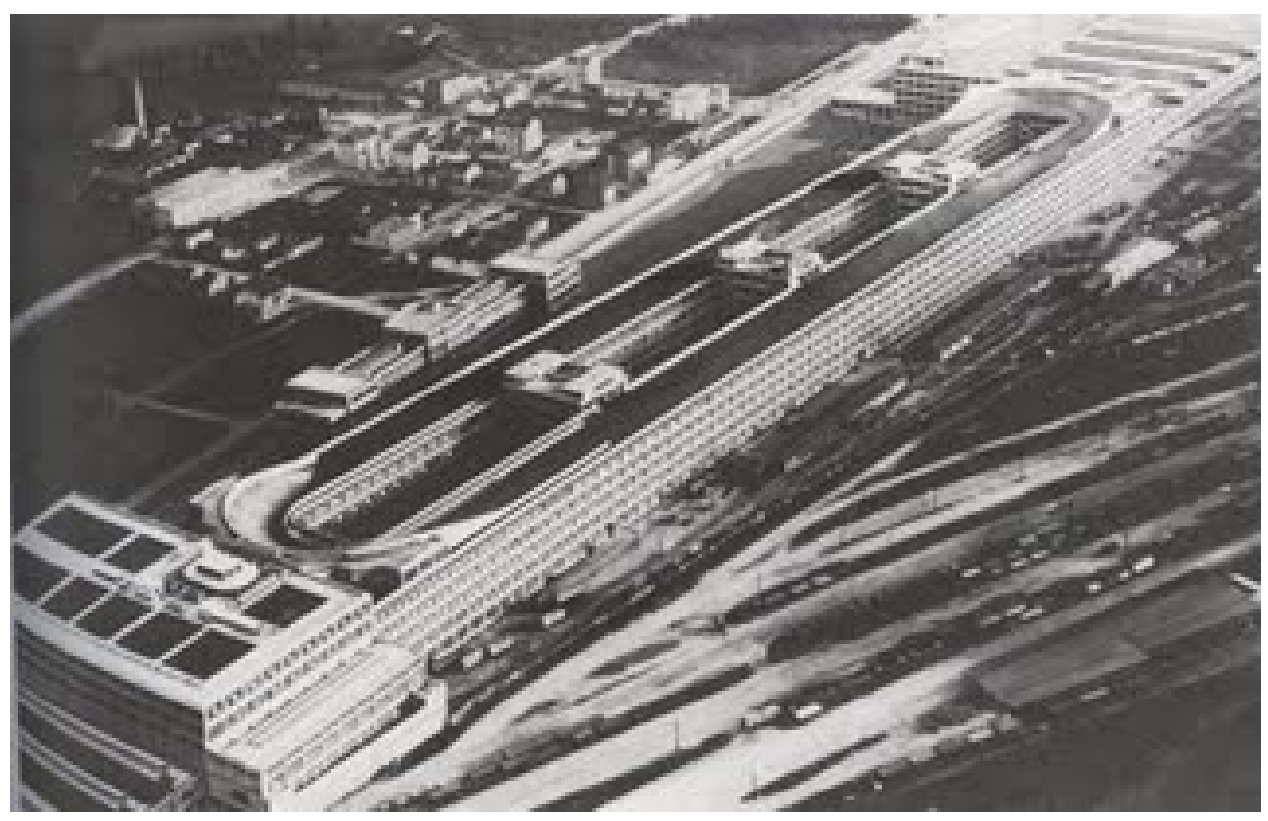

Figure 3.10: Photo of Fiat Works by Architect Giaccomo Matte-Trucco in Turin, Italy in 1920.

The scheme of the oval form at the Fuji Kindergarten, along with the central outdoor courtyard, promotes the idea of a learning community ${ }^{10}$ while challenging the designs of

\footnotetext{
${ }^{10}$ Thousands of schools throughout the United States, Canada, Australia and other countries have become "Learning Communities" (A frequent term used by the educational community) that include safe and caring environments in which children can excel. There were many years of fit it approaches that didn't do the job, and in recent research and through experience; both parents and educators agree that creating a positive
} 
all conventional school buildings or as architect Takaharu Tezuka once said: "it is an alternative to a prison!" (Monocle, 2009)

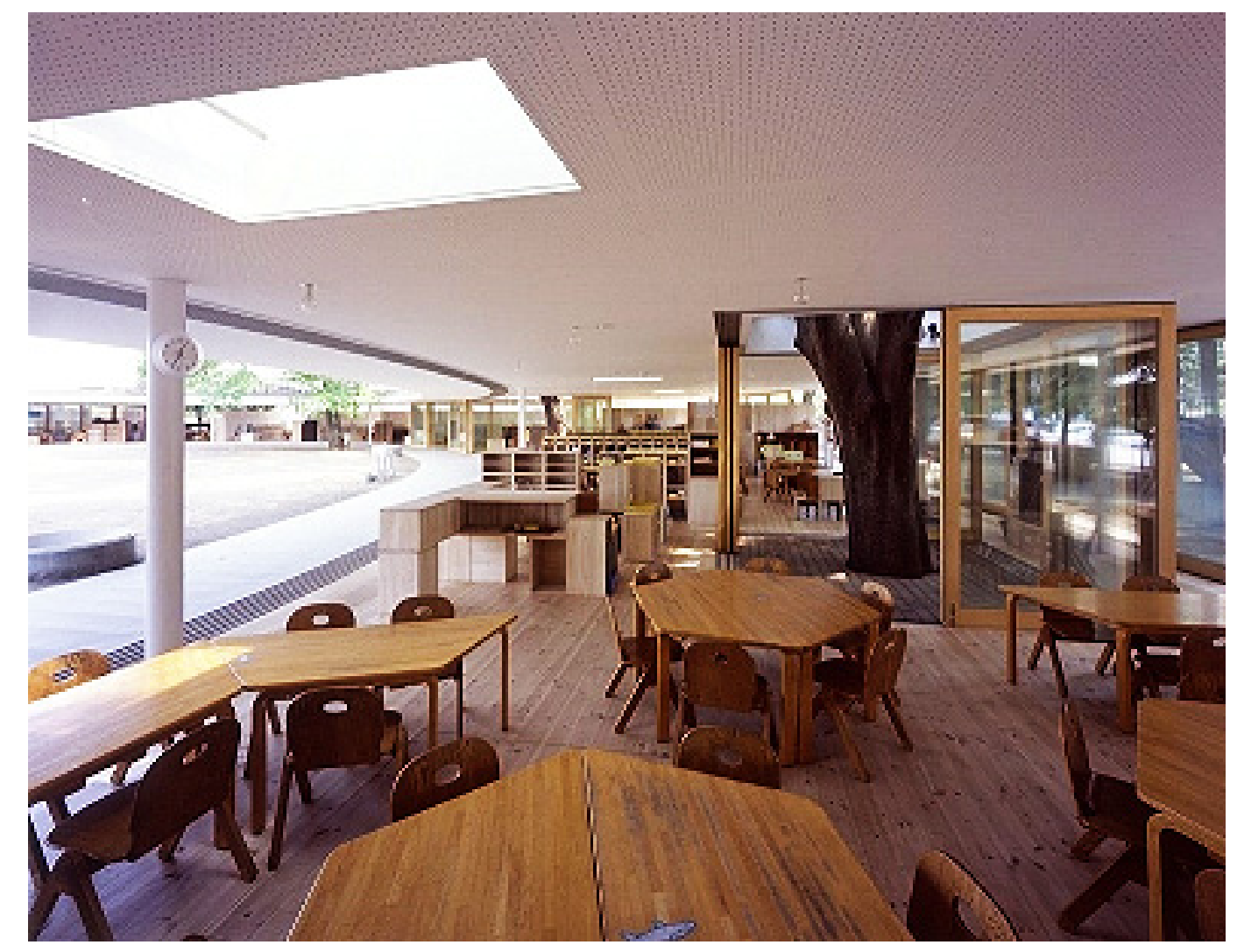

Figure 3.11: Open learning spaces of the Fuji Kindergarten

The interior of the Fuji Kindergarten has no walls in between the learning spaces. This open concept design provides open sight-lines to all the children and the teachers in the kindergarten. The design also creates an inclusive space without any hierarchy involving teachers, students or different age groups to demonstrate that everyone is part of the learning community. The only mode of space separation at all is provided by the use of wood blocks and stacked-up furniture to divide different areas. Any parent or educator can easily imagine how noisy the spaces could become since they are actually one large space without dividers or sound-proofing. One advantage to an open- space concept for a kindergarten concerns safety: in cases where one teacher has had to leave her area, a neighbouring teacher can watch the children in both learning spaces.

school environment is the most effective way to improve behaviour and learning. 
With reference to an educational theory from the initial section; some of the principles of Vygotsky's theories are:

- Children construct their knowledge

- Development cannot be separated from its social context

- Learning can lead development

- Language plays a central role in mental development (Social)

Referring to Vygotsky's theory, even though the noise level at the kindergarten can see alarming at times from an educator's standpoint, children will learn socially acceptable behaviour, such as when to use what tone of voice.

The Fuji Kindergarten also acknowledges Jean Piaget's Stages of Cognitive Development, specifically the preoperational stage involving children between the ages of 2-6. During this phase children are often self-oriented and egocentric. Having a building that encourages community through its very design ensures there will be fewer challenges when teaching the children about empathy and cooperation. The spaces themselves provide opportunities for social interactions. These ideas are also stressed by Maria Montessori, Rudolph Steiner and John Dewey in their respective theories.

\subsubsection{Experiential education and the Montessori Method}

The references from the previous precedent analysis mentioned that any type of unusual environment will encourage creativity, and the children attending this Kindergarten will agree that it is a rather unique and unusual environment. In fact, the managing directors of Fuji Kindergarten made it a privately owned and operated facility so that it could challenge government standards and regulations. Any parent would tell a child that playing on a rooftop is dangerous, but what if the rooftop was a play space and incorporated a long slide that came down from it?

The design of the Fuji Kindergarten extensively supports experiential education and the Montessori pedagogic system. By giving the children opportunities for experiences and for taking chances, they are engaging in experiential education. Children attending this Kindergarten will gain valuable experience through cause and effect. There are several particulars that make this Kindergarten unique. For one thing: the children do not wash their hands by facing a lavatory wall but rather stand around a circular sink with other 
children and socialize as they wash their hands.

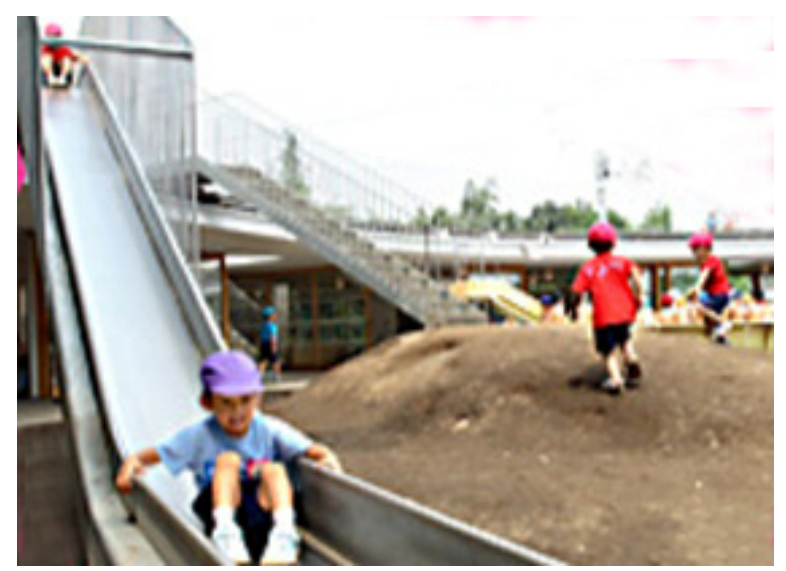

Figure 3.12: A child sliding down from the roof.

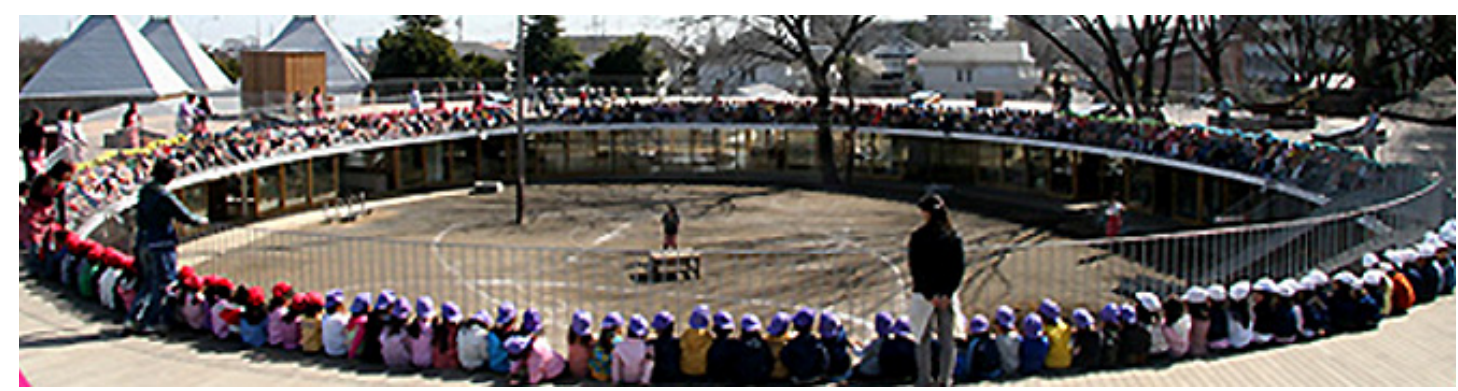

Figure 3.13: Opening day of the Fuji Kindergarten, when all the children dangled their legs through the thin balustrades.

All this is a part of the experiential education influenced by both Maria Montessori, and John Dewey, one of the most renowned advocates of experiential education. The play slide from the roof down to the courtyard provides quick access for children instead of their having to run down stairs or climb down a rope ladder. Although the Fuji Kindergarten does not have definite walls, it still defines the separation space needed for small groupings by using wooden storage boxes along with the furniture. 


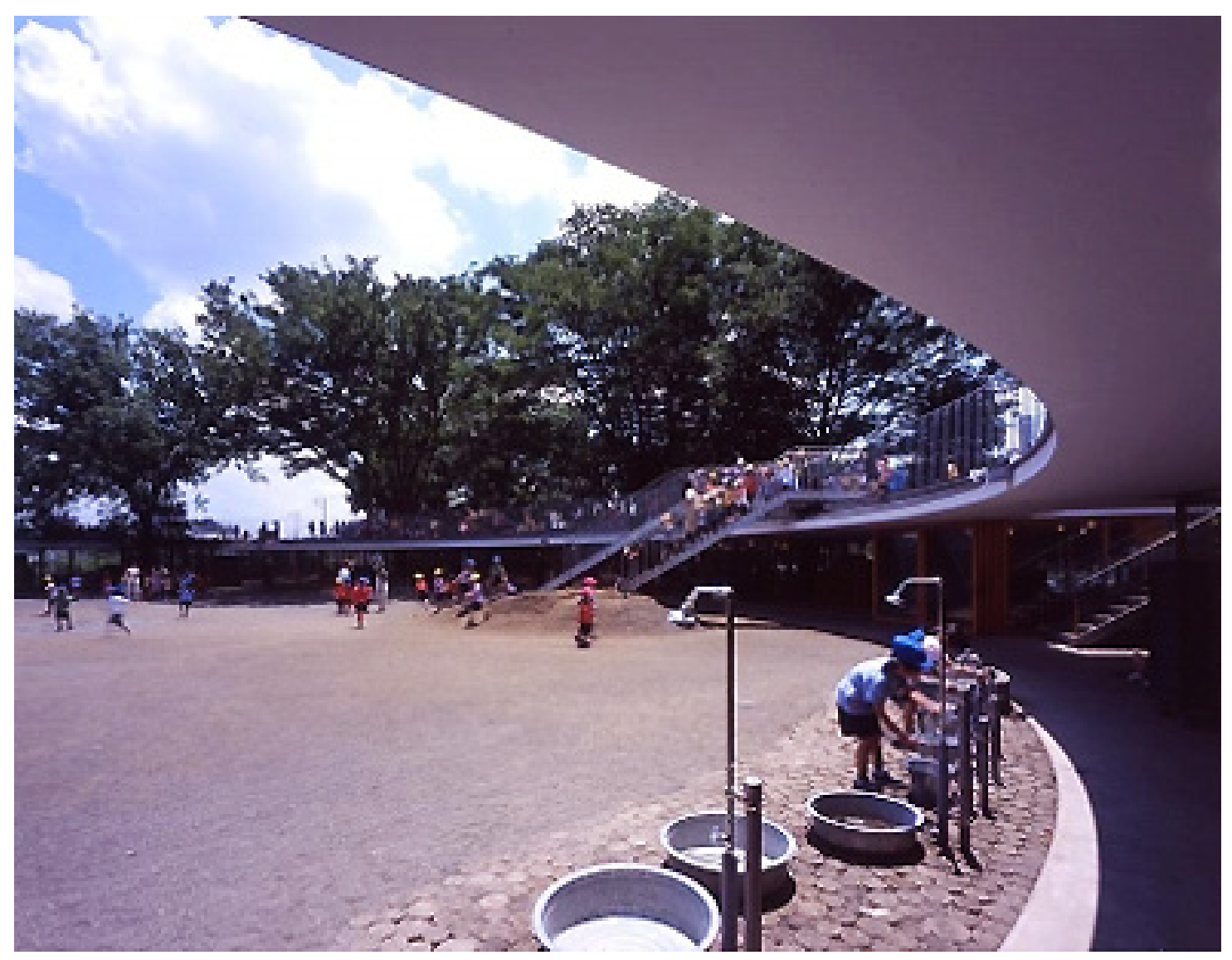

Figure 3.14: Circular sinks for hand washing and socializing.

Another thing that is unique at this kindergarten is that the children are encouraged to climb the Zelkova trees on the track level. Although this activity is encouraged at this private school, in North America any educational facility allowing this would be opening itself up to legal charges. The diverse experiences offered at this school are highly influenced by the educational theorists referenced from the initial section of this thesis.

Unlike the Luginsland Kindergarten, the Fuji Kindergarten clearly promotes itself as a Montessori School, and like all authentic Montessori schools this one also provide students with ample natural daylight. It shines through and into the learning spaces because the Fuji Kindergarten is designed with sliding doors containing see-through glass and framed with unpainted hardwood. There are also operable skylights every few meters on the roof and these provide sufficient light for the spaces in and between the furnishings. Each skylight has a rope ladder hanging below it to encourage children to climb onto the roof from their learning spaces. 


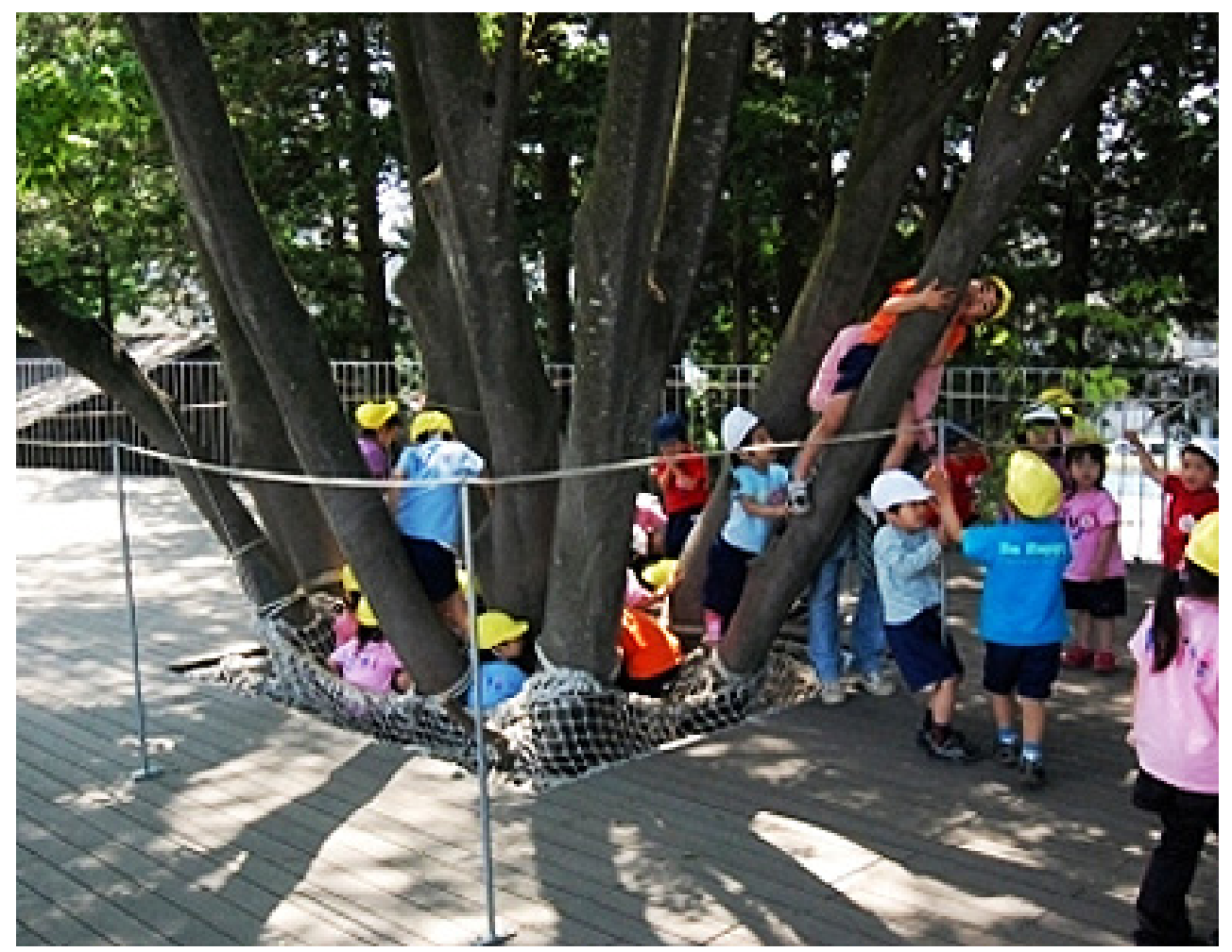

Figure 3.15: Children are encouraged to climb the Zelkova Trees on the roof.

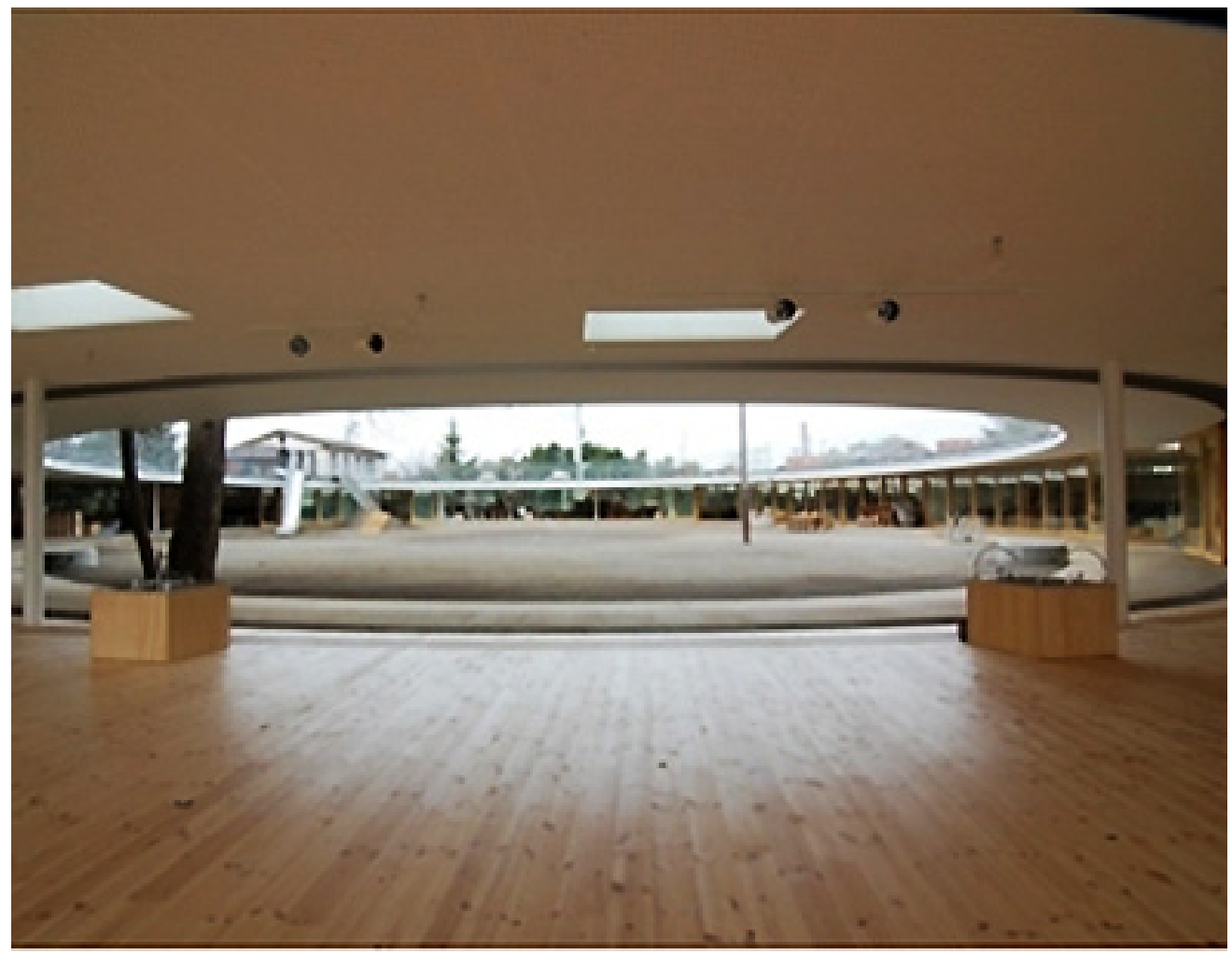

Figure 3.16: A view from the learning space at the Fuji Kindergarten. 
The sliding doors with glass also provide direct exposure between the learning spaces and the outdoors. Although the building is seamless with the outdoors, it lacks the outdoor natural green spaces that would qualify it as a Hybrid Space ${ }^{11}$. Also, hybrid spaces must have natural air ventilation and must not require air conditioning. The building is virtually an outdoors space when the sliding doors are opened.

\subsubsection{Let there be light}

If it is dark outside without much sunlight, the children will walk towards one of the strings attached to the light pods and pull on it. Each light pod consists of a naked light bulb. Unlike most schools, the artificial lights at the Fuji Kindergarten are not connected through an electrical series but each individual light within a pod acts as illumination for a small grouping space within the larger area.

\subsubsection{Imperceptible Harms near the Oval}

With reference to traffic-related pollution, infrastructures in close proximity to the kindergarten must be taken into consideration. Even though the Fuji Kindergarten encourages active exercise in the outdoors by using the sloped oval roof as a play space, it is actually in the center of an urban community surrounded by interweaving streets and a highway (See Figure 3.17).

As discussed in an earlier section, the proximity of traffic is a major concern for child care facilities. Traffic is a main source of air pollution within urban communities and there are health effects for those living near busy roads that are extremely unfavourable to a child's health over the long term. Children spend as much time in childcare centers as in their own homes and therefore children at the Fuji Kindergarten are very vulnerable since they are inhaling traffic air pollutants. Even during outdoor exercise on the roof, this is still the case. Furthermore, the drop-off and parking areas of the Fuji Kindergarten are located within meters of the entrance, in contradiction of rules set forth for a true Montessori School. 


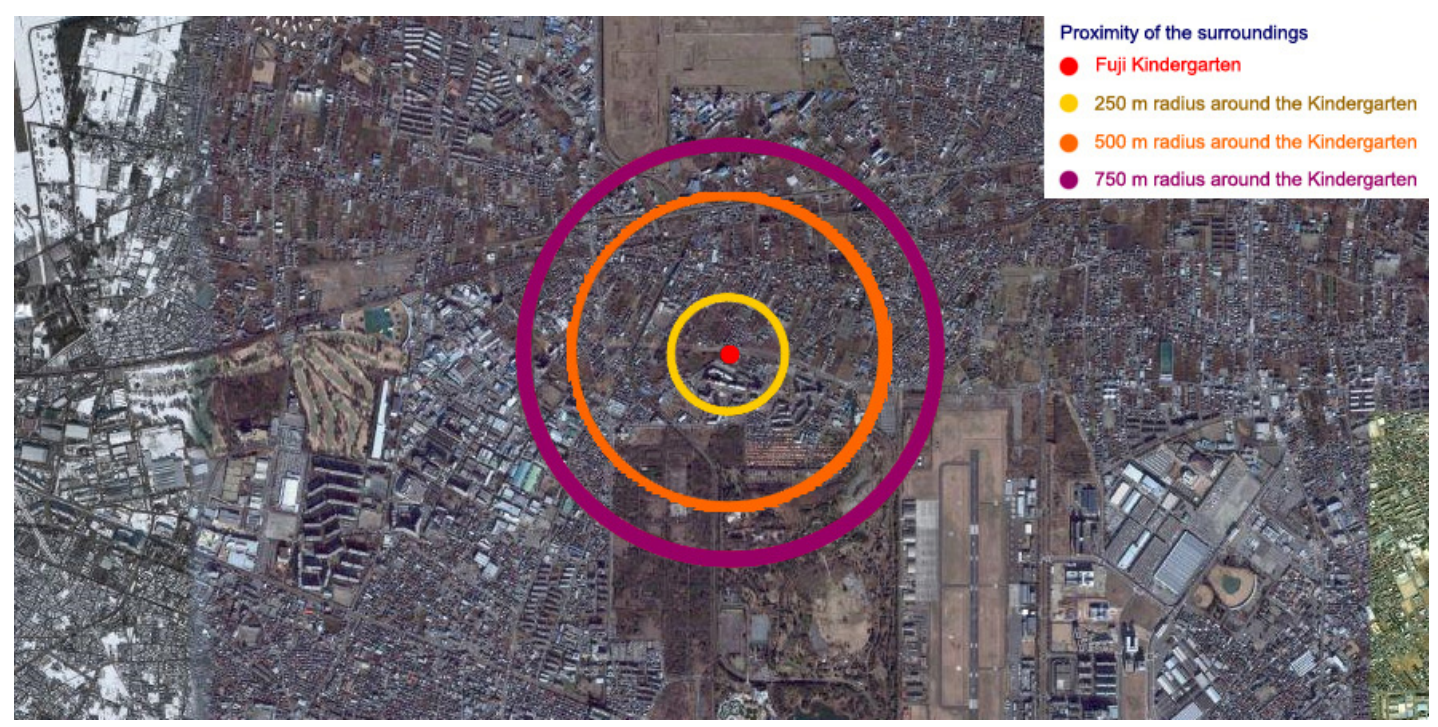

Figure 3.17: Proximity of the surrounding highways and streets at the Fuji Kindergarten

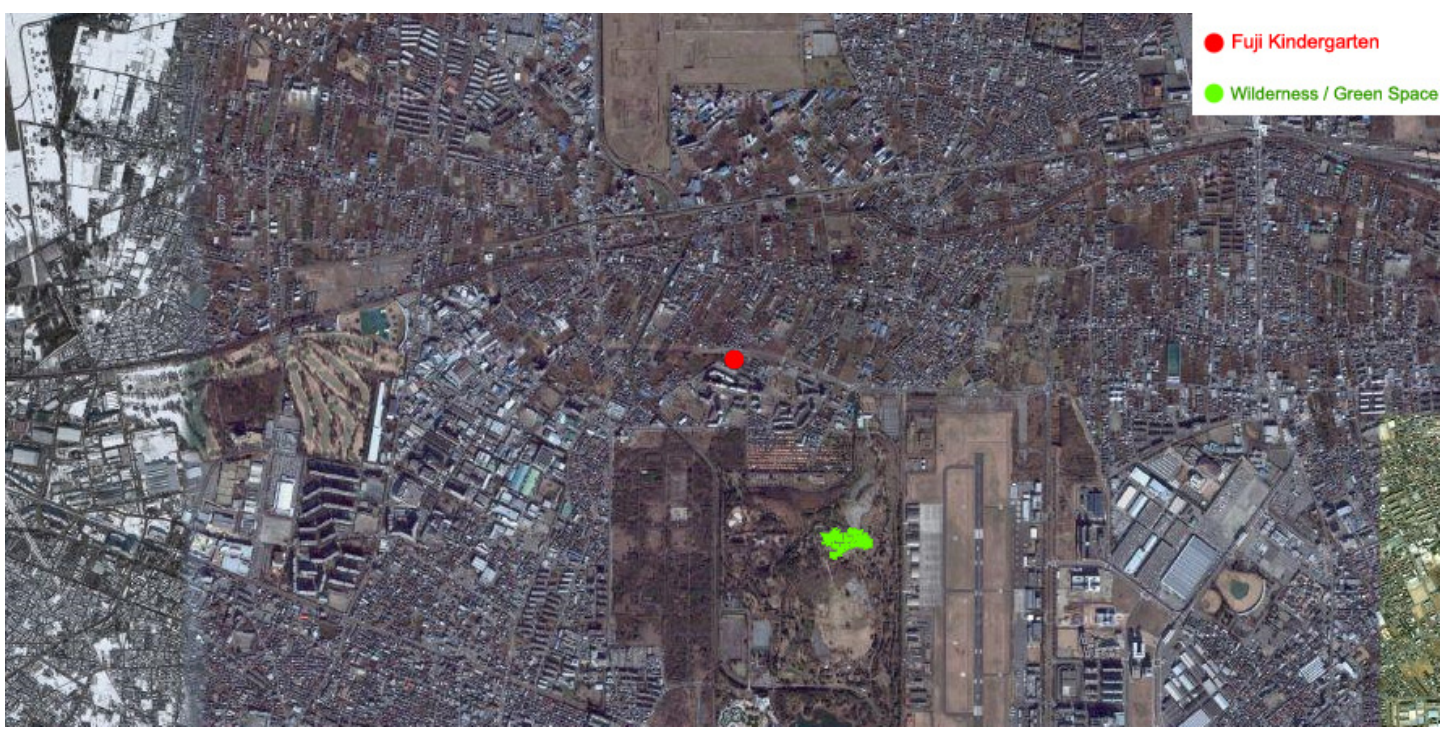

Figure 3.18: The lack of green wilderness space near the Fuji Kindergarten

\subsubsection{Summary}

The Fuji Kindergarten building can be used as a learning tool that enables children to function in society through the relationship of cause and effect. Ironically, this same cause and effect is also being expressed through the imperceptible harms related to the traffic pollution that is unavoidable at this specific location. Even though it is a well designed building, due to of the lack of outdoor nature around the kindergarten, it falls short of being deemed a hybrid space. 


\subsubsection{Outdoor Classroom Pavilions at Eib's Pond Park and at Roy Wilken's Park}

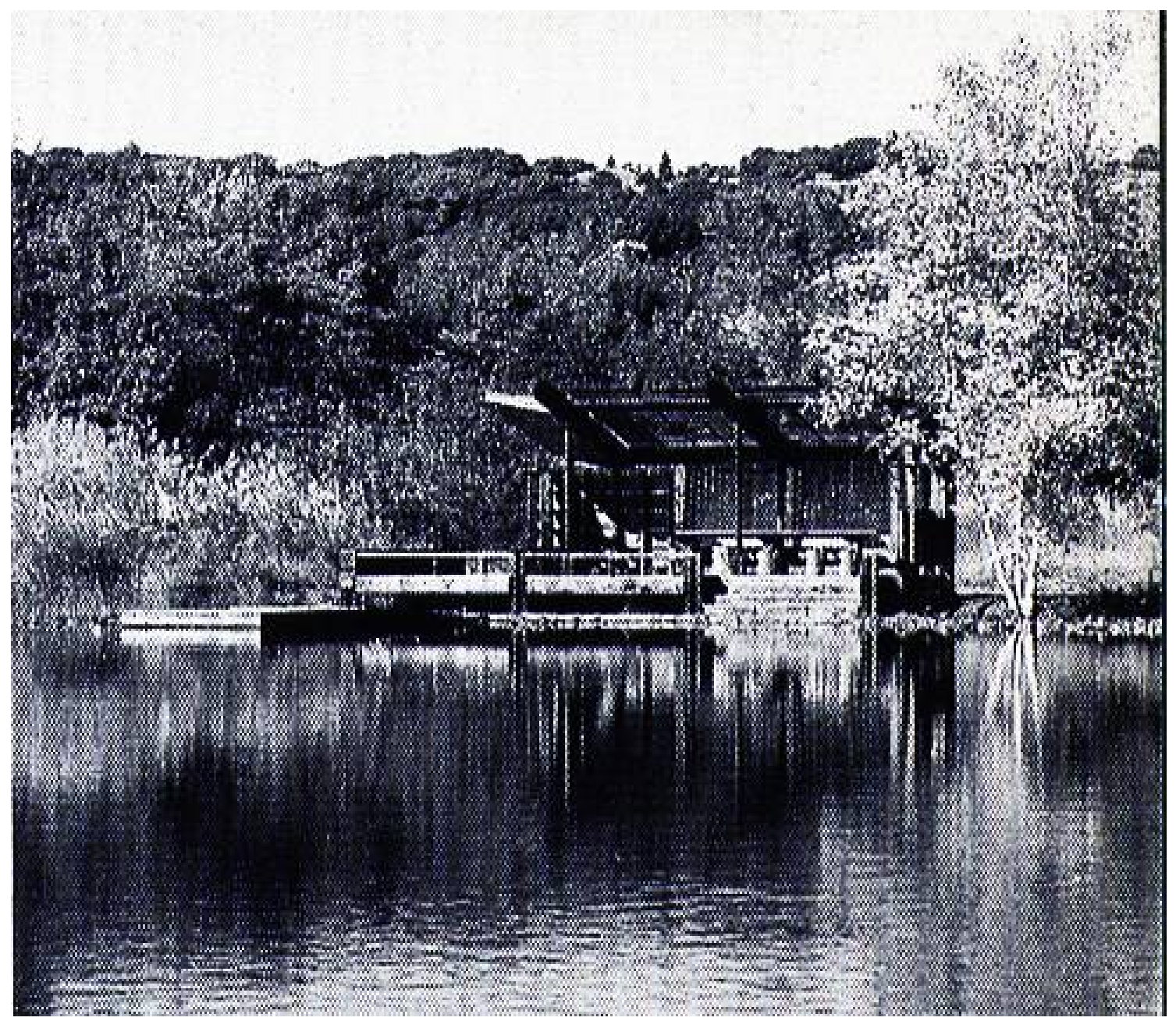

Figure 3.19: View towards Pavillion at Eib's Pond Park

\subsubsection{Outdoor Classroom}

The outdoor classroom pavilions at Eib's Pond Park, Staten Island and Roy Wilkins Park, Southern Queens, New York both provide outdoor experiential learning opportunities for local children and adults alike. The design and immediate locations of the pavilions aligns with the ideas of all the theorists mentioned in the initial chapters of this thesis.

\subsubsection{Simple structure, simple space, valuable experience}

The structures are both constructed with stock sized redwood which is easily accessible if replacement is needed in the future. The initial construction of these pavilions were put 
together by volunteers and young carpenters who had little to no experience in reading construction documents, therefore the design had to be reliable and valuable for the users and yet simple enough so that inexperienced are able to gain new skills. The project was constructed mainly with the aid of a large framing model, field sketches and homework assignments. The use of wood integrates the man made structure into their immediate natural forested sites. Both pavilions' designs emphasize openness as well as providing flexibility for different activities and curricula. The designs also challenge the idea of indoor outdoor space through the variations in height, pitch and transparency. 12
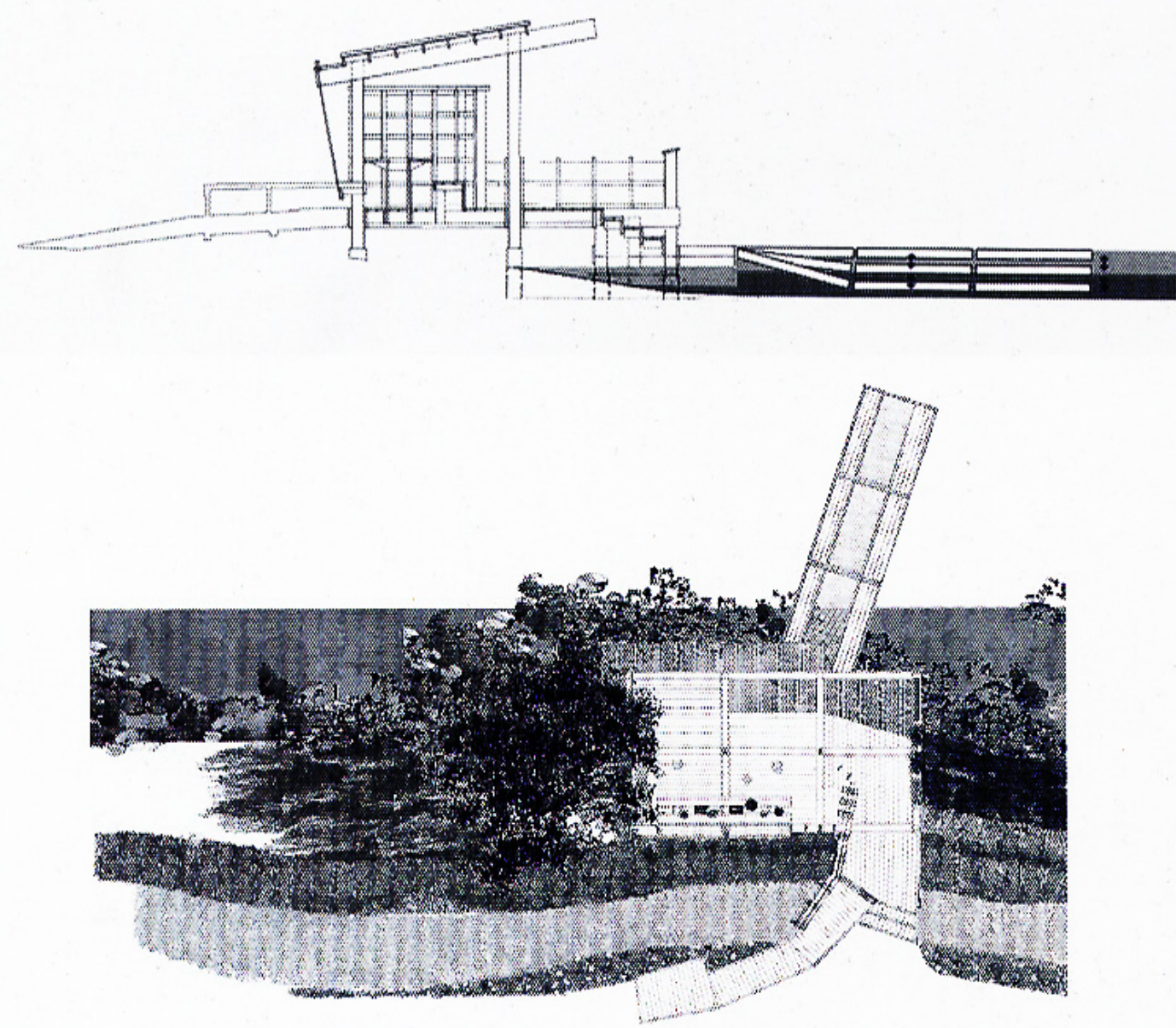

Figure 3.20: Section and Site Plan of Pavillion at Eib's Pond Park

\footnotetext{
${ }^{12}$ Wood Design Awards 2003
} 


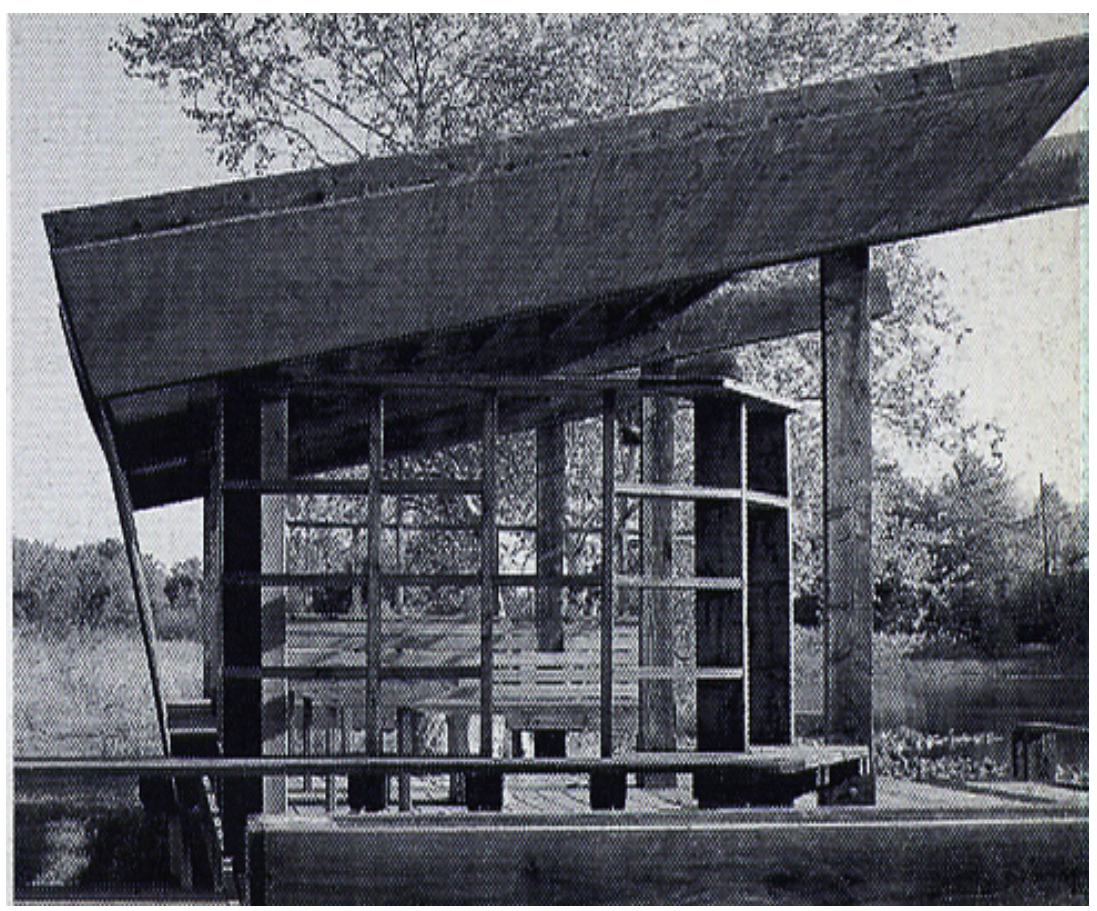

Figure 3.21: Towards inside the Pavillion at Eib's Pond Park

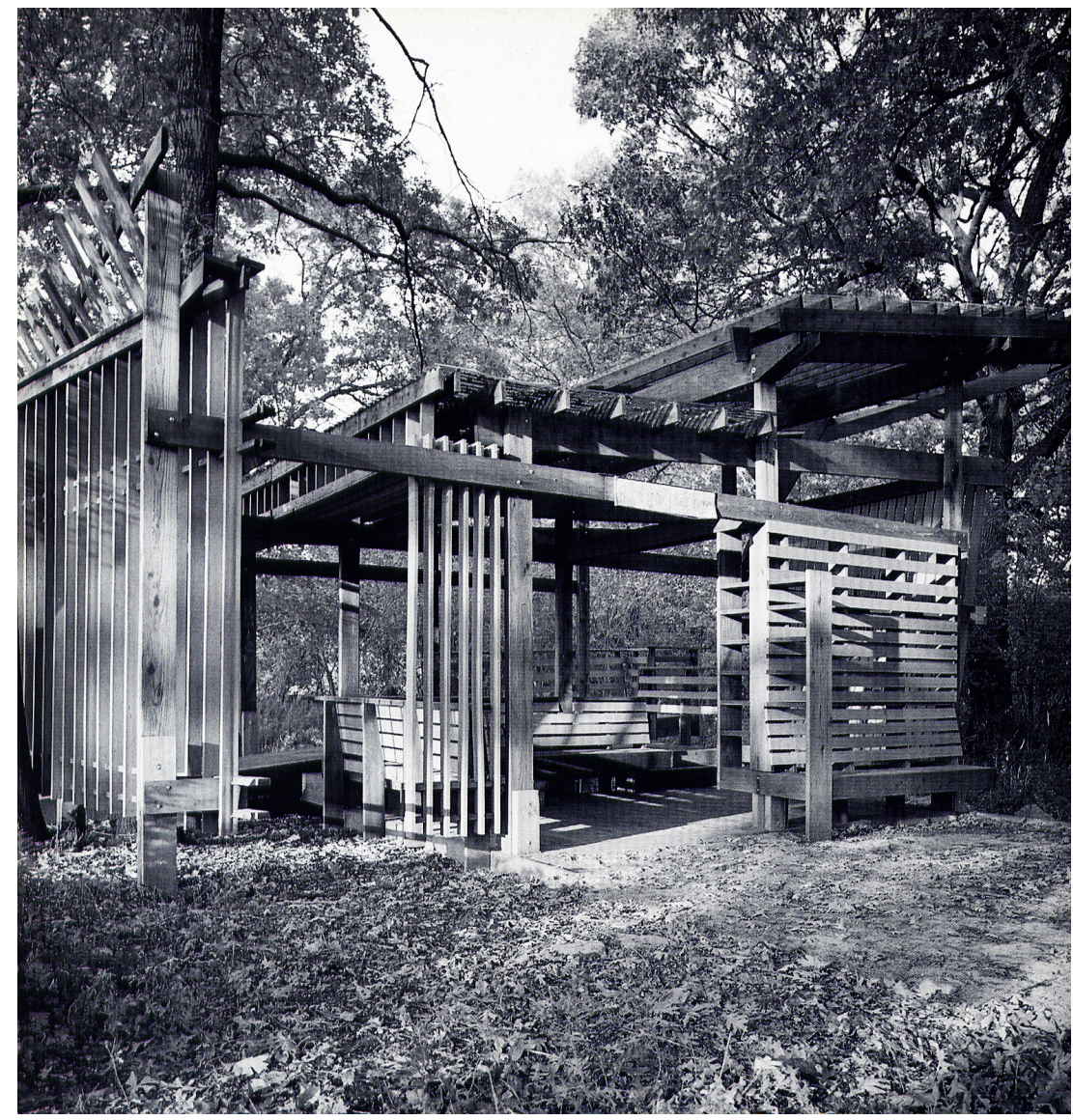

Figure 3.22: Pavillion at Roy Wilken's Park 


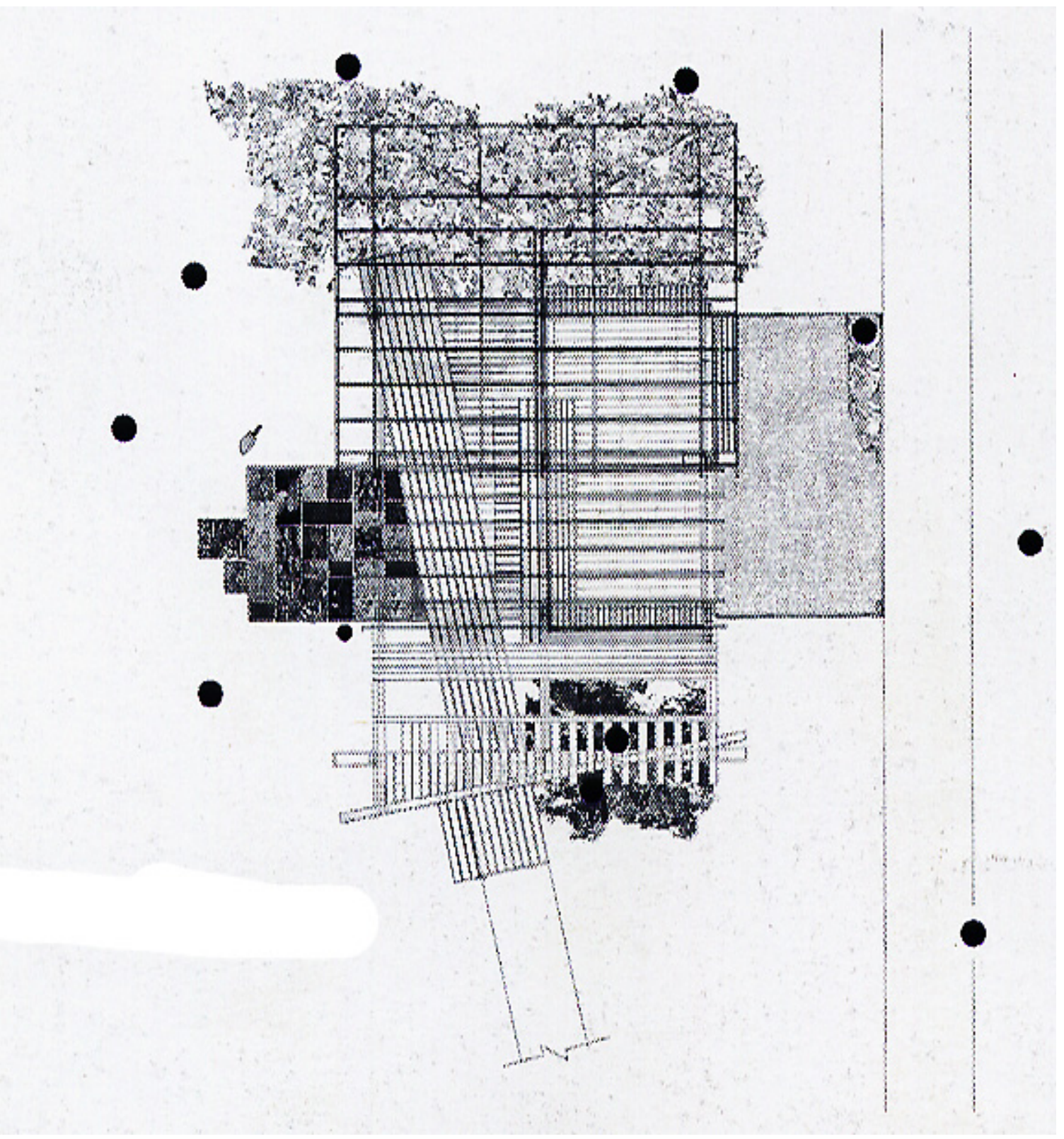

Figure 3.23: Plan of Pavillion at Roy Wilken's Park

\subsubsection{Summary}

Both outdoor classroom pavilions function as an organizing element to encourage children and families to engage with the natural and urban environments. The result of the project is that the small intervention of the individual pavilions directly affects a greater area and also tackles the issue of nature deficit in today's children while also supporting outdoor experiential education. 


\subsection{Design Response}

Architecture and its surrounding environments affect children in numerous ways, from health aspects to enhancing their motivation for life-long learning. Learning spaces shouldn't just be spaces for guardianship for children but should be viewed as spaces where endless possibilities await. Well designed spaces that adapt to diverse young learners can be used as tools to enhance learning and creativity.

An architect aspires to reorganise and reinterpret the existing learning environments in and around the city also to evaluate the history, theories, and philosophies of education to provide motivation and guidance towards developing the best possible means to educate children in our society.

Providing a context of background experience and research, this thesis explores educational environments that combine indoor and outdoor space. The result of this research is the design of three learning spaces sited in a natural environment to support education in the curricular area of natural science. These three environments are designed to supplement the provincial elementary curriculum through the use of three different natural conditions. The outdoor classrooms will provide children with an exposure to the natural outdoor environment while learning within the boundaries of a controlled environment.

\subsubsection{Design Goals and Objectives}

The design goals and objectives towards for the three outdoor classroom pavilions are:

- The material of the main structure will be durable, low maintenance and insectresistant.

- Each pavilion should respond to the immediate context of each of their sites.

- The projects shall involve minimal reshaping of the site, including minimal replanting of trees, as well as minimal scarring of the landscape during and after construction.

- The outdoor classrooms will be multi-use for flexible curriculum- based activities and allow for year-round usage. Universal access to pavilions will be provided by use of ramps. 


\subsubsection{Curricular Relationships}

One of the design responses is to create an environment that can supplement the Ontario curriculum for kindergarten, primary and junior-aged students. The following is the selected curriculum that was considered during the design process of the three outdoor classroom pavilions.

Kindergarten - Math, Science and Technology, and Physical Health

- Exploration and Experimentation

- Sensory/Seasonal (autumn, winter, spring)

- Number Sense and Numeration

- Measurement

- Spatial Sense and Geometry

- Shapes of Forest Valley

Grade 1 - Math, Science and Technology, and Physical Health

- Life Systems Needs and Characteristics of Living Things

- Matter and Energy

- Structures and Mechanisms Materials, Objects and Everyday Structures

- Earth and Space Systems Daily \& Seasonal Cycles

- Measurement

Grade 2 - Math, Science and Technology, and Physical Health

- Life Systems - Growth and Changes in Animals

- Matter and Energy - Properties of Liquids and Solids Liquids

- Earth and Space Systems - Air and Water in the Environment

- Measurement

- Geometry \& Spatial Sense Geometry

- Patterning \& Algebra

Grade 3 - Math, Science and Technology, and Physical Health

- Life Systems - Growth and Changes in Plants Growth

- Structures and Mechanisms - Strong and Stable Structures

- Earth and Space Systems - Soils in the Environment

- Measurements - Measurements 


\subsubsection{Outdoor Teacher Education}

Every teacher is unique and not every teacher will be qualified to teach and practice outdoor education. The existing Forest Valley Outdoor Education Center has its own team of Ontario-certified outdoor education teachers who have appropriate experience to execute the programs and to fully utilize the outdoor experiential classroom pavilions. Inexperienced teachers are encouraged to attend additional qualification courses through accredited teacher colleges. The Forest Valley Outdoor Education Center will hold teacher educational seminars prior to visits to classrooms in order to maximize the experience of staying at the Outdoor Education Center.

\subsubsection{Initial design sketches and draft diagrams}

As part of the initial design process, a series of sketches were created to understand the architectural spaces and to respond to selection of specific sites and to respond to the initial research.

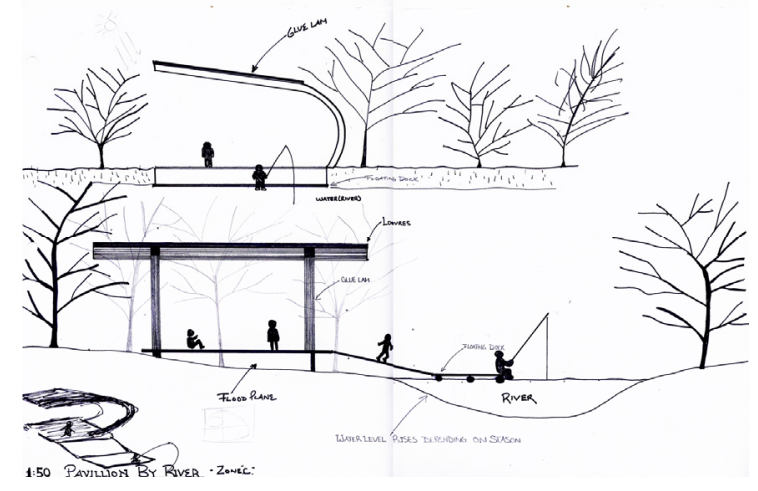

Figure 4.0: Pavillion by River

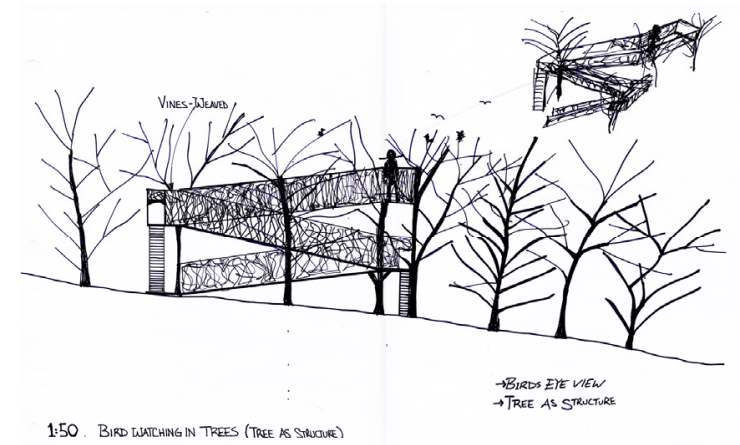

Figure 4.2: Bird Watching in Trees

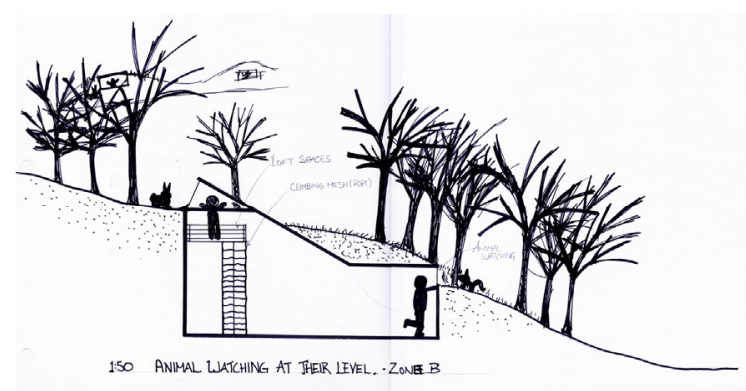

Figure 4.1: Animal Watching

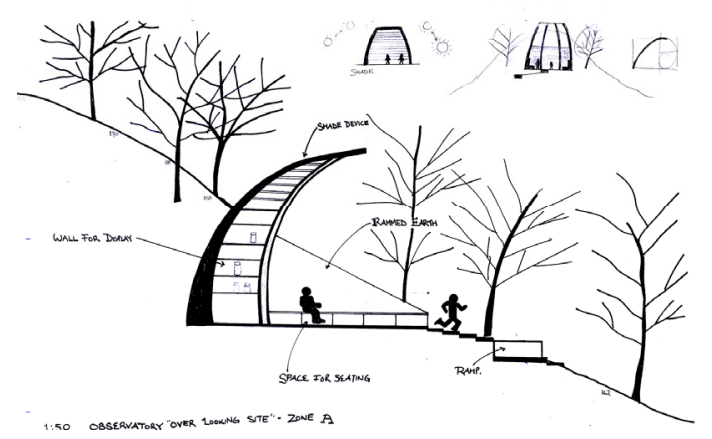

Figure 4.3: Observatory 


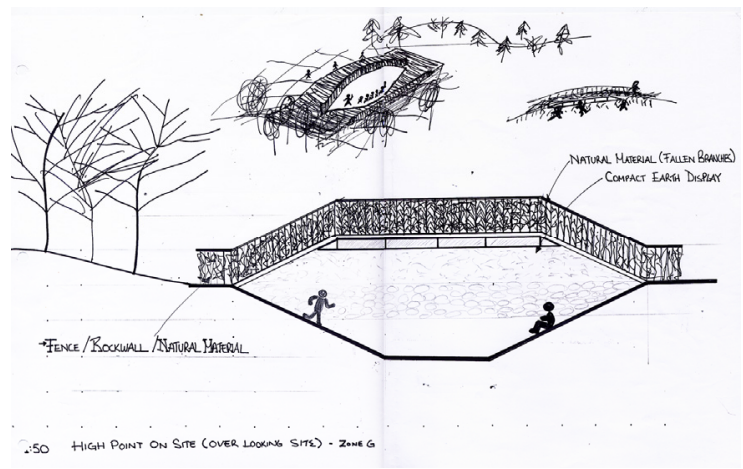

Figure 4.4: High Point on Site

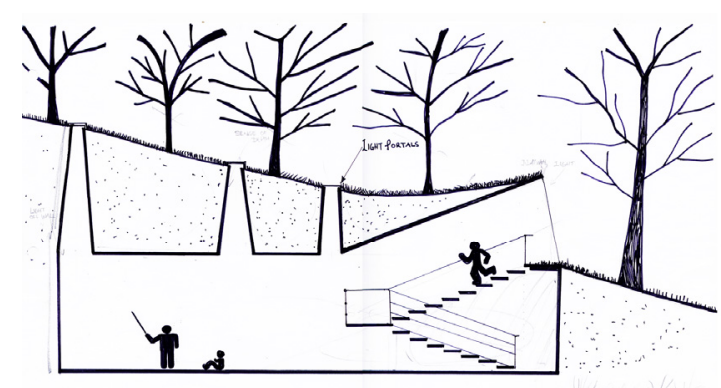

1:50 BURROW SPACE (IN GROUND) Z ZoN B

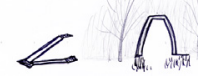

Figure 4.5: Burrow Space

\subsubsection{Site Selection}

The site selected is located north of Toronto in a natural valley that is located within an urban forest that covers an area of about $1.5 \mathrm{~km}$ by $1.5 \mathrm{~km}$ which is part of the Toronto Region Conservation Authority Land. The natural ravine system is part of the west branch from the Don River.

The valley's perimeter is surrounded by a busy urban environment that includes lowincome apartment buildings, several public schools, hospital and residences. The forest valley site provides a number of environmental conditions that can be used with outdoor classrooms and can be a support system to the existing outdoor education center.

The design intent is to enhance the existing outdoor education center with a trio of outdoor classrooms that encourage visitors to experience the different layers of the dynamic ecological systems and experience outdoor nature within the forest, meadow, wetland and river habitats. The existing path system aligns with the proposed ramps at each of the pavilions and leads visitors into a unique experience. 


\subsubsection{The Project's Impact on neighbourhood residents}

According to the City of Toronto Profiles this location is referred to as York Centre in ward 10 as specified in the map below. The area has a high immigration population, primarily first generation. Nearly half the population in this neighbourhood are couples with children, which almost exactly accords with that in the rest of Toronto. About $17 \%$ of the population in this area is single parents. Median individual income is under the Toronto average, so there are many low-income families.

After reviewing the profile, it is assumed that many of these children would not have the opportunity to attend a residential summer camp ${ }^{13}$ or to go to a family cottage where they could experience the outdoors throughout the summer.

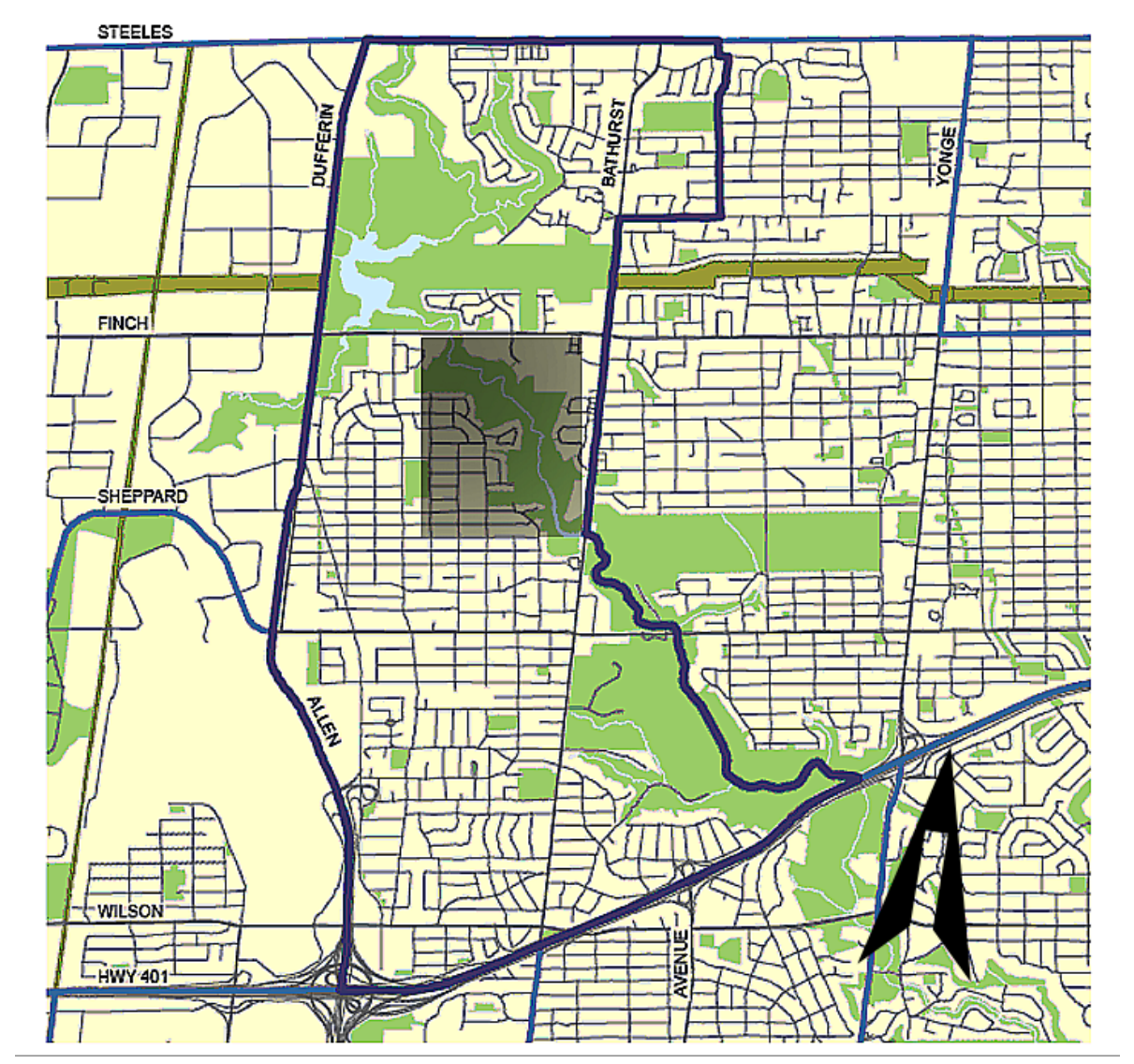

Figure 4.6: A map of Ward 10, shaded area represents the selected site of Forest Valley

\footnotetext{
${ }^{13}$ Residential Summer Camp: It is assumed here that residential summer camp has its advantages in providing the children with enough direct outdoor nature experience to make a difference in their lives.
} 


\subsubsection{Existing Condition}

The site selected is known as Forest Valley and is used by the Toronto District School Board for outdoor education purposes. Currently there are several buildings on the forest valley site; the spaces are as follows:

Parking and paths: Currently there is a 6-meter-wide path/road that allows large vehicles (and regular cars) such as school buses into the parking area on the south side of the main building. There is enough space there for as many as ten school buses to park, turn around and back out into the main street.

Main buildings: This building includes admin offices, storage, a gym, a kitchen, cafeteria space for 100 students and washrooms.

Classroom portables and learning spaces: There are several portable classrooms being used as experiential learning spaces, the students will usually spend time in these portables, in addition, there are several learning spaces spread out over the main site.

Outdoor garden: There is an existing outdoor garden area where students and campers are able to grow vegetables during the warmer months; this is located on the east side of the main structure.

Trails: There are numerous existing trails on the site; they are noted as footpaths, boardwalks and bridges in figure 4.1. They will be the paths used for hikes by students and campers throughout the year.

Proximity: As discussed in the case studies, the proximity to the urban wilderness forest is essential for the experience of outdoor experiential education and this location has just that. It provides enough nature for the full experience and is a fully grown forest with enough natural elements for it to be deemed urban wilderness. 


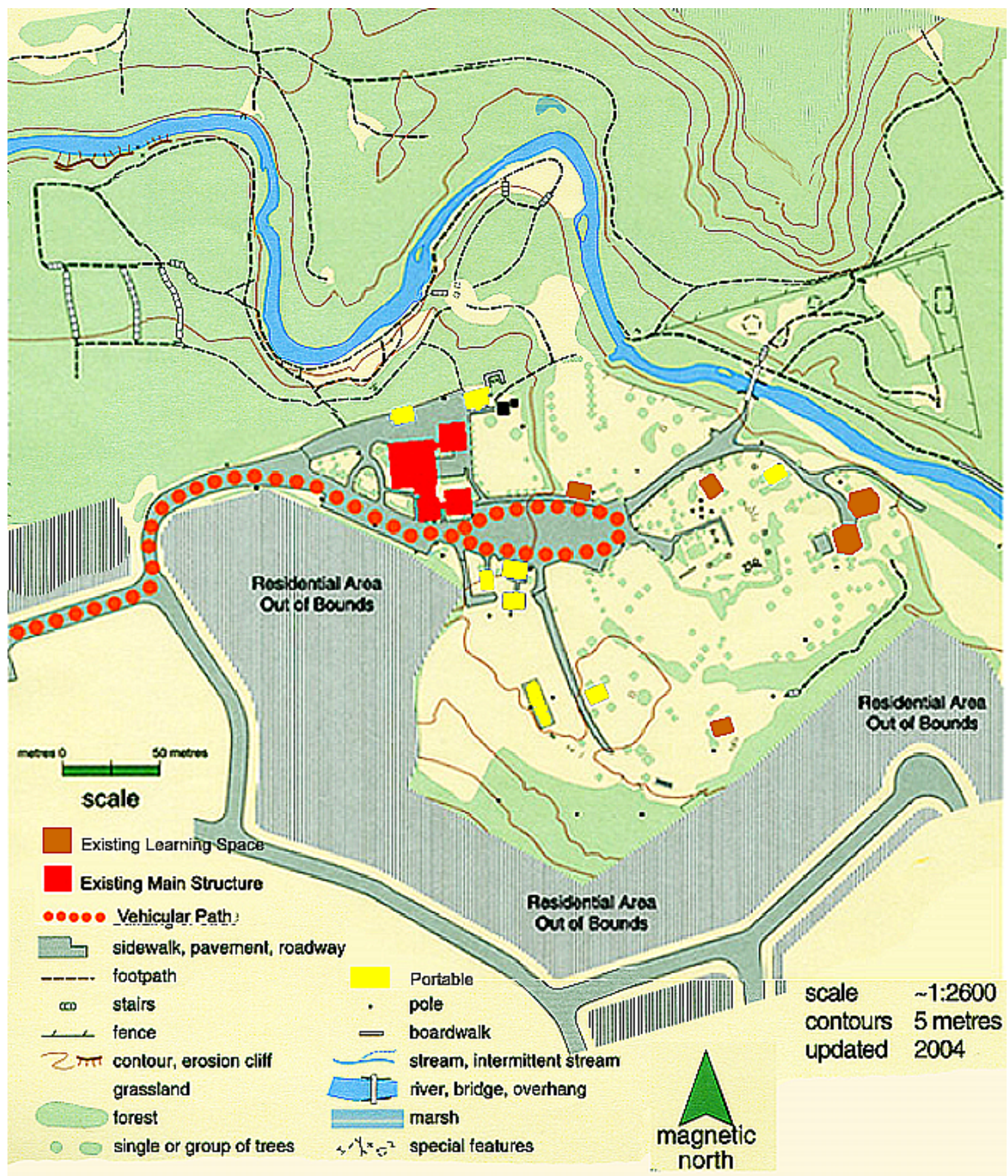

Figure 4.7: Site map of the current forest valley outdoor education center 


\subsubsection{Site Usage}

The site is currently used by several groups of people. The diagrams below illustrate the three groups of people that use the site throughout the seasons and throughout the week. In the diagrams, the inner ring with the colours yellow, brown, grey and blue shows the amount of sunlight during specified hours, days and months.

As shown in Figure 4.8 and 4.9, the community makes good use of Forest Valley during the morning and evenings from Monday to Friday and also extensively on weekends. During the morning and evenings, a high percentage of land used by the community is along the trails because the main buildings are closed to the public when school groups and classes aren't using it. For most of the months of the year, Forest Valley provides up to seven hours of block time on a daily basis from Monday to Friday so that students can engage in outdoor experiential education.
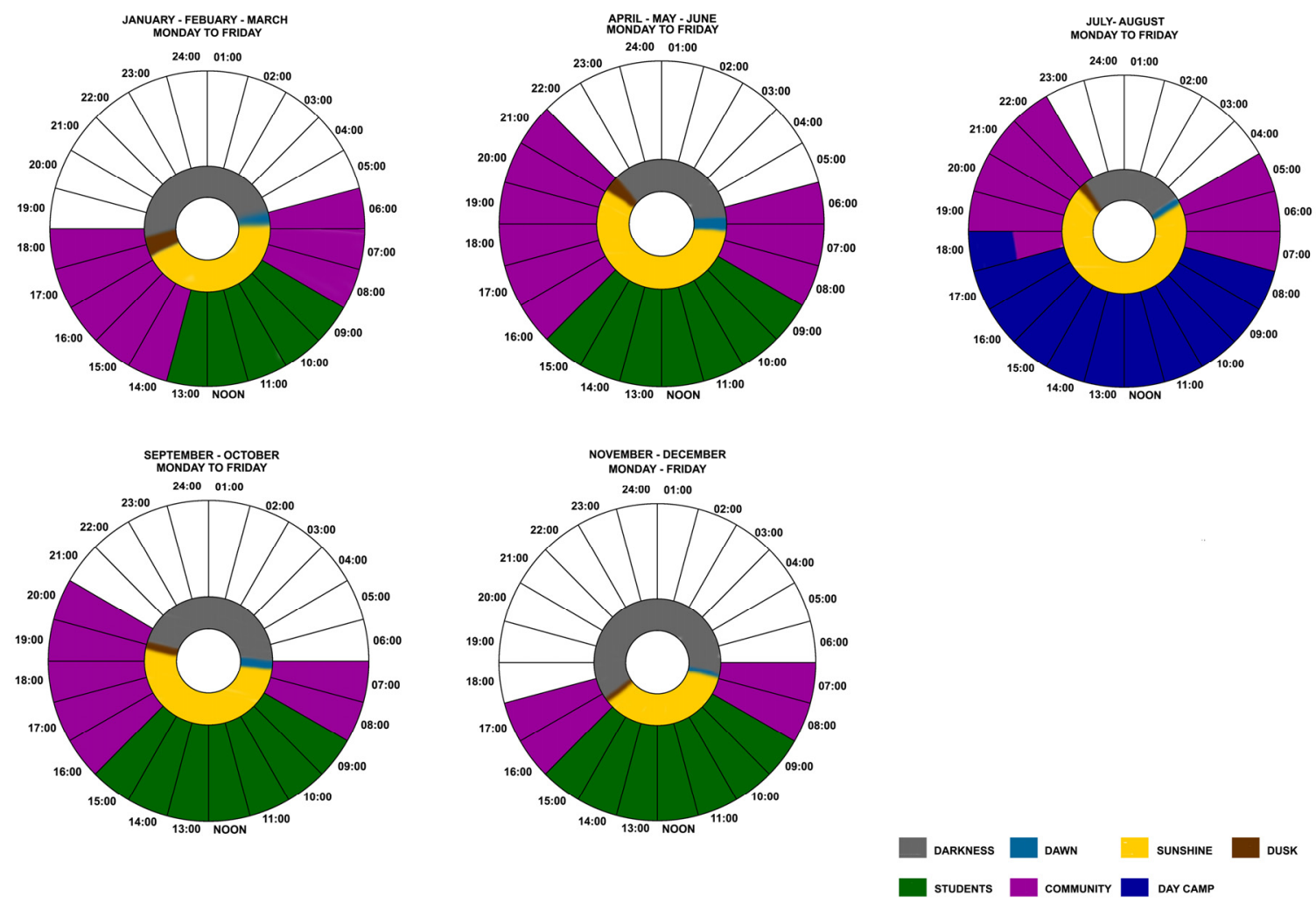

Figure 4.8: Schedule of usage for Monday to Friday throughout the seasons 

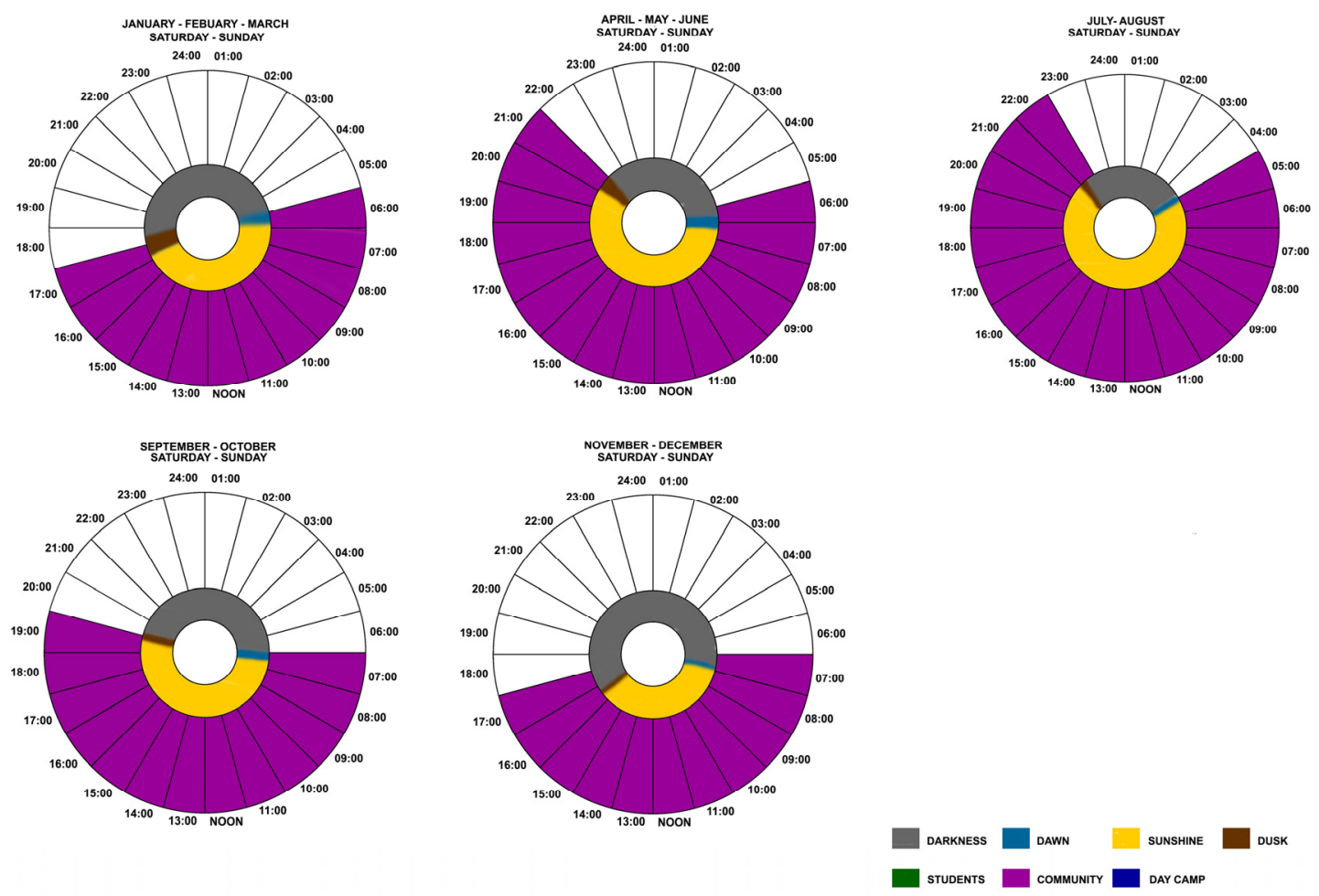

Figure 4.9: Schedule of usage for Saturday and Sunday throughout the seasons

As for July and August, Forest Valley becomes a children's day camp on weekdays from 9:00am to 6:00pm. During this time there are fewer community people walking through this site that is private property during school hours, although a few might still walk though it innocently from time to time.

\subsubsection{Site Scheduling}

Length of stay: The Forest Valley Outdoor Education Center can accommodate up to five classes a day. It has been proven that in order to fully gain the outdoor experiential experience, a single day trip is not sufficient. Therefore students at this facility use it for 3-5 days each week and for 2-3 weeks at a time, the length of time it usually takes to complete a primary grade science unit.

Daily routine: Classes will arrive by bus and leave their bags at the main building. There will be an orientation before the first activity. The day will be divided into quarters and the students will walk/hike to another activity when one quarter is up. During lunch time, the person in charge will decide where students can eat lunches. They are permitted to 
have inside the main building's cafeteria, in the open field south of the main building, at the proposed pavilions, or in the existing portables. At the end of the day, the classes will re-group at the main building to debrief and also to get set to return to their respective schools.

Learning spaces on site: There are several locations on the site that can be used for the outdoor experiential gathering spaces. As seen in figure 4.7 the site map, there are portables and other existing learning spaces that will continue to be used even after the three proposed classroom pavilions are completed. The proposed design is not meant to replace the existing facilities, but rather to supplement them and to work with existing conditions of the site.

\subsubsection{The outdoor experiential support spaces:}

Each of the three proposed outdoor experiential support spaces are located at different locations on the forest valley site, which itself contains three different site conditions.

Space: Each pavilion is designed to accommodate a class size of 20 students on each visit. Students experience all three outdoor classrooms during rotations on their weeklong visit. Each classroom is designed to provide an Individual, small group and class experience. The seating is designed for primary school students, although adults and older students will fit.

Size - Each pavilion consists of a footprint of about 6 meters by 6 meters. The Tree house Pavilion and the $\mathrm{H}_{2} \mathrm{O}$ Pavilion are single level spaces, and the Experiential Pit has an outdoor classroom deck to encourage the students to be outdoors.

Safety - Although it seems like a long hike to each pavilion, there is a direct link to the main buildings and the bus loading area. The average distance from each pavilion to the main building is 100 meters; it would take 5-10 minutes for a primary school child and adult to walk back to the main building if needed. Each pavilion would have emergency first aid kits and along the trails would be life-savers and life-saving poles. 


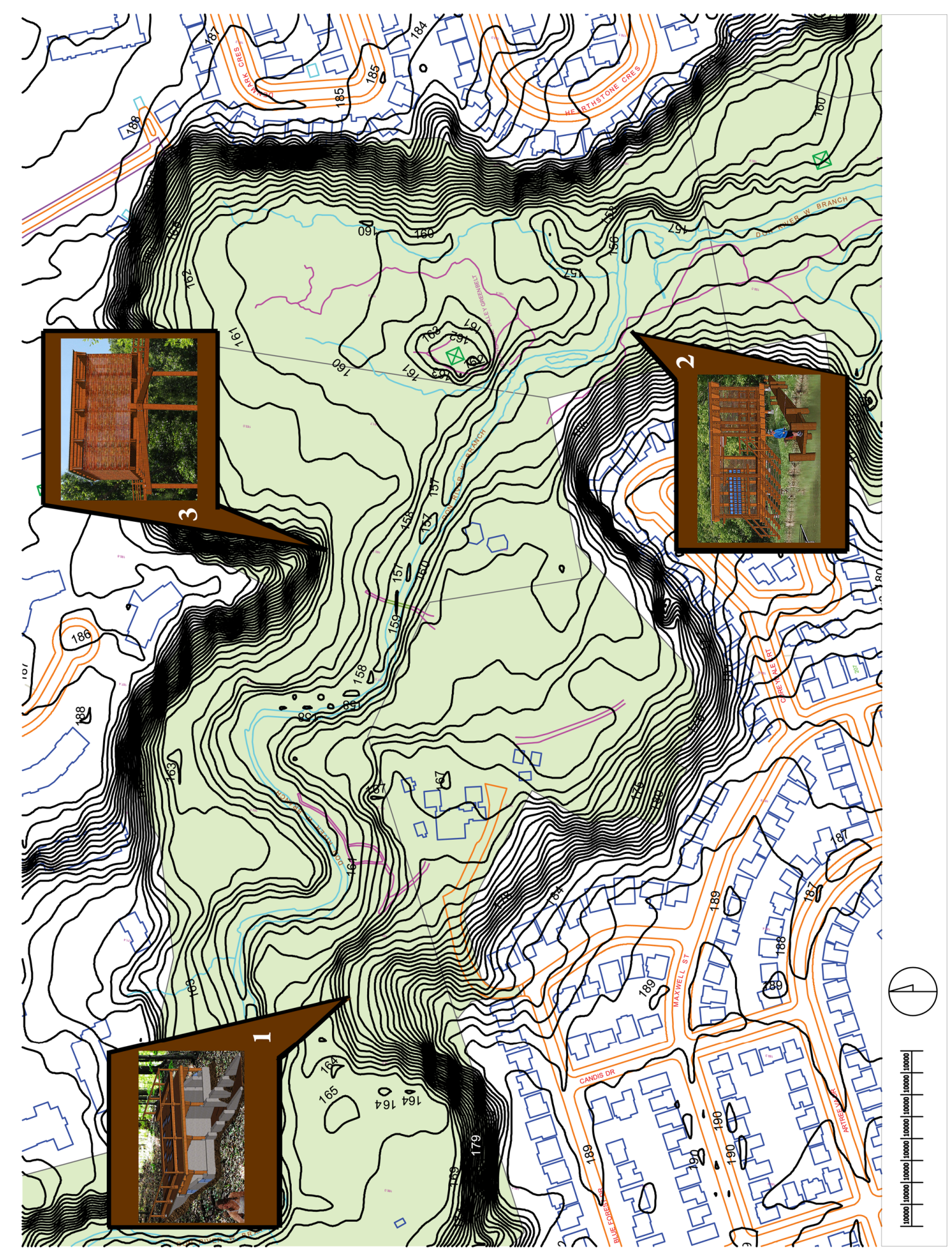

Figure 4.1.0: Site Map showing the location of the pavilions - (1) Experiential Pit, (2) $\mathrm{H}_{2} \mathrm{O}$ Pavillion, (3) Tree Pavillion 


\subsubsection{Experiential Pit ${ }^{14}$}

Each of the proposed Outdoor Experiential Classroom Pavilions provides a different experience. The Experiential Pit (1) (Figure 4.1.0, Figure 4.1.1) provides a unique experience by responding to the woodland; it is placed into a slope through a level change and into the earth. The Experiential Pit is located 80 meters north-east of the main building. To get there from the main building, the school group will hike through the west trail as can be seen as the purple trail in Figure 4.1.0 just east of (1). As mentioned in the previous section, if the need arises for child to get back to the main building, it would take less than 5 minutes. The experiential pit provides children with the sensation of being partially below the earth's surface.

\footnotetext{
${ }^{14}$ Experiential pit and the learning pit. In this thesis the Experiential Pit is the actual structure at large, and the Learning Pit is the small in-ground learning pit space where students are divided into small groups to experience their findings.
} 


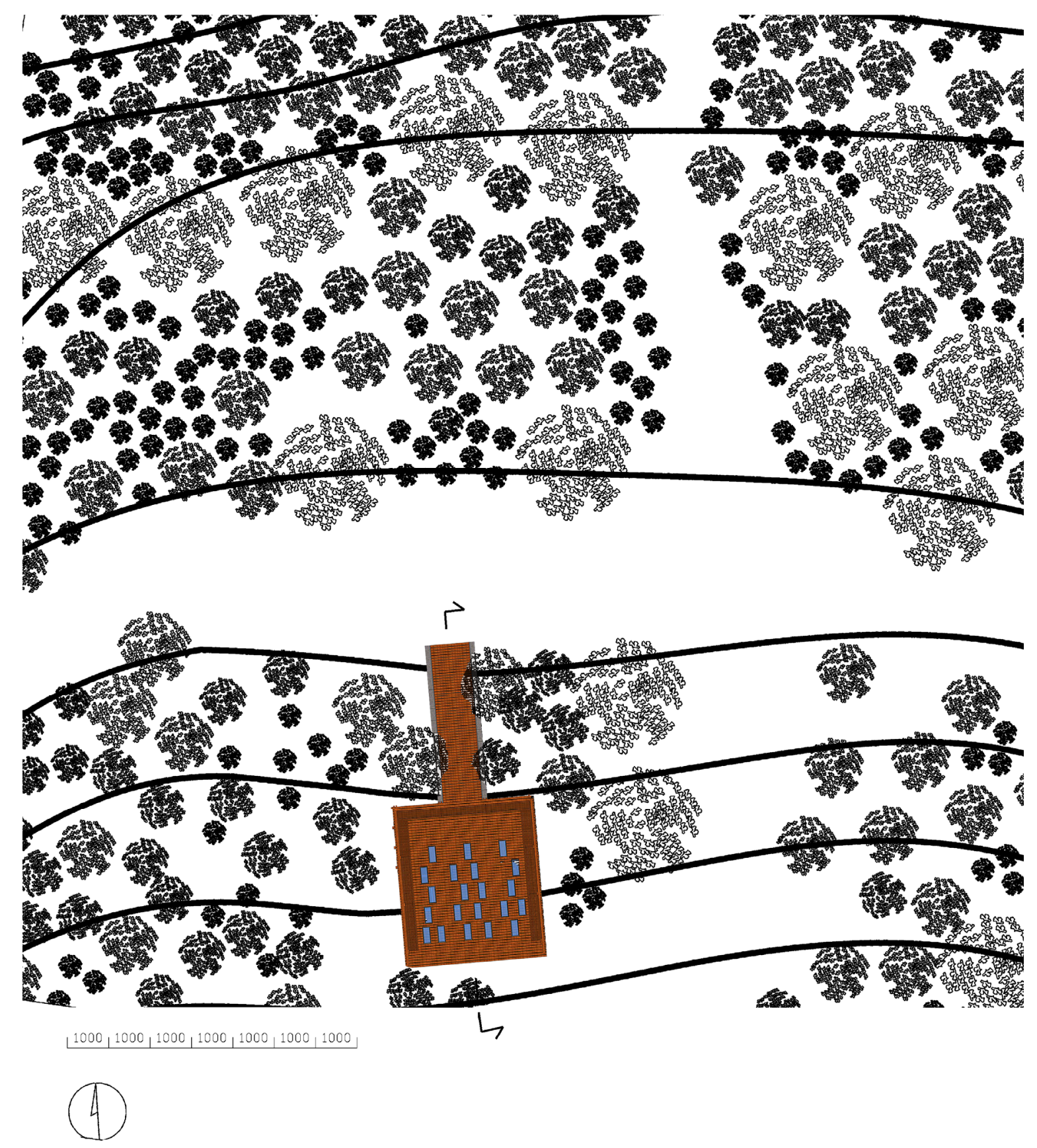

Figure 4.1.1: Immediate Site Map for (1) Experiential Pit 


\subsubsection{Skylight Condition - Experiential Pit}

Along with the placement of the building, two skylight conditions were incorporated into the design. In Figure 4.1.2 the skylights are configured east to west and in Figure 4.2.3 north to south.
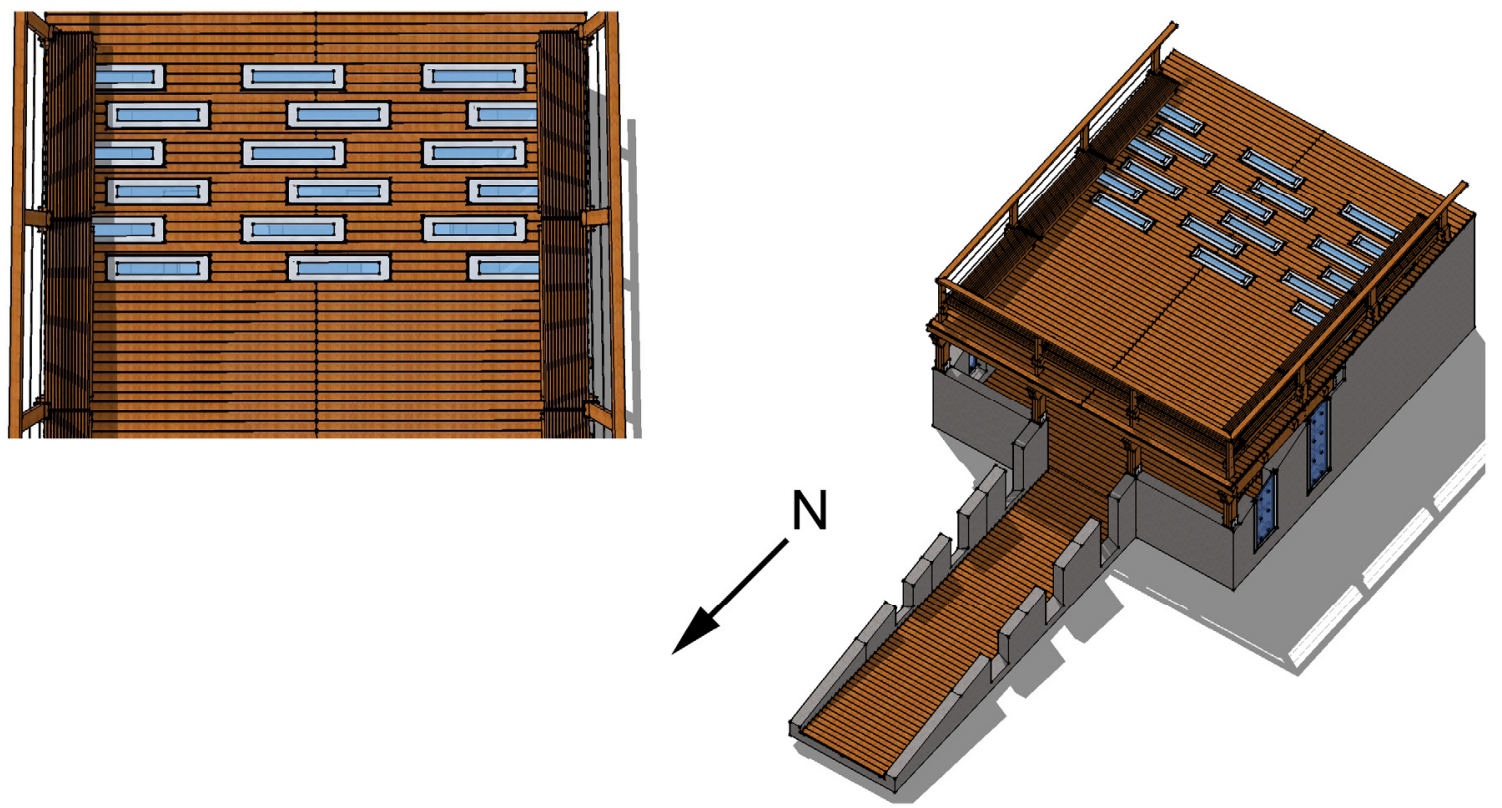

Figure 4.1.2: Horizontal Skylight Condition
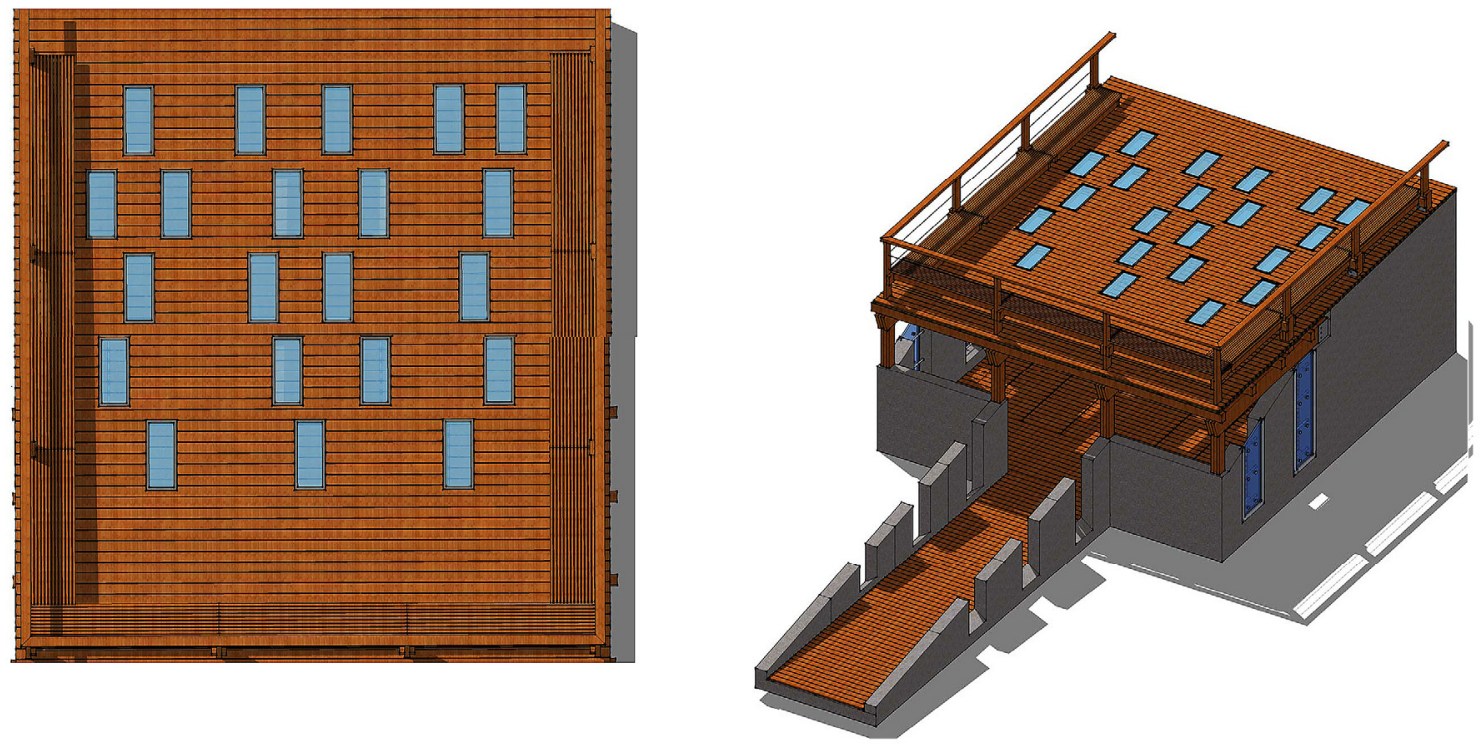

Figure 4.1.3: Vertical Skylight Condition 

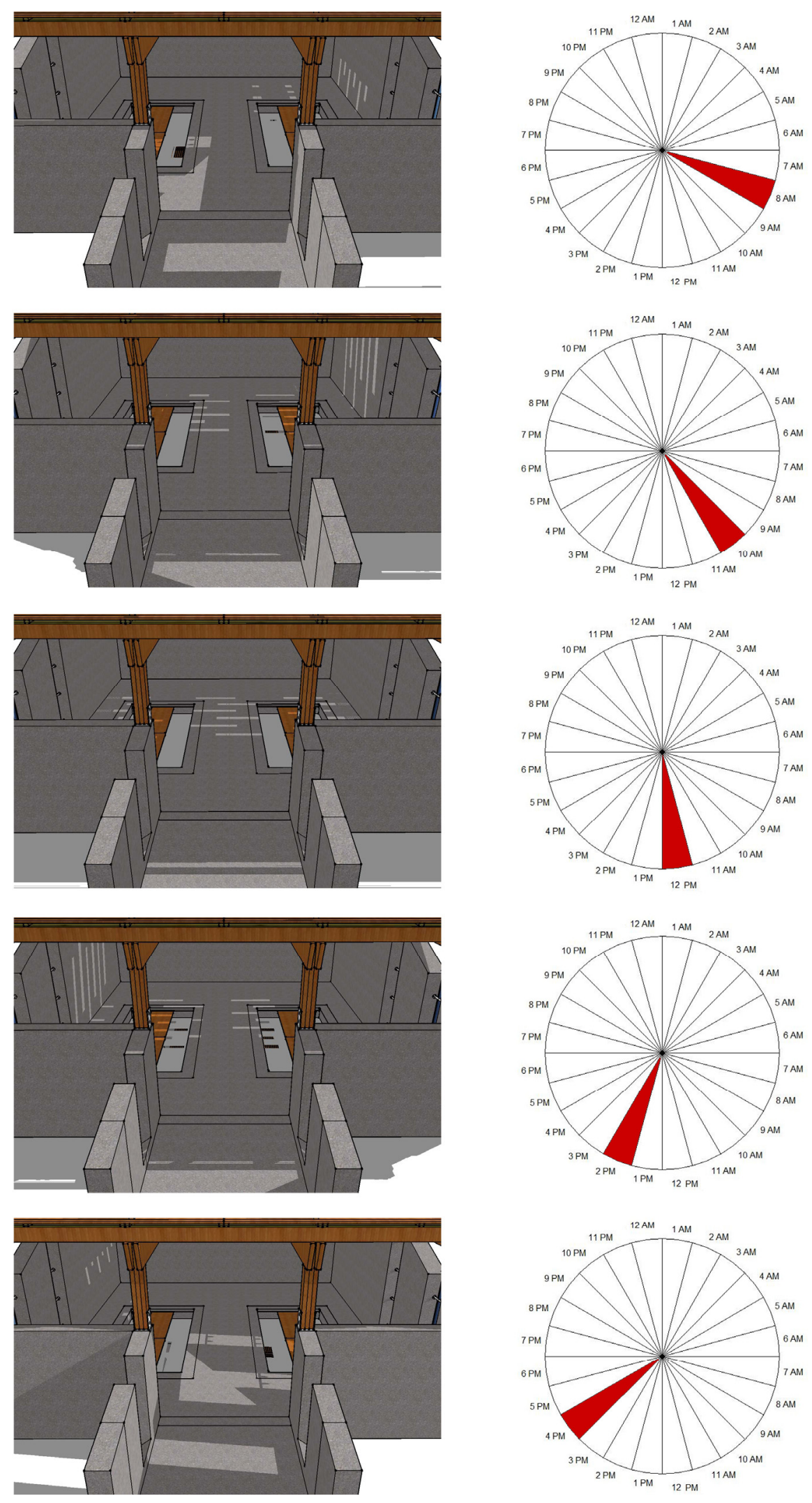

Figure 4.1.4: Horizontal Skylight Condition at the selected hours in June 

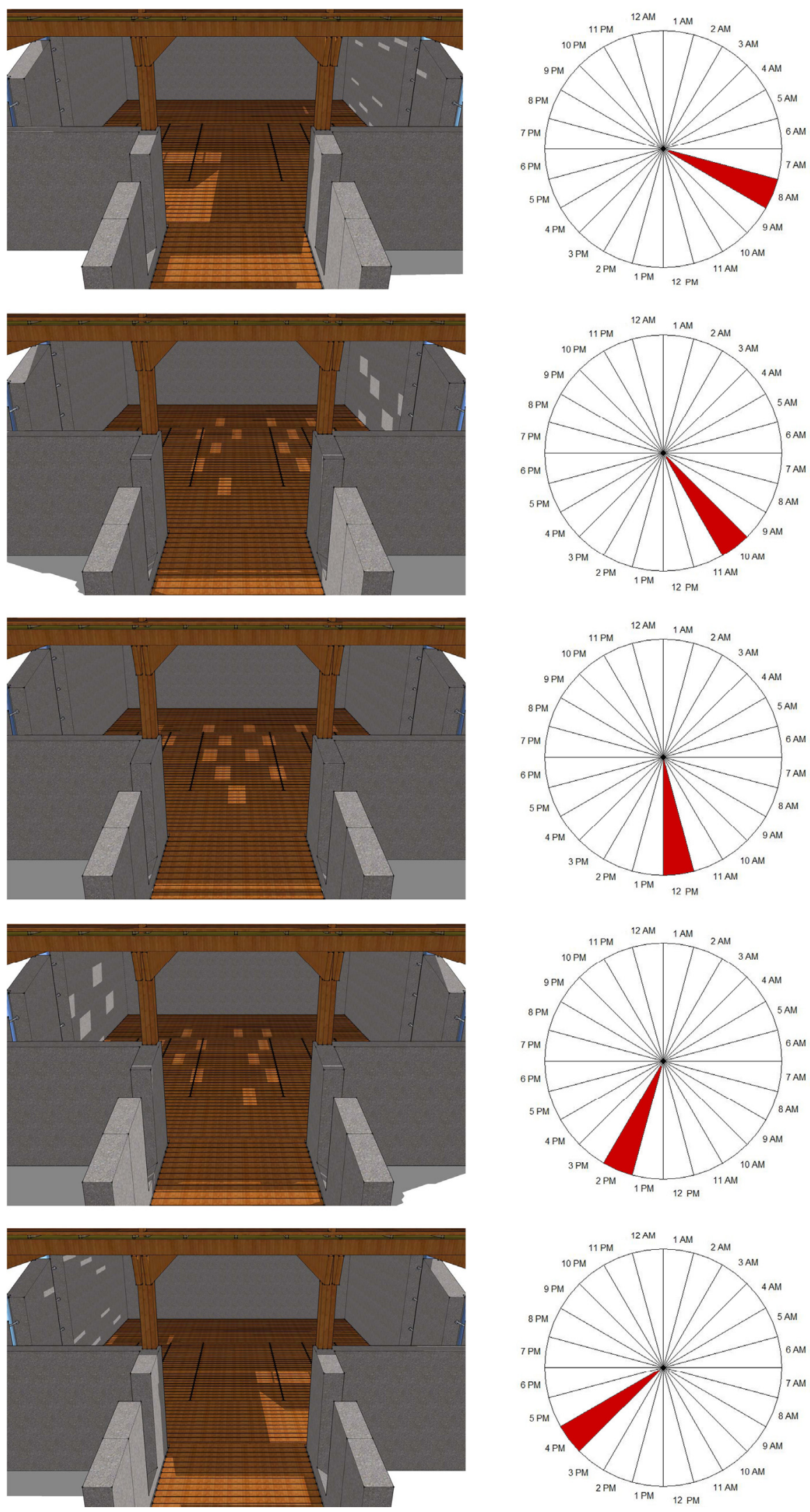

Figure 4.1.5: Vertical Skylight Condition at the selected hours in June 
Both horizontal and vertical skylight conditions provide ample sunlight into the experiential pit. However, since the design of the pit learning space is north to south the vertical skylight condition was selected. The vertical arrangement of the skylights provides a more aesthetically balanced roof deck condition, allowing students to use the space for gatherings and other activities. As demonstrated in Figure 4.1.6, the roof deck is a flex space with benches on the perimeter that allows students to sit and listen during orientation sessions prior to a hike, a demonstration, or an outdoor lesson. In addition to the skylights, the north, east and west side of the pavilion have openings for sunlight and to the outdoors to provide fresh air and ventilation.

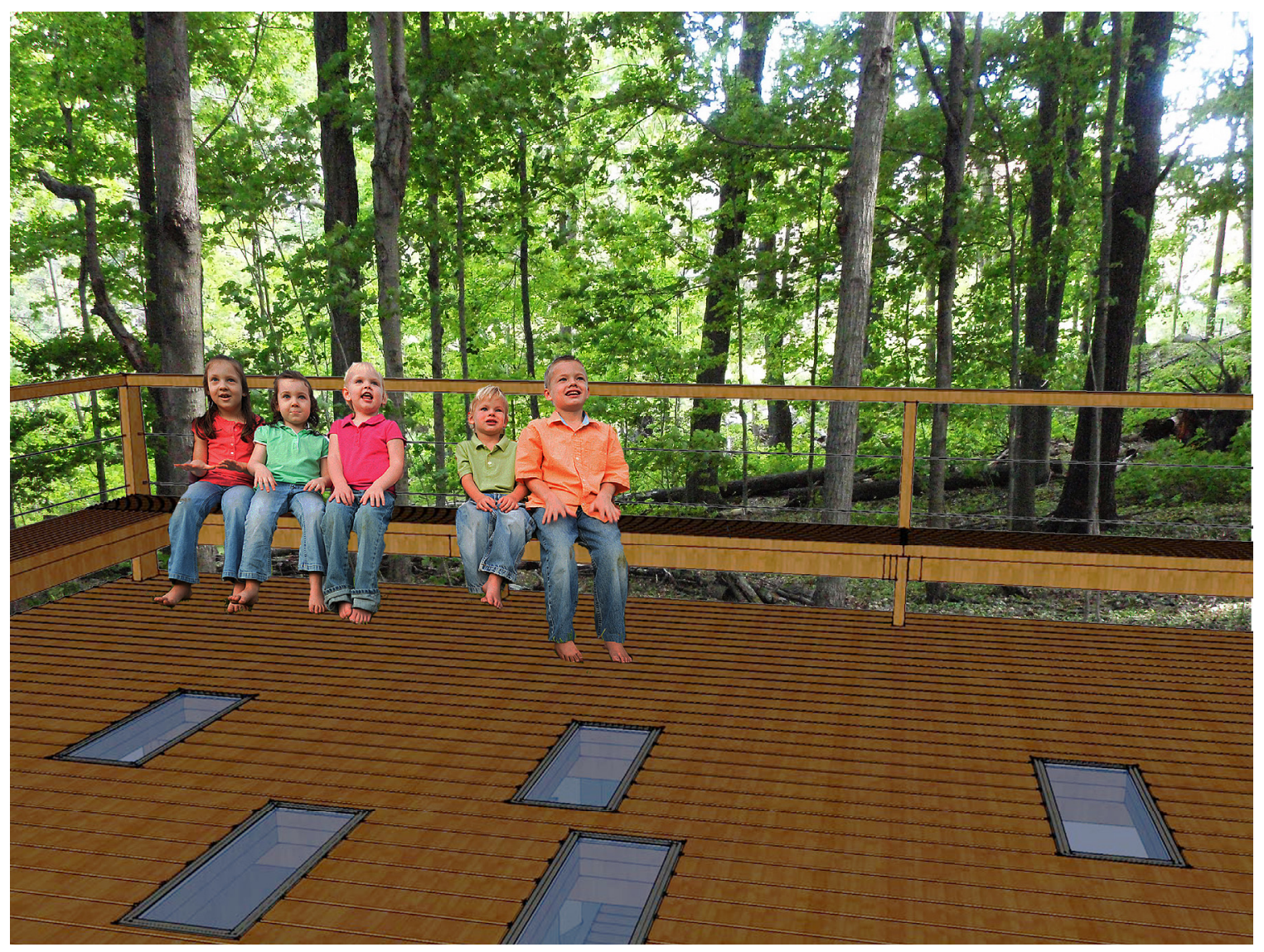

Figure 4.1.6: Experiential Pit roof deck learning space 


\subsubsection{Entry Ramp - Experiential Pit}

Upon arrival at the pavilion, students can walk down into the Experiential Pit on the ramp. As the students are passing through the ramp (Figure 4.1.7), they will notice gaps where they would expect a window. These gaps allow earth to spill past the concrete and onto the cedar deck and give the ramp a natural weathered look. The ramp is also a learning tool since students can sit behind its openings to experience the forest from an animal's perspective.

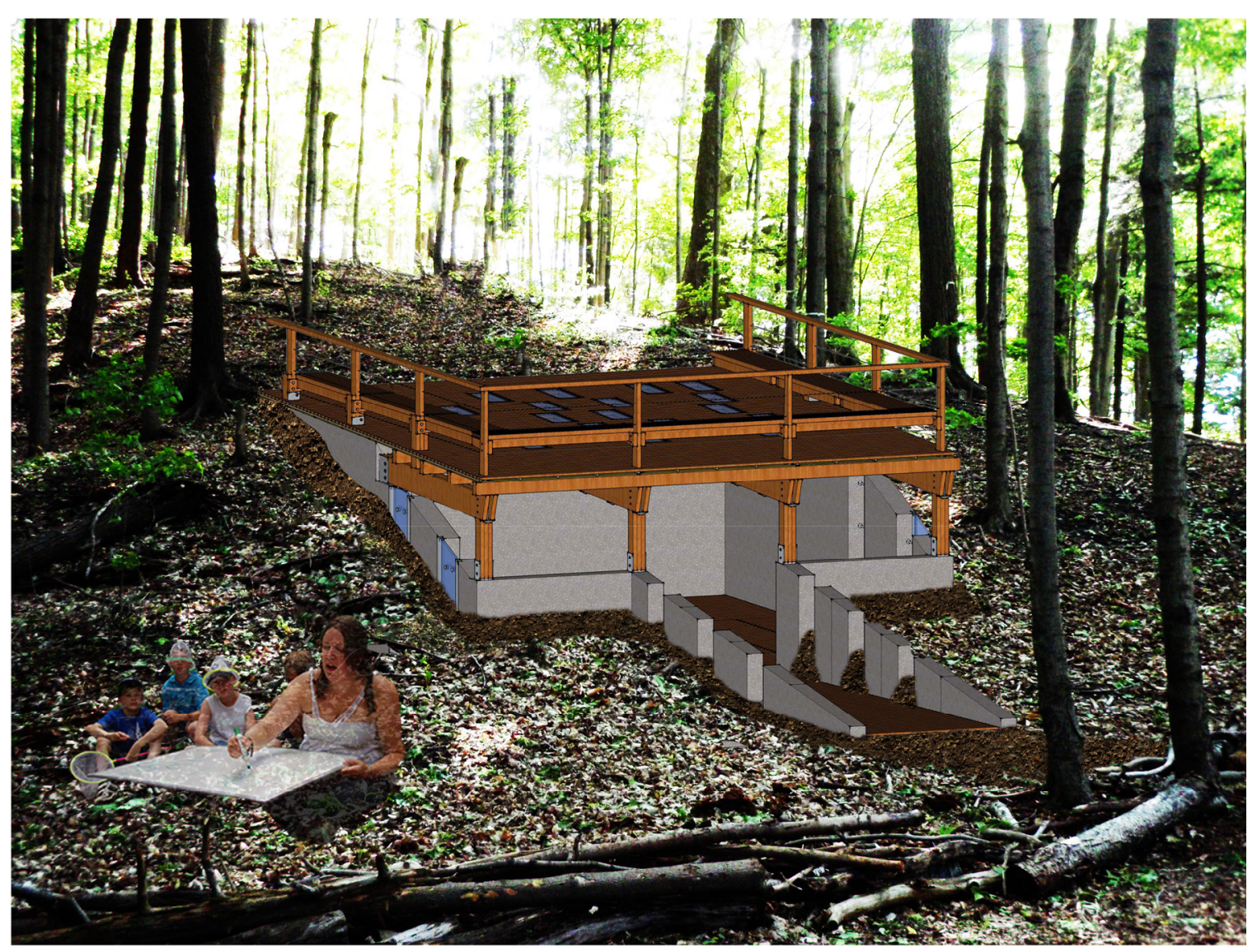

Figure 4.1.7: View looking south at the Experiential Pit 


\subsubsection{Floor Plans and Sections - Experiential Pit}

All three of the proposed outdoor classroom pavilions have a footprint of approximately $6000 \mathrm{~mm} \times 6000 \mathrm{~mm}$ and also have experiential learning tools built within them.

The experiential pit (which includes the learning pit space) is designed to support a class of 20-25 students and teachers. The plan allows for flexibility of activities as well as individual and group experiences. (For more detail drawings please see Appendix A)
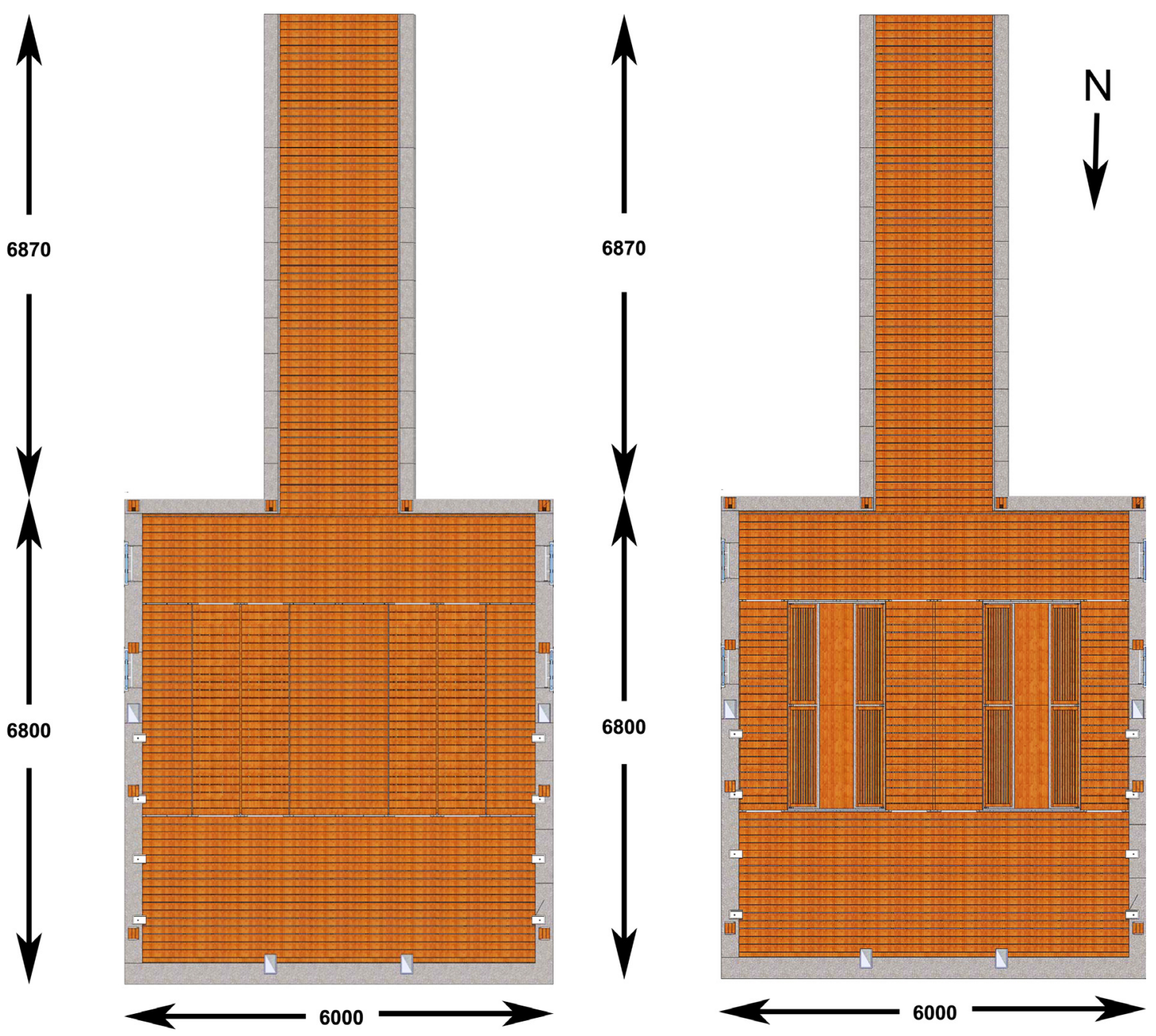

Figure 4.1.8: Floor Plan with closed pit condition, and Figure 4.1.9; Floor Plan with open pit condition. (For detailed drawings see appendix A) 


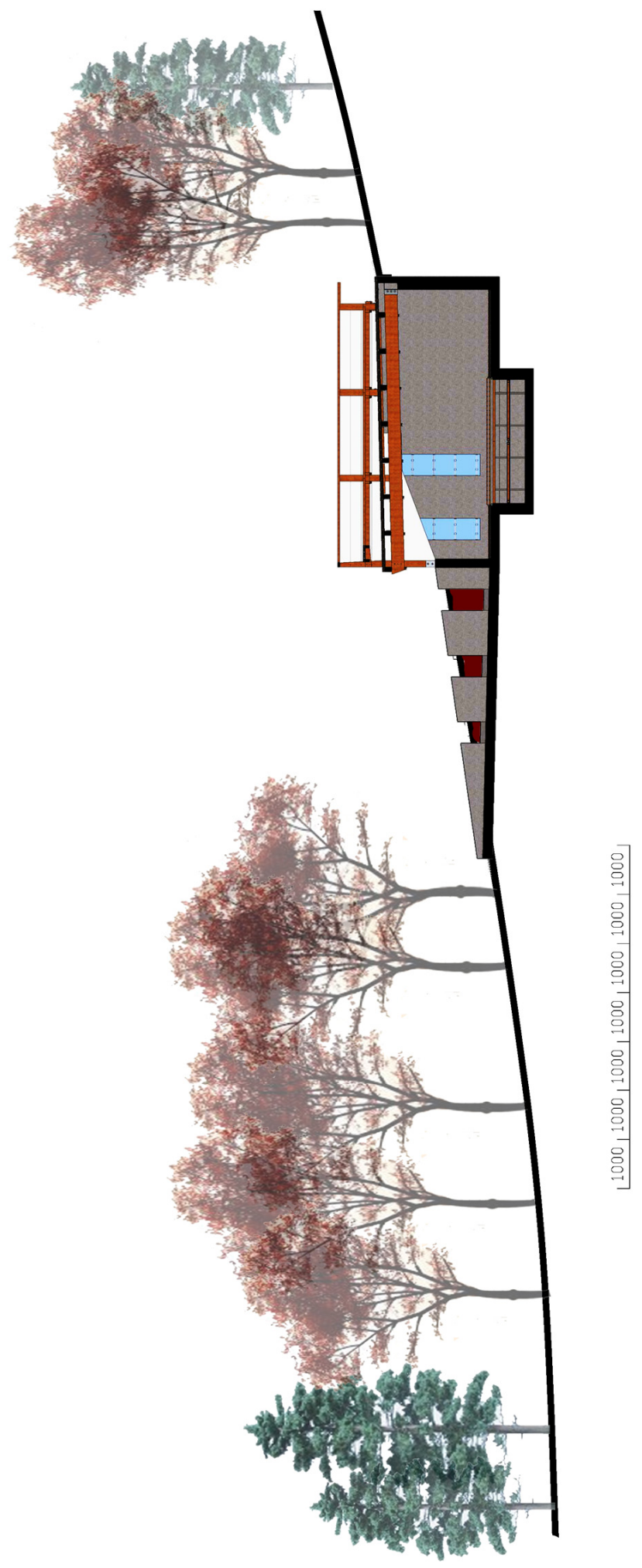

Figure 4.2.0: Immediate site and building section looking east showing the pit space 


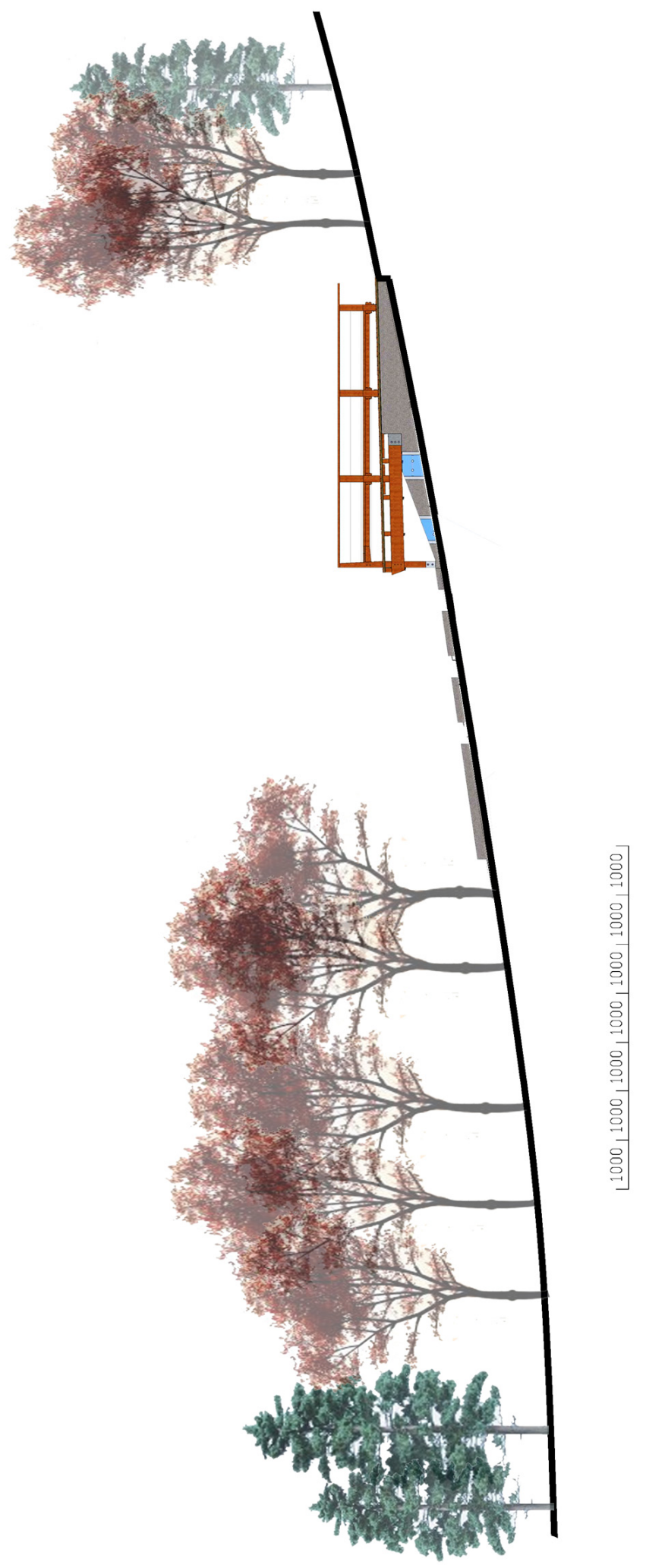

Figure 4.2.1: Immediate site and building section looking east 


\subsubsection{The Learning Pit (Learning tool) - Experiential Pit}

The learning space (Figure 4.2.0) is a pit within the Experiential Pit that allows students to gather their findings and engage in hands-on activities providing a unique experience that the other pavilions cannot. The scale and size of each learning pit is designed to fit ten to twelve primary students at one time. The learning pit is equipped with cedar benches scaled to fit primary school-aged students and can be folded up for cleaning purposes. In between the benches there is a table top which is resting on two steel posts; this cedar platform is removable if needed. When the Pit learning spaces are not in use, they can be slid into a closed position by an adult. The learning pit's movable decks are supported by an aluminum brace on urethane wheels that run on a stainless steel track. (For detail drawings see appendix B and C)

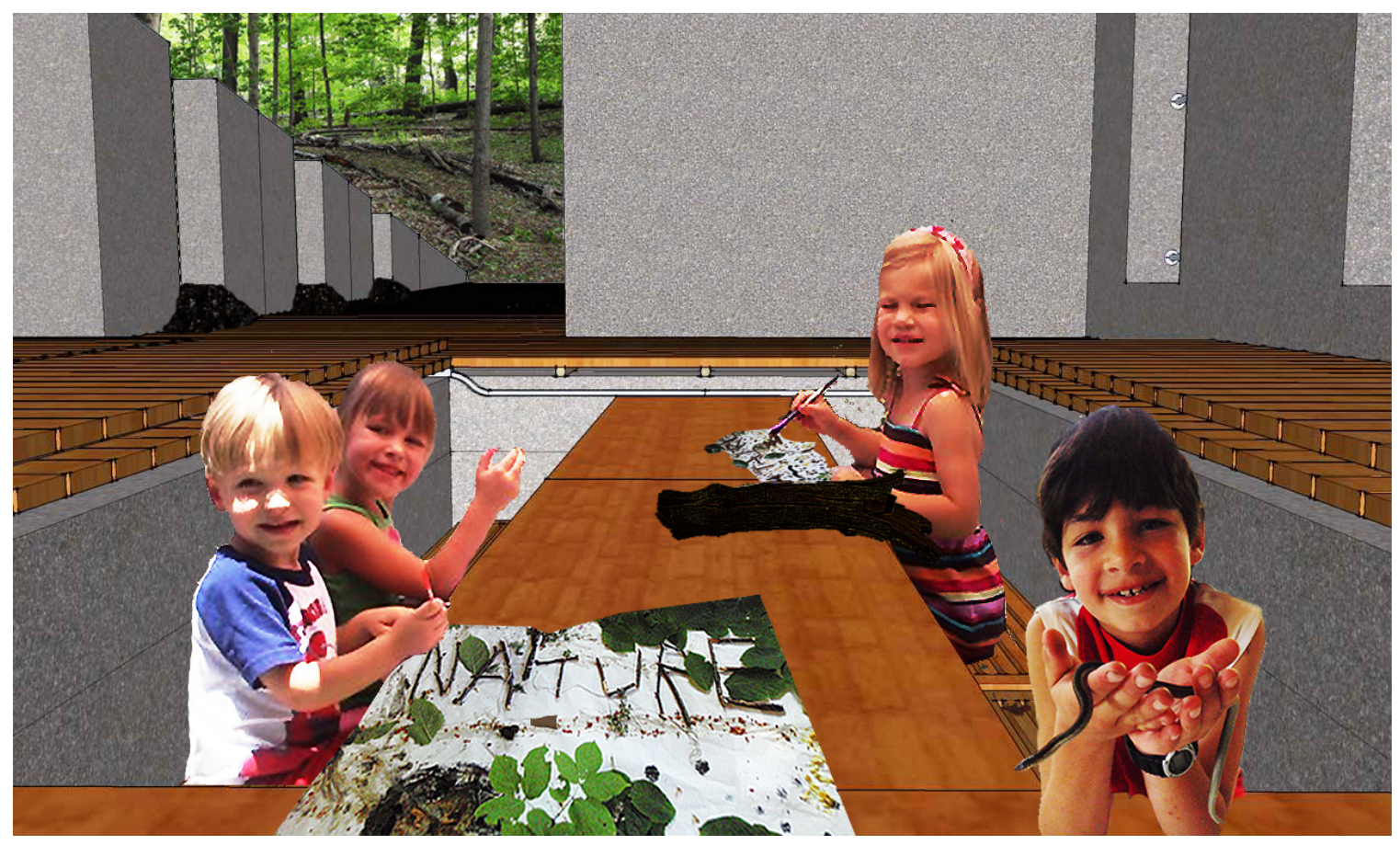

Figure 4.2.2: Students in the Pit learning Space

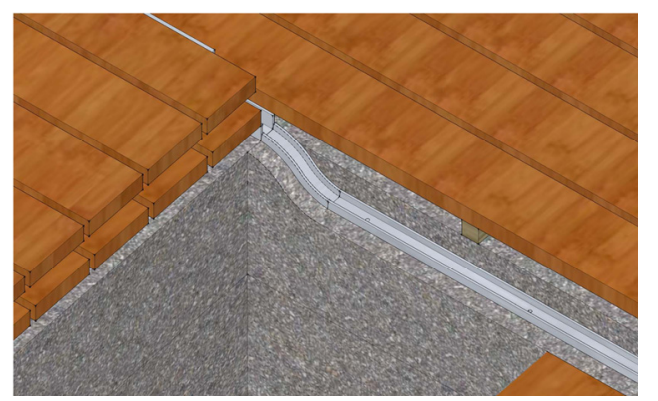

Figure 4.2.3: Stainless Steel Rail and Track

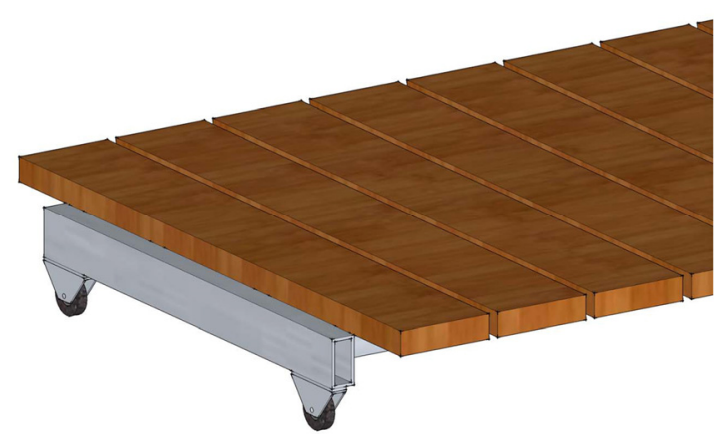

Figure 4.2.4 Track with urethane wheels 


\subsubsection{Earth Window (Learning tool) - Experiential Pit}

Another unique experience in the Experiential Pit Pavilion is provided by the earth windows. The earth windows are a response to the children's curiosity, providing a live display of what is going on under the earth. Students will be fascinated with the windows as they are able to see insect tunnels, layers of earth, moisture and water run-off and much more. To support the pressure of the earth on the glass, the glazing (Lexan) is braced with stainless steel bars which also can act as support for smaller children when they are outside looking for animals.

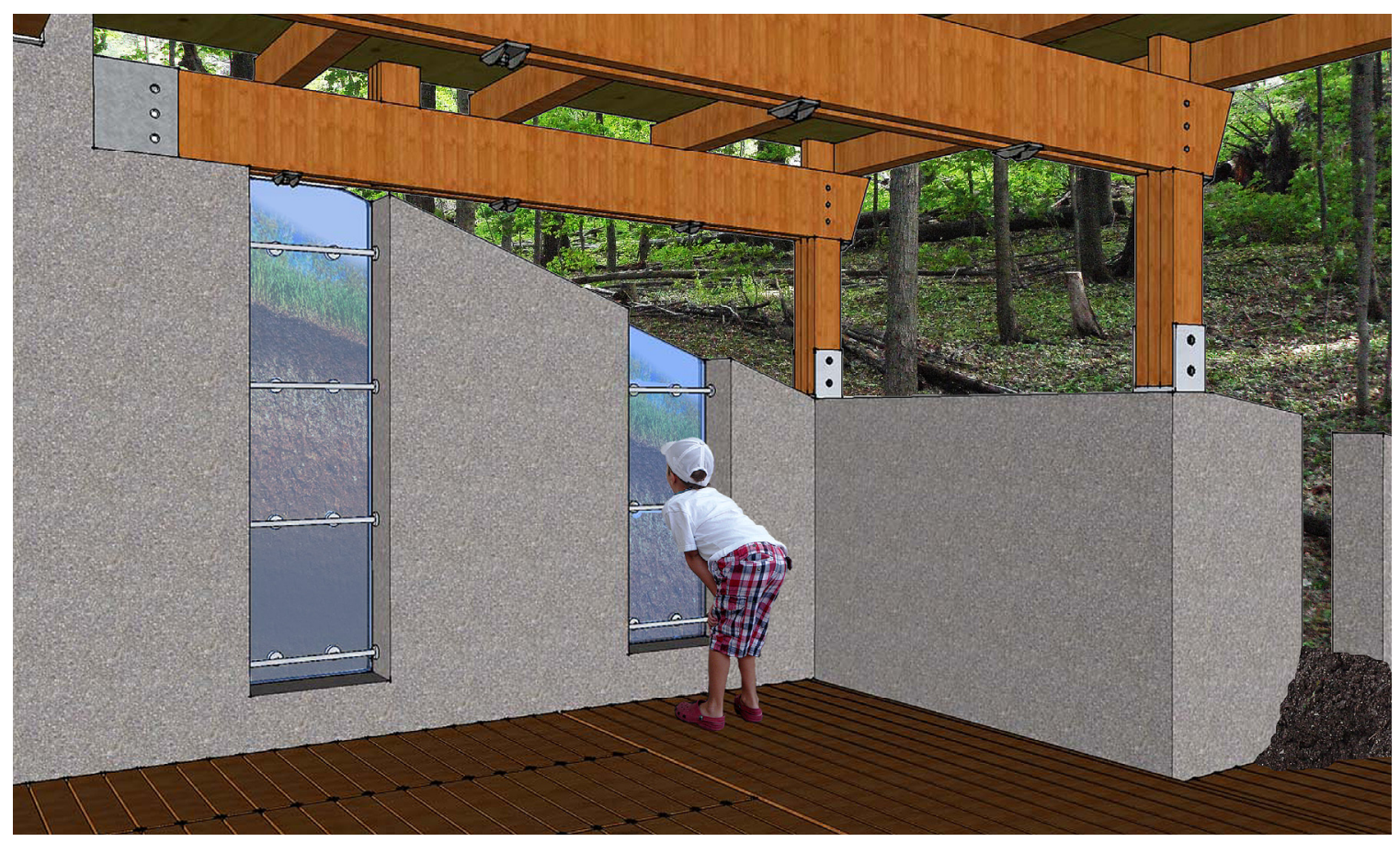

Figure 4.2.5: A curious child looking at the earth window inside the Experiential Pit 


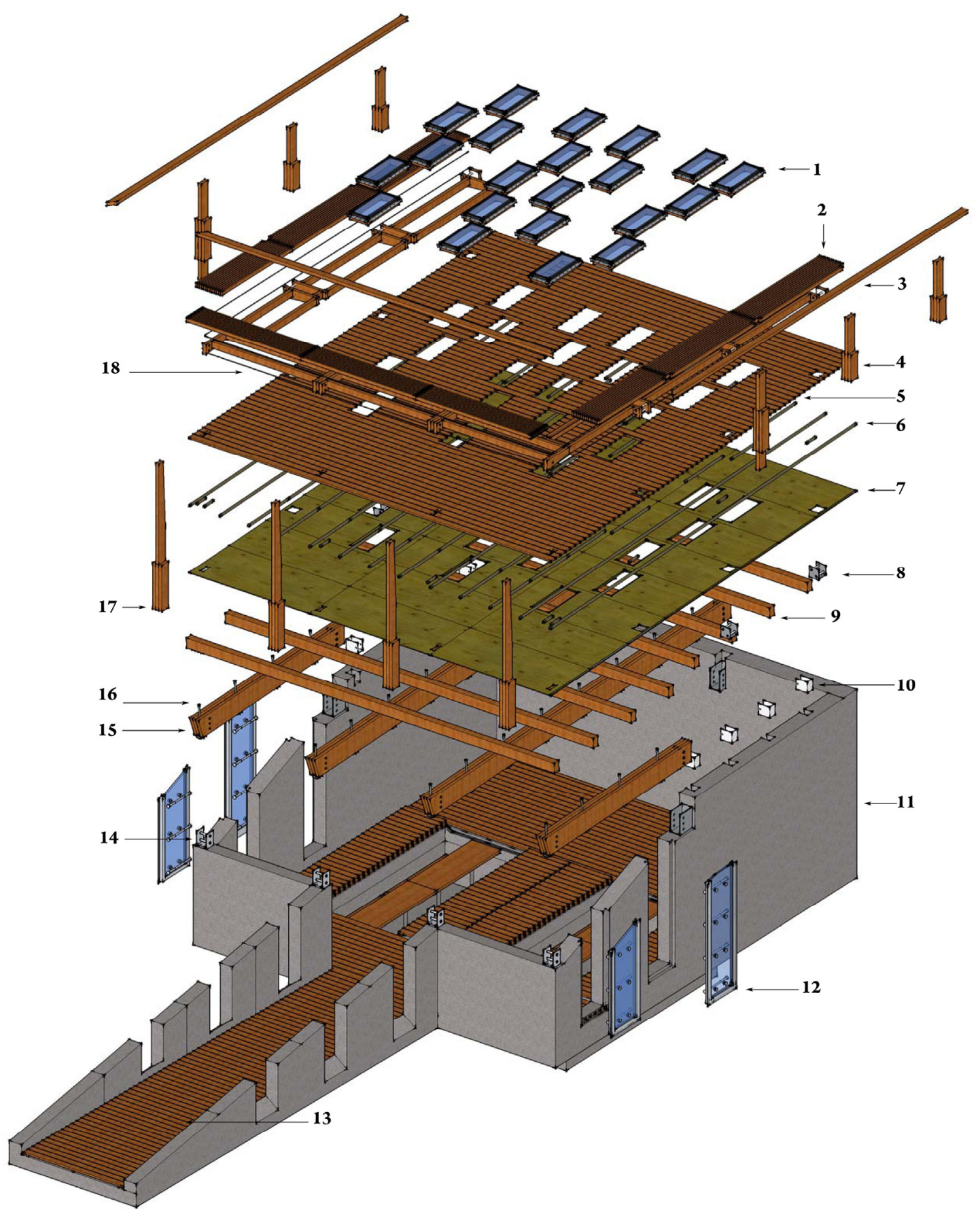

1 - Skylight (308mm x 708mm)

2 - Cedar Bench

3 - Handrail (50mm x 100mm)

4 - Handrail / bench build up post $(50 \mathrm{~mm} \times 150 \mathrm{~mm})$

5 - Cedar Deck (100mm x 25mm)

6 - Strapping $(25 \mathrm{~mm} \times 25 \mathrm{~mm})$

7 - 1/2" Ply-wood shealthing

8 - Stainless steel post support with through bolts

9 - Cedar Beams (100mm x 150mm)

10 - Stainless steel beam hanger
11 - Casted concrete foundation wall $(250 \mathrm{~mm}-300 \mathrm{~mm})$

12 - Steel frame earth window with steel support brace and 1 " lexan glass 13 - Cedar Deck $(100 \mathrm{~mm} \times 25 \mathrm{~mm})$

14 - Stainless steel post support with through bolt

15 - Cedar joist $(50 \mathrm{~mm} \times 300 \mathrm{~mm})$

16 - Through bolt hanger

17 - Build up post (50mm x 150mm)

18 - Tensioned steel cable railing

Figure 4.2.6: Exploded Axonometric of Experiential Pit (For selected details see Appendix C) 


\subsection{6 $\mathrm{H}_{2} \mathrm{O}$ Pavillion}

The $\mathrm{H}_{2} \mathrm{O}$ Pavilion consists of a different set of conditions as compared to the Experiential Pit. This pavilion is located approximately 90 meters from the main building and parking area (Figure: 4.1.0). A school group would get the opportunity to hike through a single track trail through the forest to get to this location. The $\mathrm{H}_{2} \mathrm{O}$ pavilion is situated beside the 11-meters wide river which can experience varying water levels depending on the season and weather conditions. Although the river is approximately 11 meters wide, the deepest center part of the river is no more than 1.2 meters deep. From May to October, the water levels tend to be consistent during days when there is no rain. Students are able to engage in several experiences at $\mathrm{H}_{2} \mathrm{O}$ Pavilion are dissimilar to those of the other outdoor classroom pavilions.

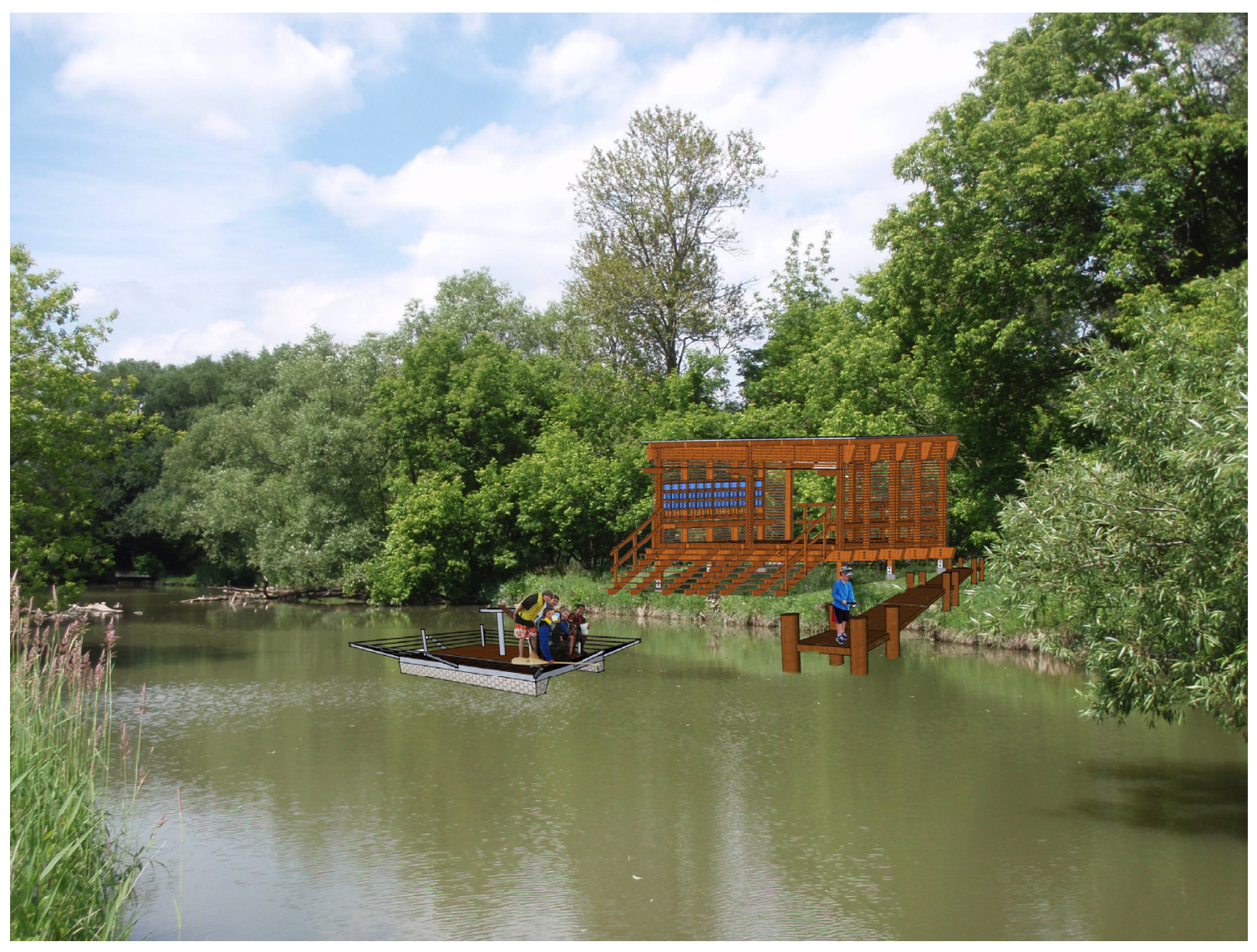

Figure 4.2.7: Looking south at $\mathrm{H}_{2} \mathrm{O}$ Pavillion across the river 

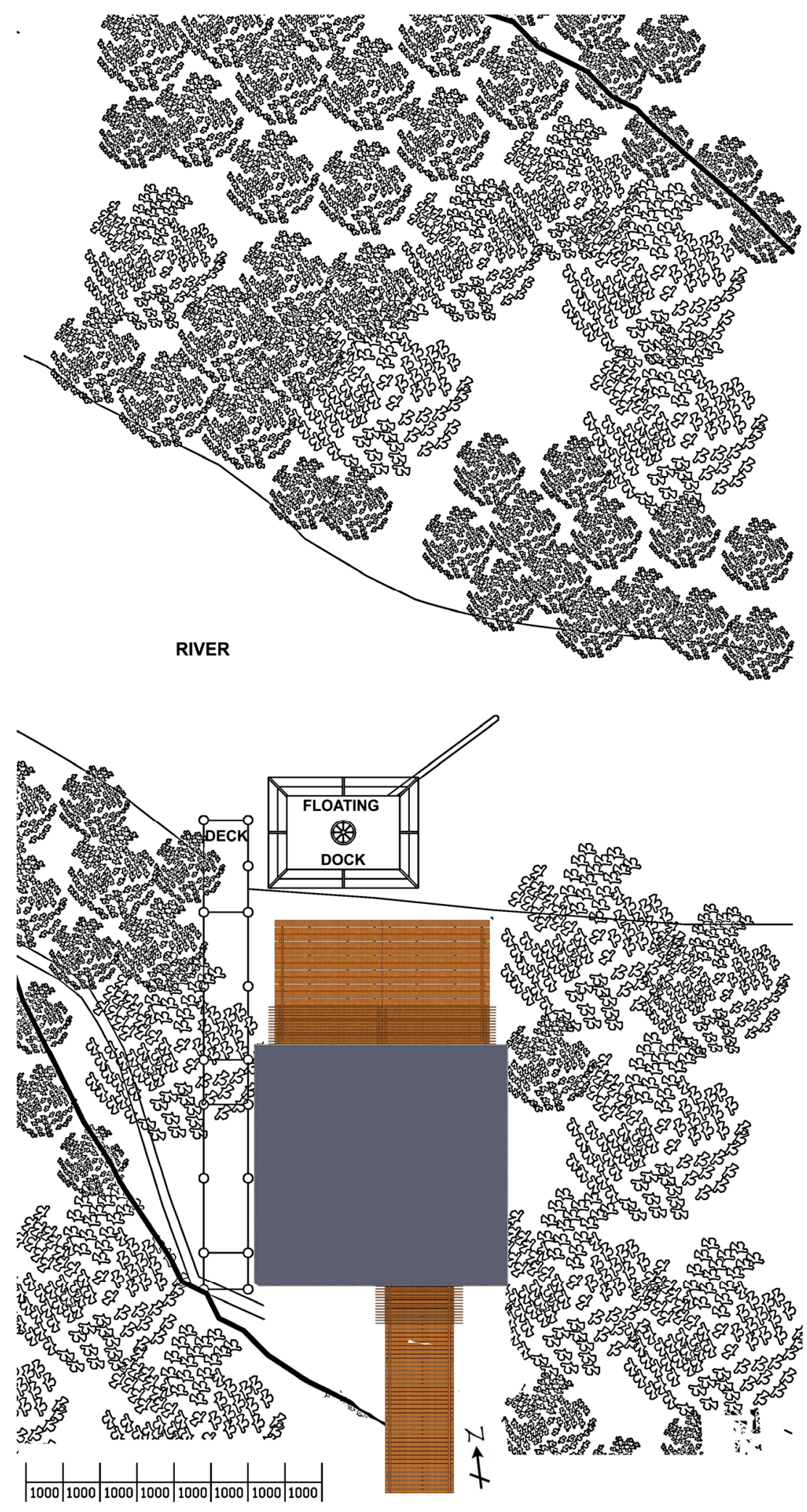

Figure 4.2.8: Immediate Site Map for (2) $\mathrm{H}_{2} \mathrm{O}$ Pavillion 


\subsubsection{Plan and Section - $\mathrm{H}_{2} \mathrm{O}$ Pavillion}

The plan of the $\mathrm{H}_{2} \mathrm{O}$ Pavilion is consistent with the Experiential Pit. The $\mathrm{H}_{2} \mathrm{O}$ Pavilion is designed to support a class of 20-25 students and their teachers. Much like that of the Experiential Pit, the plan of the $\mathrm{H}_{2} \mathrm{O}$ Pavilion allows for flexibility of individual as well as group activities. (For a detail drawing see appendix D)

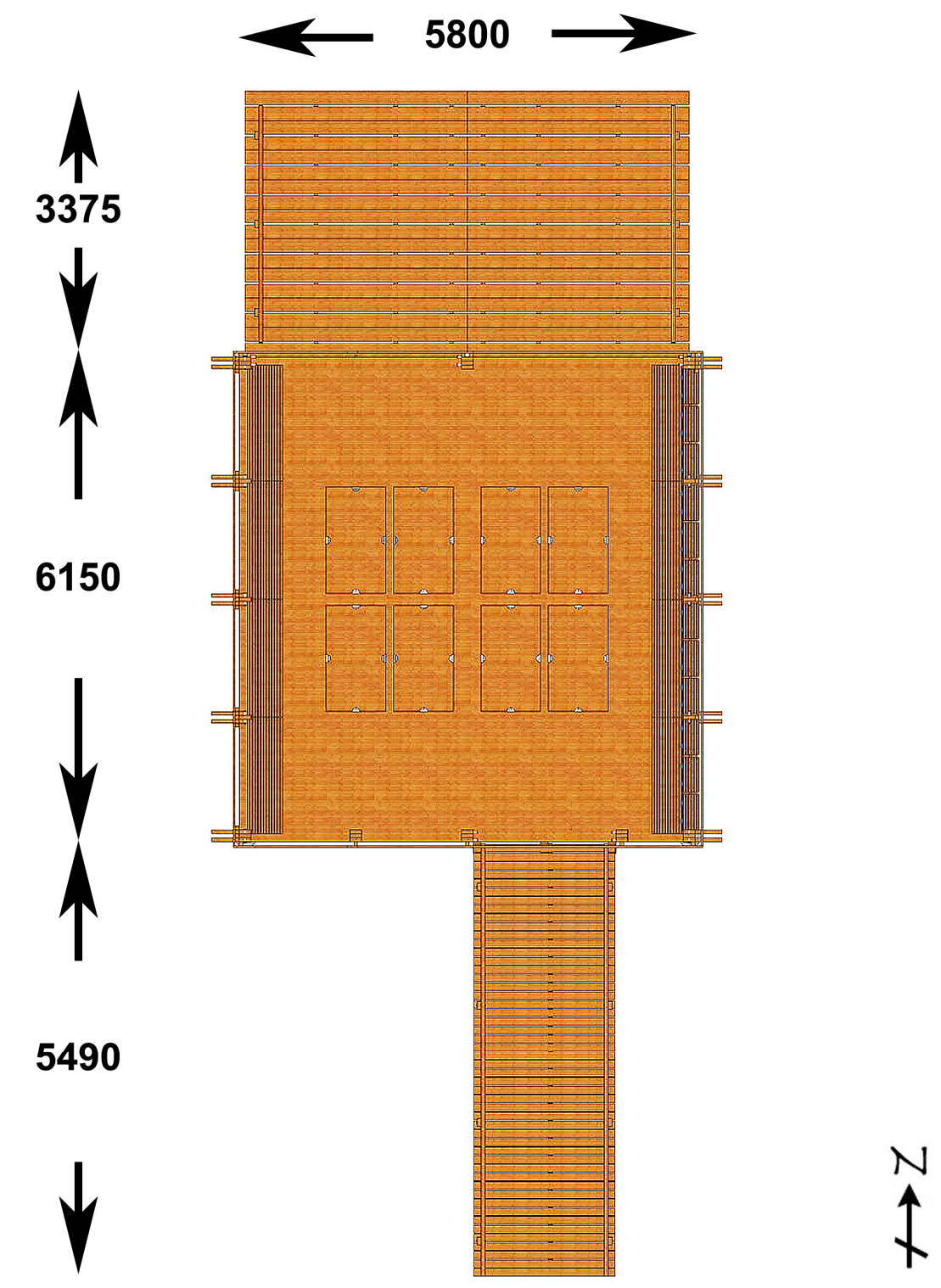

Figure 4.2.9: Floor Plan $\mathrm{H}_{2} \mathrm{O}$ Pavillion 


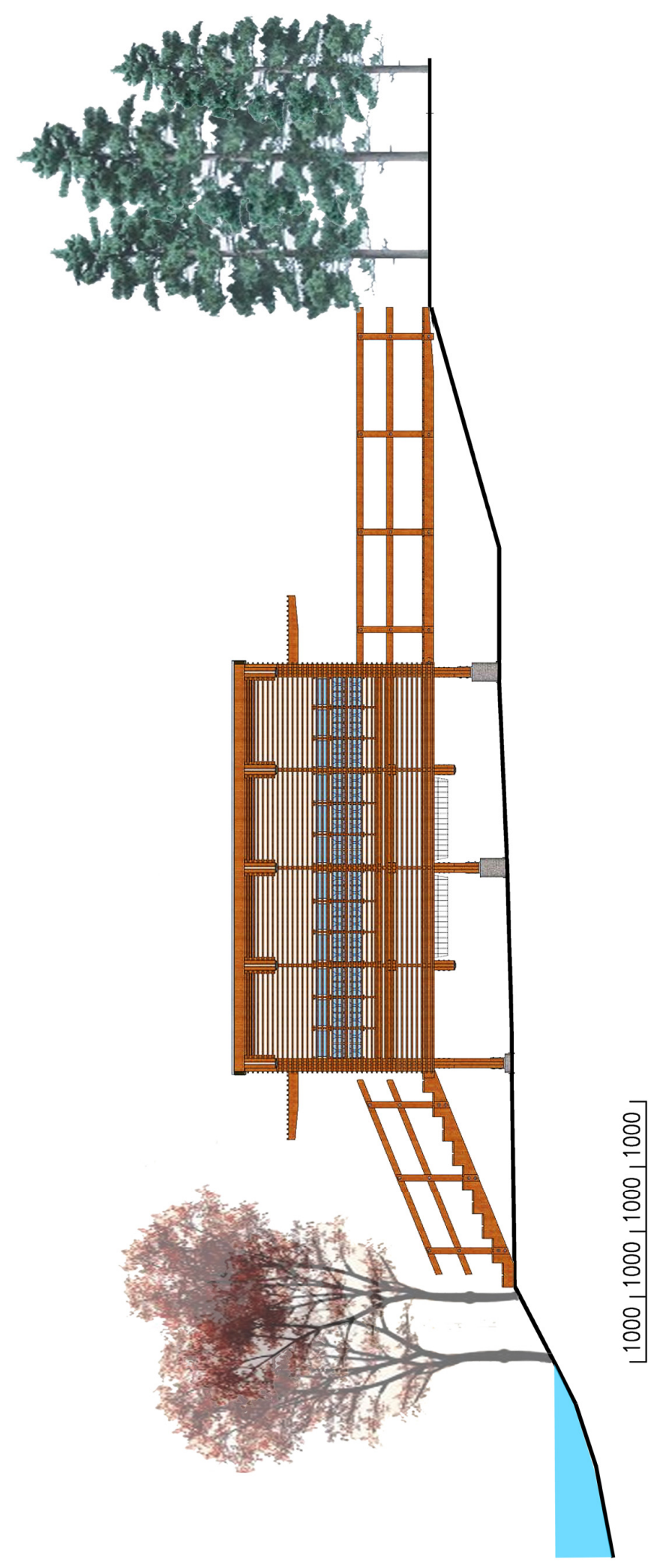

Figure 4.3.0: Site section of $\mathrm{H}_{2} \mathrm{O}$ Pavillion looking east and showing the level changes (For detail drawings see appendix E) 


\subsubsection{Indoor / Outdoor $-\mathrm{H}_{2} \mathrm{O}$ Pavillion}

The $\mathrm{H}_{2} \mathrm{O}$ Pavilion's design encourages users to experience the outdoors by mean of a building that is almost transparent. On the North elevation of the pavillion there are two openings that lead to the instructional stairs near the river. On the south elevation, there is a universal accessible ramp that aligns with the trail connected to the main buildings. The suggestion that it is semi transparent can also be validated with the material and design of the exterior of the pavillion. The exterior of the building consist of 1 " $\times 1$ " $(25 \mathrm{~mm} \times 25 \mathrm{~mm})$ cedar that run that horizontally around the building with $100 \mathrm{~mm}$ space in between, these cedar strips are attached to the main structural posts through the use of a vertical piece of 2" $\times 2$ " $(50 \mathrm{~mm} \times 50 \mathrm{~mm})$ nailer with stainless steel screws. By using this design, there is enough daylight that goes through the building, as well as a sense of protection from the elements. (For detail drawings see appendix $F$ and $G$ )

\subsubsection{Experience Wall (Learning tool) - H2O Pavillion}

The ultimate goal for the $\mathrm{H}_{2} \mathrm{O}$ Pavilion is to enhance learning in the natural science curriculum, which includes relationships to water and also incorporates matters, organisms and natural things in related to or near the water. All this involvement with water means that the pavilion will need to have several safety measures such as storage for fishing nets, life jackets and individual experimental jugs for crayfish, etc. There is also a selection of group buckets so the children can put all their findings in one to share with the class.

Upon entering the $\mathrm{H}_{2} \mathrm{O}$ Pavilion, the students will go through an orientation inside the pavilion and be seated on the benches that are lined along the inside perimeter of it. After a safety and lesson, each individual get their own personal jug.

As shown in Figure 4.3.1; a primary student using the bench that is attached to the experience wall. The experience wall is designed behind the bench as an intermediate barrier to help manage the children when they arrive so that they will not immediate play with the jugs before the orientation. 


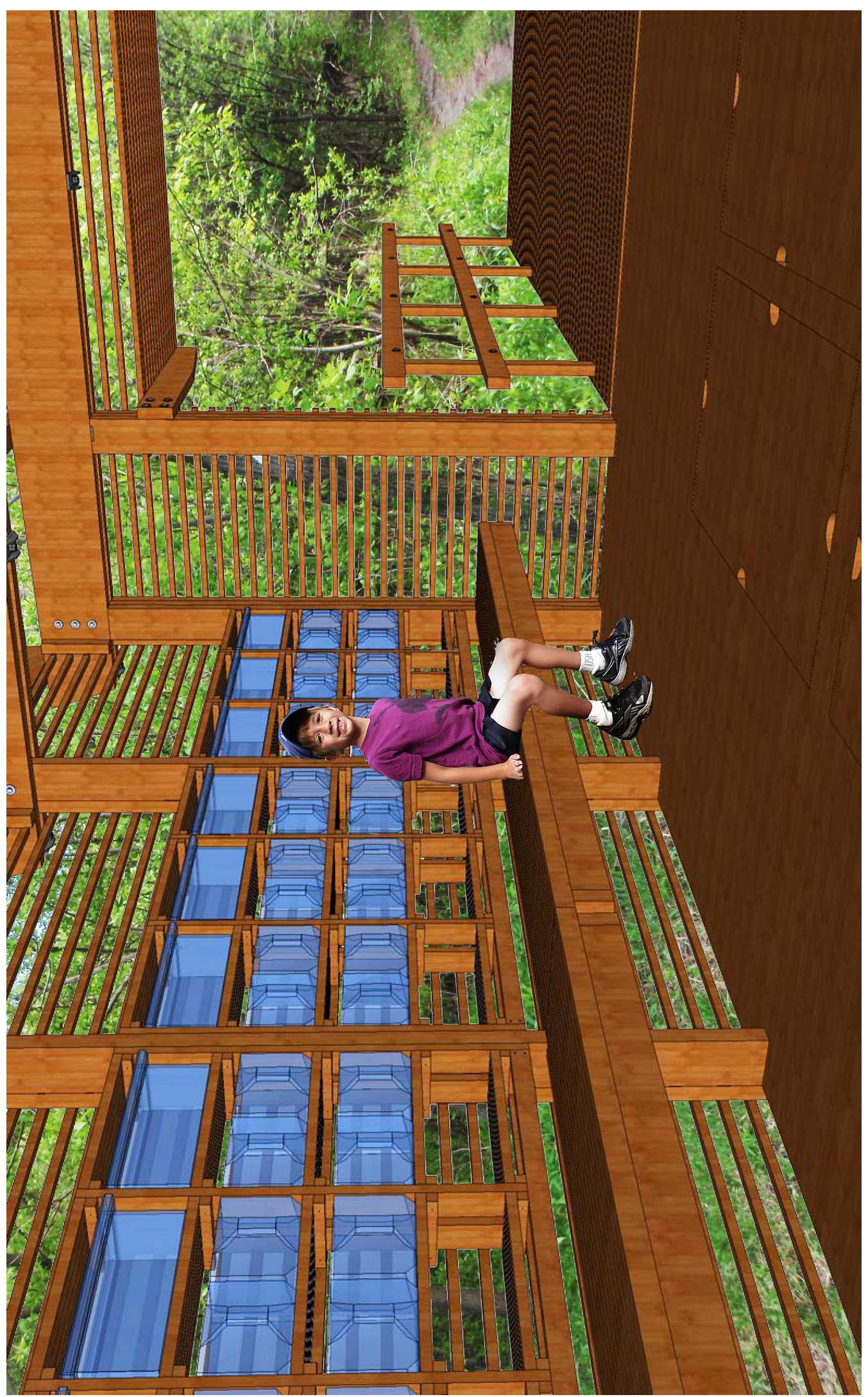

Figure 4.3.1 Interior of the $\mathrm{H}_{2} \mathrm{O}$ Pavilion showing the scale of the experience wall and the bench 


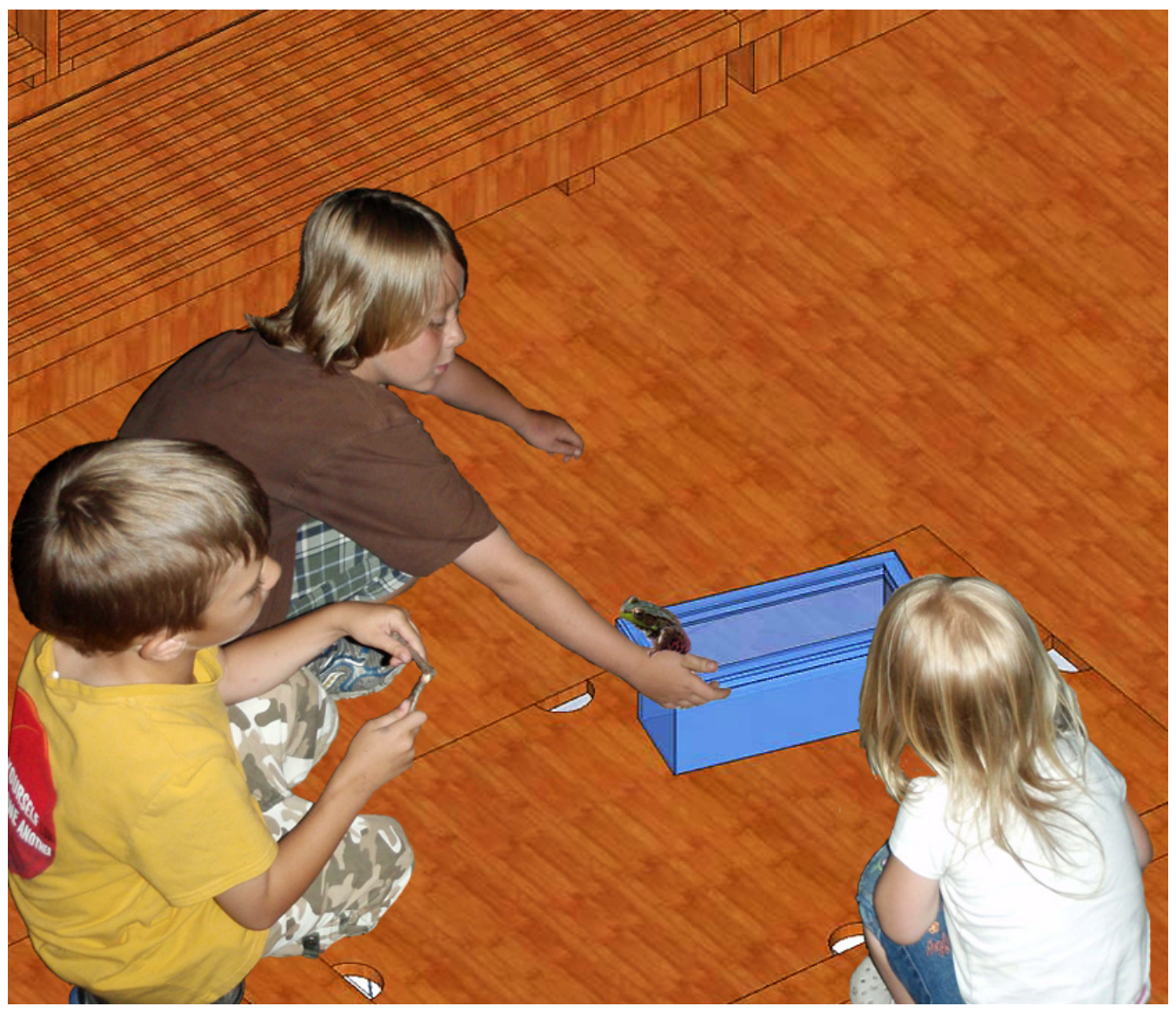

Figure 4.3.2 Students using group buckets to share their findings in the $\mathrm{H}_{2} 0$ Pavillion

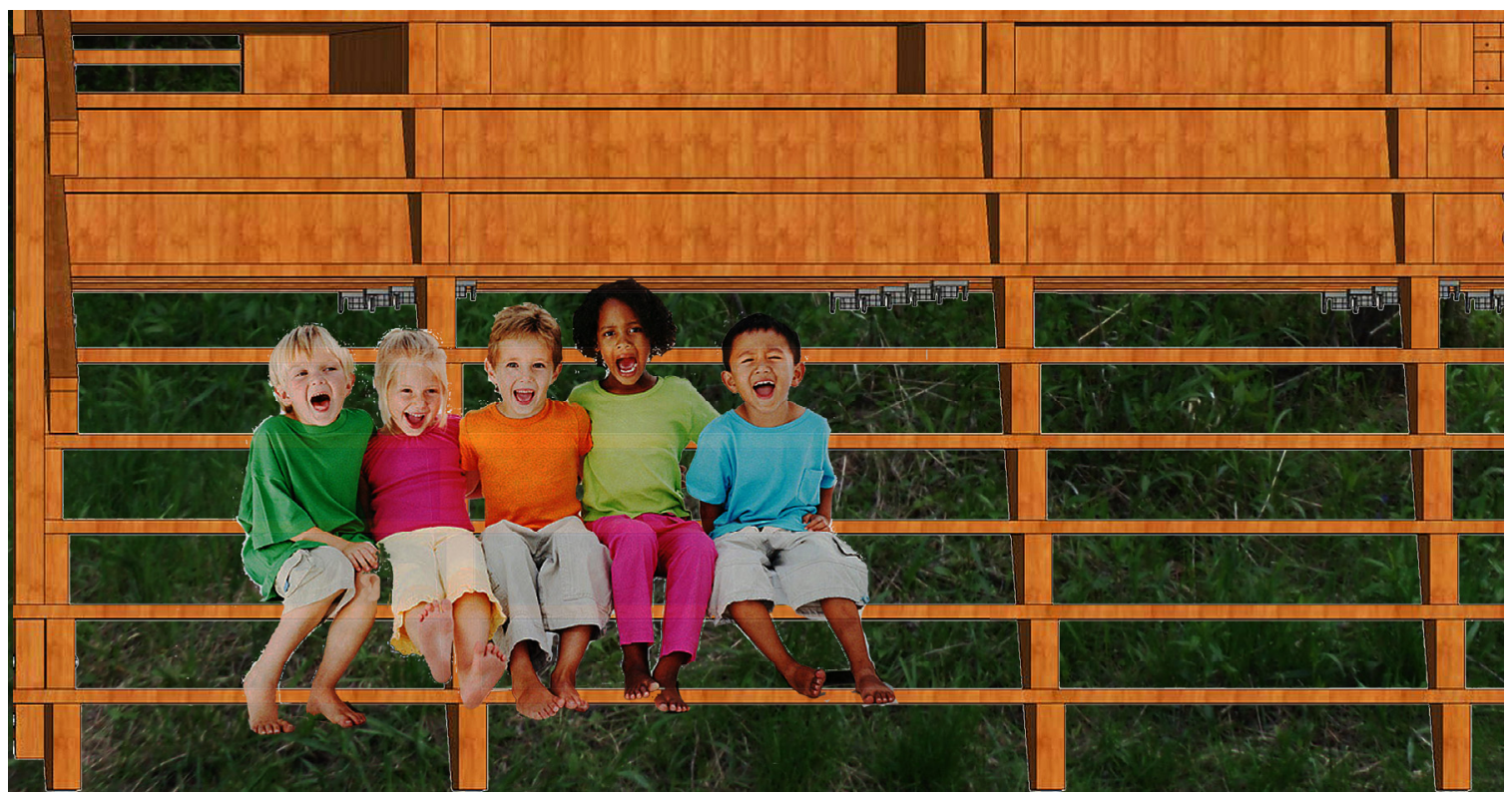

Figure 4.3.3: Primary aged students on instructional stairs (Learning tool) 


\subsubsection{In-ground storage for learning tools $-\mathrm{H}_{2} \mathrm{O}$ Pavillion}

In order to have a successful outdoor education program, teachers and students will need learning tools such as the jugs on the experiential wall. The learning tools for outdoor education vary depending on who is teaching. The $\mathrm{H}_{2} \mathrm{O}$ Pavilion's design is consistent with the design used for the Experiential Pit. In both structures there are hidden compartments under the floor and other elements of surprise.

The $\mathrm{H}_{2} \mathrm{O}$ Pavilion provides in-ground storage for the fishing nets, and other learning tools and safety equipment that may be needed. The storage areas can be opened by removing the floor board; this can be done by the children. It is designed so that fishing nets can be tossed in after being use when they are still wet. Removable metal baskets in the in-ground storage allow the fishing nets to be air-dried for use in another session.

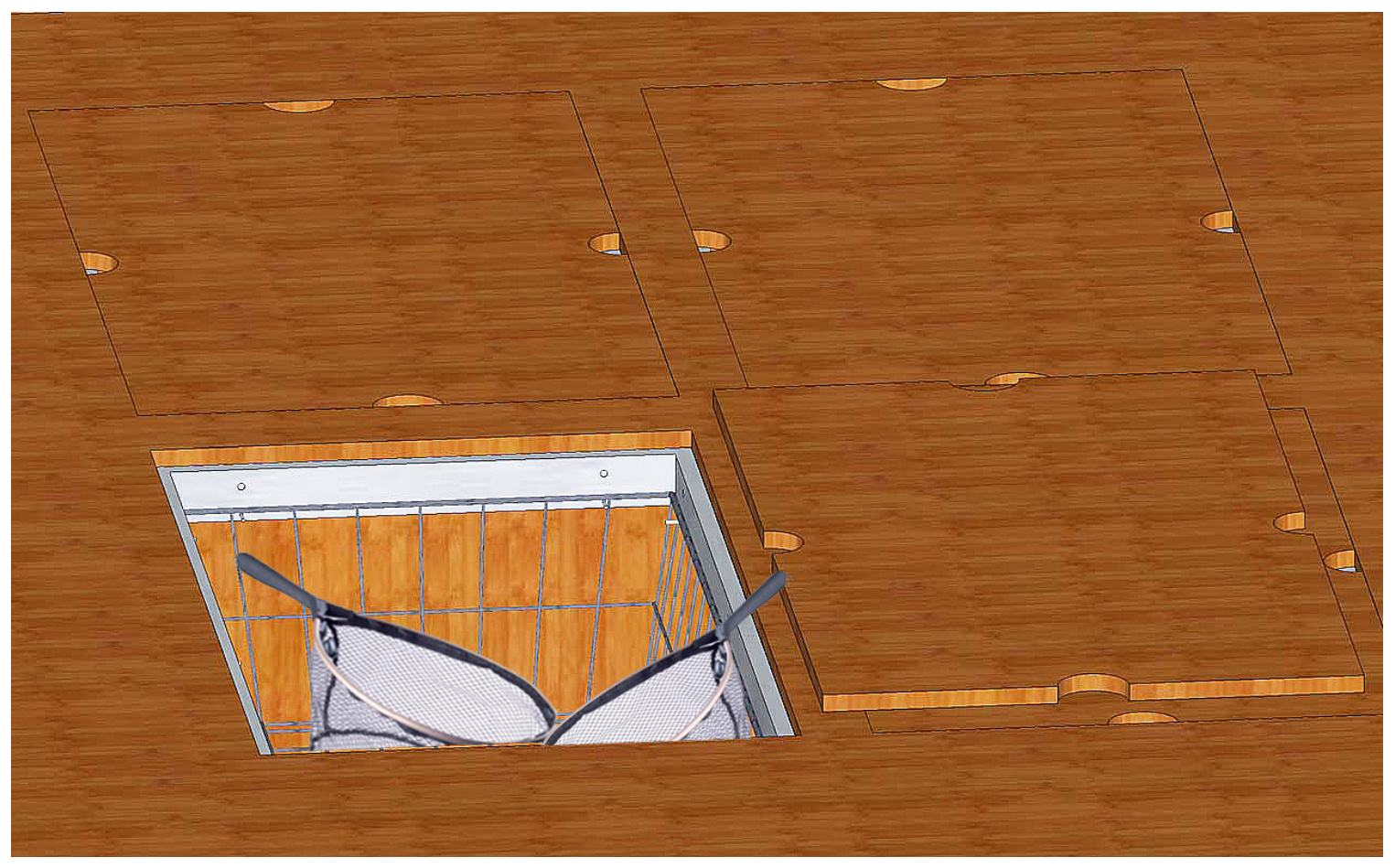

Figure 4.3.4 In-ground storage inside the $\mathrm{H}_{2} \mathrm{O}$ Pavillion 


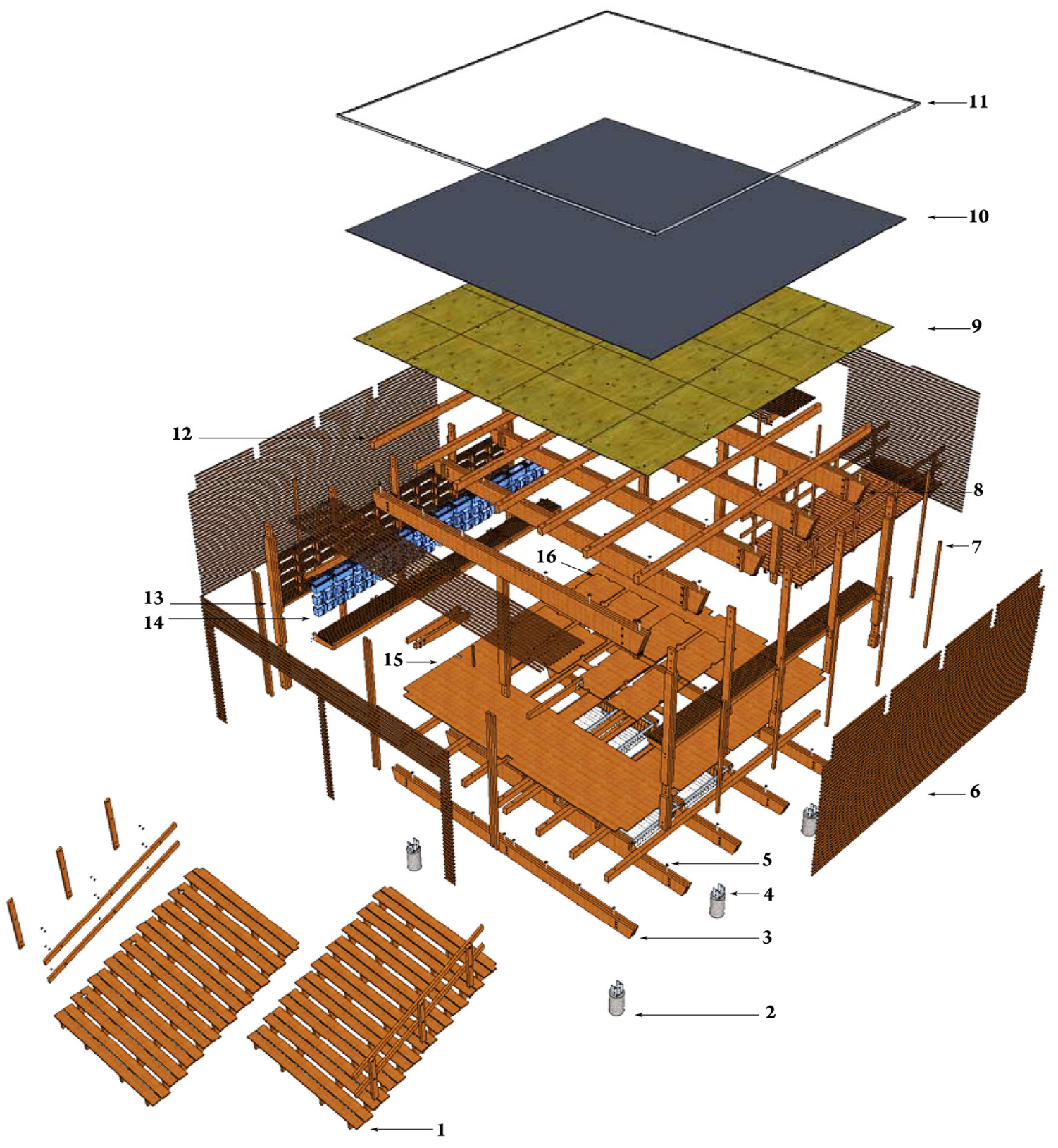

1 - Instructional Stairs

2 - Concrete Pier Footing $(R=150)$

9 - 1/2" Ply Wood Shealthing

3 - Cedar Joist $(50 \mathrm{~mm} \times 300 \mathrm{~mm})$

10 - Roofing membrane

4 - Steel post support

5 - Through Bolt Hanger

6 - Horizontal Cedar Screen

11 - Stainless Steel Flashing

12 - Cedar Roof Beam (100mm x 150mm)

13 - Built up post $(150 \mathrm{~mm} \times 150 \mathrm{~mm})$

14 - Individual and group jugs and buckets

15 - Cedar flooring (rough unfinished)

(25mm $\times 25 \mathrm{~mm}$ with $50 \mathrm{~mm}$ spacing)

16 - Removable floor storage with steel wire baskets

8 - Angled Roof joist

Figure 4.3.5: Exploded Axonometric of the $\mathrm{H}_{2} \mathrm{O}$ Pavillion (For a detail drawing see appendix $\mathrm{G}$ ) 


\subsubsection{Tree Pavillion}

The Tree Pavilion provides a unique experience that will challenge the children in various ways into a new level of wonder and curiosity. Most children that live in the city do not get to experience being high up in the trees or as they would not have the resource or space within their backyards to have a tree house ${ }^{15}$. According to Christopher Day ${ }^{16}$, Tree houses demand children to have greater resourcefulness, imagination and freer thinking, as well he also believes that children need adventure and partly unsupervised to be fully creative (Day, 2007) The Tree Pavillion (3) (Figure: 4.1.0) is approximately 90 meters from the main building area. The school groups will have the opportunity to take a direct hike and walk through the narrow bridge that crosses over the river, for many primary student; the experience of crossing a bridge can be a new challenge in itself. From the bridge, the school group will walk towards the universally accessible ramp that leads the students to the tree pavillion; this can be seen in the site plan in Figure 4.3.7 and 4.3.8. As well, in the site plan; each contour represents a meter difference.

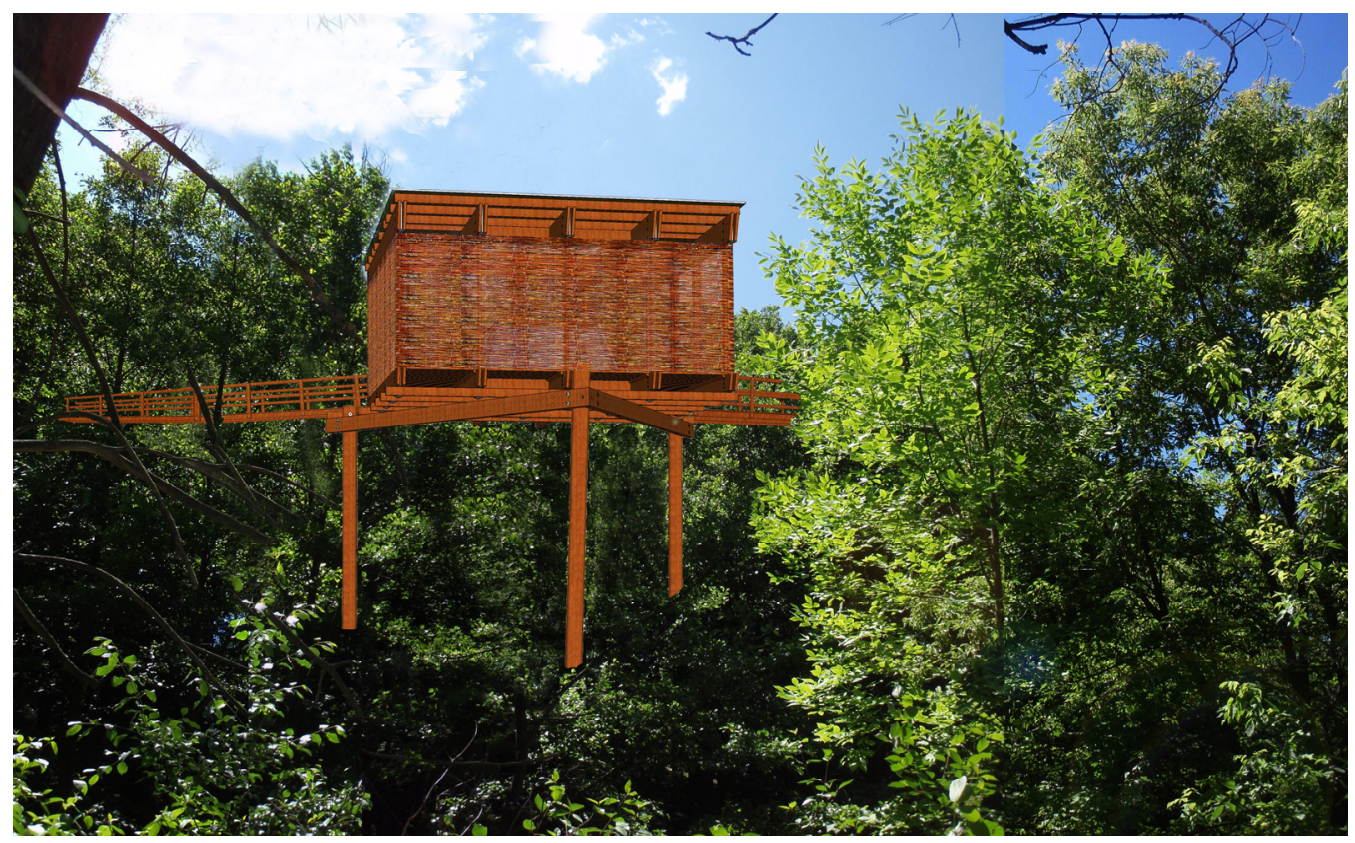

Figure 4.3.6: A view toward north at the Tree Pavillion

\footnotetext{
${ }^{15}$ Children the live in the city would not experience a tree house; this is as assumption that their family do not own a cottage outside the city.

${ }^{16}$ Christopher Day is an Architect that has extensive experience designing schools and early childhood centers and is the author of Environment and Children.
} 


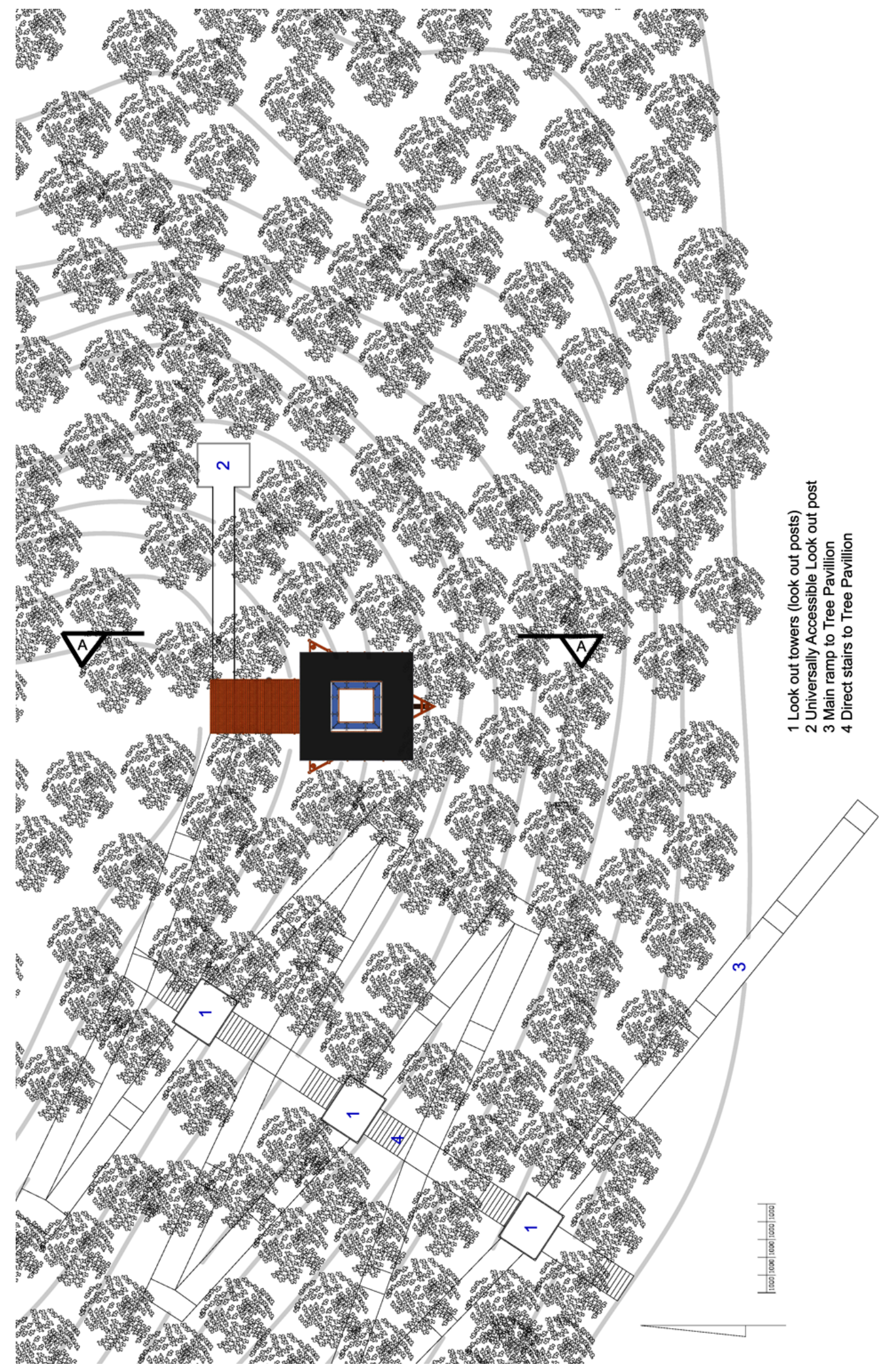

Figure 4.3.7: Site Plan of the Tree Pavillion 


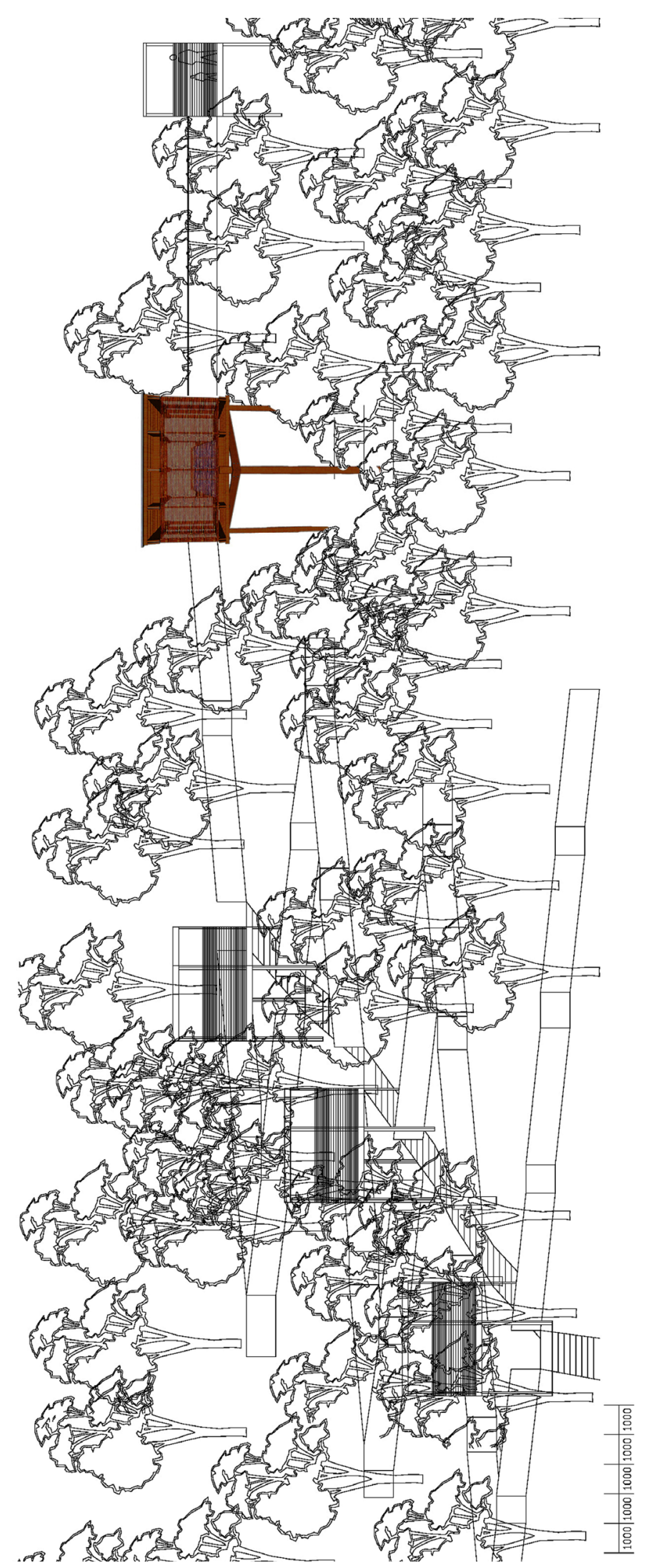

Figure 4.3.8: Site Elevation of the Tree Pavillion facing north 


\subsubsection{Access ramp, lookout points and lookout posts - Tree Pavillion}

Hiking up a hill isn't for everyone, especially for young primary school students. The Access ramp as seen on the site plan and the site elevation plan in Figure 4.3.7 and 4.3.8 provides universal access to all students. The ramp provides an adventure for students to get the Tree Pavillion through the forest. It is designed so that the students are able to rest at the end of the ramps to experience the varying level changes in the forest. In addition, there are lookout posts that the students can climb into and experience what it feels like to be at the varying levels of the trees. Furthermore, as an alternate route, the school group may choose to use the more direct stairs that also goes through the look out post and eventually leads to the Tree Pavillion. As for the children in wheel chairs or children that are not comfortable with climbing ladders, there is also a universally accessible lookout post east of the Tree Pavillion that is accessible with a bridge.

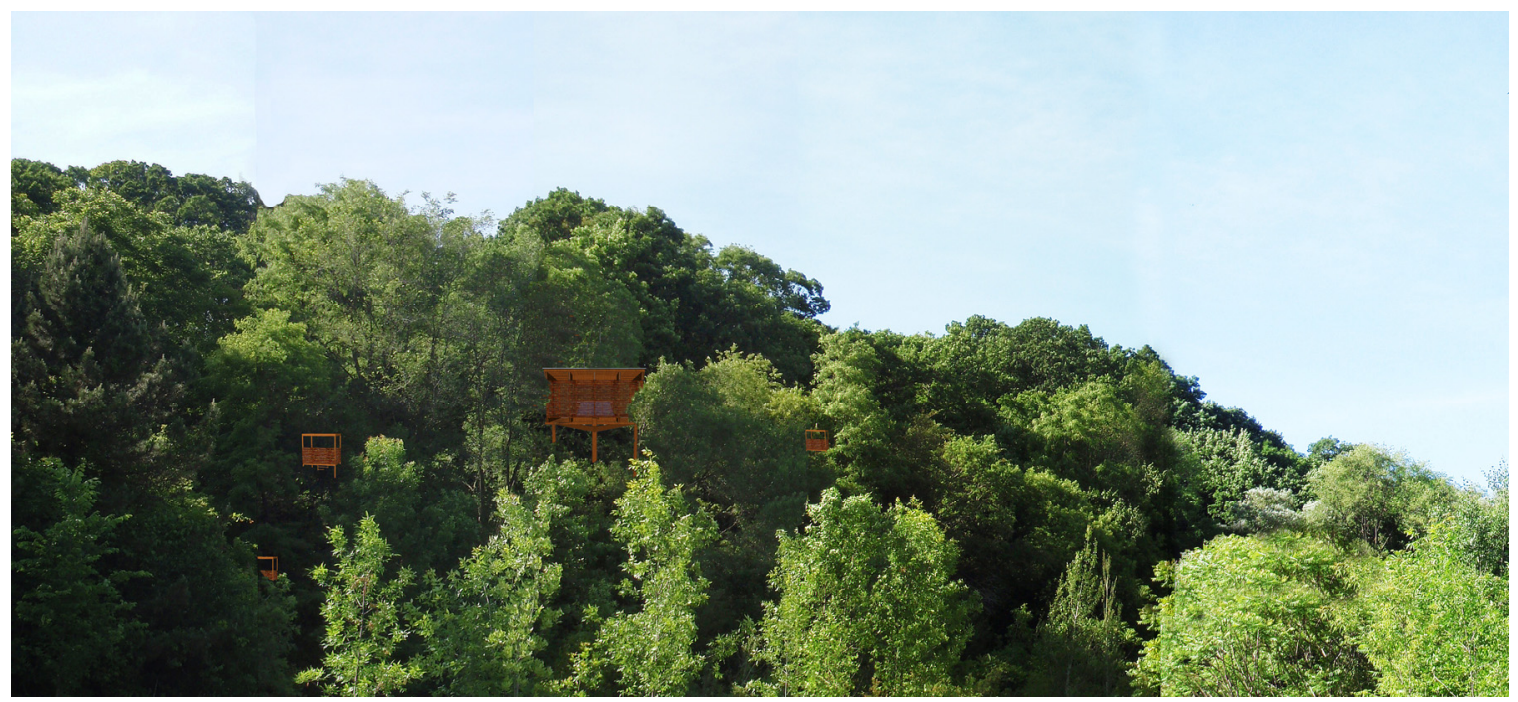

Figure 4.3.9: Looking north at the Tree Pavillion and the ramp lookout posts 


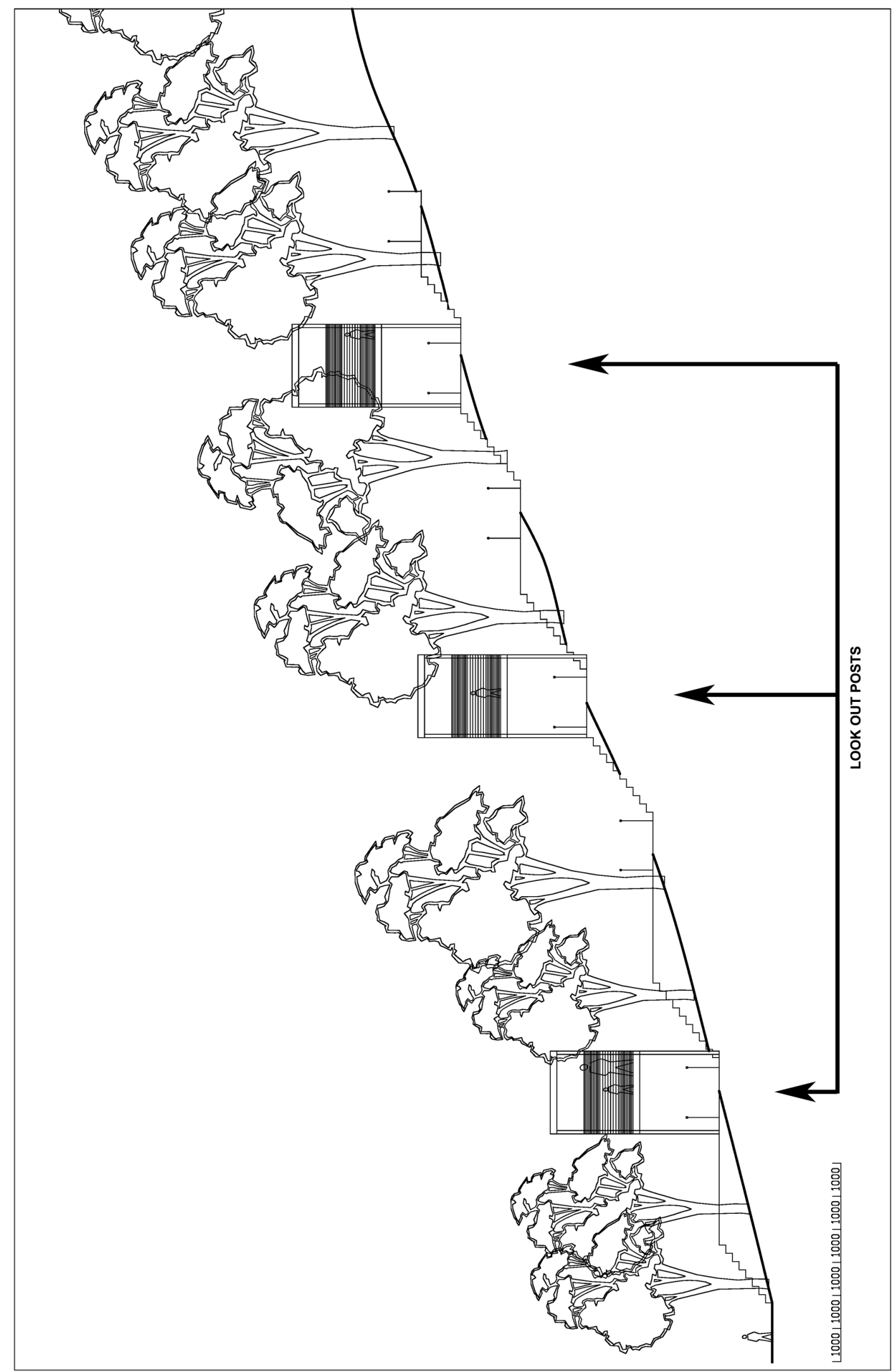

Figure 4.4.0: Site section, looking east at the ramp lookout posts and stairs 


\subsubsection{Plan and Section - Tree Pavillion}

The design of the Tree Pavilion's floor plan has similar characteristics in size and in material when compared to the Experiential Pit and the H2O Pavillion, but the main difference is the experience. The design allows students to literally experience the environment at different elevations. The students will arrive through the access ramp and then gather on the deck that is on the north side of the pavillion, then students will have the opportunity to experience the Tree Pavillion by looking out at various tree levels and over the top of the trees, as well as spying on animals below the pavillion through the space (Figure 4.4.5) in the center of the pavillion. As well, students are able to watch for different species of birds by looking through the woven willow weed envelope of the Tree Pavillion. (For detail drawings see appendix $\mathrm{H}$ )

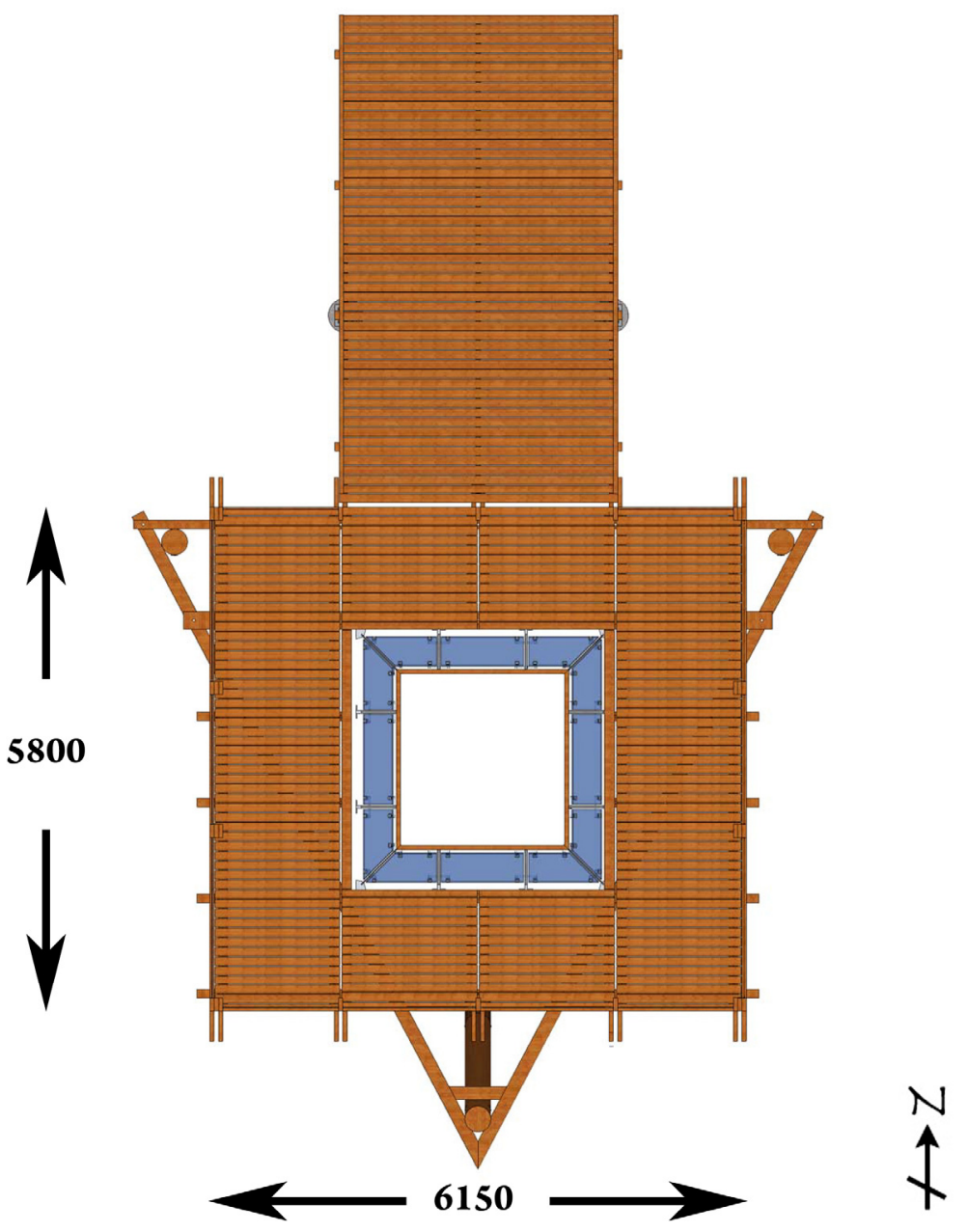

Figure 4.4.1: Floor Plan of Tree Pavillion 


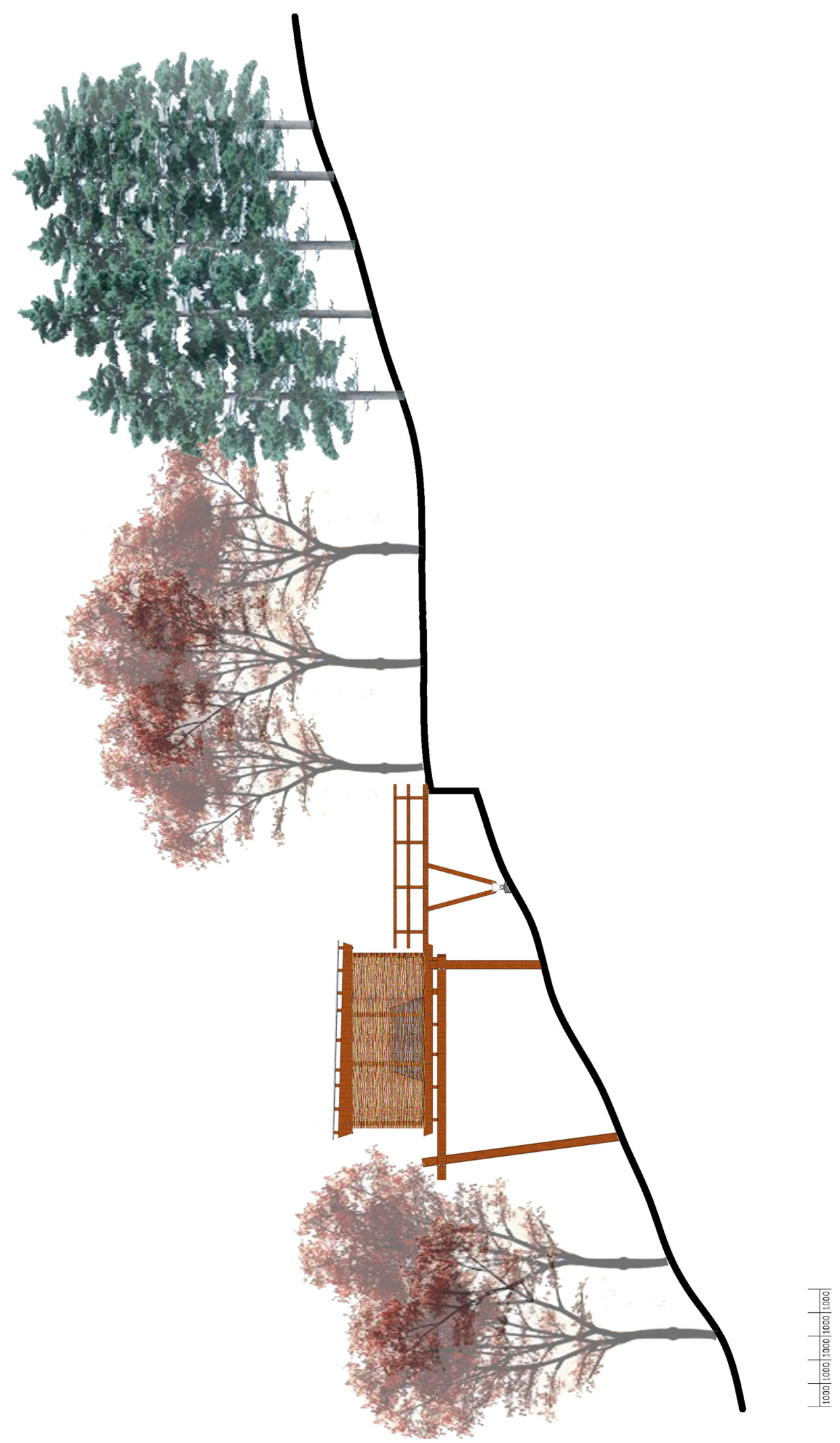

Figure 4.4.2: Site section "A" looking east at the Tree Pavillion 


\subsubsection{Woven Willow Weed - Tree Pavillion}

A façade of woven willow weeds, reminiscent of a basket is the envelope of the Tree Pavillion that is in the midst of the sloped forest. The material is natural and sustainable; as well it blends into the forest almost like a bird nest would. The reason why this was selected is because it is a flexible material that is natural and can be moved around by the children to spy on animals as if they were camouflaged into the forest. Overall, the building envelope provides enough filtered light to operate throughout the day and to generate curiosity for the children. For additional images see Figure 4.4.7 for the overall exploded axonometric.

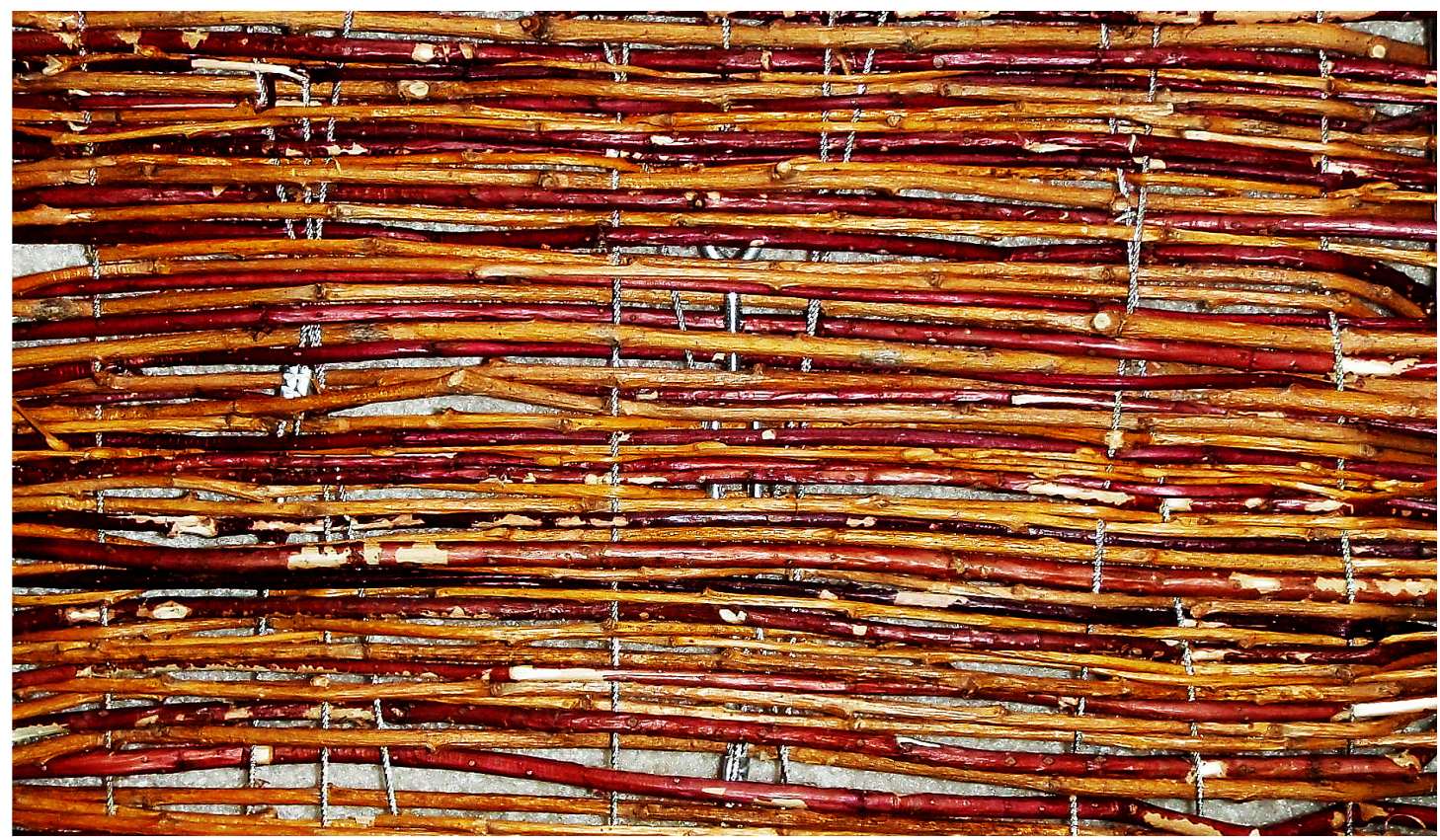

Figure 4.4.3: Woven Willow Weed Model

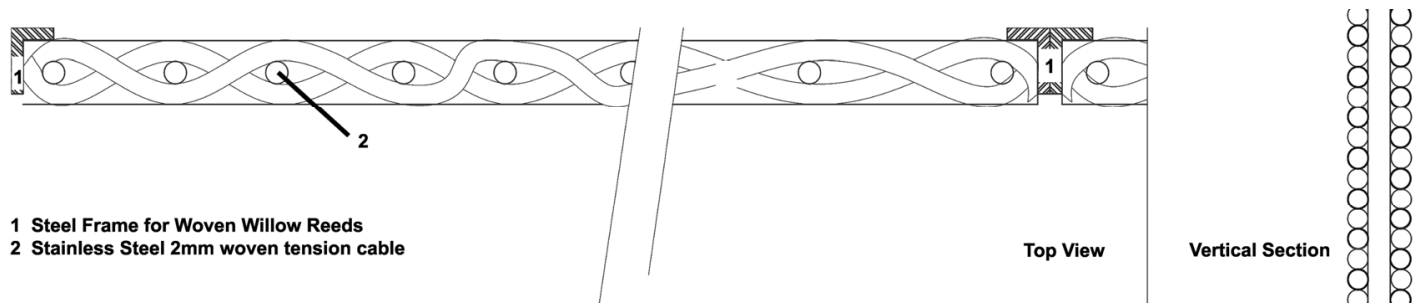

Figure 4.4.4: Woven Willow Weed Top View and Vertical Section 


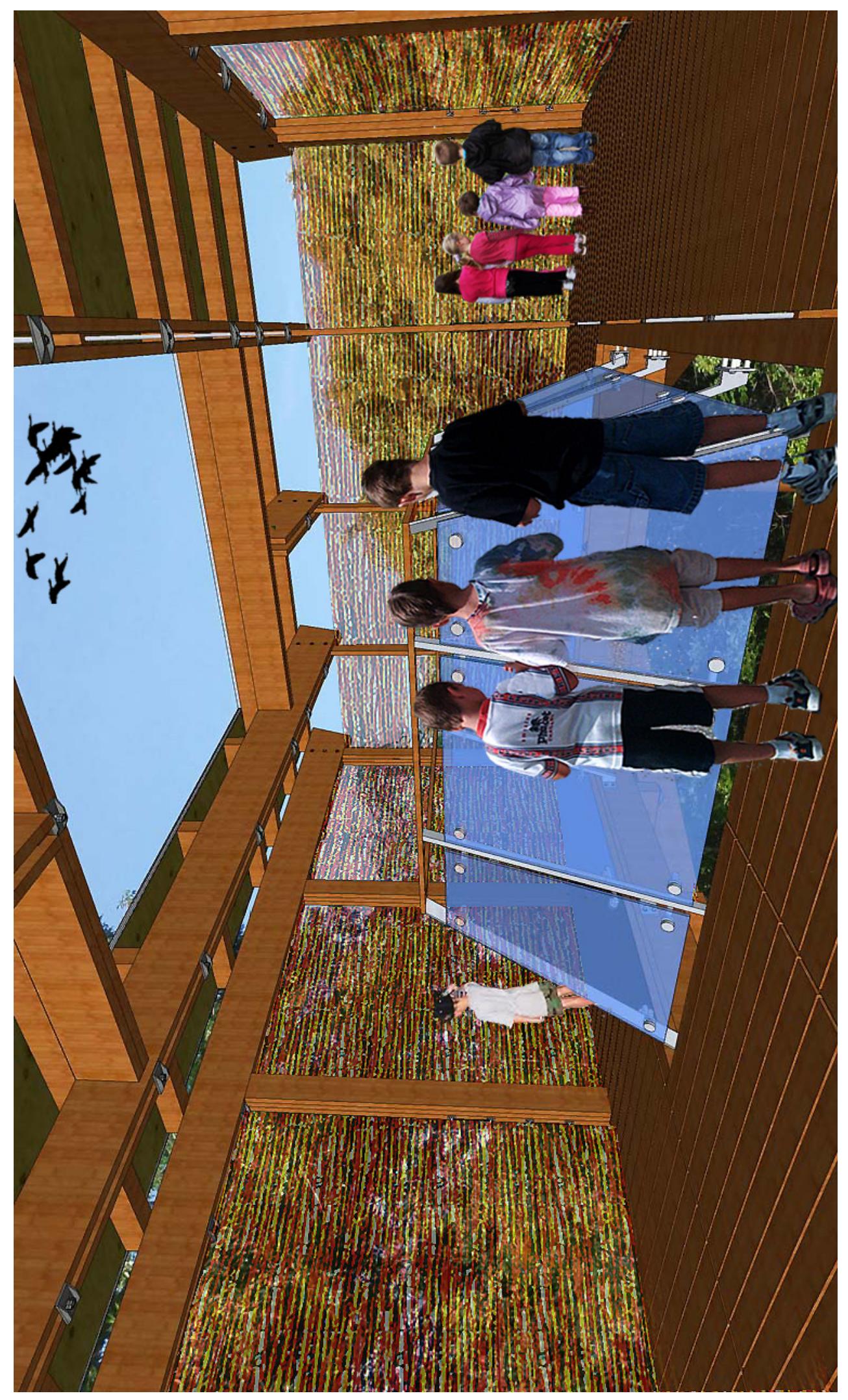

Figure 4.4.5: Primary school students exploring the Tree Pavillion 


\subsubsection{Structure - Tree Pavillion}

The Tree Pavillion is designed to act as a tri-pod. The pavillion and viewing deck is held up by 3 telegraph poles with 3 beams attached to these poles as the base for the overall post and beam structure (Figure: 4.4.6). The post, beams and decking are spaced to let children be alert as they are able to sense the $10 \mathrm{~mm}$ gaps between the $100 \mathrm{~mm}$ cedar decking, and with the spacing in the Woven Willow Weed Envelope. With this design, students will experience the lightness of the building when they are inside, and from a distance, the pavillion looks as if it is floating among the trees in the forest (Figure 4.4.6 and 4.4.7). (For detail drawings see appendix I and $\mathrm{J}$ )

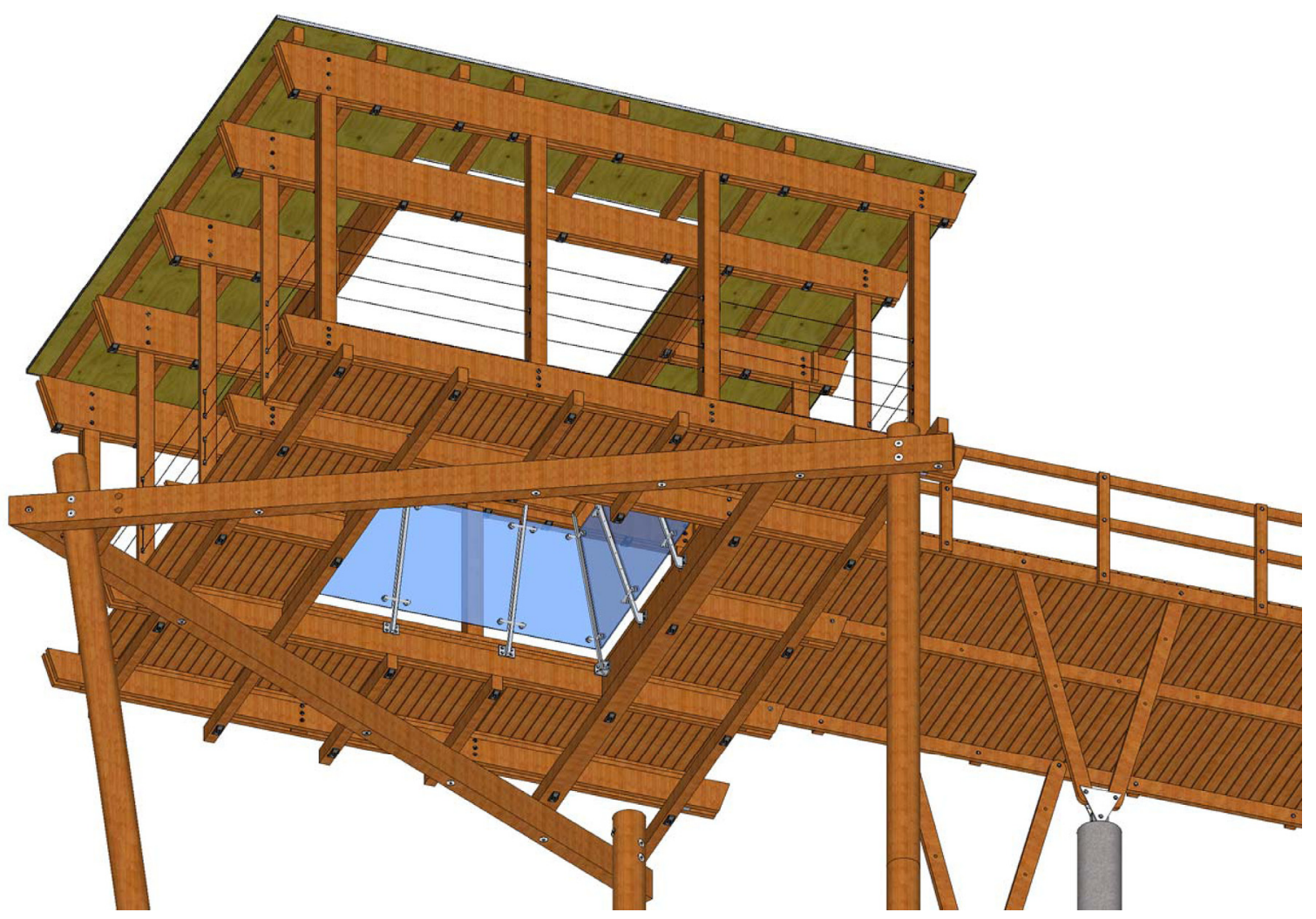

Figure 4.4.6: Looking at the Tree Pavillion from below 


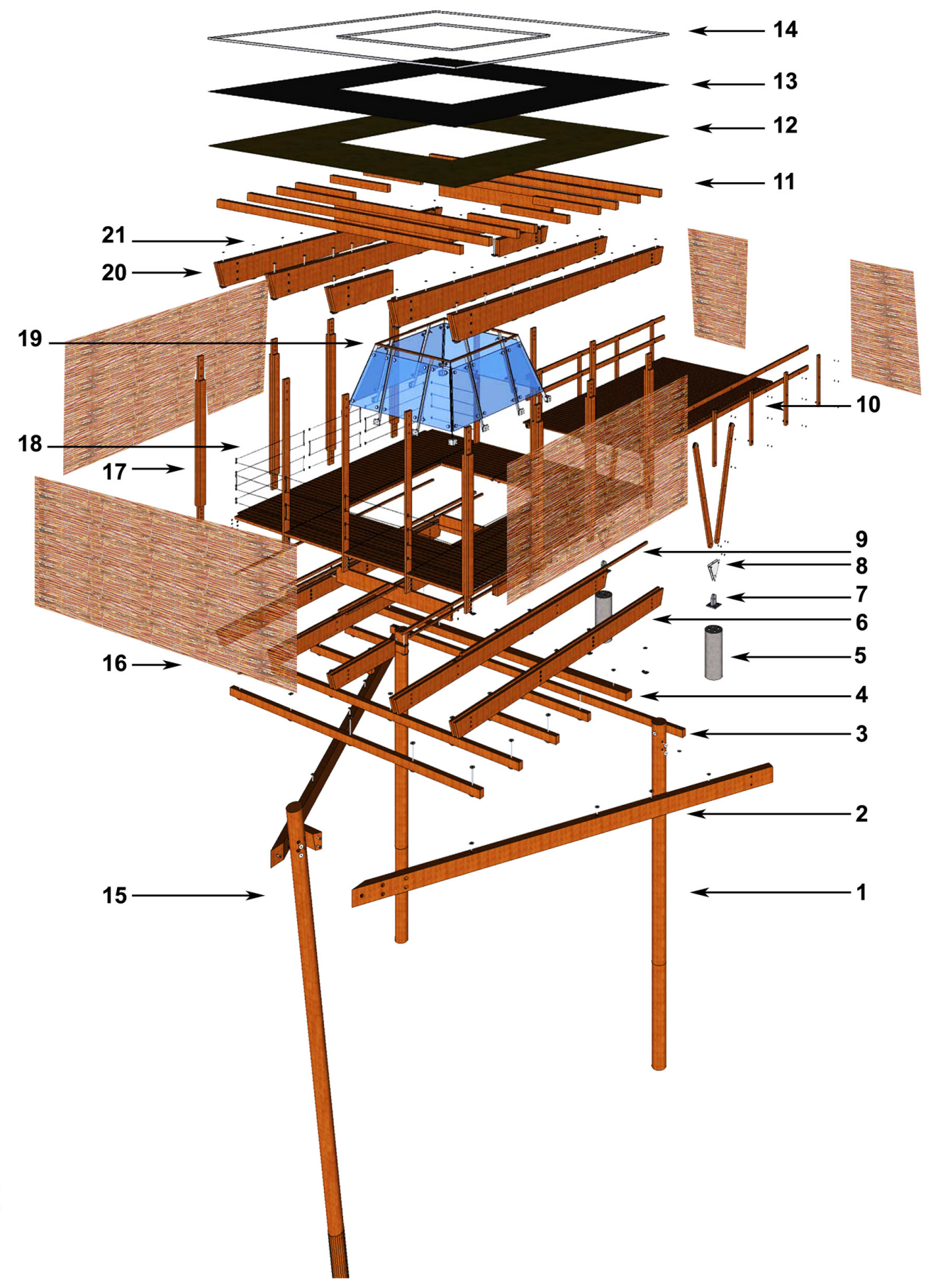

1 - Reclaimed telegraph pole $(R=150 \mathrm{~mm})$

2 - Secondary beams $(150 \mathrm{~mm} \times 300 \mathrm{~mm})$

3 - Primary beams $(150 \mathrm{~mm} \times 100 \mathrm{~mm})$

4 - Primary beams II (150mm $\times 200 \mathrm{~mm})$

5 - Concrete Foundation $(R=200)$

6 - Joist (50mm x 300mm)

7 - Steel hinge support

8 - Steel hinge with through bolts

9 - Strapping $(25 \mathrm{~mm} \times 25 \mathrm{~mm})$

10 - Cedar Railing

11 - Roof Beams (100mm-150mm)

12 - 1/2" Ply-Wood shealthing

13 - Roofing membrane

14 - Stainless steel flashing

15 - Reclaimed telegraph pole @ 7 degrees $(R=150)$

16 - Willowweave frame

17 - Build up post (50mm x 150mm)

18 - Tensioned steel cable railing

19 - Steel supported glazing with cedar handrail

20 - Primary Joist $(50 \mathrm{~mm} \times 300 \mathrm{~mm})$

21 - Through bolt hanger

Figure 4.4.7: Exploded Axonometric of Tree Pavillion (For detail drawings see appendix I and J) 


\subsection{Summary and Conclusions}

The principles of educational theorists, health recommendations, and the adaption of the outdoor environment were all applied to the design of proposed outdoor experiential support spaces to improve learning and problem-solving skills, enhance creativity, and encourage risk- taking in children.

Forest Valley is an ideal site to promote outdoor experiential education and has minimal imperceptible harms. The site has existing trails scattering its $1.5 \mathrm{~km} \times 1.5 \mathrm{~km}$ area, along with current outdoor education facilities, and has enough space for buses to unload school groups. Yet it still does not overwhelm the natural surroundings. Existing selected trails will be connected to the proposed outdoor experiential support spaces to provide ease of access to younger students; as well, all the trails will be universally accessible including in and around the proposed pavilions.

The proposed pavilions, the Experiential Pit, the $\mathrm{H}_{2} \mathrm{O}$ Pavilion and the Tree Pavilion provide the children with direct experience in engaging with nature. The pavilions' designs are reflective of the theories and ideas of Maria Montessori, John Dewey, Rudolph Steiner and other contemporary theorists mentioned in this thesis.

The overall ideas from the theorists are implemented in the designs to provide a sense of community to encourage children to engage in social interactions as well as to promote experiential education. Each of the pavilions also provides unique learning experiences, known as "learning tools" within the building; these are designed to encourage learning through play, exploration, and observation, all of which are advocated by the theorists discussed. The end result is that children will engage with the outdoors and at the same time learning natural science with nature as a learning tool. 


\subsubsection{Sustainability considerations}

As a prototype of outdoor experiential learning in the Toronto area, it is essential to showcase this project and to promote green design to the rest of the city. The Forest Valley Outdoor Education Center is currently ranked as a Certified Platinum Eco-School. This certification is recognized province-wide: school facilities are certified bronze, silver, gold or platinum based on points scored in various categories such as energy conservation, waste reduction, ecological literacy and greening of the school grounds. With the addition of the three proposed pavilions, it will have to maintain its status, continue to contribute to the reduction of any negative environmental impact, and also contribute positively to the ecosystem. With that in mind, there are important points that need to be addressed. Some of these are: durability and maintenance of material used on the pavilions, waste material from construction, and minimal scarring of the existing forest.

Prior to the design stage of the pavilions, specific materials were selected that would suit the conditions of this site. The idea was to create a healthy environment for play and learning and to limit any negative ecological impacts associated with the manufacture and transportation of construction materials.

The materials used for the pavilions were specifically selected for this site and their designs. Since the decking of all the pavilion spaces will be prone to wear and tear, cedar was selected. The cedar selected is the heartwood of the tree (the deeper coloured red part, not the white sap part), known to be rot-resistant. Cedar doesn't easily absorb moisture, and since moisture is what creates twisting and splitting, cedar decking tends to lie flat and straight. Cedar deck boards can last 15 to 20 years and it is also durable and low-maintenance, all qualities that make it a good choice for the pavilions.

The main structural material for the beams and joists of the pavilions is also cedar, for the same reasons. Another advantage is that the structural members' sizing are locally available if there is a need for replacement.

Overall, the proposed pavillions were designed to be durable with adaptable interior spaces flexible enough to respond to changing uses over time. All the materials are modular, lightweight, and pre-cut off site and can be easily assembled on site by a small 
group of workers. In addition, some of the materials such as telegraph poles and the willow weed can even be salvaged and recycled.

Waste material from the construction process is also a consideration. Since the Forest Valley Outdoor Education Center is planned as a model facility and currently holds the status of Platinum Eco-School facility, it needs to target zero landfill waste during construction and operations. Materials will be recycled back into nature to protect the environment. The idea here is that the construction and land-clearing debris will be diverted from landfill for reuse at this facility. Any wood left over will be used for wood chips and for trail maintenance.

Another major concern was possible scarring of the site during construction. Transportation and delivery of the construction materials had to be considered. As mentioned in the above section, all of the construction materials are modular and can be delivered by means of dollies.

The construction of the Tree Pavilion can only be completed after the access ramp is created. The construction materials will need to be dollied up to the elevated location, and a crane will have to be brought in from the north side of the site through the parking area of the apartment buildings; this will be convenient for reaching the Tree Pavilion.

Concrete is needed for the foundation walls of the Experiential Pit. A trailer-mounted concrete pump could pump wet concrete through the distance of approximately 30 meters to the Pit, and a mounted concrete mixer could even fit through the wider trails that surround the Experiential Pit location if necessary.

A ready-mix concrete will be employed for the $\mathrm{H}_{2} \mathrm{O}$ 's Pavilion cast-concrete foundations. Ready-mix concrete sets quicker, and come in bags that can be brought on dollies through the trail that leads to the Pavilion. A small water filter trailer can be wheeled to the location on the trail and water from the ravine will be used for the concrete.

All these measures will help ensure minimal scarring of the existing Forest Valley site during and after the construction of the proposed outdoor experiential pavilions. 


\subsubsection{Speculation and Future Application}

School and outdoor education facilities such as this will continue to be plagued by the lack of funds. That is why spaces must be flexible and materials durable and lowmaintenance. There are opportunities to provide public/private partnerships as a solution for maintaining such facilities.

As stated in the scheduling of the site, weekends and evenings are opportunities for public/private groups to visit the facility and to generate the funding needed to continue to enhance and maintain it.

This project is to provide a prototype solution to address the social and environmental challenges that are affecting our children today.

This thesis raises concerns in the fields of education and architecture, and effectively merges them into solutions for the challenges our society is facing in the $20^{\text {th }}$ century.

Although the location of the subject of this thesis is a Toronto District School Board site and facility, its concepts may be applied to benefit school boards whose districts that are in and around urban cities, municipal, provincial, national parks and planning boards, outdoor education facilities, and teacher education faculties, just to name a few.

The ideas and designs in this thesis are very practicable and are achievable through careful logistic planning and some altering of current educational policies. The end result will be that they will lead to enhanced learning and also inspire children to build a culture of caring for nature and communities 


\subsubsection{Closing Statement}

The quality and diversity of education in the world today is greatly influenced by the philosophies, theories, ideas and approaches that John Dewey, Maria Montessori, and John Steiner advocated.

Children deserve a well designed architectural space that will help achieve a positive social learning experience, whatever their curriculum or the teaching methods used.

These three buildings and their unique conditions will support the current Forest Valley Outdoor Center, Toronto District School Board and the local residences for many years to come. 


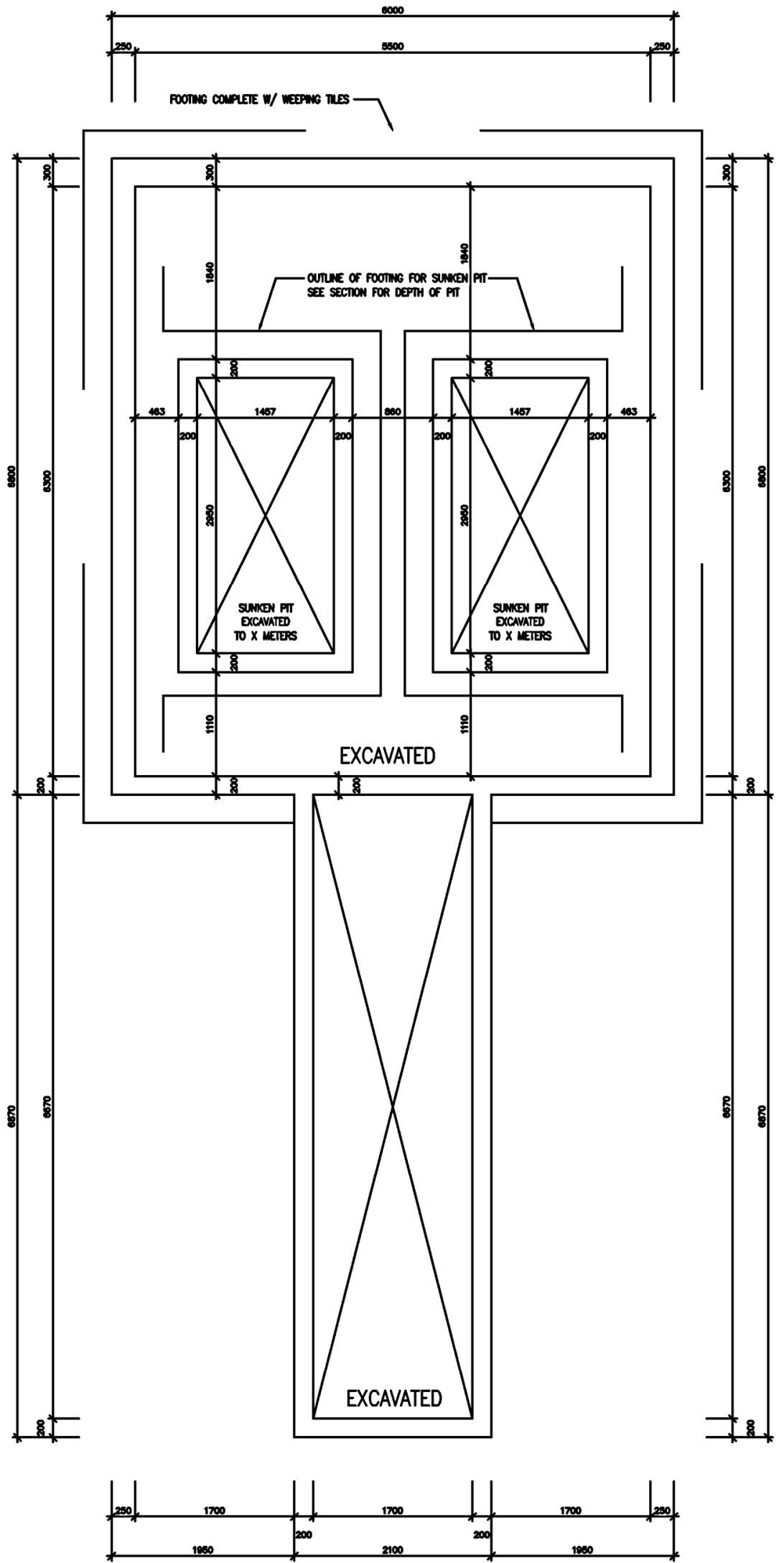



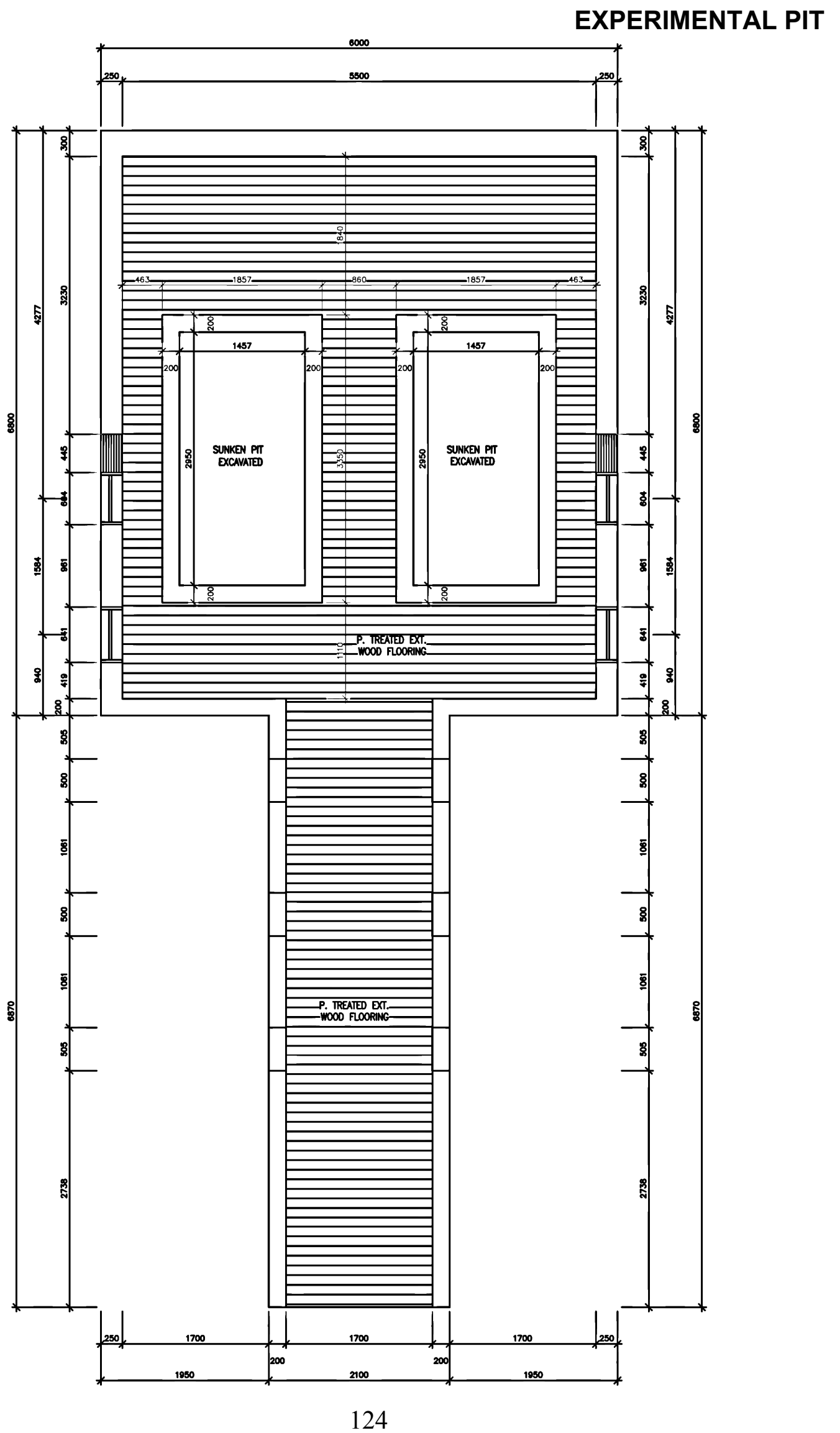
APPENDIX A

ROOF PLAN
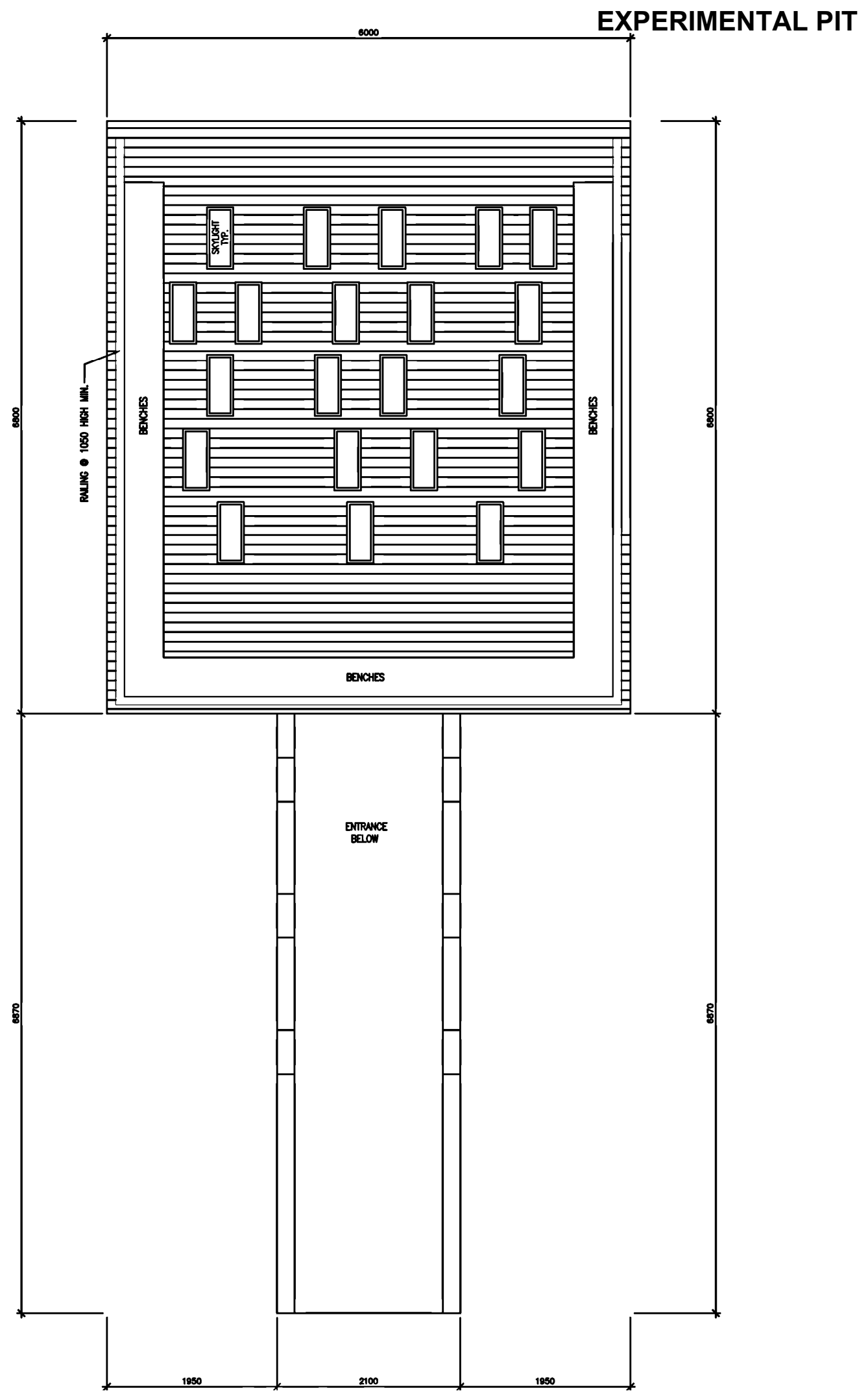


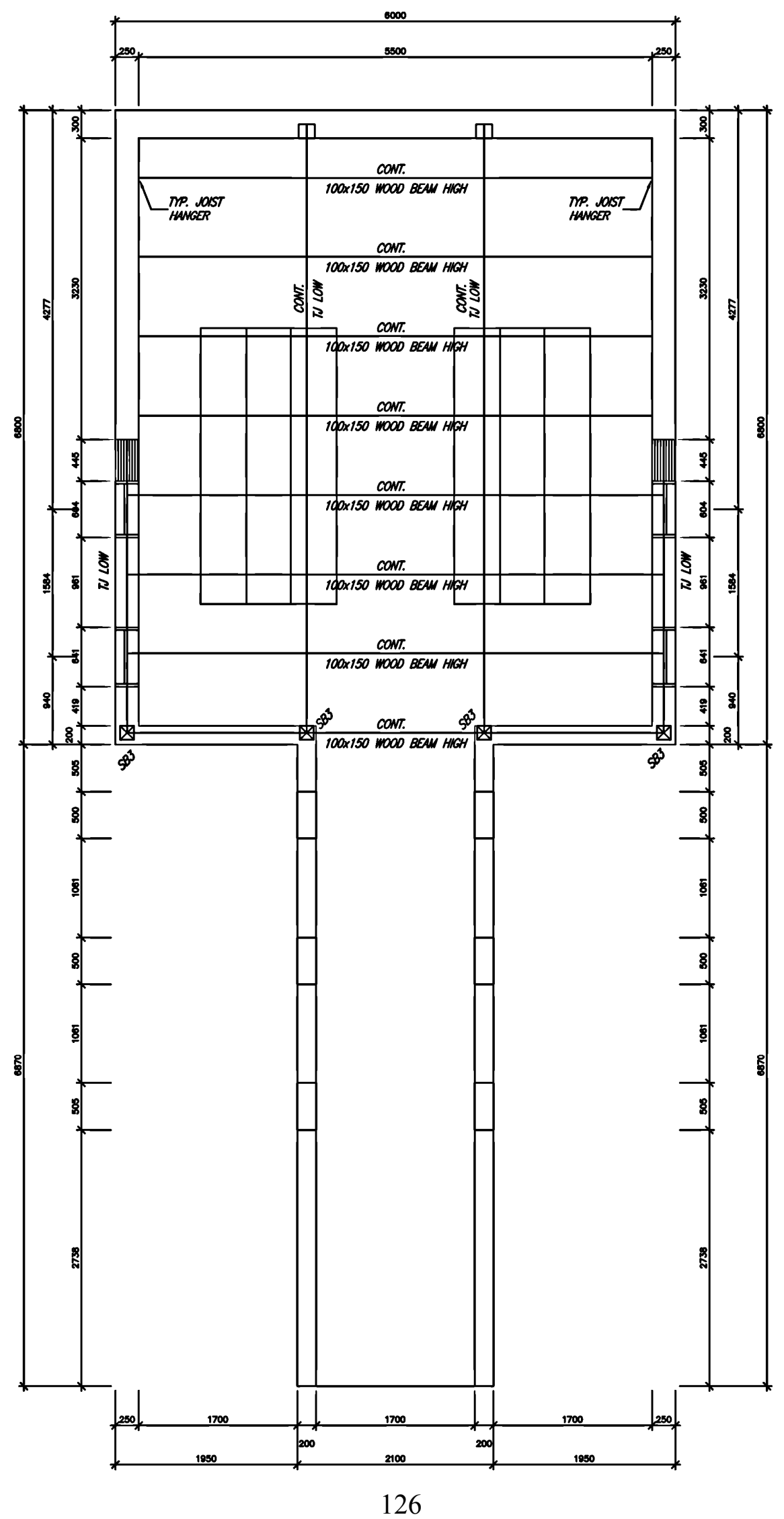




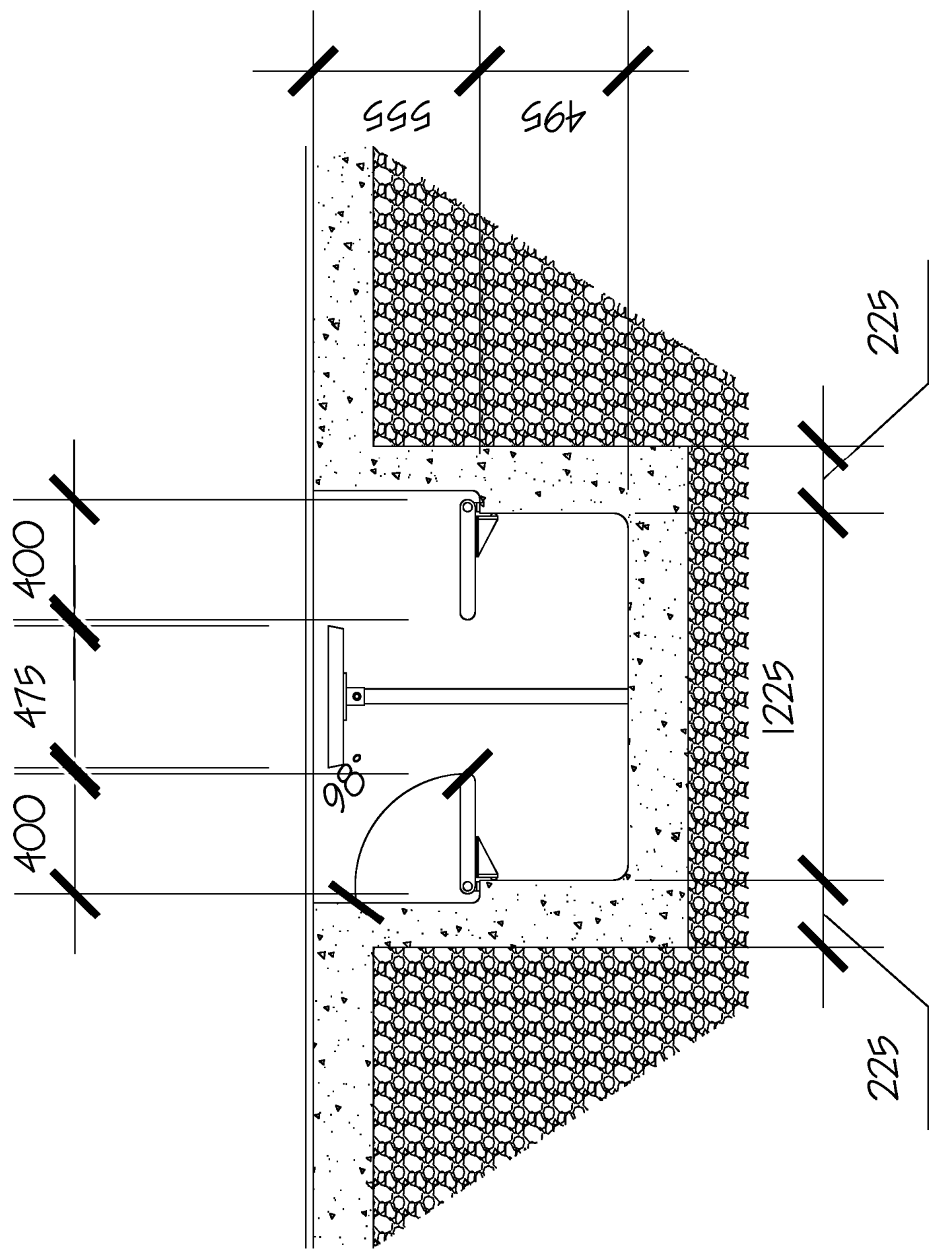

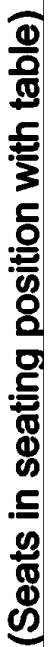



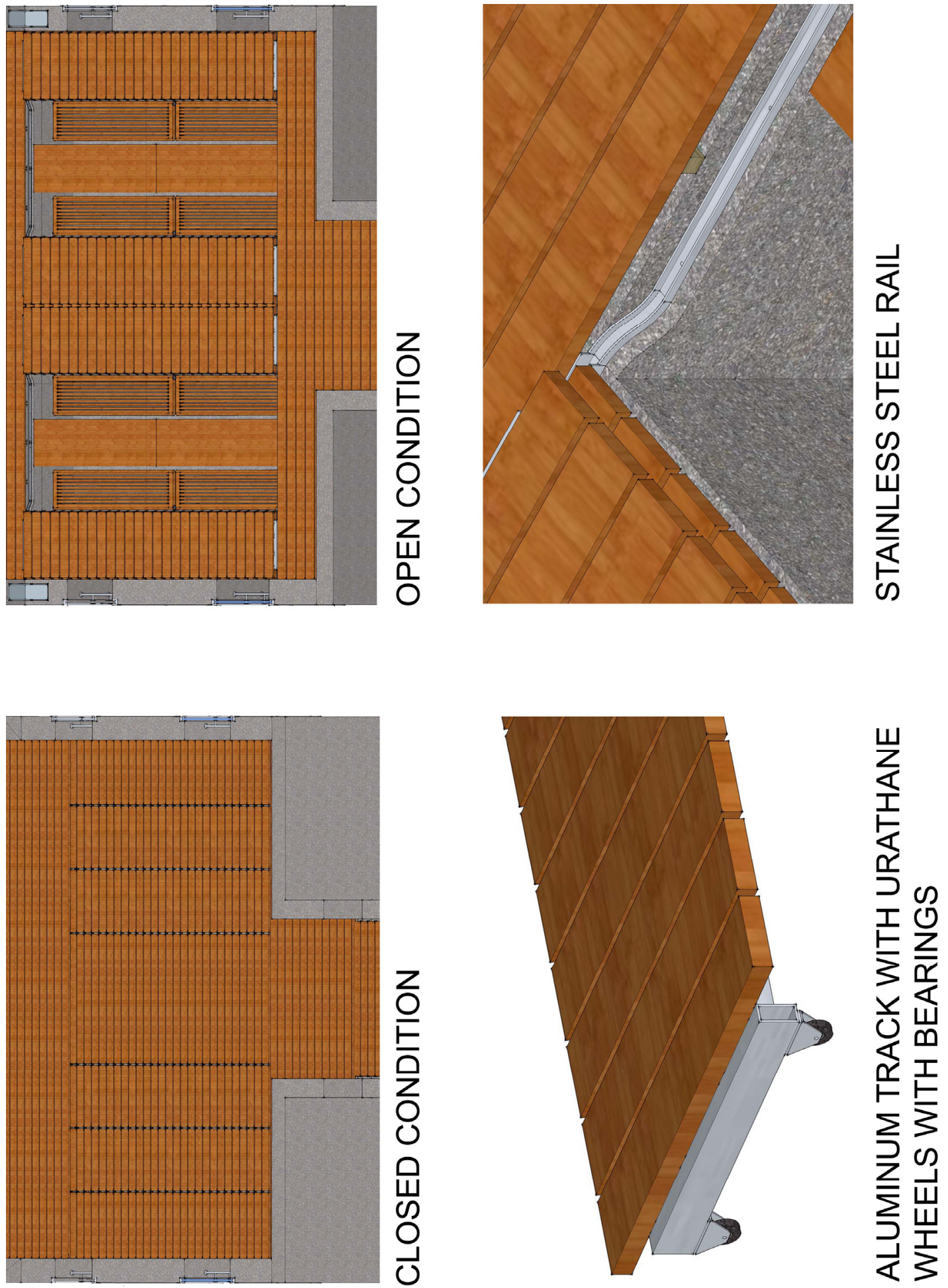

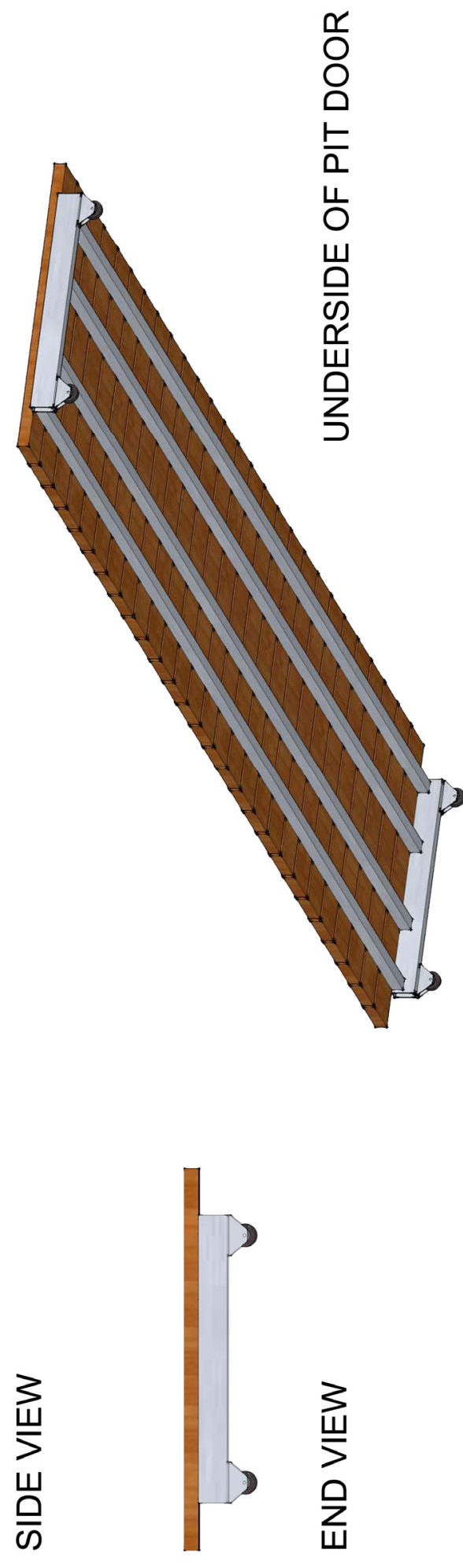


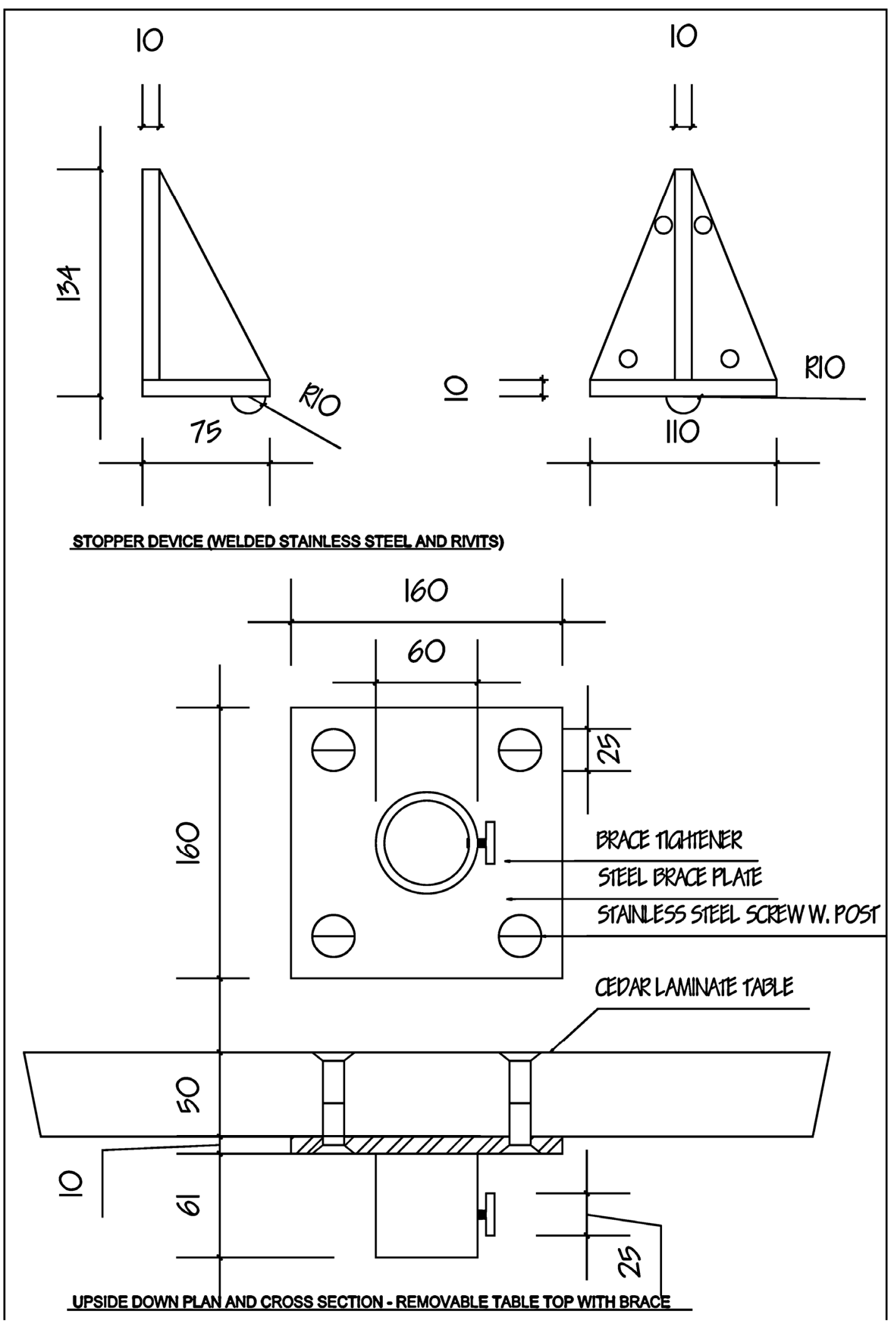



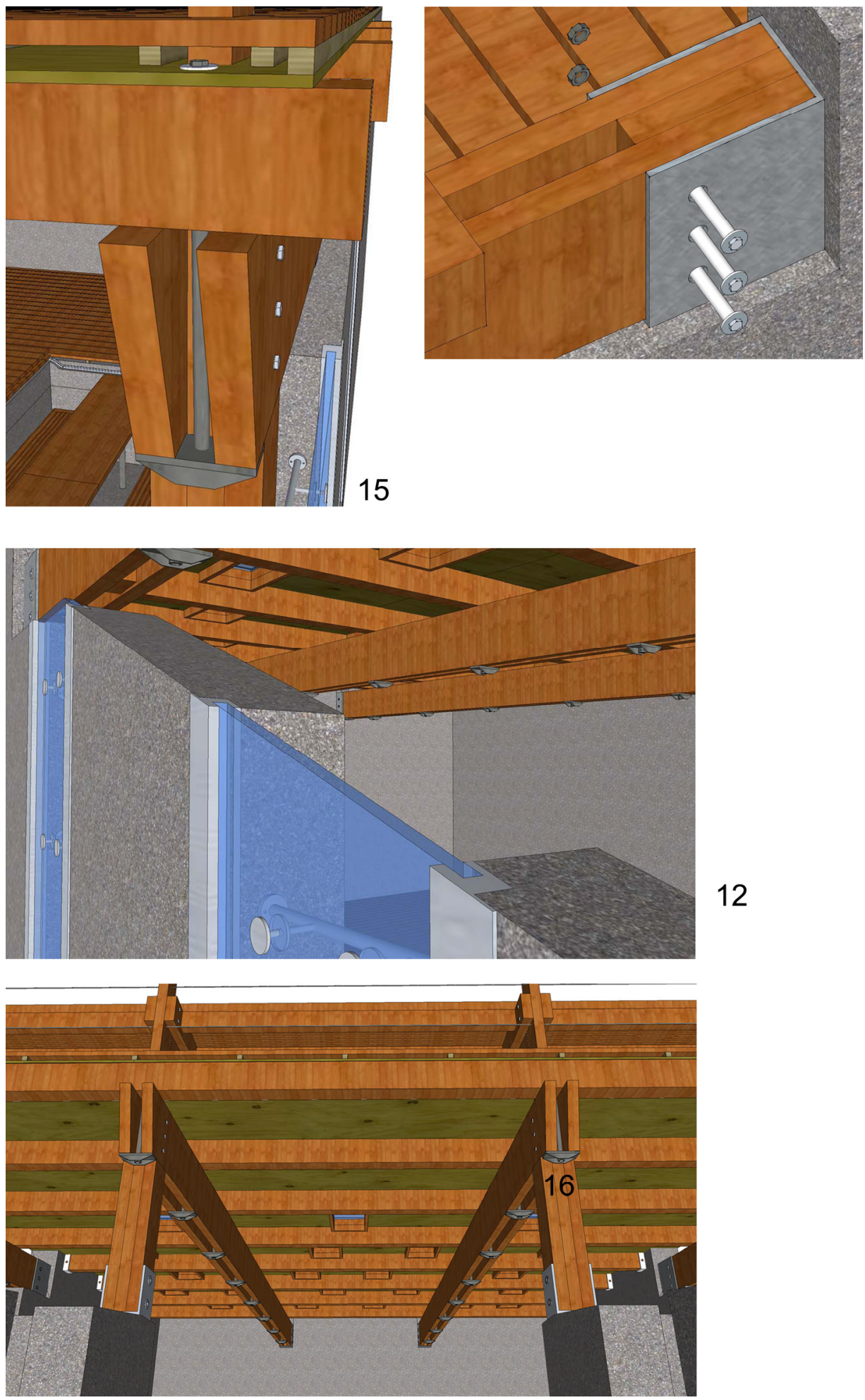


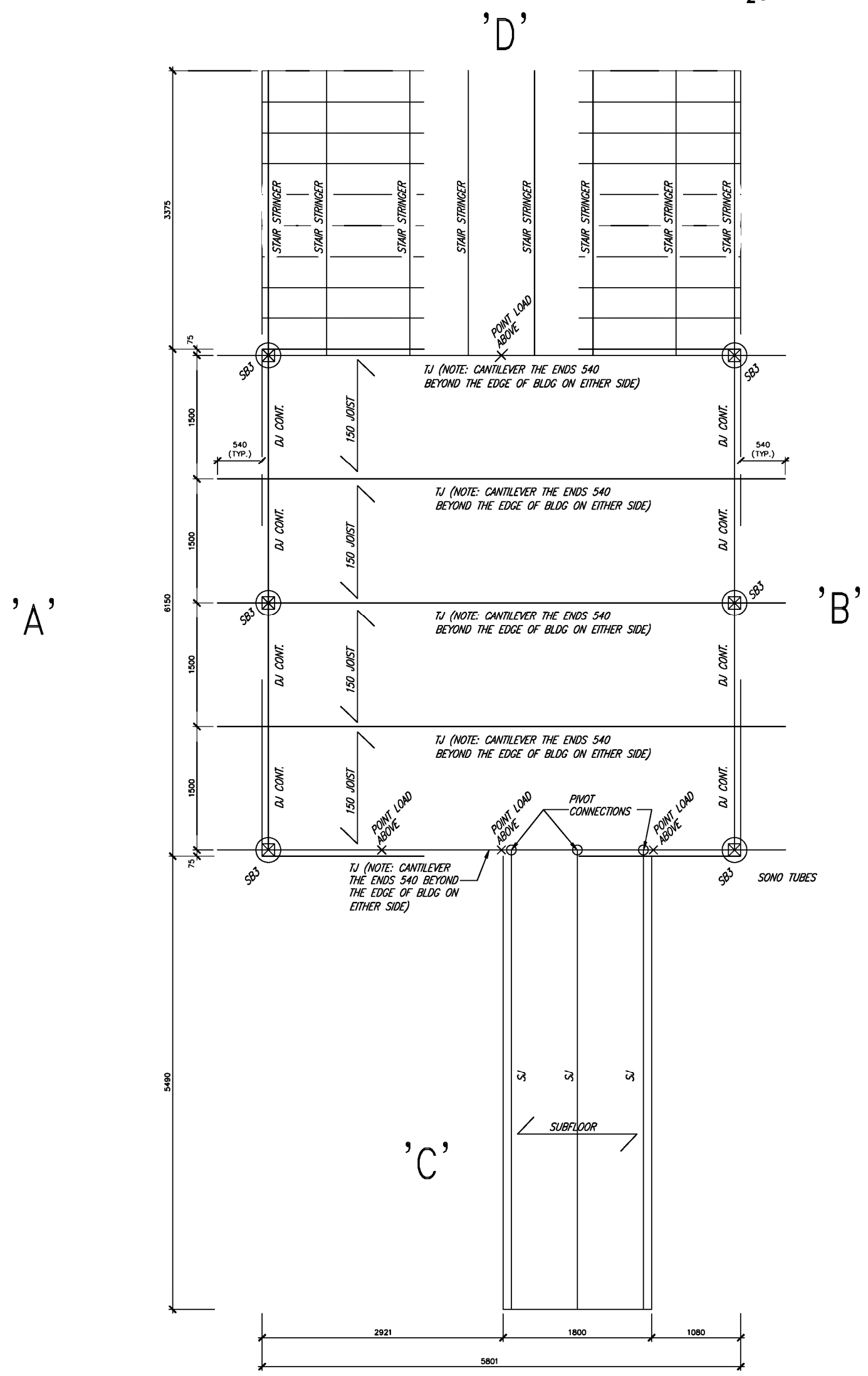



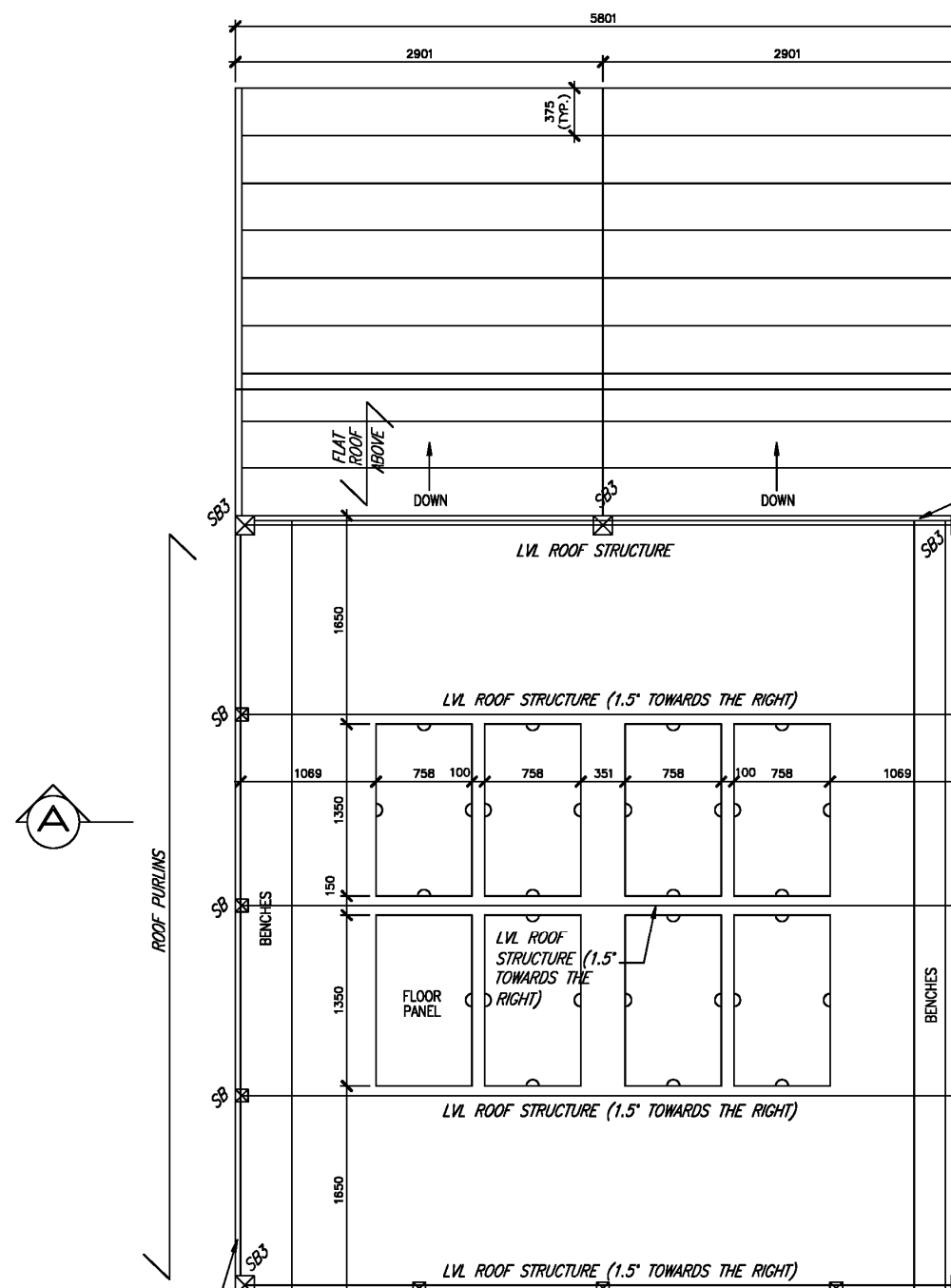
$\mathrm{H}_{2} \mathrm{O}$ PAVILLION EXTERIOR STRAPPING
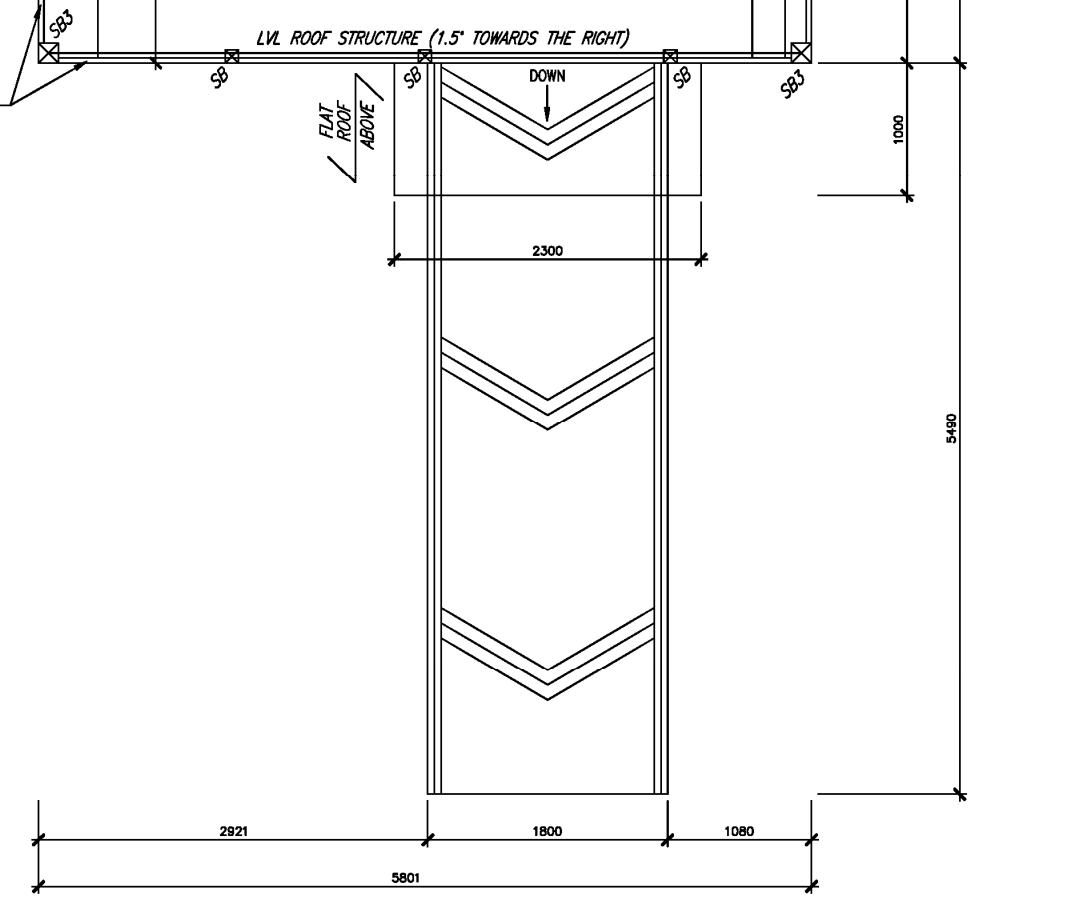

LU ROOF STRUCTURE (1.5 TOWAROS THE RIGHT)

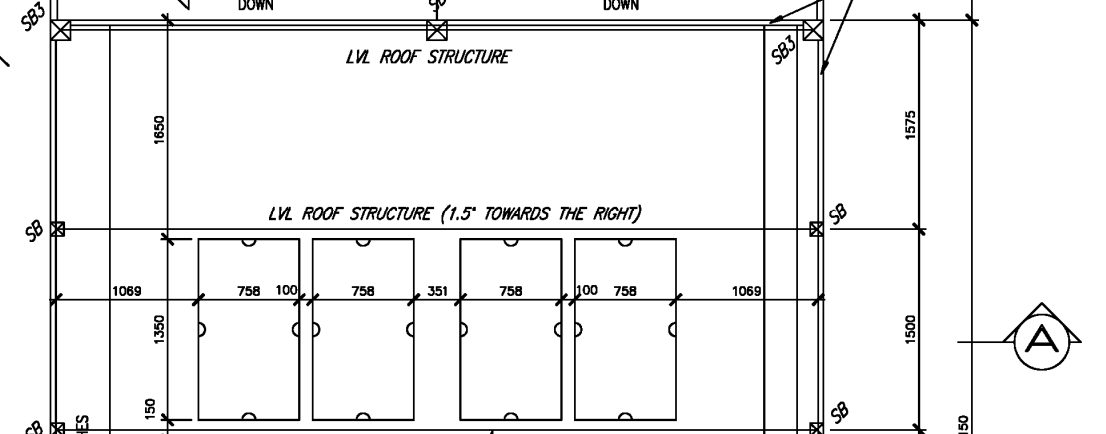

5
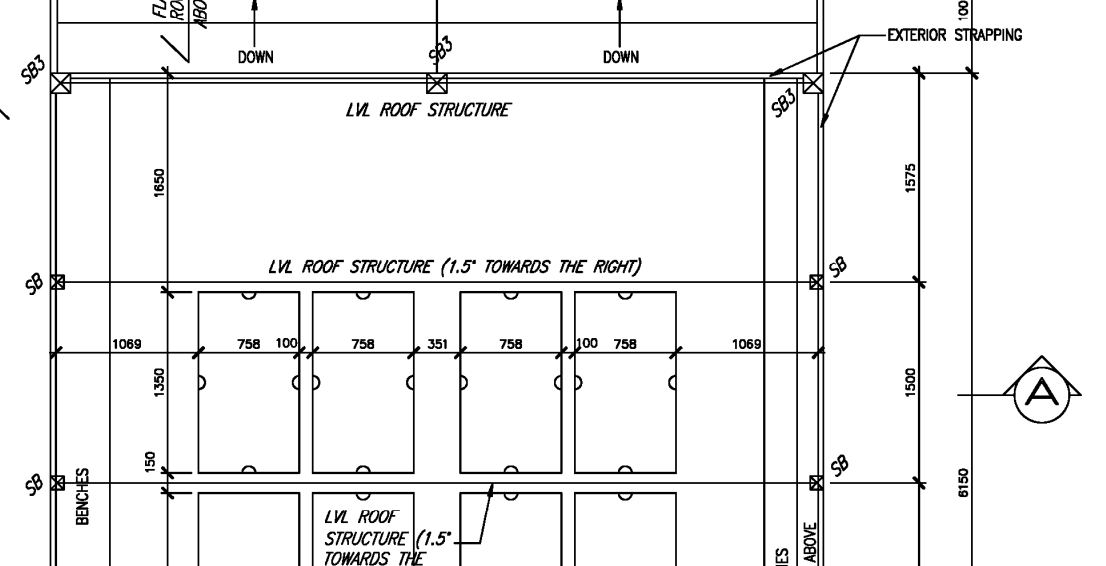

FLOOR
PANEL TOWARDS TTE TOWARDS 


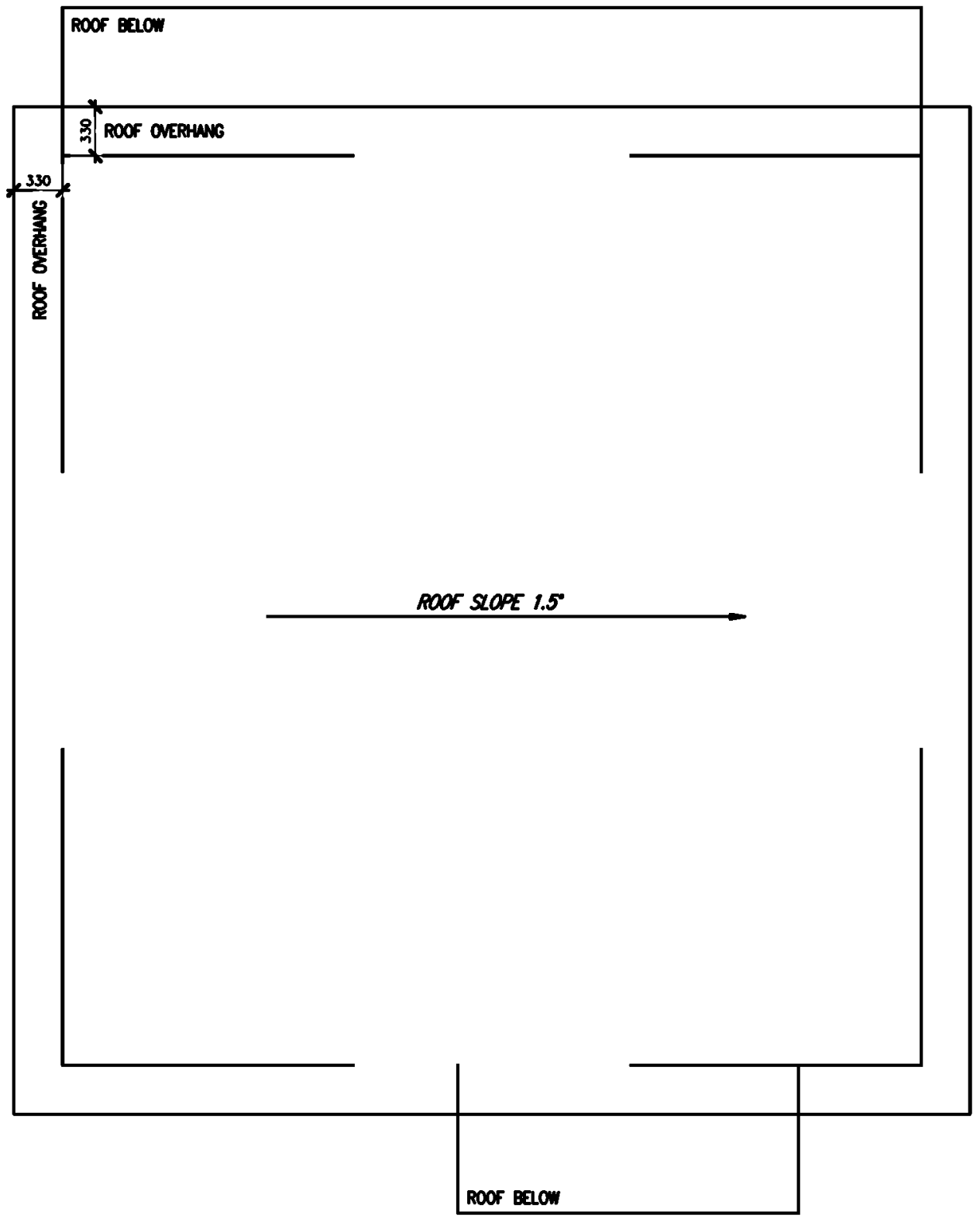




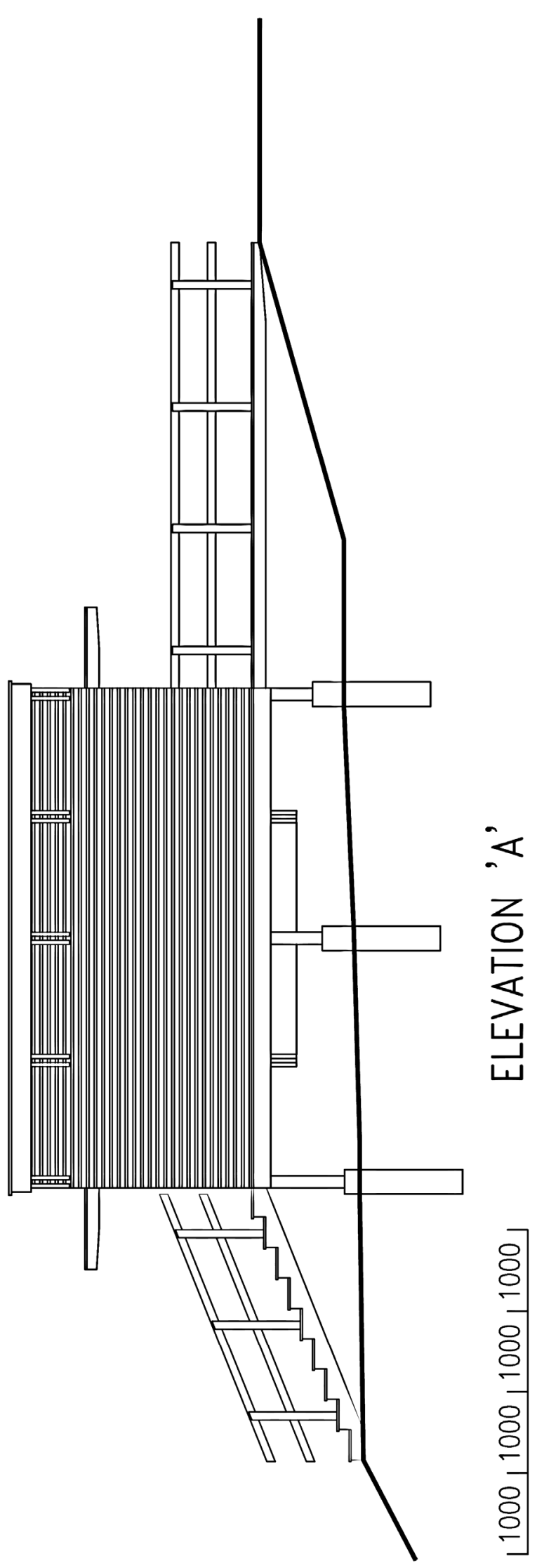

$\mathrm{H}_{2} \mathrm{O}$ PAVILLION 
APPENDIX E

ELEVATION B

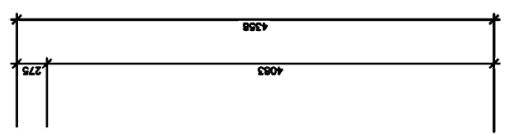

$\mathrm{H}_{2} \mathrm{O}$ PAVILLION

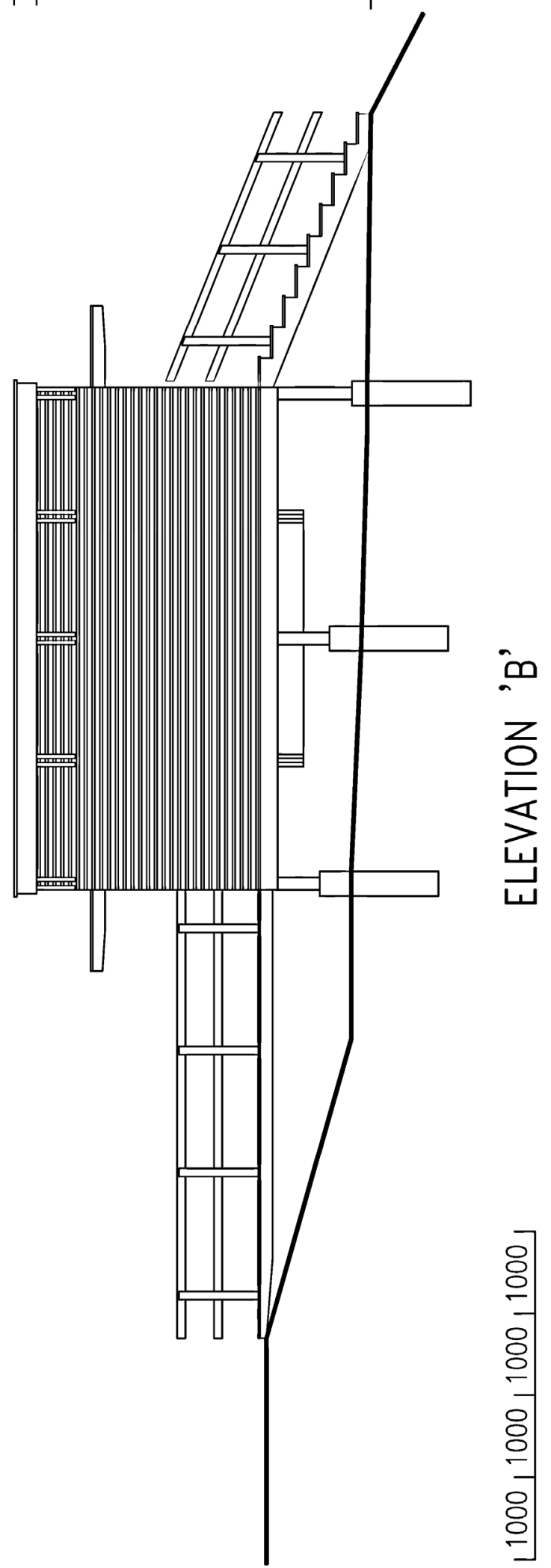



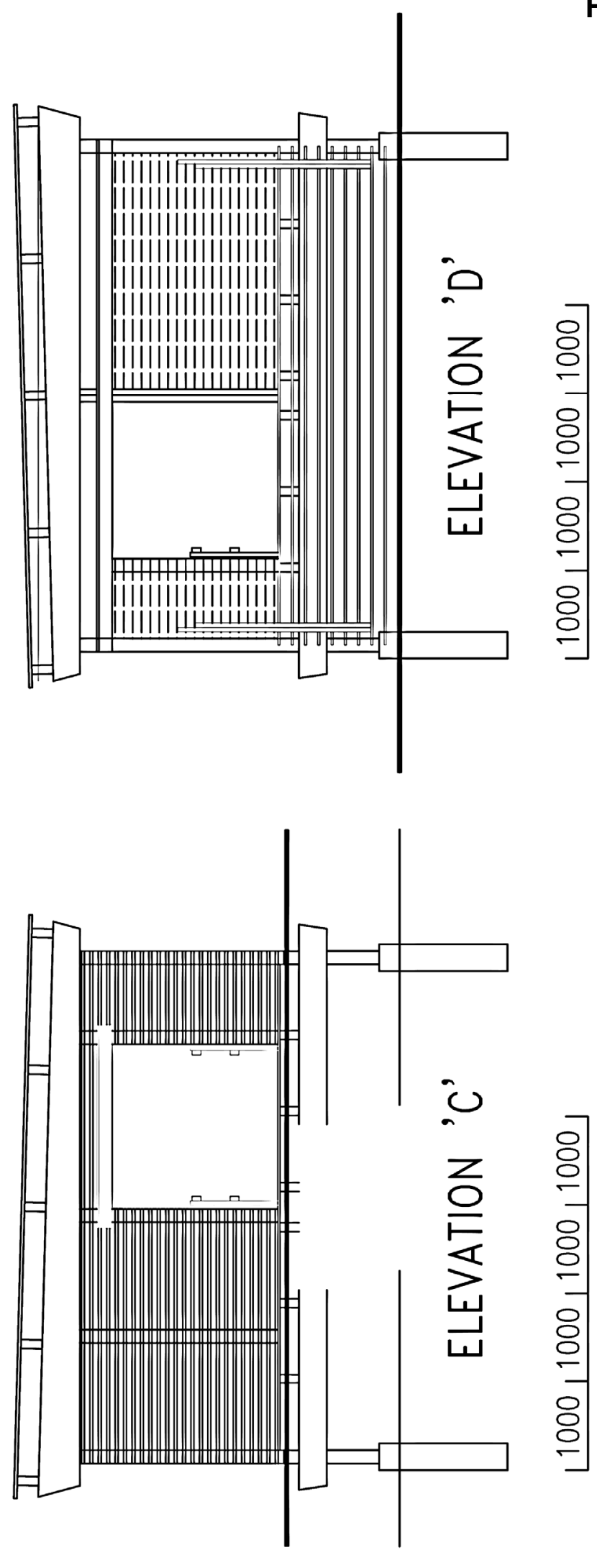


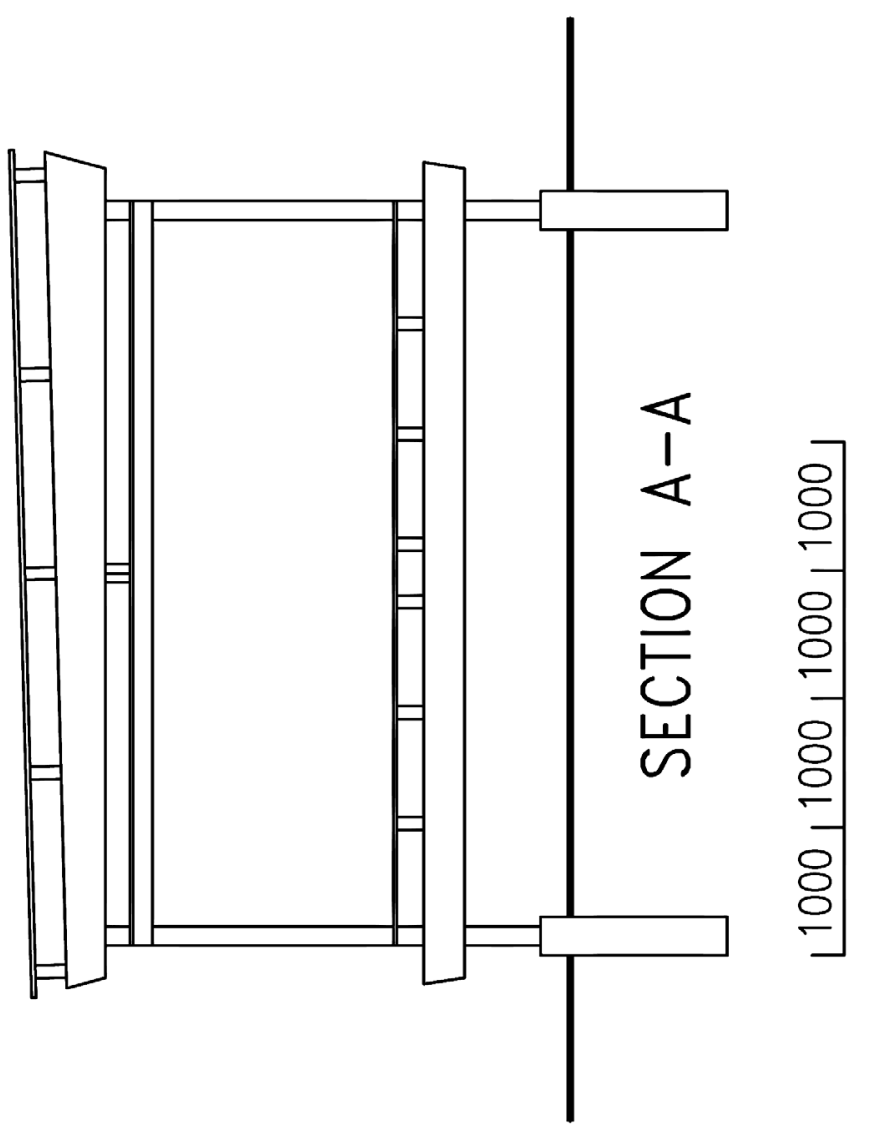




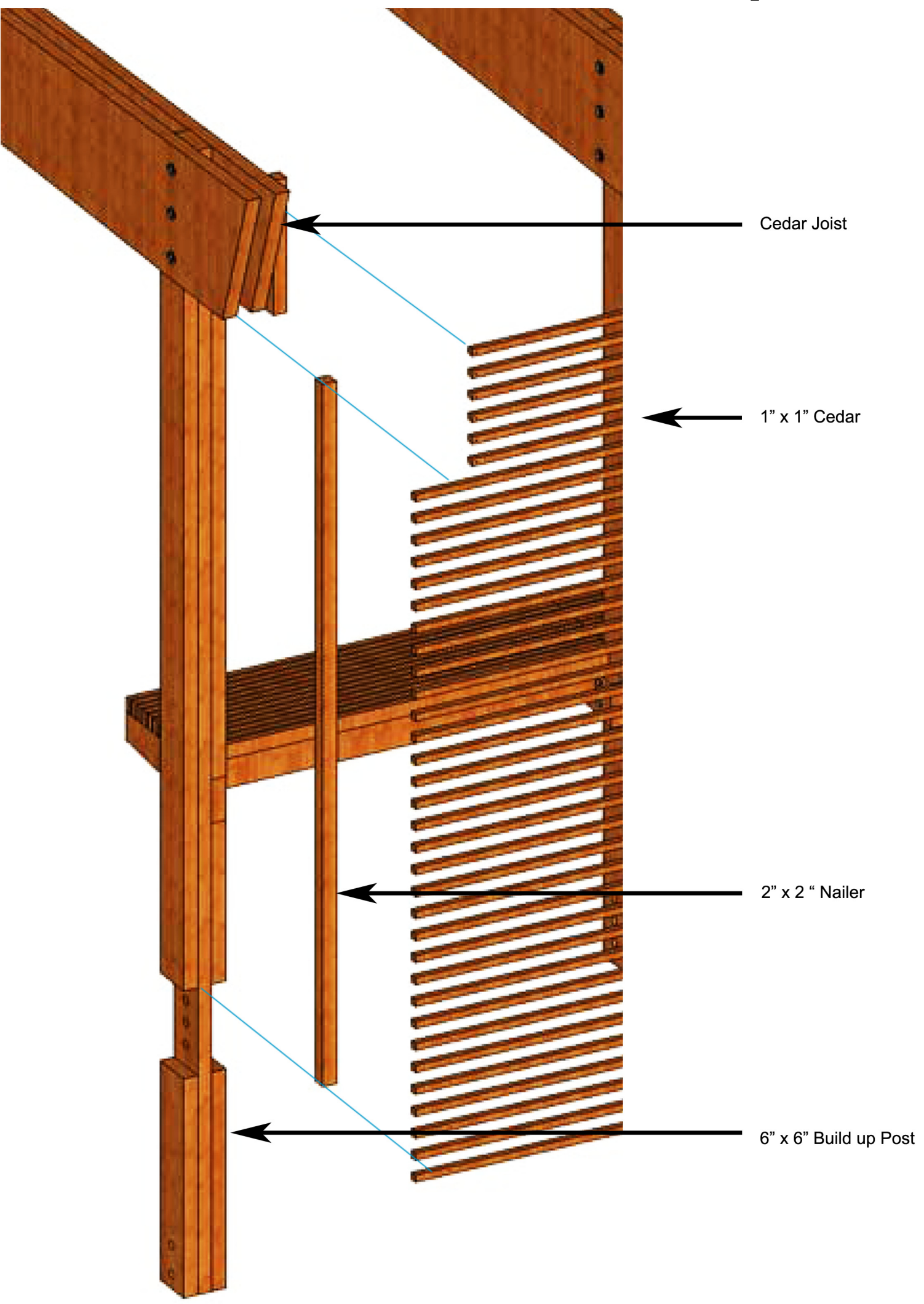


APPENDIX G

SELECTED DETAILS

$\mathrm{H}_{2} \mathrm{O}$ PAVILLION

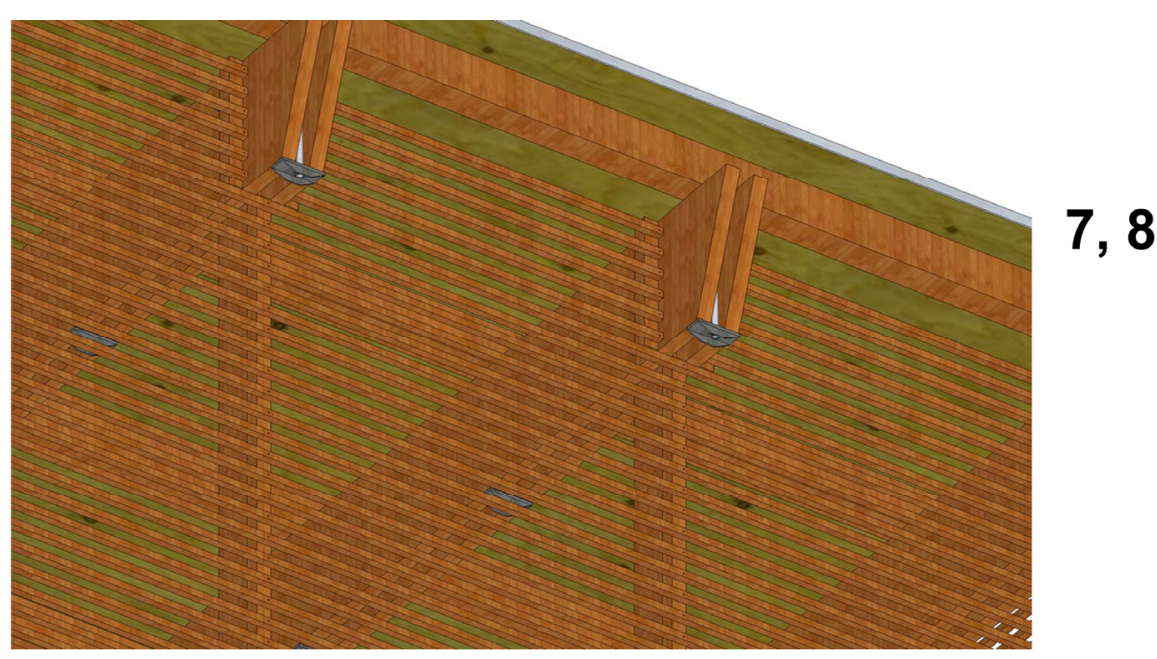

12

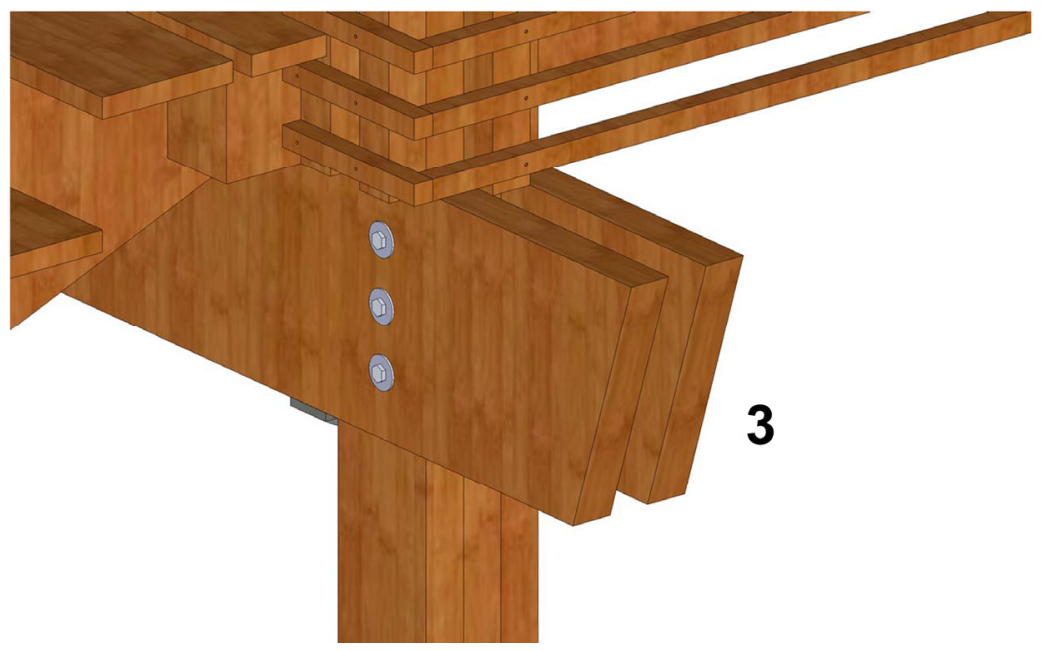




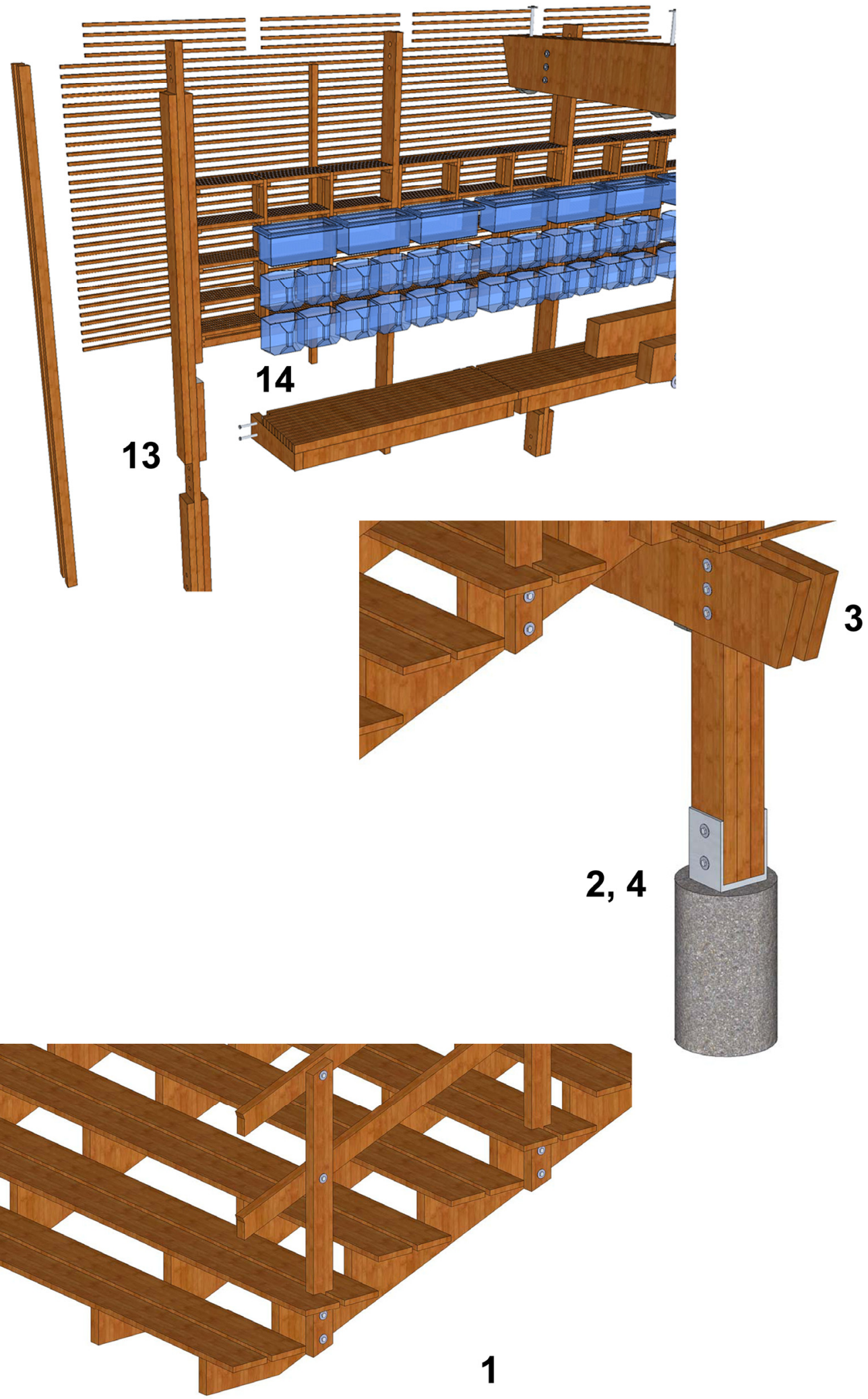




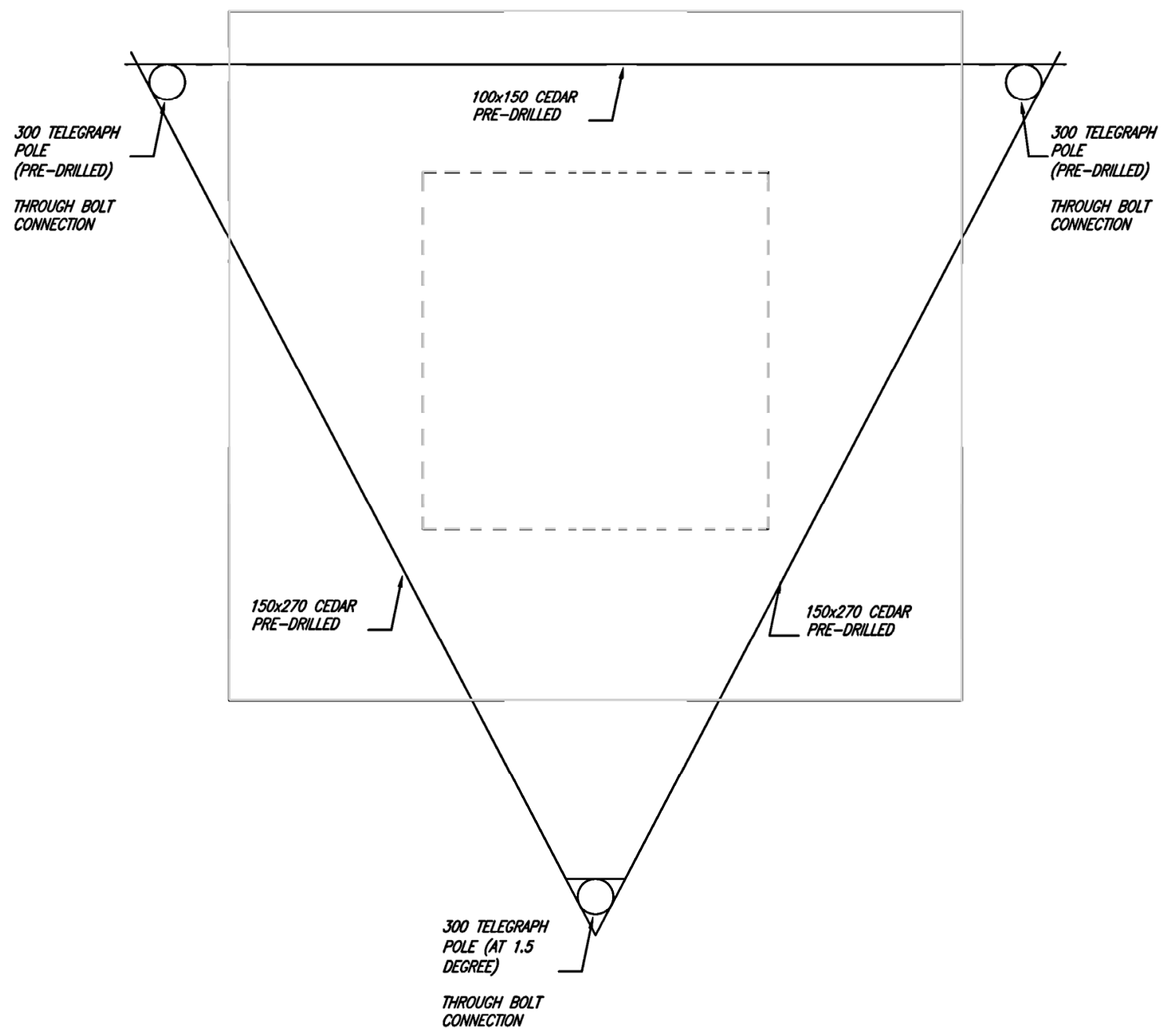




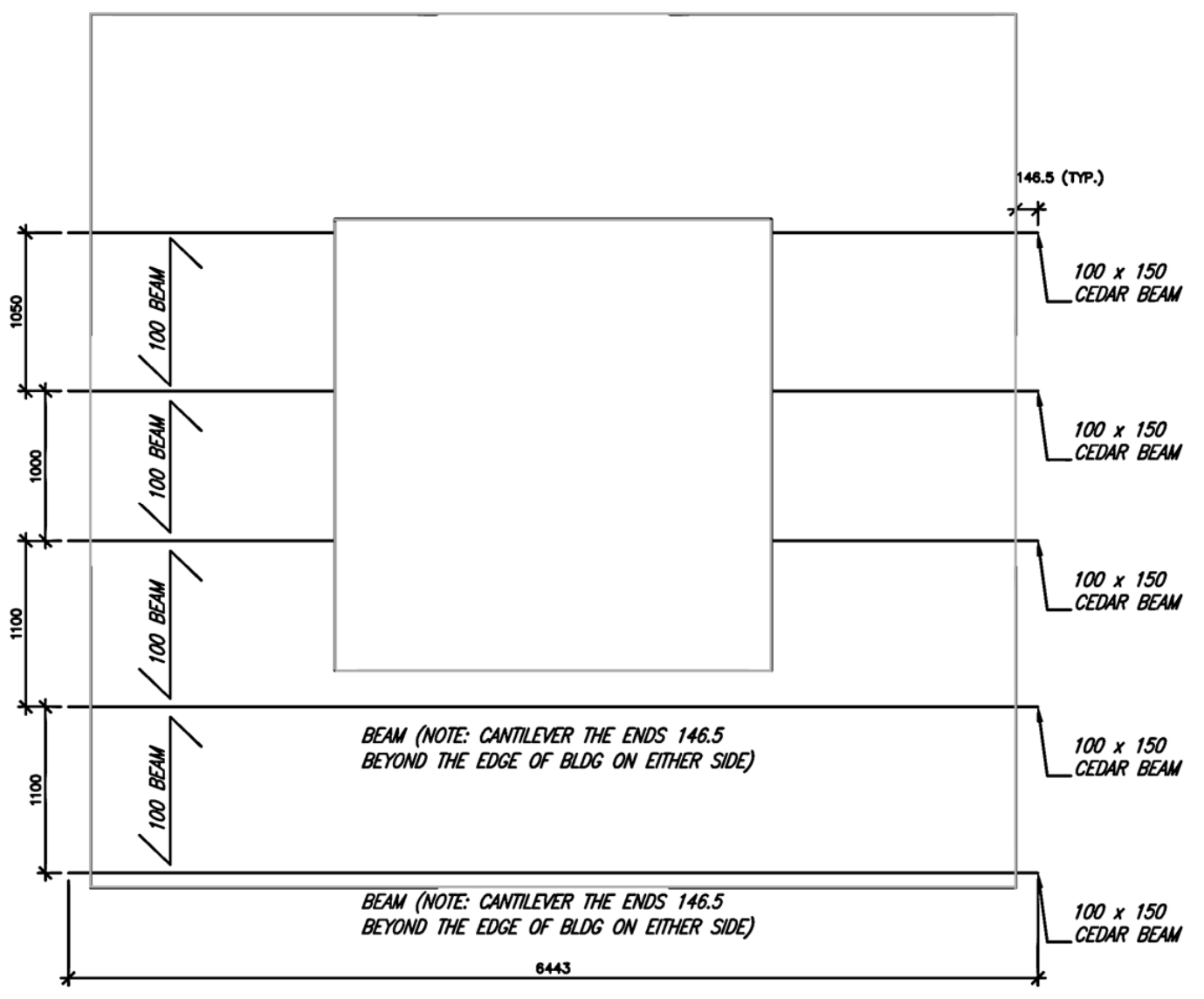




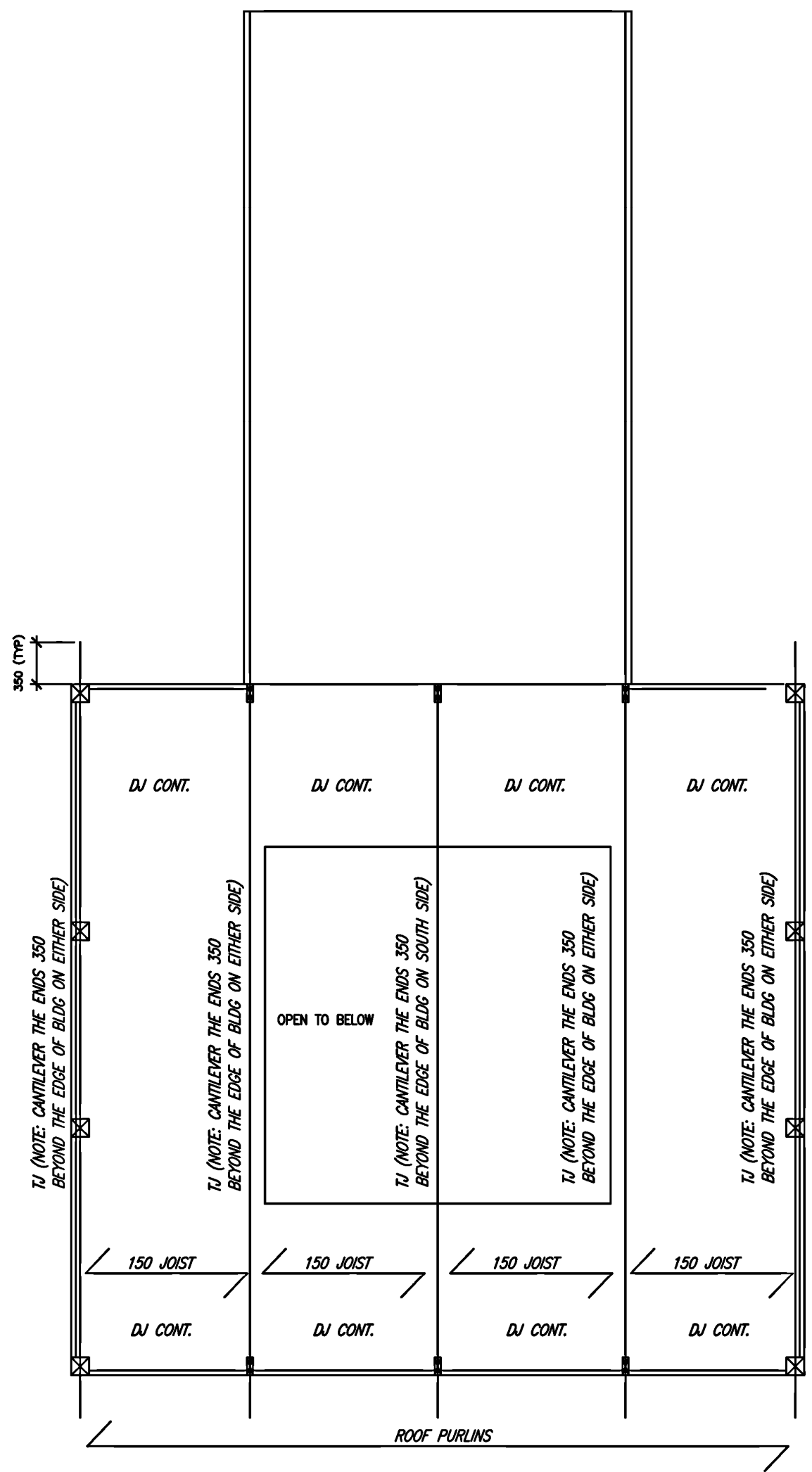




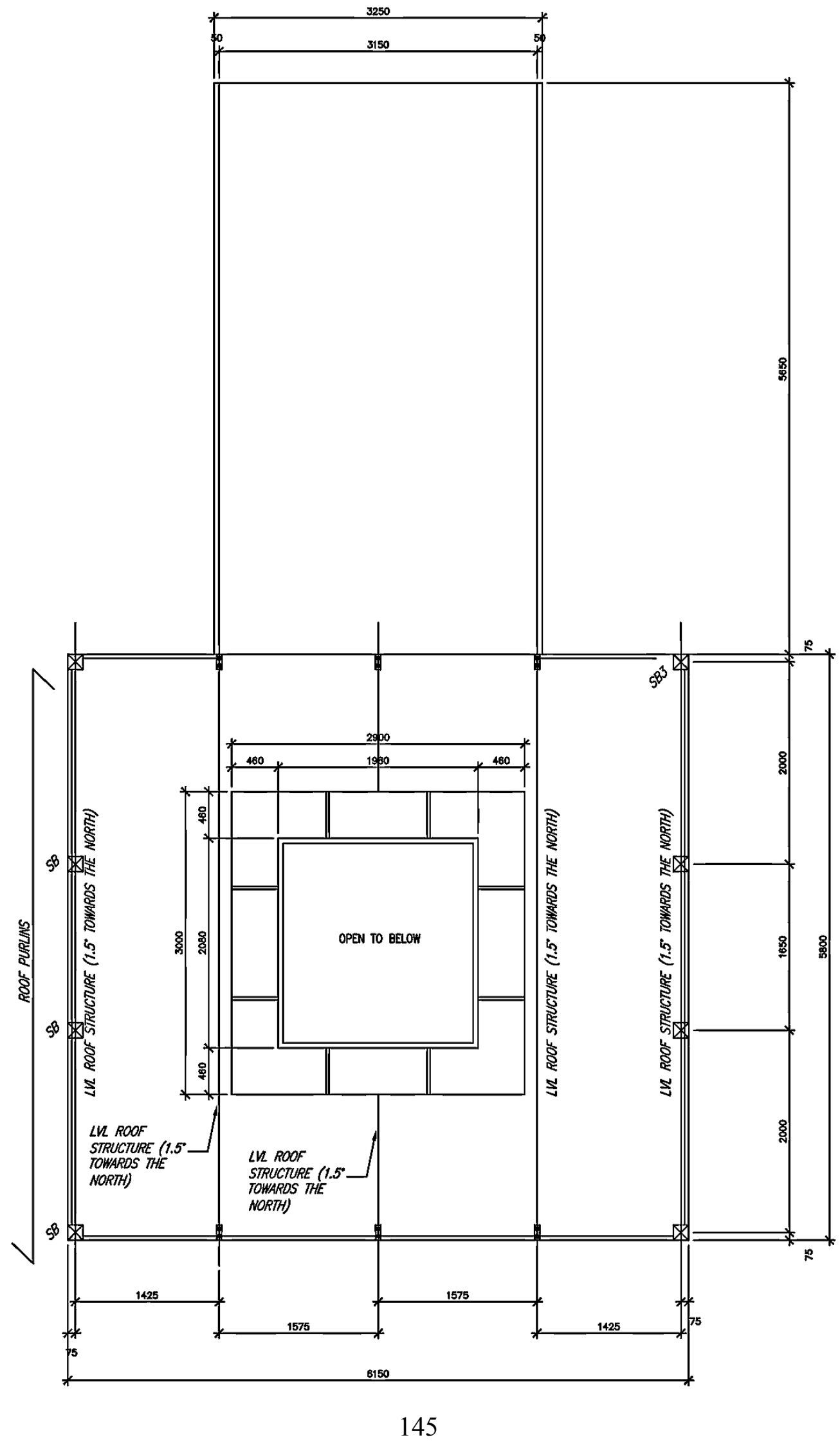




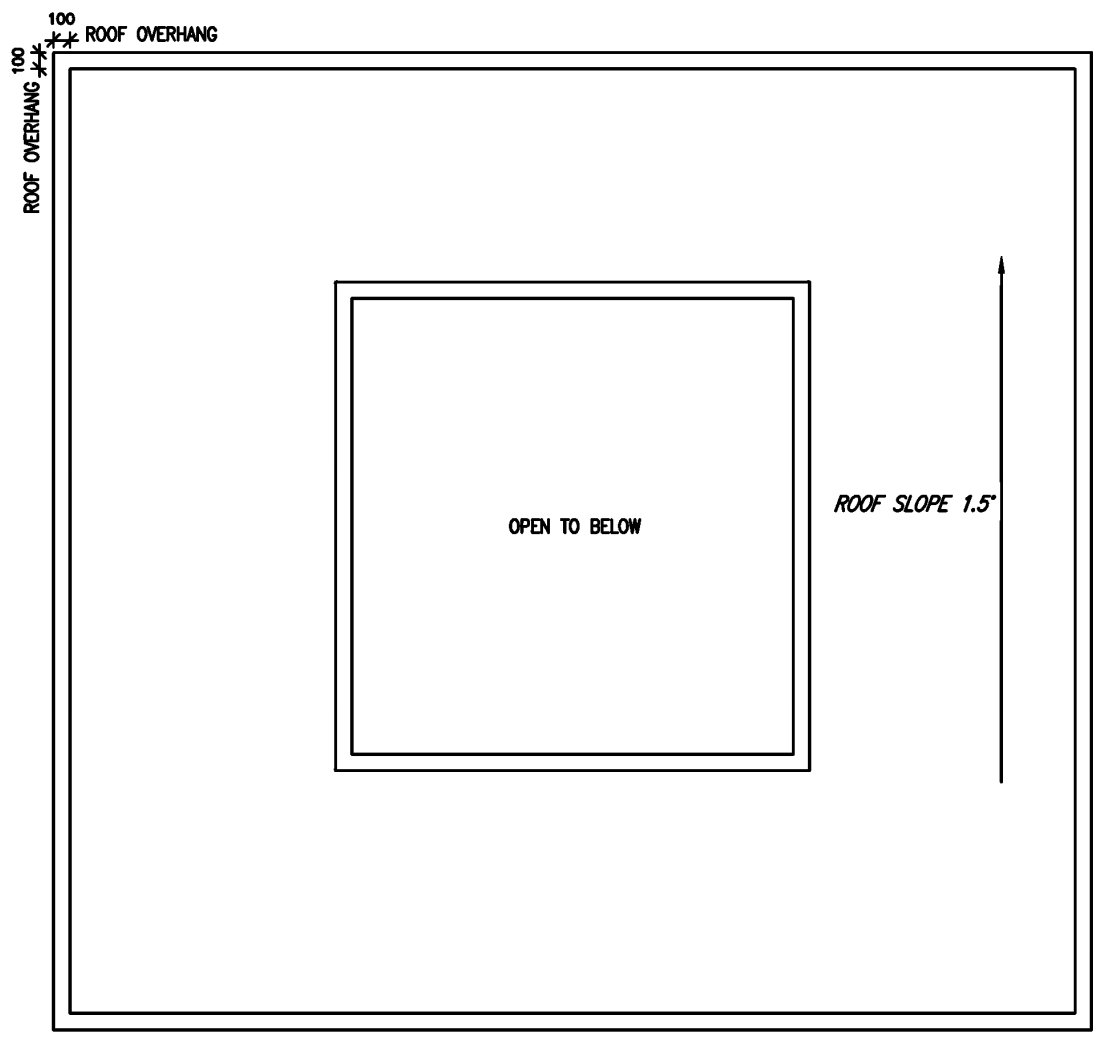

ROOF BelOW 

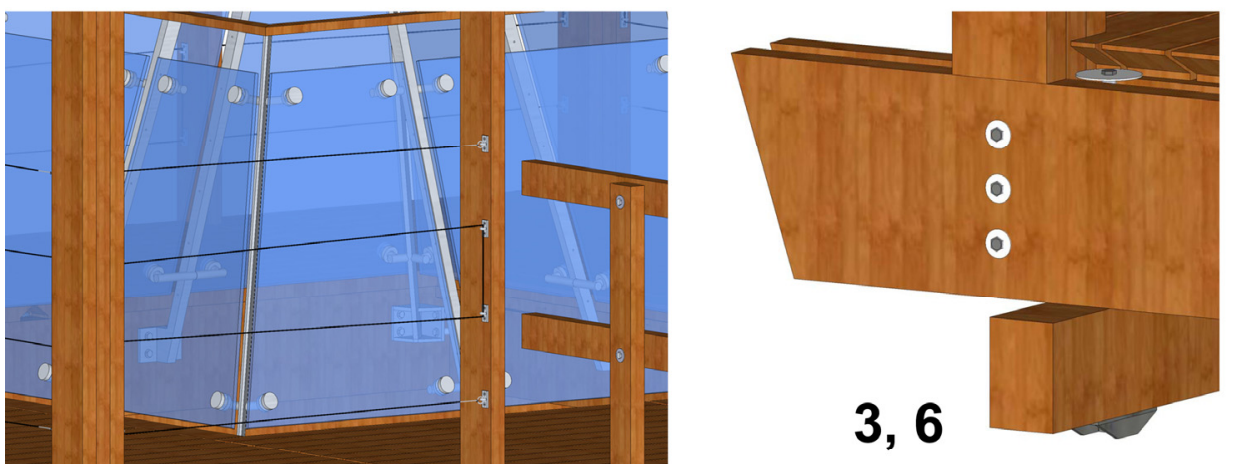

18,19
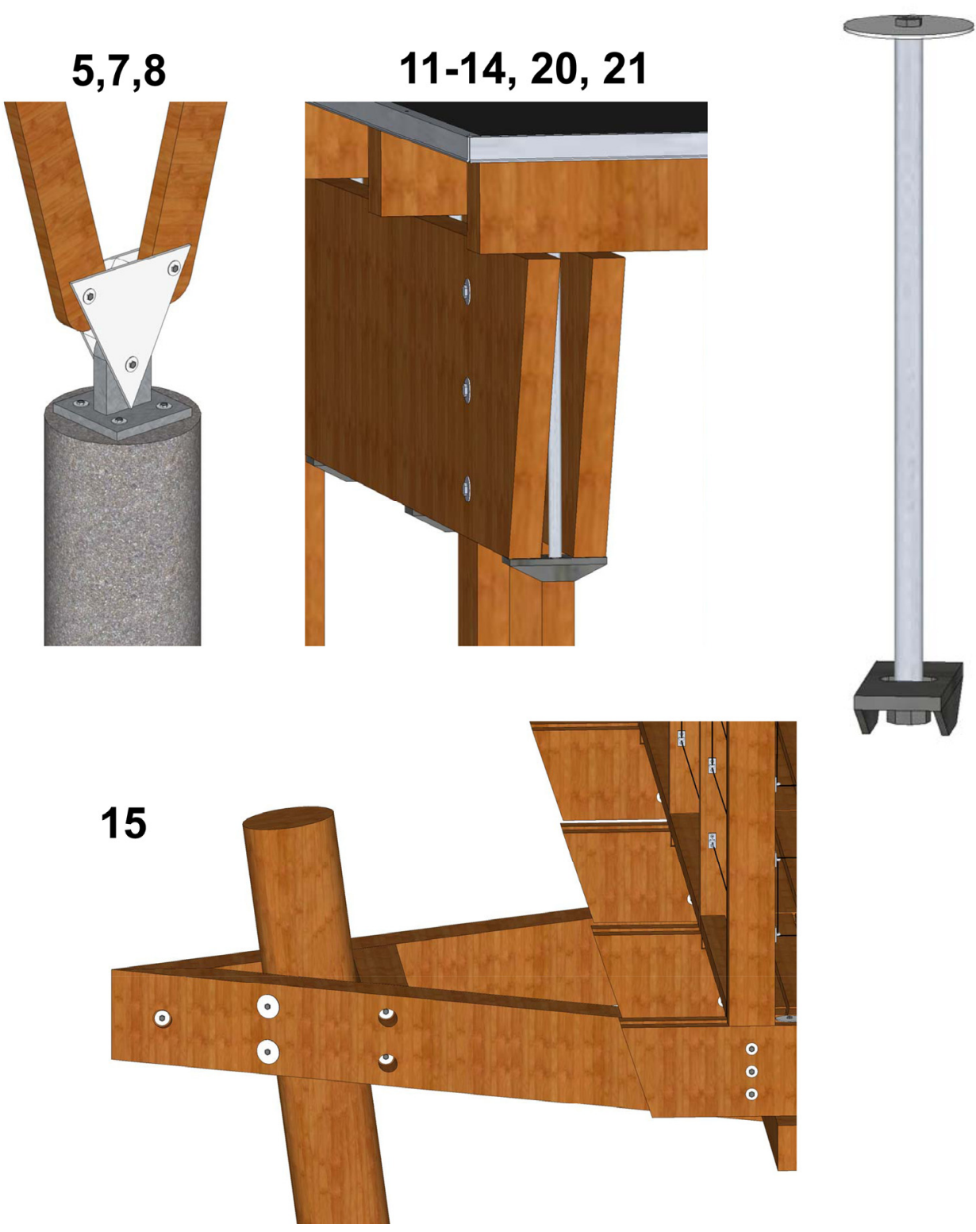


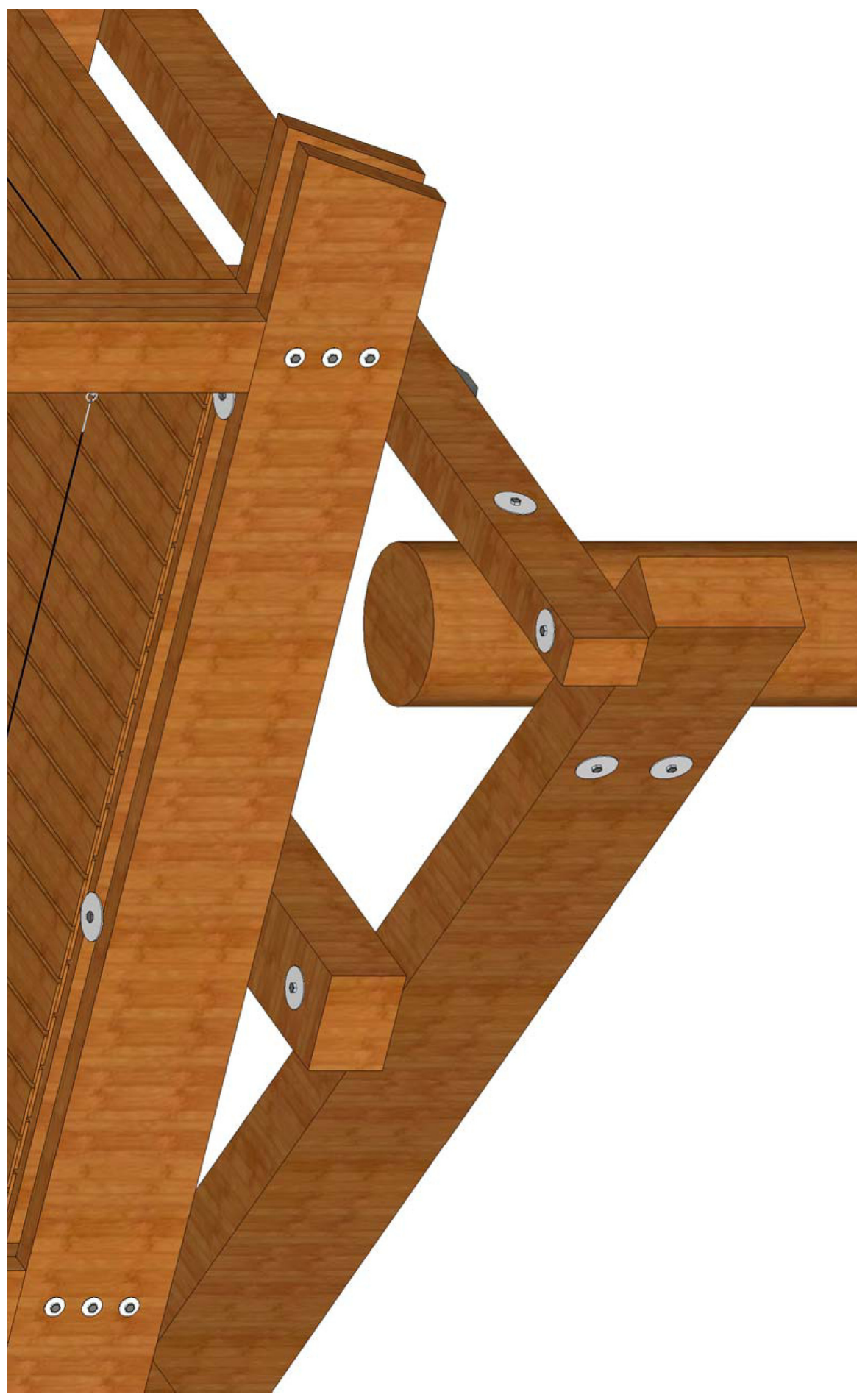




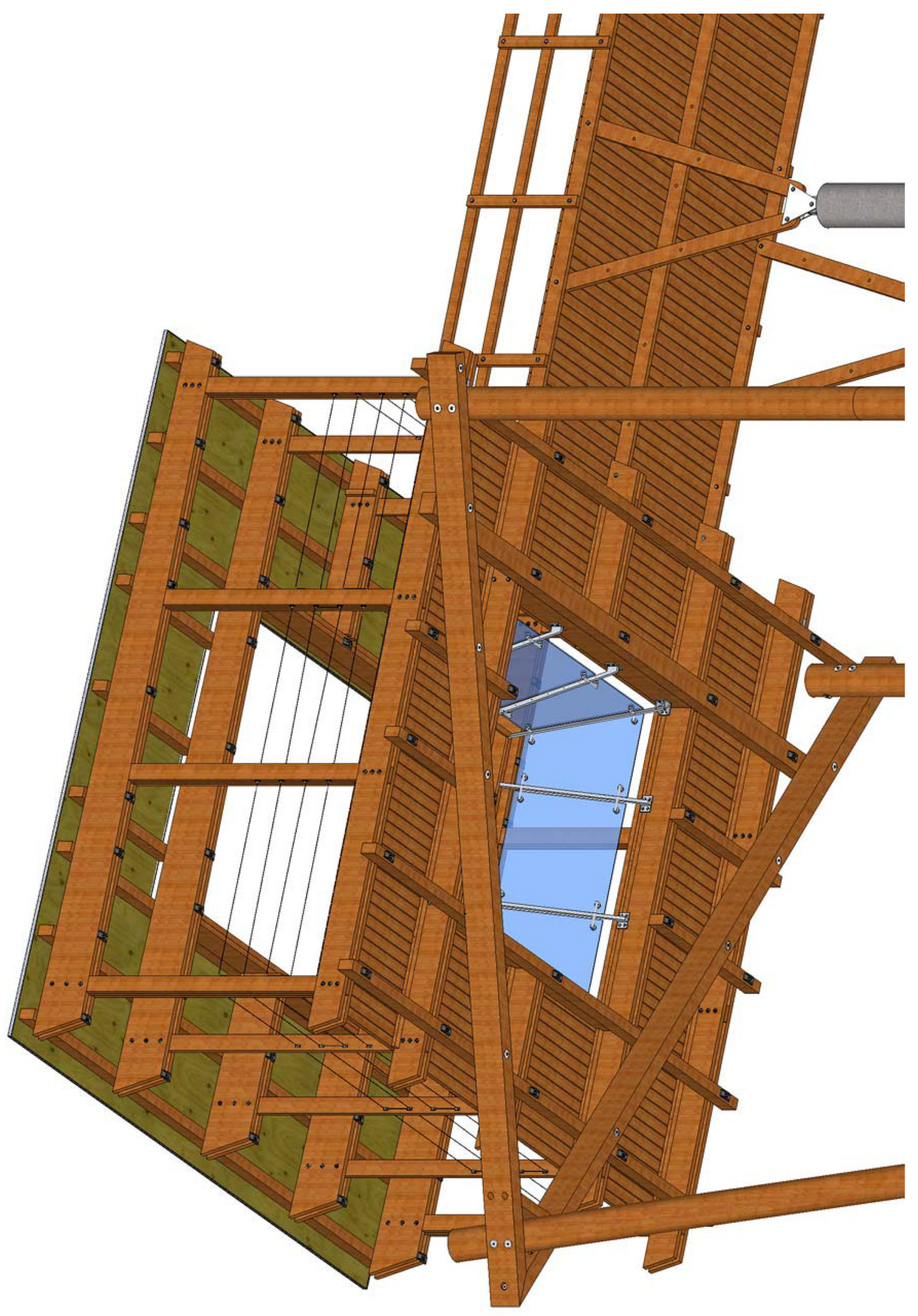




\section{REFERENCE LIST}

Bateson, Gregory. (2000) Steps to an Ecology of Mind. Chicago: Chicago University Press.

Carson, Rachel (1965) The Sense of Wonder. NY: Harper \& Row Publishers.

Casey, E.S. (1976) Imagining: A Phenomenological Study. Bloomington, IN: Indiana University Press.

Lewis. C.S (1960) The Four Loves. New York. Harcourt, Brace

C. M. (1999) Reasserting the Philosophy of Experiential Education as a Vehicle for Change in the 21st Century. The Journal of Experiential Education.

(2004) Committee on Environmental Health Ambient Air Pollution: Health Hazards to Children. PEDIATRICS Vol. 114 No. 6

Day, Christopher. (2007). Environment and Children. Architectural Press

Daniels, Christopher and Orgeig (2003). "Pulmonary Surfactant: The Key to the Evolution of Air Breathing". News in Physiological Sciences 18 (4): 151-157.

Delfino RJ. (2002) Epidemiologic evidence for asthma and exposure to air toxics: linkages between occupational, indoor, and community air pollution research. Environ Health Perspect.

Dewey. John (1956) Child and the curriculum: and the school and society. Chicago: University of Chicago Press

Dewey, John (1963) Experience and education. New York, N.Y. Collier Books.

Elwood, J. and J. Jopson (1997) Melanoma and sun exposure: an overview of published studies. Int J Cancer: p. 198-203

Faculty of Architecture and Planning (2003) Wood Awards 2003, TUNS Press and 
Janam Publications.

Feychting M, Svensson D, Ahlbom A. (1998) Exposure to motor vehicle exhaust and childhood cancer. Scand J Work Environ Health.

Fomenko (2008) Green play settings as treatments for ADHD. McMaster University, Hamilton, ON.

Fromm, Erich (1964). The Heart of Man. Harper \& Row.

Frost, J (2006). The Dissolution of Children's outdoor play: Causes and Consequences

Frost. J, Wortham. C, Reifel. S (2008) Play and child development Edition 3rd ed. Harlow: Prentice Hall.

Gilchrest, B., et al., (1999) The pathogenesis of melanoma induced by ultraviolet radiation. $\mathrm{N}$ Engl J Med.

Hartman, S (2003) Antibacterial and Disinfectants: Are They Necessary?

Heart and Stroke Foundation. Healthy Living.

http://www.heartandstroke.com/site/apps/nlnet/content2.aspx?c=ikIQLcMWJtE\&b=40168 59\&ct=7515613 Retrived Oct 20, 2009.

Hemleben, Johannes (1975) Rudolf Steiner: A documentary biography, Henry Goulden Ltd, , pp. 121-126

Itin, C. M. (1999). Reasserting the Philosophy of Experiential Education as a Vehicle for Change in the 21st Century. The Journal of Experiential Education.

Johannes Hemleben, Rudolf Steiner: A documentary biography, Henry Goulden Ltd. Kaplan, S. (1995). The restorative effects of nature: Towards an integrative framework. Journal of Environmental Psychology, 15, 169-182.

Kellert, Stephen R. (ed.) (1993). The Biophilia Hypothesis. Island Press. 
Kahn, Peter; Kellert, Stephen (2002). Children and nature: psychological, sociocultural, and evolutionary investigations. MIT Press.

Koralek, D.G., Newman, R.L, \& Colker, L.J (1995) Caring for Children in School-Age Programs: A competency-Based Training Program, Volume $1 \& 2$, Teaching Strategies, Washington

Kuo, F.E., \& Faber Taylor, A. (2001). Coping with ADD: The surprising connection to green play settings. Environment and Behavior, 33, 54-77.

Kuo, F. E., Taylor, A. F. \& Sullivan, W. C. (2002). Views of Nature and Self-Discipline: Evidence from Inner City Children. Journal of Environmental Psychology, 22, 49-63.

Kuo, F. E. \& Faber Taylor, A. (2005). Kuo and Faber Taylor Respond. American Journal of Public Health. 95: 371-372.

Kuo, F. E., \& Taylor, A. F. (2004). A potential natural treatment for attentiondeficit/hyperactivity disorder: Evidence from a national study. American Journal of Public Health, 94, 1580-1586.

Kuo and Taylor (2008) Children With Attention Deficits Concentrate Better After Walk in the Park. Journal of Attention Disorders.

Kustka. S (2009) Personal Interview.

Lambert, N. M., Sandoval, J., Sassone, D. (1978). Prevalence of hyperactivity in elementary school children as a function of social system definers. Am J Orthopsychiatry, 48, 446-463.

Lercher, Schmitzberger and Kofler (1995) Perceived traffic air pollution, associated behaviour and health in an alpine area. Elsevier Science B.V.

Lia,Tummer (2001) Rudolf Steiner and Anthroposophy for Beginners, Writers and Readers Publishing.

Lipsett M, Campleman S. Occupational exposure to diesel exhaust and lung cancer: a 
meta-analysis. Am J Public Health. 1999

Littlefield, Adams (1966) Philosophy of education: problems of men / by John Dewey.

Paterson, N.J

Louv, R. (2005). Last child in the woods: saving our children from nature-deficit disorder, Algonquin Books of Chapel Hill: New York

Mayer and Holms (1996). Bite-Size Einstein. New York, N.Y. St. Martin's Press.

Montessori Foundation. Florida. http://www.montessori.org Retrieved: November 9, 2009

Montessori, Maria (1936) The Secret of Childhood. India: Orient Longman Ltd.

Mooney, Carol (2006) Theories of childhood : an introduction to Dewey, Montessori, Erickson, Piaget \& Vygotsky [Special ed.] Upper Saddle River, N.J.: Pearson/Merrill Prentice Hall

McDermott, Robert (1984) The Essential Steiner, Lindisfarne Books pp. 3-11, 392-5

Melemed. Albert Einstein Hospital. Millions of U.S. Children Low In Vitamin D http://www.einstein.yu.edu/home/news.asp?id=392 Retrieved: September. 30, 2009,

Moya, Bearer and Etzel (2004) Children's Behaviour and Physiology and How It Affects Exposure to Environmental Contaminants. PEDIATRICS. American Academy of Pediatrics.

National Environmental Trust et. al (2000) Polluting Our Future: Chemical Pollution in the U.S. that Affects Child Development and Learning

North American Montessori Teachers Association. Ohio. http://www.montessorinamta.org/NAMTA/geninfo/whatismont.html Retrieved: November 9, 2009

A.A.P (2004) Committee on Environmental Health Ambient Air Pollution: Health Hazards to Children. PEDIATRICS Vol. 114 No. 6 
Pearson RL, Wachtel H, Ebi KL. (2000) Distance-weighted traffic density in proximity to a home is a risk factor for leukemia and other childhood cancers. J Air Waste Manag Assoc.

Piaget, J. (1962). Play, Dreams and Imitation in Childhood. New York: Norton.

Prescott. S.L (2001) Clinical \& Experimental Allergy. Volume 31 Number 8. University of Western Australia Princess Margaret Hospital

Rist and Schneider (1979) Integrating Vocational and General Education: A Rudolf Steiner School. Hamberg: Unesco Institute for Education

Schittich, C. (2008) Kindergarten. DETAIL Konzept Review of Architecture.

Selwyn, S (1972) Skin Bacteria and Skin Disinfection Reconsidered. British Medical Journal.

Slavin, R. E. (2003). Educational Psychology: Theory and practice (7th ed.). Boston: Pearson Education.

Smith, Kendra Schank. (2008) Architects' sketches: dialogue and design. Amsterdam. Architectural Press/Elsevier. Boston.

Smith, Kendra Schank. (2005) Architects' drawings : a selection of sketches by world famous architects through history. Burlington, MA : Elsevier/Architectural Press, Oxford.

Schuster, Wolfgang. (2007) Stuttgart: City for the Children. Stuttgart, Germany.

Taylor \& Vlastos (1975) School Zone: learning Environments for Children. New York: Van Nostrand Reinhold Company

Tolerance: The Threshold of Peace. UNESCO.

Tummer, Lia (2001) Rudolf Steiner and Anthroposophy for Beginners, Writers and Readers Publishing, pp. 123-126. 
UNESCO (1994) Tolerance: The Threshold of Peace

Urban Climate Stuttgart. Stuttgart, Germany. http://www.stadtklimastuttgart.de/index.php?air_condition_stgt_en Retrieved: November 11, 2009

Vygotsky, L. (1978). Interaction between Learning and Development. In Mind in Society. (Trans. M. Cole). Cambridge, MA: Harvard University Press.

Williams, R. (1980). "Ideas of Nature," in Problems of Materialism and Culture. (London: Verso, 1980): 67-85.

Wilson, Edward O. (1984). Biophilia. Cambridge: Harvard University Press.

Wirth, Arthur (1966) John Dewey as educator: his design for work in education, 18941904. New York: Wiley.

Zentall, S. S. (2005). Theory- and evidence-based strategies for children with attentional problems. Psychology in the Schools, 42, 821-836.

Zhai, Wilhelm, and Maibach (2007) Dermatotoxicology, Informa HealthCare; 7 edition.

Zhu Y, Hinds WC, Kim S, Sioutas C. (2002) Concentration and size distribution of ultrafine particles near a major highway. J Air Waste Manag Assoc. 